\title{
MODELO DESCRITIVO DA OPERAÇÃO DE CONJUNTOS INJETOR- BOMBA CENTRÍFUGA UTILIZADOS EM POÇOS
}

\section{Fernando CAMPOS MENDonÇa}

Engenheiro Agrônomo

Orientador: Prof. Dr. TARLEI ARRIEL BOTREL

Tese apresentada à Escola Superior de Agricultura "Luiz de Queiroz", Universidade de São Paulo, para obtenção do título de Doutor em Agronomia, Área de Concentração: Irrigação e Drenagem.

PIRACICABA

Estado de São Paulo - Brasil

Maio, 1999 


\section{ERRATA}

1) Na página 4 , último parágrafo, onde se lê:

"Abreu et al. (1987), trabalhando com injetores...", leia-se

"Abreu et al. (1987), escrevendo sobre injetores..."

2) Na página 5 , último parágrafo, onde se lê:

"Ballofett et al. (1955) afirmaram que...", leia-se

"Ballofett et al. (1955), citados por Botrel (1996), afirmaram que..."

3) Na página $6,2^{\circ}$ parágrafo, onde se lê:

"O autor também afirmou que deve haver uma relação entre os diâmetros dos bocais convergente $\left(d_{1}\right)$ e divergente $\left(d_{2}\right)$, recomendando que $d_{1}: d_{2}$ seja de 3:1.", leia-se

"O autor também afirmou que deve haver uma relação entre os diâmetros dos bocais convergente $\left(d_{1}\right)$ e divergente $\left(d_{2}\right)$, recomendando que $d_{1}: d_{2}$ seja de 1:3."

4) Na página $14,14^{\mathrm{a}}$ linha, onde se lê:

c) Hazen-Williams (diâmetro entre 50 e 3000 mm, $\mathbf{n}^{0}$ de Reynolds maior que $10^{5}$ ), leia-se

c) Hazen-Williams (diâmetro entre 50 e 3000 mm, nº de Reynolds maior que $\left.10^{4}\right)$.

5) Na página $29,2^{\varrho}$ parágrafo, onde se lê:

"b) se o valor de $\Delta H_{\text {bomba }}$ tornar-se negativo", leia-se

"b) se o valor de $\Delta \mathrm{H}_{\text {bomba }}$ tornar-se negativo ou igual a zero"

6) Na página 48, o título correto da Tabela 3 é "Tabela 3 - Valores médios dos coeficientes de descarga $(\mathrm{Cd})$ e de perda de carga $(\mathrm{K})$ dos injetores para cada pressão de entrada"

7) Na página 62, Figura 22, e na página 63, Figuras 23 e 24, onde se lê: “...Curva $П$ Hútil x Dboc para...", leia-se “...Curva $\Delta H u ́ t i l$ x Dboc para...". 


\title{
Dados Internacionais de Catalogaçāo na Publicação (CIP) DIVISÃo DE BIBLIOTECA E DOCUMENTAÇÃO - Campus "Luiz de Queiroz"/USP
}

\author{
Mendonça, Fernando Campos \\ Modelo descritivo da operação de conjuntos injetor-bomba centrifuga \\ utilizados em poços / Fernando Campos Mendonça. - - Piracicaba, 1999. \\ $101 \mathrm{p}$. : if.
}

Tese (doutorado) - - Escola Superior de Agricultura Luiz de Queiroz, 1999. Bibliografia.

1. Bomba centrifuga 2. Bomba hidráulica 3. Fonte de àgua 4. Hidráulica agrícola 5. Injetor 6. Modelo matemático 7. Poço 8. Programa de computação 9 Simulação I. Título

CDD 621.67

"Permitida a cópia total ou parcial deste docunento, desde que citada a fonte + O Autor" 
"Tudo tem o seu tempo determinado e há tempo para todo o propósito debaixo do céu:"

Há tempo para de nascer e tempo de morrer; tempo de plantar e tempo de arrancar o que se plantou;

tempo de matar e tempo de curar; tempo de derrubar e tempo de edificar;

tempo de chorar e tempo de rir; tempo de prantear e tempo de dançar;

tempo de espalhar pedras e tempo de ajuntar pedras; tempo de abraçar e tempo de afastar-se de abraçar;

tempo de buscar e tempo de perder; tempo de guardar e tempo de deitar fora;

tempo de rasgar e tempo de coser; tempo de estar calado e tempo de falar;

tempo de amar e tempo de odiar; tempo de guerra e tempo de paz."

(Provérbios, 3:1-8)

Dedico este trabalho a Deus, por me presentear com o tempo, e aos meus pais, Antônio e Antônia, pelo tempo e dedicação para fazer crescer o responsável pela realização deste trabalho.

Ofereço este trabalho à minha esposa, Janea, pela luta, perseverança e apoio durante os vários anos gastos nesta etapa de minha formação profissional. 
“Tudo posso naquele que me fortalece" (Fp, 4:13)

\section{AGRADECIMENTOS}

A Deus, Senhor da vida, pela fé e perseverança sempre concedidas, e pelas próximas bênçãos que certamente virão.

À minha esposa, Janea Falcão dos Santos Mendonça, pela atenção e carinho dispensados a mim e pelas muitas horas concedidas a este trabalho.

Ao Prof. Tarlei Arriel Botrel, pela amizade, orientação, apoio e incentivo recebidos no decorrer de dez anos de convivência e, principalmente, no decorrer deste trabalho.

À Escola Superior de Agricultura "Luiz de Queiroz", por intermédio do Departamento de Engenharia Rural, pelas condições proporcionadas para a realização deste trabalho.

Ao CNPq - Conselho Nacional de Desenvolvimento Científico e Tecnológico, pelo apoio financeiro concedido. Aos funcionários José Figueiredo, Hélio de Toledo Gomes, Gilmar Batista Grigolon e Antônio César de Souza Rocha, pela amizade, apoio e auxílio na realização deste trabalho.

Aos colegas de curso Luís Fernando de Souza Campeche, Jarbas Honório de Miranda, Sérgio Antônio Veronez de Sousa, Dáucio Ricardo Botelho Alves e Cristina Miranda Alencar, pelo auxílio logístico, na coleta de dados e principalmente pela amizade, contribuições fundamentais à realização desta obra.

Aos demais professores do Curso de Pós-graduação em Irrigação e Drenagem, pela formação científica proporcionada.

A todos aqueles que, de alguma forma, contribuiram para a execução deste trabalho. 


\section{SUMÁRIO}

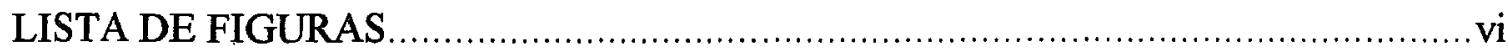

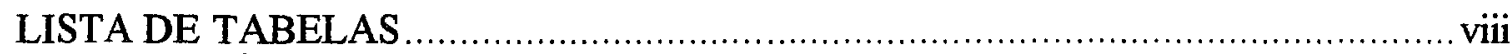

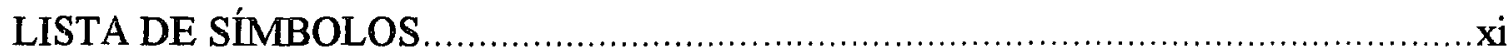

RESUMO

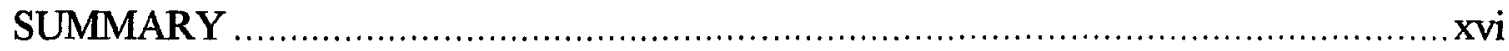

1. INTRODUÇÃO

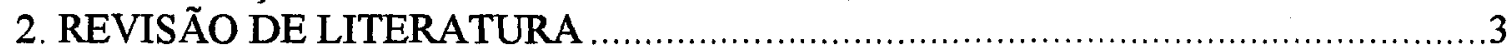

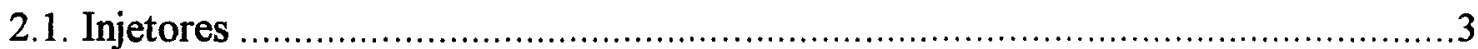

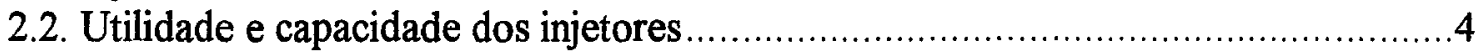

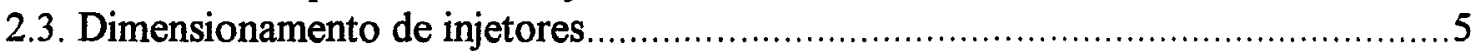

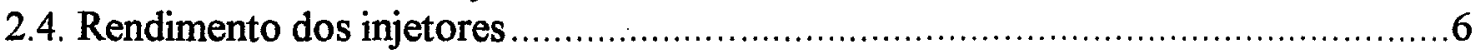

2.5. Rendimento do conjunto injetor-bomba centrífuga ..................................... 10

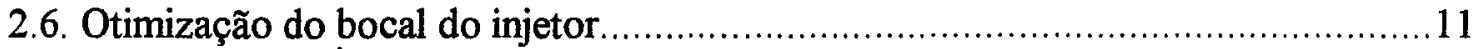

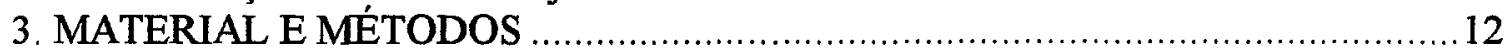

3.1. Pressuposições para o desenvolvimento teórico............................................. 12

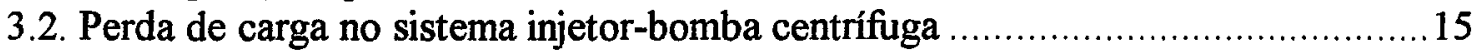

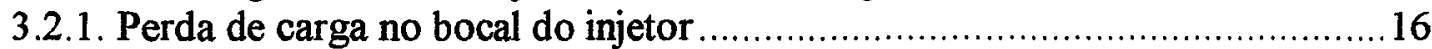

3.2.2. Combinação 1 (Flamant - Flamant) ................................................17

3.2.3. Combinação 2 (Flamant - Hazen-Williams) ...........................................19

3.2.4. Combinação 3 (Hazen-Williams _ Hazen-Williams) ..................................20

3.3. Explicitação da vazão circulante (qcirc) em equações solucionáveis

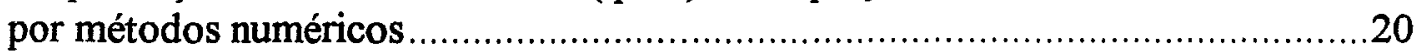

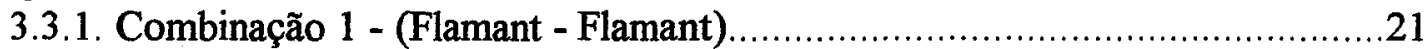

3.3.2. Combinação 2 (Flamant - Hazen-Williams) ...........................................2

3.3.3. Combinação 3 (Hazen-Williams - Hazen-Williams) ................................25

3.3.4. Resolução das equações de vazão circulante (qcirc) ................................26

3.4. Cálculo do rendimento do conjunto injetor-bomba centrífuga .........................27

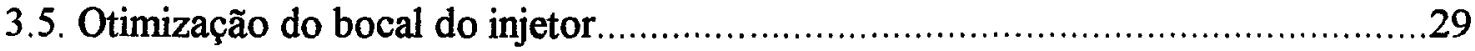

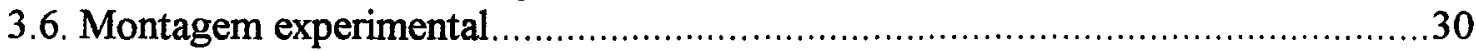

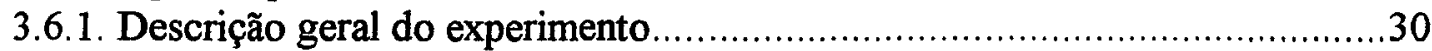

3.6.2. Testes para obtenção de parâmetros das bombas centrífugas.......................31

3.6.3. Testes para obtenção de parâmetros dos injetores ......................................31

3.6.4. Cálculos com o modelo matemático proposto ...........................................34

3.6.5. Testes com o sistema injetor-bomba centrífuga .......................................43

3.6.6. Equipamentos empregados nos experimentos .......................................4

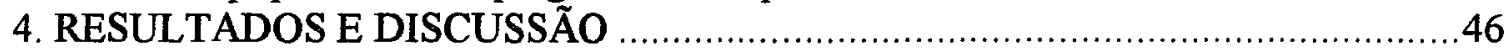

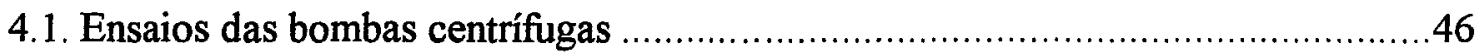

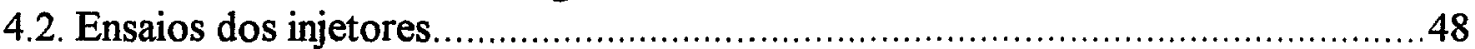

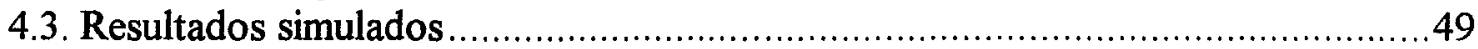

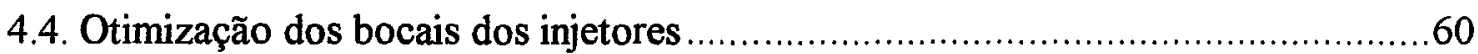

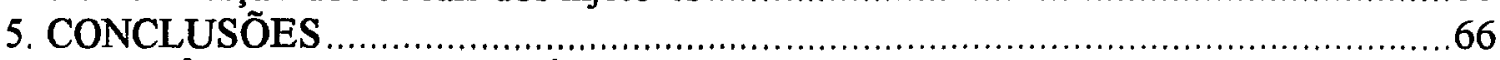

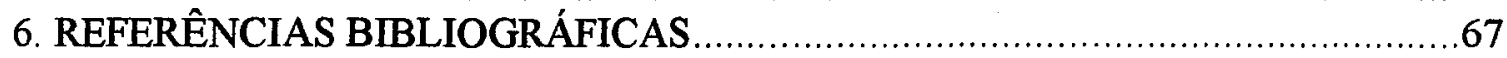




\section{LISTA DE FIGURAS}

Página

Figura 1 - Esquema de injetor para bombas de poços 3

Figura 2 - Características de $\mu(\delta)$ e $\eta(\delta)$ para m constante...................................... 7

Figura 3 - Variação dos coeficientes $\mu$ e $\delta$ para $\eta=0,3$ e vários valores de m...........8

Figura 4 - Sistema injetor-bomba centrifuga ...................................................... 11

Figura 5 - Esquema experimental para obtenção dos parâmetros dos injetores ..............30

Figura 6 - Esquema de testes com o sistema injetor-bomba centrífuga .....................41

Figura 7 - Representação gráfica dos dados observados e estimados - Bomba

JACUZZI mod. 1VJF15-M 38J

Figura 8 - Representação gráfica dos dados observados e estimados - Bomba

JACUZZI mod. 2VJF15-T 39B

Figura 9 - Representação gráfica dos dados observados e estimados - Bomba

JACUZZI mod. 3VJE15-M 39G. 48

Figura 10 - Comparação de resultados simulados e observados do conjunto

bomba-injetor 3VJE15-M $39 \mathrm{G}$ - Altura de sucção de 16,47 m.

Figura 11 - Comparação de resultados simulados e observados do conjunto

bomba-injetor 2VJF15-T 39 B - Altura de sucção de 16,47 m.

Figura 12 - Comparação de resultados simulados e observados do conjunto

bomba-injetor 1VJF15-M $38 \mathrm{~J}$ - Altura de sucção de 16,47 m.

Figura 13 - Comparação de resultados simulados e observados do conjunto

bomba-injetor 3VJE15-M $39 \mathrm{G}$ - Altura de sucção de 11,97 m

Figura 14 - Comparação de resultados simulados e observados do conjunto

bomba-injetor 2VJF15-T 39 B - Altura de sucção de 11,97 m.

Figura 15 - Comparação de resultados simulados e observados do conjunto

bomba-injetor 1VJF15-M $38 \mathrm{~J}$ - Altura de sucção de 11,97 m.

Figura 16 - Comparação de Hfsist e $\Delta$ Hútil estimados e observados do conjunto bomba- injetor 1VJF15-M 38J operando a uma altura de sucção de $16,47 \mathrm{~m}$ 
Figura 17 - Comparação de Hfsist e $\Delta$ Hútil estimados e observados do conjunto bomba-injetor 3VJE15-M 39G .58

Figura 18 - Comparação de Hfsist e $\Delta$ Hútil estimados e observados do conjunto bomba-injetor 2VJF15-T 39B. .58

Figura 19 - Sistema bomba-injetor 3VJE15-M 39G - Curvas $\Delta$ Hútil x Dboc para otimização do bocal do injetor (Altura de sucção de 16,47 m)

Figura 20 - Sistema bomba-injetor 3VJE15-M 39G - Curvas $\triangle$ Hútil x Dboc para otimização do bocal do injetor (Altura de sucção de 11,97 m)

Figura 21 - Sistema bomba-injetor 2VJF15-T 39B - Curvas $\Delta$ Hútil x Dboc para otimização do bocal do injetor (Altura de sucção de 16,47 m)

Figura 22 - Sistema bomba-injetor 2VJF15-T 39B - Curvas $\Delta$ Hútil x Dboc para otimização do bocal do injetor (Altura de sucção de 11,97 m) 62

Figura 23 - Sistema bomba-injetor 1VJF15-M 38J - Curvas $\Delta$ Hútil x Dboc para otimização do bocal do injetor (Altura de sucção de 16,47 m)

Figura 24 - Sistema bomba-injetor 1VJF15-M 38J - Curvas $\Delta$ Hútil x Dboc para otimização do bocal do injetor (Altura de sucção de $11,97 \mathrm{~m}$ ) .63 


\section{LISTA DE TABEL،AS}

Página

Tabela 1 - Combinações de fórmulas de perda de carga de acordo com o diầmetro das tubulações de recirculação e sucção 16

Tabela 2 - Conjuntos bomba-injetor JACUZZI utilizados no experimento. 30

Tabela 3 - Valores médios e média geral dos coeficientes de descarga (Cd)

e de perda de carga dos injetores para cada pressão de entrada.

Tabela 4 - Dados experimentais de vazão e pressão da bomba JACUZZI, modelo 1VJF15-M 38J

Tabela 5 - Dados experimentais de vazão e pressão da bomba JACUZZI, modelo 2VJF15-T 39B 68

Tabela 6 - Dados experimentais de vazâo e pressão da bomba JACUZZI, modelo 3VJE15-M 39G

Tabela 7 - Injetor 3VJE15-M 39G (1/3 CV) - $\Delta z=16,47 \mathrm{~m}$ - Teste $1 \ldots \ldots \ldots \ldots \ldots \ldots . . \ldots$

Tabela 8 - Injetor 3VJE15-M 39G (1/3 CV) - $\Delta \mathrm{z}=16,47 \mathrm{~m}$ - Teste $2 \ldots \ldots \ldots \ldots \ldots \ldots . . . . . .70$

Tabela 9 - Injetor 2VJF15-T 39B (2 CV) - $\Delta \mathrm{z}=16,47 \mathrm{~m}$ - Teste 1.......................71

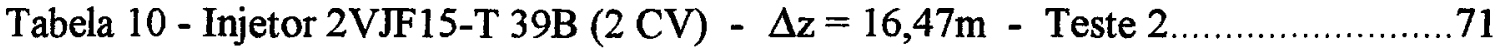

Tabela 11 - Injetor 1VJF15-M 38J (1 CV) - $\Delta z=16,47 \mathrm{~m}$ - Teste $1 \ldots \ldots \ldots \ldots \ldots \ldots \ldots . . \ldots 2$

Tabela 12 - Injetor 1VJF15-M 38J (1 CV) - $\Delta \mathrm{z}=16,47 \mathrm{~m}$ - Teste 2 .....................73

Tabela 13 - Injetor 3VJE15-M 39G (1/3 CV) - $\Delta z=11,97 m$ - Teste $1 \ldots \ldots \ldots \ldots \ldots \ldots . . . . .73$

Tabela 14 - Injetor 3VJE15-M 39G (1/3 CV) - $\Delta z=11,97 \mathrm{~m}$ - Teste $2 \ldots \ldots \ldots \ldots \ldots \ldots . . .74$

Tabela 15 - Injetor 2VJF15-T 39B (2 CV) - $\Delta z=11,97 \mathrm{~m}$ - Teste 1......................74

Tabela 16 - Injetor 2VJF 15-T 39B (2 CV) - $\Delta z=11,97 m$ - Teste 2 .....................75

Tabela 17 - Injetor IVJF15-M 38J (1 CV) - $\Delta z=11,97 \mathrm{~m}$ - Teste 1 ........................75

Tabela 18 - Injetor 1VJF15-M 38J (1 CV) - $\Delta \mathrm{z}=11,97 \mathrm{~m}$ - Teste 2 …...................76

Tabela 19 - Simulação da relação entre vazão útil e diferencial de pressão útil - Conjunto 3VJE15-M 39G - $\Delta \mathrm{z}=16,47 \mathrm{~m}$ - Teste 1

Tabela 20 - Dados coletados dos sistema injetor-bomba centrífuga (Obtidos por experimentação) - Conjunto 3VJE15-M 39G $\Delta \mathrm{z}=16,47 \mathrm{~m}$ - Teste 1 . 
Tabela 21 - Simulação da relação entre vazão útil e diferencial de pressão útil - Conjunto 3VJE15-M 39G - $\Delta \mathrm{z}=16,47 \mathrm{~m}$ - Teste 2

Tabela 22 - Dados coletados dos sistema injetor-bomba centrífuga (Obtidos por experimentação) - Conjunto 3VJE15-M 39G $\Delta \mathrm{z}=16,47 \mathrm{~m}$ - Teste 2 .

Tabela 23 - Simulação da relação entre vazão útil e diferencial de pressão útil - Conjunto 3VJE15-M 39G - $\Delta \mathrm{z}=11,97 \mathrm{~m}$ - Teste 1 80

Tabela 24 - Dados coletados dos sistema injetor-bomba centrífuga (Obtidos por experimentação) - Conjunto 3VJE15-M 39G $\Delta \mathrm{z}=11,97 \mathrm{~m}$ - Teste 1

Tabela 25 - Simulação da relação entre vazão útil e diferencial de pressão útil - Conjunto 3VJE15-M 39G - $\Delta \mathrm{z}=11,97 \mathrm{~m}$ - Teste 2 .

Tabela 26 - Dados coletados dos sistema injetor-bomba centrífuga (Obtidos por experimentação) - Conjunto 3VJE15-M 39G $\Delta z=11,97 \mathrm{~m}$ - Teste 2

Tabela 27 - Simulação da relação entre vazão útil e diferencial de pressão útil - Conjunto 2VJF15-T 39B - $\Delta \mathrm{z}=16,47 \mathrm{~m}$ - Teste 1

Tabela 28 - Dados coletados dos sistema injetor-bomba centrífuga (Obtidos por experimentação) - Conjunto 2VJF15-T 39B $\Delta \mathrm{z}=16,47 \mathrm{~m}$ - Teste 1 .85

Tabela 29 - Simulação da relação entre vazão útil e diferencial de pressão útil - Conjunto 2VJF15-T 39B - $\Delta \mathrm{z}=16,47 \mathrm{~m}$ - Teste 2

Tabela 30 - Dados coletados dos sistema injetor-bomba centrífuga (Obtidos por experimentação) - Conjunto 2VJF15-T 39B $\Delta \mathrm{z}=16,47 \mathrm{~m}$ - Teste 2

Tabela 31 - Simulação da relação entre vazão útil e diferencial de pressão útil - Conjunto 2VJF15-T 39B - $\Delta \mathrm{z}=11,97 \mathrm{~m}$ - Teste 1 88

Tabela 32 - Dados coletados dos sistema injetor-bomba centrífuga (Obtidos por experimentação) - Conjunto 2VJF15-T 39B $\Delta z=11,97 \mathrm{~m}-$ Teste 1 
Tabela 33 - Simulação da relação entre vazão útil e diferencial de pressão útil - Conjunto 2VJF15-T 39B - $\Delta \mathrm{z}=11,97 \mathrm{~m}$ - Teste 2.

Tabela 34 - Dados coletados dos sistema injetor-bomba centrífuga (Obtidos por experimentação) - Conjunto 2VJF15-T 39B $\Delta \mathrm{z}=11,97 \mathrm{~m}$ - Teste 2 .

Tabela 35 - Simulação da relação entre vazão útil e diferencial de pressão útil - Conjunto $1 \mathrm{VJF} 15-\mathrm{M} 38 \mathrm{~J}-\Delta \mathrm{z}=16,47 \mathrm{~m}$ - Teste 1 .

Tabela 36 - Dados coletados dos sistema injetor-bomba centrífuga (Obtidos por experimentação) - Conjunto 1VJF15-M 38J $\Delta \mathrm{z}=16,47 \mathrm{~m}$ - Teste 1

Tabela 37 - Simulação da relação entre vazão útil e diferencial de pressão útil - Conjunto IVJF15-M 38J - $\Delta \mathrm{z}=16,47 \mathrm{~m}$ - Teste 2 .94

Tabela 38 - Dados coletados dos sistema injetor-bomba centrífuga (Obtidos por experimentação) - Conjunto 1VJF15-M 38J $\Delta \mathrm{z}=16,47 \mathrm{~m}$ - Teste 2 .

Tabela 39 - Simulação da relação entre vazão útil e diferencial de pressão útil - Conjunto IVJF15-M 38J - $\Delta \mathrm{z}=11,97 \mathrm{~m}$ - Teste 1 .96

Tabela 40 - Dados coletados dos sistema injetor-bomba centrífuga (Obtidos por experimentação) - Conjunto 1VJF15-M 38J $\Delta \mathrm{z}=11,97 \mathrm{~m}$ - Teste 1 .

Tabela 41 - Simulação da relação entre vazão útil e diferencial de pressão útil - Conjunto IVJF15-M 38J - $\Delta \mathrm{z}=11,97 \mathrm{~m}$ - Teste 2 ...... .98

Tabela 42 - Dados coletados dos sistema injetor-bomba centrífuga (Obtidos por experimentação) - Conjunto 1VJF15-M 38J $\Delta \mathrm{z}=11,97 \mathrm{~m}$ - Teste 2 . 


\section{LISTA DE SÍMBOLOS}

$\mathrm{Q}_{1}$ - vazão motriz ou circulante do sistema injetor-bomba centrífuga $\left[\mathrm{m}^{3} . \mathrm{s}^{-1}\right]$

$\mathrm{Q}_{2}$ - vazão succionada pelo injetor $\left[\mathrm{m}^{3} . \mathrm{s}^{-1}\right]$

$\mathrm{Q}_{\mathrm{d}}$ - vazão total do sistema injetor-bomba centrífuga $\left[\mathrm{m}^{3} . \mathrm{s}^{-1}\right]$

$\mathrm{H}_{1}$ - pressão do fluido bombeado à entrada do injetor [ $\mathrm{kPa}$ ou mca]

$\mathrm{H}_{\mathrm{s}}$ - pressão do fluido aspirado à entrada do injetor [ $\mathrm{kPa}$ ou mca]

$\mathrm{H}_{\mathrm{d}}$ - pressão do fluido à saída do injetor [ $\mathrm{kPa}$ ou mca]

$\mathrm{d}_{1}$ - diâmetro do bocal convergente do injetor [mm]

$\mathrm{d}_{2}$ - diâmetro do bocal divergente do injetor [mm]

$\mu$ - razão entre altura líquida de elevação $\left(\Delta H_{\text {utii }}\right)$ e altura líquida motriz $\left(H_{m}\right)$

$\left(\mu=\Delta \mathbf{H}_{\text {util }} / \mathrm{H}_{\mathrm{m}}\right) \quad[-]$

$\Delta \mathrm{H}_{\text {util }}$ - diferencial de pressão útil do conjunto injetor-bomba centrífuga

[ $\mathrm{kPa}$ ou mca]

$\mathrm{H}_{\mathrm{m}}$ - altura líquida motriz, proporcionada pelo trabalho da bomba centrífuga e pelo desnivel entre a mesma e o injetor [ $\mathrm{kPa}$ ou mca]

$\mathbf{P}_{\mathrm{s}}$ - pressão na saída do injetor [ $\mathrm{kPa}$ ou mca]

$\mathbf{P}_{\mathrm{a}}-$ pressão na seção contraída do injetor [ $\mathrm{kPa}$ ou mca]

$P_{e}$ - pressão na entrada do injetor [ $\mathrm{kPa}$ ou mca]

$\delta$ - relação entre vazão motriz e vazão succionada pelo injetor $\left(\delta=-Q_{1} / Q_{2}\right) \quad[$ - ]

$\eta$ - rendimento do injetor tipo Venturi no recalque de fluidos [\%]

$\mathbf{H}=\mathbf{P}_{\mathrm{s}}-\mathbf{P}_{\mathrm{a}}$ - altura líquida de elevação do fluido após o injetor [kPa ou mca]

$\mathrm{h}=\mathrm{P}_{\mathrm{e}}-\mathrm{P}_{\mathrm{s}}$ - diferencial de pressão fluido motriz [kPa ou mca]

$\mu_{0}$ - valor de $\mu$ quando $\delta=0$ (vazão motriz nula) [ - ]

$\delta_{0}$ - valor de $\delta$ quando $\mu=0$ (pressão totalmente transformada em velocidade na seção de estrangulamento) [ - ]

m - relação entre áreas do bocal convergente e divergente do injetor [ - ]

$\mathrm{S}_{\mathrm{c}}$ - área do bocal convergente do injetor $\left[\mathrm{m}^{2}\right]$

$\mathrm{S}_{\mathrm{d}}$ - área do bocal divergente do injetor $\left[\mathrm{m}^{2}\right]$

$\eta$ '- rendimento do conjunto injetor-bomba centrífuga [\%] 
$P_{u t i 1}$ - Potência útil desenvolvida pelo conjunto injetor-bomba centrífuga [ $\mathrm{W}$ ou $\mathrm{CV}]$

$\mathrm{P}_{\text {bomba }}$ - potência desenvolvida pela bomba $[\mathrm{W}$ ou $\mathrm{CV}]$

$\mathrm{P}_{\mathrm{Hf}}$ - potència consumida para suprir a perda de carga do sistema [ $\mathrm{W}$ ou $\mathrm{CV}$ ]

$\mathrm{Cd}$ - coeficiente de descarga do bocal convergente do injetor [ - ]

$\mathrm{K}$ - coeficiente de perda de carga do injetor [ - ]

$\mathrm{D}_{\mathrm{boc}}$ - diâmetro do bocal convergente do injetor [ $\mathrm{mm}$ ]

$\Delta \mathrm{H}_{\text {bomba }}$ - diferencial de pressão proporcionado pela bomba centrífuga [ $\mathrm{kPa}$ ou mca]

$a, b, c$ - coeficientes de regressão polinomial da relação vazão versus pressão de uma bomba centrífuga [ - ]

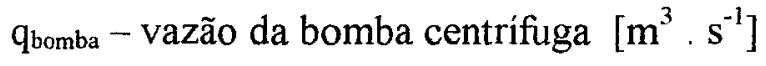

$\mathrm{q}_{\text {circ }}$ - vazão circulante do conjunto injetor-bomba centrífuga $\left[\mathrm{m}^{3} \cdot \mathrm{s}^{-1}\right]$

$\mathrm{S}_{\text {bocal }}$ - área do bocal convergente do injetor $\left[\mathrm{m}^{2}\right]$

$\mathrm{g}$ - aceleração da gravidade $\left[\mathrm{m} \cdot \mathrm{s}^{-2}\right.$ ]

$\mathrm{H}_{1}$ - pressão de alimentação do bocal do injetor (entrada) [kPa ou mca]

$\mathrm{H}_{2}$ - pressão de descarga do bocal do injetor (saída) [kPa ou mca]

$q_{u t i l}$ - vazão útil do conjunto injetor-bomba centrífuga $\left[\mathrm{m}^{3} \cdot \mathrm{s}^{-1}\right]$

$\Delta Z_{1}, \Delta Z_{2}$ - diferenças de nível entre a bomba centrífuga e o injetor, considerado-se

os trechos 1 e 2 da tubulação de sucção, respectivamente [m]

$\Delta Z_{\text {sub }}$ - profundidade de imersão do injetor [m]

$\mathrm{Hf}_{\text {sist }}$ - perda de carga no sistema (conjunto injetor-bomba centrífuga) [ $\mathrm{kPa}$ ou mca]

$\mathrm{Hf}_{\text {boc }}$ - perda de carga no bocal do injetor [ $\mathrm{kPa}$ ou mca]

$\mathrm{Hf}_{\mathrm{l}}$ - perda de carga no trecho 1 da tubulação de sucção [kPa ou mca]

$\mathrm{Hf}_{2}$ - perda de carga no trecho 2 da tubulação de sucção [ $\mathrm{kPa}$ ou mca]

$\mathrm{P}_{\text {Hfsist }}$ - potência dissipada pela perda de carga do sistema injetor-bomba centrífuga [W ou CV]

$P_{\text {hid }}$ - potência hidráulica desenvolvida por um dispositivo de bombeamento [W ou CV]

$\gamma$ - peso específico do fluido $\left[\mathrm{kgf} / \mathrm{m}^{3}\right]$ 
$\mathrm{Q}$ - vazão de um fluido qualquer em um sistema de bombeamento $\left[\mathrm{m}^{3} / \mathrm{s}\right.$ ]

$\mathrm{H}^{\prime}$ - pressão de um sistema de bombeamento [kPa ou mca]

Hf - perda de carga em um sistema hidráulico [ $\mathrm{kPa}$ ou mca]

$b_{i}$ - coefiente de atrito de Flamant para o trecho "i" da tubulação de sucção [ - ]

$\mathrm{L}_{\mathrm{i}}$ - comprimento do trecho "i" da tubulação de sucção [m]

$D_{i}$ - diâmetro do trecho "i $i$ " da tubulação de sucção [mm]

$\mathrm{V}_{\mathrm{i}}$ - velocidade de escoamento no trecho "ị”' da tubulação de sucção [m. $\mathrm{s}^{-1}$ ]

$S_{i}$ - área da seção transversal do trecho "i" da tubulação de sucção $\left[\mathrm{m}^{2}\right]$

$\mathrm{C}_{\mathrm{i}}$ - coeficiente de atrito da fórmula de Hazen - Williams para o trecho "i" da tubulação de sucção [ - ]

$\mathrm{Hf}_{\text {boc }}$ - perda de carga no bocal do injetor [ $\mathrm{kPa}$ ou mca]

$\mathrm{V}_{\text {boc }}$ - velocidade de escoamento de fluido no bocal do injetor $\left[\mathrm{m} . \mathrm{s}^{-1}\right]$

$q_{\max }$ - vazão máxima da bomba centrífuga $\left[\mathrm{m}^{3} / \mathrm{s}\right]$

$\mathrm{E}_{1}, \mathrm{E}_{2}, \mathrm{E}_{3}$ - energia disponível nos pontos 1 (imediatamente antes do injetor),

2 (sucção do injetor) e 3 (imediatamente após o injetor) [W ou CV]

$\mathrm{HfE}_{1-3}$ - energia dissipada devido à perda de carga do injetor [W ou CV]

$\pi$ - constante matemática $(\pi=3,141592)[$ - ] 


\title{
MODELO DESCRITIVO DA OPERAÇÃO DE CONJUNTOS INJETOR- BOMBA CENTRÍFUGA UTILIZADOS EM POÇOS
}

\author{
Autor: FERNANDO CAMPOS MENDONÇA \\ Orientador: PROF. DR. TARLEI ARRIEL BOTREL
}

\section{RESUMO}

Este trabalho teve por objetivo desenvolver um modelo matemático para simulação da operação de conjuntos formados por uma bomba centrífuga e um injetor, para retirada de água de poços. O modelo simula a operação e permite obter a máxima pressão útil proporcionada pela associação bomba-injetor. Utiliza como parâmetros de entrada as características individuais da bomba, do injetor e da tubulação de sucção, simulando-se o funcionamento do conjunto na sucção de água de poços. Os parâmetros da bomba são a curva de vazão versus pressão e a vazão máxima. A tubulação de sucção foi dividida em dois trechos: descida ao poço e subida até a bomba. Os parâmetros da tubulação são o diâmetro, material constituinte, comprimento e desnível do trecho entre a bomba e o nível da água no poço. Os parâmetros do injetor a inserir no modelo são o coeficiente de descarga, coeficiente de perda de carga e diâmetro do bocal. Para aferir os resultados da simulação do modelo foram feitos dois experimentos, utilizando-se três conjuntos bomba-injetor de diferentes dimensões e capacidade operacional. O modelo proporcionou um bom ajuste da relação vazão útil versus pressão útil, bem como do rendimento da associação bomba-injetor para todos os conjuntos. A partir dos resultados de simulação do modelo é possível otimizar o diâmetro do bocal do injetor a fim de se obter a máxima pressão útil possível. Isto possibilita seu uso no planejamento de instalações de conjuntos bomba-injetor e também a otimização da pressão útil fornecida pelos mesmos, chegando ao máximo rendimento. 


\title{
OPERATIONAL DESCRIPTIVE MODEL OF CENTRIFUGAL-JET PUMP ASSOCIATIONS USED IN WELLS
}

\author{
Author: FERNANDO CAMPOS MENDONÇA \\ Adviser: PROF. DR. TARLEI ARRIEL BOTREL
}

\section{SUMMARY}

This work aimed the development of a mathematical model for simulating the operation of centrifugal and jet pump associations, for suctioning water of wells. The model simulates the operation and allows to obtain the maximum net pressure head provided by centrifugal-jet pump associations, varying the jet pump nozzle diameter. The model uses, as incoming parameters, the individual parameters of centrifugal pumps, jet pumps, and suction pipeline, allowing a simulation of water suction from centrifugal-jet pump associations. The centrifugal pump parameters are the relation between flow rate and pressure head, and the maximum flow rate. The suction pipeline is divided on two parts: the fist one going down to the well, and the second one, going back up to the centrifugal pump. Data from the suction pipeline are: pipe diameter, building material, lenght and level difference from centrifugal pump to well's water level. The jet pump parameters for inserting on the model are the nozzle discharge coefficient, friction loss coefficient and the nozzle diameter. In order to verify the results of simulation, it were made two experiments, using three centrifugal-jet pump associations of different dimensions and operational capacity. The model allowed a good adjustment for the flow rate-pressurehead relation, as well as the pressure efficiency of jet pump-centrifugal pump associations, for all associations. Model has also allowed the optimization of jet pump nozzle diameter, in order to obtain the maximum net pressure head. This allows its use on designing installations of centrifugal-jet pump associations, as well as the optimization of net pressure head provided by the jet pump nozzle, reaching the maximum efficiency 


\section{INTRODUÇÃO}

A instalação de uma unidade de bombeamento é projetada para determinadas condições fisicas, considerando-se várias situações e vários parâmetros. Entre eles estão os limites superior e inferior de altura de sucção. Uma bomba centrífuga só é capaz de retirar água de uma fonte qualquer, sem o auxílio de qualquer outro equipamento, até um certo limite de profundidade. Essa profundidade depende das características da bomba, da tubulação de sucção, da pressão atmosférica e da temperatura reinante no local da fonte de água.

A pressão atmosférica proporciona a energia necessária à elevação de água. Por este motivo a profundidade do poço não pode ser maior do que o valor da pressão atmosférica local (convertida em metros de coluna do líquido succionado), a não ser que se consiga aumentar o nível de energia disponível na sucção. Uma forma de se fazer isto é a utilização de injetores.

Os injetores normalmente são associados às bombas centrífugas para retirar água a uma profundidade maior do que seria possivel utilizando-se apenas essas bombas. São utilizados também na quimigação, escorva de bombas hidráulicas, aeração de água e lavagem de máquinas agrícolas, entre outras funções.

As principais vantagens da utilização de injetores são a ausência de partes móveis, simplicidade de construção, dispensa de lubrificação, facilidade de instalação, baixo custo de aquisição e manutenção, boa relação custo-beneficio e grande variação de vazão. As principais limitações são a faixa de pressão de para funcionamento (normalmente abaixo de $407,6 \mathrm{kPa}$, ou 40 mca) e o rendimento energético do equipamento (transmissão de energia), que geralmente situa-se abaixo de $30 \%$.

Observa-se porém, que a sua utilização geralmente não se realiza com base em características técnicas bem definidas, como é o caso dos sistemas de bombea- 
mento de água em poços (Botrel, 1996). Para que se possa utilizar adequadamente a associação injetor-bomba centrífuga é necessário conhecer as características hidráulicas da bomba e do injetor, bem como as perdas de carga que ocorrem no processo de sucção de água pelo sistema de bombeamento.

Os objetivos deste trabalho foram: a) obtenção de um modelo matemático para descrever a operação de conjuntos formados por um injetor e uma bomba centrífuga operando em poços, a fim de determinar a relação vazão útil versus pressão útil do conjunto injetor-bomba centrífuga e a maximização da pressão útil obtida através da determinação do diâmetro ótimo do bocal do injetor; b) o desenvolvimento de um programa computacional para solucionar as equações do modelo matemático. 


\section{REVISÃO DE LITERATURA}

\subsection{Injetores}

Botrel (1996) afirmou que, inicialmente, os tubos Venturi só foram foram utilizados para medicao de vazão. Segundo Delmée (1983), G.B. Venturi desenvolveu, em 1797, o primeiro trabalho sobre tubos com seção estrangulada para medição de vazão, em pesquisas sobre o princípio de comunicação lateral do movimento nos fluidos. Somente 90 anos depois é que Clemens Herschel desenvolveu o tubo Venturi.

Troskolanski (1977) observou que os aparelhos a jato valem-se do princípio de Venturi, sendo definidos como dispositivos apropriados para aspirar e recalcar simultaneamente um fluido (líquido, gás ou vapor) ou uma mistura fluido-sólido.

Macintyre (1987) citou várias aplicações da associação entre injetor e bomba centrífuga: obtenção de vácuo em recipientes de instalações industriais de secagem e em certos condensadores de vapor; injeção de ar para o interior de reservatórios hidropneumáticos; esvaziamento de poços de esgotos e retirada de água de poços com profundidade da ordem de 20 a 40 metros, ou até mais que isto.

$\mathrm{O}$ autor afirmou que o funcionamento dos injetores baseia-se numa aplicação direta do Princípio da Conservação da Energia. São dispositivos que constam essencialmente de um tubo aspirador e um bocal convergente, alimentando um bocal convergente-divergente, isto é, um "Venturi" (Vide Figura 1). Os injetores são muito empregados em instalações de poços freáticos de profundidades relativamente pequenas, porém superiores às que permitiriam uma bomba funcionar segundo a instalação convencional, isto é, com a bomba acima do nivel do reservatório.

A vazão motriz $\left(Q_{1}\right)$, proveniente de uma bomba e que produzirá a elevação desejada, atravessa o bocal convergente e passa por uma câmara de mistura, che- 
gando, a seguir, ao bocal divergente (difusor). Na passagem pelo bocal convergente a pressão diminui, podendo tornar-se menor que a pressão atmosférica na câmara de mistura. Quando isto ocorre a pressão relativa negativa formada no injetor, aliada à velocidade da veia liquida, produz o arrasto do ar existente na tubulação de sucção do injetor e, em seguida, do próprio líquido que deve ser aspirado $\left(\mathrm{Q}_{2}\right)$, seguindo ambos pela tubulação de recalque.

\footnotetext{
$\mathbf{H}_{\mathrm{s}}$ - pressão do fluido aspirado à entrada do injetor $\mathbf{H}_{1}$ - pressão do fluido bombeado à entrada do injetor

$\mathbf{H}_{\mathbf{d}}$ - pressão do fluido à saída do injetor

$\mathbf{Q}_{1}$ - vazão circulante

$\mathbf{Q}_{2}$ - vazão succionada

Q - vazão total do sistema
}

Figura 1- Esquema de ihjetor para bombas de poços

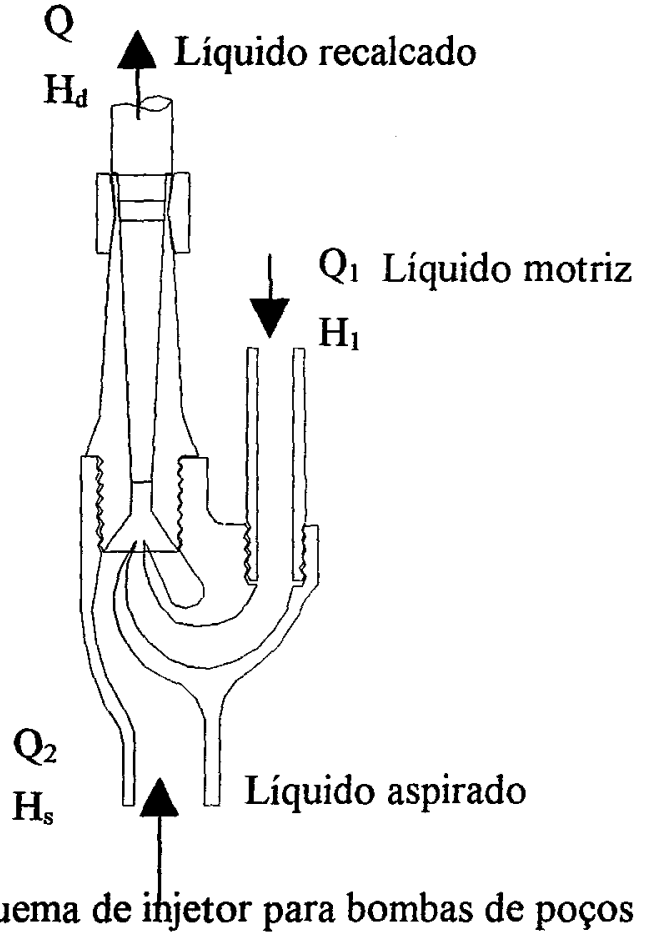

Macintyre (1987) recomendou a utilização do injetor quando a profundidade do poço for maior que 6 ou 7 metros, ou melhor, quando for superior ao valor da máxima altura estática de aspiração permitida.

\subsection{Utilidade e capacidade dos injetores}

Abreu et al. (1987), trabalhando com injetores para injeção de fertilizantes, observaram que o fluxo de fertilizante injetado tem uma relação direta com a pressão da água na entrada do mecanismo, com pressão mínima em torno de $152,85 \mathrm{kPa}$ (15 
mca). Os autores ainda relataram que os modelos usuais apresentam vazão entre 0,05 e 3 $\mathrm{m}^{3} / \mathrm{h}(50$ e $3000 \mathrm{~L} / \mathrm{h})$, sendo que a vazão mínima a passar pelo injetor depende da sua capacidade, variando de $1 \mathrm{~m}^{3} / \mathrm{h}$ (para injetores de 1 ") a mais de $20 \mathrm{~m}^{3} / \mathrm{h}$ (para alguns injetores de 2"). Observando os catálogos dos injetores, os autores notaram que as vazões são referentes à água na forma natural, e que a sua capacidade diminui à medida que aumenta a densidade da solução de fertilizante.

Ferreira (1994) estudou dois tipos de injetores tipo Venturi, constatando que a vazão de sucção aumenta com o aumento do diferencial de pressão, para uma mesma pressão de alimentação. A vazão de sucção diminui com o acréscimo da pressão de alimentação, para um mesmo diferencial de pressão. A última conclusão do autor foi que a vazão de sucção aumenta juntamente com o aumento da pressão relativa de sucção (tensão), para todos os casos estudados.

Macintyre (1987) citou um caso específico, o das bombas fabricadas pela Jacuzzi do Brasil. As bombas possuem um registro de controle de vazão incorporado à própria bomba, que também possui um manômetro adaptado. As bombas são fabricadas para potências de $1 / 3$ a $15 \mathrm{CV}$, conforme o modelo, podendo atender à profundidade de mais de $100 \mathrm{~m}$, altura manométrica de $200 \mathrm{~m}$ e descargas de até $26 \mathrm{~m}^{3} / \mathrm{h}$.

\subsection{Dimensionamento de injetores}

Feitosa Filho \& Arruda (1994) observaram que os parâmetros para dimensionamento dos injetores são: vazão que deve passar pelo injetor, pressão de serviço próximo ao início da seção convergente do injetor, altura de sucção e pressão negativa desejada na seção estrangulada do injetor.

Urquhart (1950) afirmou que o ângulo do bocal convergente do venturímetro é $21^{\circ}$, o diâmetro da garganta deve estar entre 1/2 e 1/4 do diâmetro da tubulação de entrada, e o ângulo de divergência, entre 5 e $7^{\circ}$. Ballofett et al. (1955) afirmaram que o diâmetro da garganta deve ser de $1 / 3$ do diâmetro da tubulação em que o injetor está instalado. A seção convergente pode ter um comprimento de 2,5 vezes o diâmetro da tubulação, correspondendo a um ângulo de $15^{\circ}$, e a seção divergente deve ter um com- 
primento de 7,5 vezes o diâmetro da tubulação, correspondente a um ângulo de $5^{\circ}$ (ângulo ótimo). Vennard \& Street (1978) recomendaram um cone de entrada lisa com ângulo em torno de $20^{\circ}$, um cilindro de seção curta e um cone difusor com ângulo entre $5 \mathrm{e}$ $7^{\circ}$ para minimizar a perda de carga.

Outros autores observaram que a relação entre os diâmetros ou áreas dos bocais divergente e convergente também são importantes para o funcionamento dos injetores. Russel (1971) afirmou que a porção convergente do medidor Venturi varia de 2 a 2,5 vezes o diâmetro da tubulação, e a porção divergente deve ter um ângulo de $5^{\circ}$. O autor também afirmou que deve haver uma relação entre os diâmetros dos bocais convergente $\left(d_{1}\right)$ e divergente $\left(d_{2}\right)$, recomendando que $d_{1}: d_{2}$ seja de $3: 1$.

Botrel (1996) desenvolveu um modelo computacional que permite simular a relação vazão versus pressão de um conjunto injetor-bomba centrífuga a partir das características hidráulicas próprias da bomba e do injetor. $O$ autor dividiu seu trabalho em duas partes: a) simulação do relacionamento entre a vazão e a pressão de um conjunto injetor-bomba centrífuga, a partir do conhecimento dos parâmetros hidráulicos próprios do injetor e da bomba centrífuga; e b) simulação da máxima pressão que se pode obter com uma determinada bomba centrífuga em função do diâmetro do bocal do injetor, a uma vazão preestabelecida. $\mathrm{O}$ autor criou dois modelos matemáticos, e também dois programas computacionais para resolvê-los. Após a criação dos modelos e dos programas, o autor montou um experimento para testar e validar os resultados de seus modelos. Os resultados validaram os modelos criados, permitindo conclusões a respeito da maximização de pressão para um determinado injetor e do rendimento da associação injetor-bomba centrífuga.

\subsection{Rendimento dos injetores}

Silvester \& Mueller (1968) afirmaram que a eficiência dos injetores pode ser expressa por várias fórmulas, dependendo dos pontos de tomada de pressão e da forma de energia considerada em cada ponto. Acrescentaram que na dedução da fórmula geral do rendimento de injetores tipo Venturi, a relação de energia utilizada baseia-se no 
conceito de energia útil para realizar o trabalho em relação à energia gasta para executálo.

Flügel ${ }^{1}$, citado por Hirschmann(1958) afirmou que qualquer injetor de água tem como valor característico o quociente $\mu$, dado por:

$$
\mu=\frac{P_{s}-P_{a}}{P_{e}-P_{s}}
$$

em que,

$\mu$ - razão entre altura líquida de elevação $\left(\mathrm{H}_{u}\right.$ til $)$ e altura líquida motriz $\left(\mathrm{H}_{m}\right)$

$P_{\mathrm{s}}$ - pressão na saída do injetor (após)

$\mathrm{P}_{\mathrm{a}}$ - pressão na seção contraída do injetor

$P_{e}$ - pressão na entrada (antes) do injetor

$\mathrm{O}$ autor também citou como características do injetor o quociente de vazão $(\delta)$ e o rendimento $(\eta)$ :

$$
\delta=\frac{Q_{2}}{Q_{1}}
$$

em que,

$\mathrm{Q}_{1}$ - vazão de elevação

$\mathrm{Q}_{2}$ - vazão motriz

$$
\eta=\frac{Q_{2} H}{Q_{1} h}=\delta \mu
$$

Carlier(1968) utilizou a mesma expressão de Flügel para o rendimento global de ejetores, admitindo que os fluidos motor e de sucção são comuns (mesmo tipo fluido). O autor assumiu que as curvas características de $H\left(Q_{2}\right)$ e $\eta\left(Q_{2}\right)$, sob carga motriz constante (h), são semelhantes às das bombas centrífugas. $\mathrm{O}$ rendimento encontrado foi sempre pequeno, no máximo 0,3 . O rendimento máximo para um injetor é dado pelo valor máximo do produto de $\mu$ por $\delta$, isto é, para

$$
\mu=\frac{\mu_{o}}{2} \quad \delta=\frac{\delta_{o}}{2}
$$

${ }^{1}$ FLÜGEL, G. Berechnung Von Strahlapparaten, VDI - Zeitschrift Bd. 83, Nr.38. 
em que,

$\mu_{0}$ - valor de $\mu$ quando $\delta=0$ (vazão motriz nula)

$\delta_{0}$ - valor de $\delta$ quando $\mu=0$ (pressão totalmente transformada em velocidade na seção de estrangulamento)

Além de $\mu$ e $\delta$ Carlier(1968) citou outro parâmetro característico do emissor, a relação m:

$$
m=\frac{S_{c}}{S_{d}}
$$

em que,

$\mathrm{S}_{\mathrm{c}}$ - área do bocal convergente

$S_{d}$ - área do bocal divergente

$\mathrm{O}$ autor apresentou um gráfico que mostra as características de $\mu(\delta) \mathrm{e}$ $\eta(\delta)$ para valores constantes da relação $m$, conforme mostra a Figura 2 . De acordo com o gráfico, o maior rendimento é obtido quando $\mathrm{m}=0,25$.

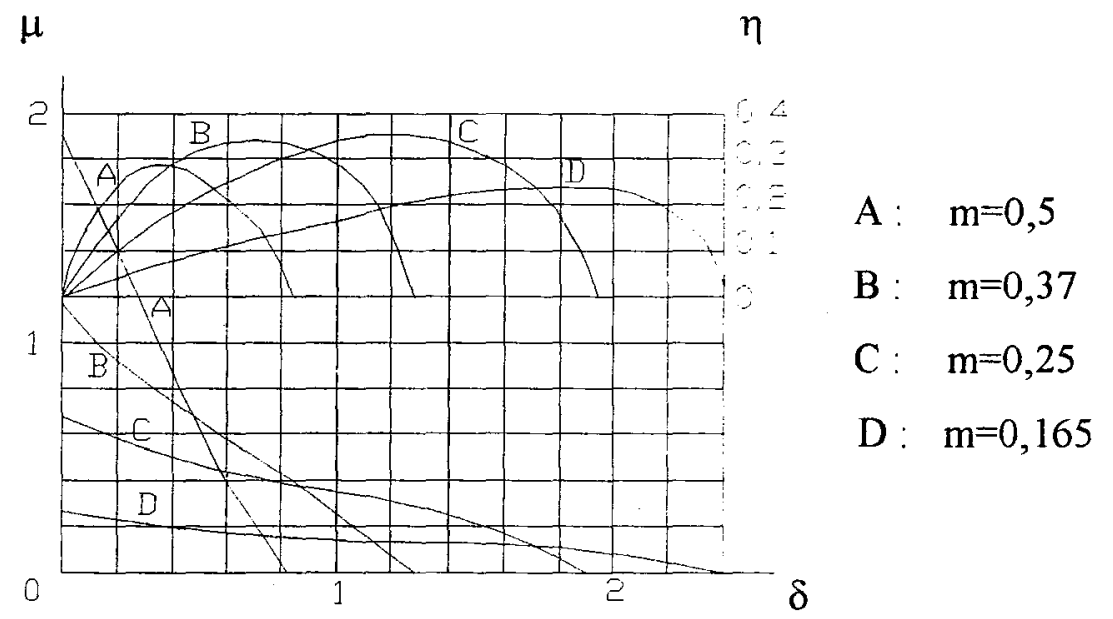

Figura 2 - Características de $\mu(\delta)$ e $\eta(\delta)$ para m constante

$\mathrm{O}$ autor também apresentou um gráfico da variação dos coeficientes $\mu \mathrm{e}$ $\delta$ para um rendimento fixo e igual a $0,3 \quad(\eta=0,3)$, conforme mostra a Figura 3.

A relação $m$ é, na verdade, uma relação entre os diâmetros dos bocais convergente e divergente. Feitosa Filho et al. (1998) avaliou o desempenho de três injeto- 
res tipo Venturi com câmara de mistura e relação m igual a $0,509,0,723$ e 0,932, comparando-os a um injetor tipo Venturi sem câmara de mistura. A presença da câmara de mistura aumentou o rendimento dos injetores, e o maior rendimento foi conseguido para o injetor de relação $\mathrm{m}$ igual a 0,509 . Os autores afirmaram que a relação $\mathrm{m}$ influiu no desempenho dos equipamentos, principalmente na vazão succionada e no rendimento. Também afirmaram que a velocidade do fluido motriz no interior da câmara de mistura foi o parâmetro que mais interferiu na variação da vazão succionada e no rendimento dos injetores.

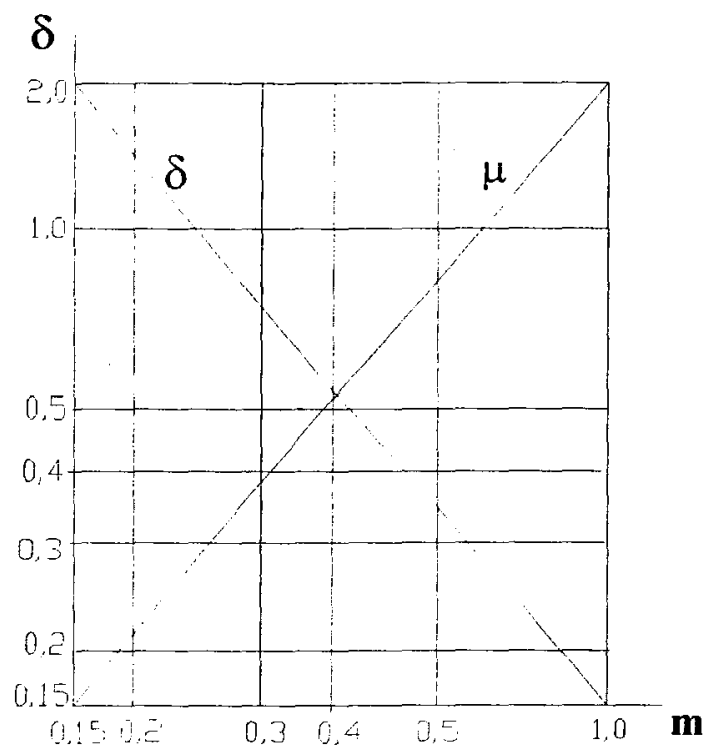

Figura 3 - Variação dos coeficientes $\mu$ e $\delta$ para $\eta=0,3$ e vários valores de $\mathrm{m}$

Zárate Rojas et al. (1996) apresentaram metodologias de desenvolvimento e avaliação de dois injetores tipo venturi para tubulações com diâmetro de $3 / 4$ e de 1 polegada (20 e $25 \mathrm{~mm}$, respectivamente). Os autores afirmaram que o maior rendimento $(10,46 \%)$ foi obtido com o injetor de 1 polegada, sob pressão de alimentação de $101,9 \mathrm{kPa}$ (10 mca). Também observaram que a vazão de sucção dos injetores diminui com o aumento da tensão de sucção.

Feitosa Filho et al. (1996) afirmaram que o injetor tipo Venturi é um equipamento que apresenta baixo rendimento e seu uso é criticado por este motivo. Os autores deduziram equações para determinar a perda de carga e o rendimento dos injeto- 
res, visando determinar as melhores condições de trabalho para cada equipamento testado. Observaram que a perda de carga média foi de $37,5 \%$ da pressão de serviço e que o maior rendimento obtido foi de $15,4 \%$. Os autores também fizeram análises de regressão polinomial para a vazão succionada em função da pressão motriz, da vazão motriz e do diferencial de pressão dos injetores, concluindo que os dados analisados são melhor representados por um modelo polinomial quadrático.

\subsection{Rendimento do conjunto injetor-bomba centrífuga}

Botrel (1996) afirmou que o rendimento energético do conjunto injetorbomba centrífuga sofre redução com o aumento do coeficiente de descarga do bocal injetor, da altura manométrica resultante, da área do bocal do injetor e do coeficiente de perda de carga do injetor.

$\mathrm{O}$ autor considerou como rendimento hidráulico do conjunto injetorbomba centrífuga $\left(\eta^{\prime}\right)$ a relação entre a potência hidráulica proveniente do conjunto injetor-bomba centrífuga e a potência hidráulica desenvolvida pela bomba centrífuga, ou seja:

$$
\eta^{\prime}=\frac{P_{u t i l}}{P_{\text {bomba }}}
$$

em que,

$\eta^{`}$ - rendimento hidráulico do conjunto injetor-bomba centrífuga

$P_{\text {bomba }}$ - potência desenvolvida pela bomba

$P_{u}$ til - potência desenvolvida pelo conjunto injetor bomba centrífuga

A potência útil pode ser descrita pela seguinte equação:

$$
P_{u t i l}=P_{b o m b a}-P_{H f}
$$

Introduzindo os termos da Equação 7 na Equação 6, o autor obteve:

$$
\eta^{\prime}=1-\frac{P_{H f}}{P_{b o m b a}}
$$

em que,

$\mathrm{P}_{\mathrm{Hf}}$ - potência consumida para suprir a perda de carga do sistema 


\subsection{Otimização do bocal do injetor}

Botrel (1996) definiu o injetor de bocal ótimo como sendo aquele que produz a máxima pressão quando associado a uma bomba centrífuga, para uma vazão preestabelecida. $\mathrm{O}$ autor criou um modelo matemático para encontrar o bocal ótimo de um injetor associado a uma bomba centrífuga.

Para proceder a otimização do bocal do injetor o autor utilizou um processo de varredura e uma equação que relaciona a vazão útil e o diferencial de pressão útil. Esta equação tem como parâmetros de entrada: os coeficiente de descarga e de perda de carga do injetor ( $\mathrm{Cd}$ e $\mathrm{K}$, respectivamente), o diâmetro do bocal do injetor $\left(\mathrm{D}_{\mathrm{boc}}\right)$, os parâmetros característicos da relação vazão-pressão de uma bomba centrífuga e a vazão útil (qutil) do sistema. Estabelecendo um valor para vazão útil e para o diâmetro do bocal do injetor, a única variável restante é o diferencial de pressão útil $\left(\Delta H_{\text {tili }}\right)$, que pode ser calculado por métodos numéricos. O autor utilizou o método de Newton-Raphson para solucionar a equação obtida.

$\mathrm{O}$ autor realizou o processo de varredura variando o valor do diâmetro do bocal do injetor desde um valor mínimo até um máximo e repetindo o cálculo do diferencial de pressão útil através do modelo matemático. Para agilizar a solução o autor criou um modelo computacional que apresenta, ao final dos cálculos, uma tabela com os valores de diâmetro do bocal, vazão útil e diferencial de pressão útil. Assim é possivel determinar qual é o diâmetro que proporciona o maior diferencial de pressão para uma determinada vazão útil. 


\section{MATERIAL E MÉTODOS}

\subsection{Pressuposições para o desenvolvimento teórico}

Há quatro pressuposições propostas por Botrel (1996) que devem ser feitas para descrever a operação de conjuntos injetor-bomba centrífuga.

A primeira pressuposição é que a relação entre vazão e pressão em bombas centrífugas é conhecida e pode ser representada pela equação

$$
\Delta H_{b o m b a}=a+b q_{b o m b a}+c q_{b o m b a}^{2}
$$

em que,

$$
\begin{aligned}
& \Delta \mathrm{H}_{\text {bomba }} \text { - diferença de pressão propiciada pela bomba centrífuga } \\
& \text { a, b e c - coeficientes da regressão polinomial } \\
& q_{\text {bomba }} \text { - vazão da bomba centrífuga }
\end{aligned}
$$

A segunda é que a relação entre vazão e pressão do bocal do injetor também é conhecida e pode ser representada pela equação

$$
q_{\text {circ }}=C_{d} S_{\text {bocal }} \sqrt{2 g\left(H_{1}-H_{2}\right)}
$$

em que,

$q_{\text {circ }}$ - vazão de recirculação

$\mathrm{C}_{\mathrm{d}}$ - coeficiente de descarga do bocal do injetor

$\mathrm{S}_{\text {bocal }}$ - área do bocal do injetor

g - aceleração da gravidade

$\mathrm{H}_{1}$ - pressão de alimentação do bocal do injetor (entrada)

$\mathrm{H}_{2}$ - pressão de descarga do bocal do injetor (saída)

A terceira é que o acoplamento do injetor será feito na tubulação de sucção 
da bomba centrífuga. Para descrever a perda de carga que ocorre no sistema formado pela bomba e o injetor, são utilizadas as fórmulas de perda de carga já conhecidas.

Para facilitar a compreensão apresenta-se, na Figura 4, o esquema de montagem do sistema injetor-bomba centrífuga.

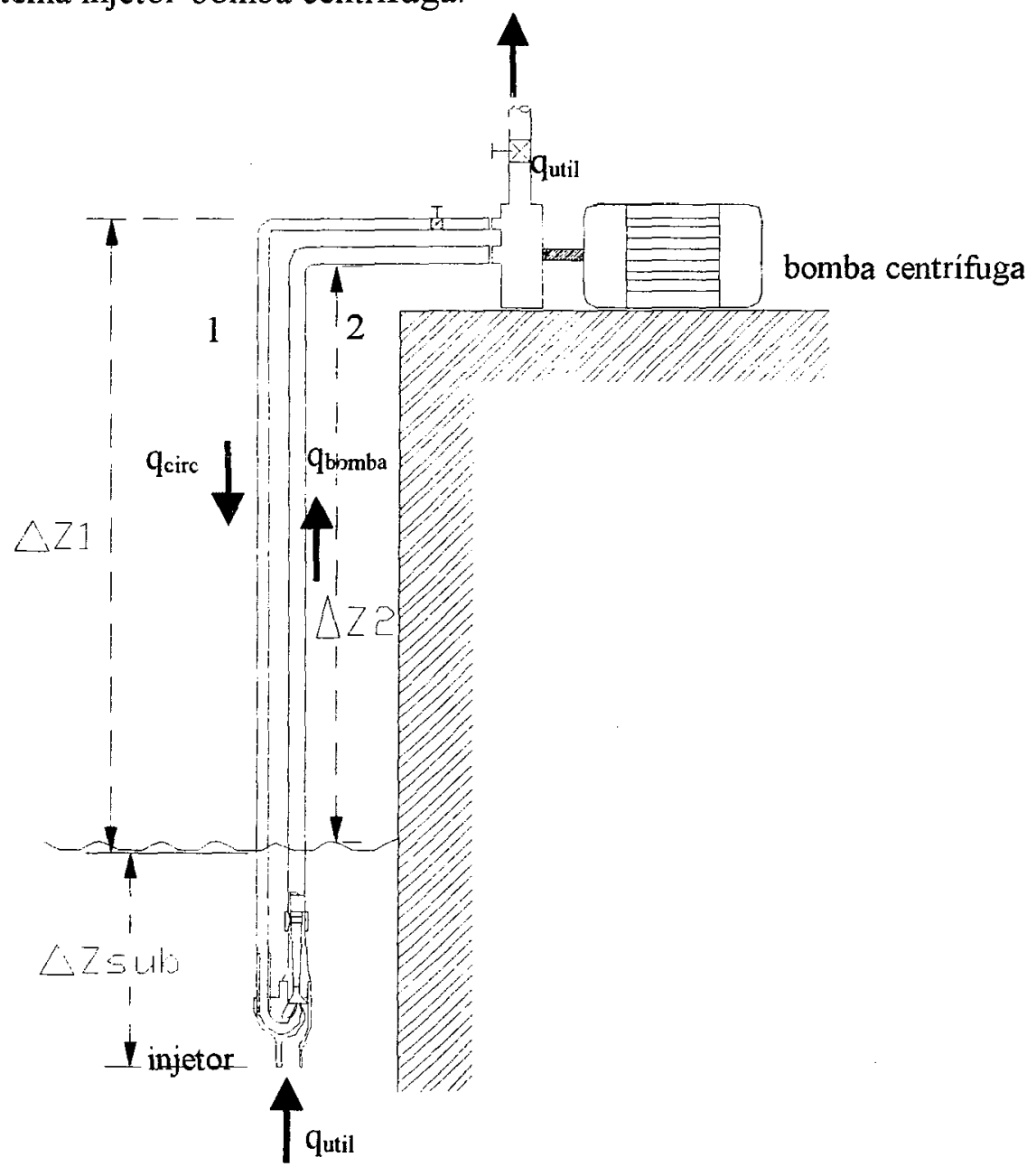

Figura 4 - Sistema injetor-bomba centrífuga

Pelo esquema é possível perceber que a bomba centrífuga envia parte de sua vazão para a tubulação de sucção (trecho 1). A passagem da água pelo bocal do injetor promove a sucção de água da fonte (poço, rio, lago etc.). A vazão elevada (qbomba) é composta por duas partes: a vazão circulante ( $\mathrm{q}_{\text {circ }}$ ) e a vazão útil ( $\left.\mathrm{q}_{\text {utii }}\right)$.

A perda de carga que ocorre no sistema é o somatório das perdas de carga 
que ocorrem no bocal do injetor, no trecho 1 e no trecho 2 da tubulação de sucção da bomba centrífuga, ou seja:

$$
H f_{\text {sist }}=H f_{b o c}+H f_{1}+H f_{2}
$$

em que,

$\mathrm{Hf}_{\text {sist }}$ - perda de carga que ocorre no sistema injetor-bomba centrífuga

$\mathrm{Hf}_{\text {boc }}$ - perda de carga no bocal do injetor

$\mathrm{Hf}_{1}$ - perda de carga no trecho da tubulação anterior ao injetor

$\mathrm{Hf}_{2}$ - perda de carga no trecho da tubulação posterior ao injetor

Várias fórmulas de perda de carga podem ser utilizadas nos cálculos, desde que sejam respeitadas as suas recomendações de utilização. Em condutos de escoamento forçado, as fórmulas mais utilizadas são:

a) Universal (Darcy-Weissbach);

b) Flamant (diâmetro menor ou igual a $50 \mathrm{~mm}$ );

c) Hazen-Williams (diâmetro entre 50 e $3000 \mathrm{~mm}, \mathrm{n}^{\circ}$ de Reynolds maior que $10^{5}$ ).

A quarta pressuposição a respeito da operação de conjuntos injetor-bomba centrífuga é que a potência desenvolvida pela bomba é igual à potência hidráulica do conjunto injetor-bomba centrifuga mais a potência hidráulica perdida no sistema de recirculação:

$$
P_{\text {bomba }}=P_{u t i l}+P_{H f s i s t}
$$

em que,

$\mathrm{P}_{\text {bomba }}$ - potência da bomba centrífuga

$P_{\text {útil }}$ - potência útil do sistema injetor-bomba centrífuga

$P_{H f s i s t}$ - potência dissipada devido à perda de carga do sistema injetor-bomba centrífuga

A potência hidráulica pode ser obtida pela equação:

$$
P_{h i d}=\gamma Q H
$$


em que,

$\gamma$ - peso específico do líquido

$\mathrm{Q}$ - vazão

H' - pressão

\subsection{Perda de carga no sistema injetor-bomba centrífuga}

No Brasil as fórmulas mais utilizadas em condutos forçados de projetos são as de Flamant e Hazen-Williams.

A equação de Flamant é utilizada em condutos com diâmetro igual ou inferior a $50 \mathrm{~mm}$, e normalmente é representada da seguinte forma:

$$
H f=\frac{4 b L}{D^{1,25}} V^{1.75}
$$

ou ainda

$$
H f=\frac{4 b L}{D^{1,25} S^{1.75}} \mathrm{Q}^{1,75}
$$

em que,

b - fator de atrito, que depende do material da tubulação

$S$ - área da seção transversal da tubulação

Q - vazão que passa pela tubulação

$\mathrm{L}$ - comprimento da tubulação

A equação de Hazen-Williams é utilizada em condutos com diâmetro entre 50 e $3000 \mathrm{~mm}$, em escoamentos de regime turbulento (Número de Reynolds acima de $5 \times 10^{5}$ ). Esta equação tem a seguinte forma:

$$
H f=\frac{10,65 L}{C^{1,852} D^{4,87}} Q^{1,852}
$$

em que,

C - fator de atrito, que depende do material da tubulação e do tempo de uso

A partir daqui será feito o desenvolvimento teórico utilizando-se as combinações possíveis entre as fórmulas de perda de carga de Flamant e de HazenWilliams, para os dois trechos da tubulação de sucção. Para o bocal do injetor será utilizada a fórmula de perdas de carga localizadas. 
Considerando-se o diâmetro dos trechos 1 e 2 da tubulação de sucção podese ter as seguintes combinações de uso das formulas de perda de carga:

Tabela 1 - Combinações de fórmulas de perda de carga de acordo com o diâmetro das tubulações de recirculação e sucção

\begin{tabular}{c|c|c|c|c}
\hline \multirow{3}{*}{ Combinação } & \multicolumn{4}{|c}{ Tubulação de Sucção } \\
\cline { 2 - 5 } & Trecho 1 & $\begin{array}{c}\text { Diâmetro } \\
(\mathrm{mm})\end{array}$ & Trecho 2 & $\begin{array}{c}\text { Diâmetro } \\
(\mathrm{mm})\end{array}$ \\
\hline 1 & Flamant & $\leq 50$ & Flamant & $\leq 50$ \\
2 & Flamant & $\leq 50$ & Hazen-Williams & $>50$ \\
3 & Hazen-Williams & $>50$ & Flamant & $\leq 50$ \\
4 & Hazen-Williams & $>50$ & Hazen-Williams & $>50$ \\
\hline
\end{tabular}

Há um detalhe, porém, que reduz o número de combinações possiveis. Os injetores são construídos de tal forma que o trecho 1 da tubulação (descida) tem diâmetro inferior ao do trecho 2 (subida). Assim conclui-se que não há a possibilidade de ocorrência do uso da fórmula de Hazen-Williams no primeiro trecho e de Flamant no segundo, eliminando-se a Combinação 3.

$\mathrm{O}$ desenvolvimento dos modelos matemáticos e do modelo computacional incluirão, portanto, as combinações 1,2 e 4 no cálculo das perdas de carga na tubulação de sucção.

\subsubsection{Perda de carga no bocal do injetor}

A perda de carga no bocal não muda com o diâmetro dos trechos 1 e 2 da tubulação de sucção, mas varia com a vazão circulante $\left(\mathrm{q}_{\text {circ }}\right)$. A equação que representa essa perda de carga é:

$$
H f_{b o c}=K \frac{V_{b o c}^{2}}{2 g}
$$

em que,

$$
\begin{aligned}
& \mathrm{K} \text { - constante obtida experimentalmente } \\
& \mathrm{V}_{\text {boc }} \text { - velocidade de escoamento do líquido no bocal } \\
& \mathrm{g} \text { - aceleração da gravidade }
\end{aligned}
$$


Sabe-se que a vazão que passa pelo bocal é a vazão circulante $\left(\mathrm{q}_{\text {circ }}\right)$. Pela Equação da Continuidade é possível concluir que:

$$
V=\frac{Q}{S}
$$

em que,

$Q$ - vazão que passa pela seção circular de um conduto forçado

$\mathrm{V}$ - velocidade de escoamento

S - área da seção transversal de um conduto forçado

Pode-se, então, reescrever a equação 17 da seguinte forma:

$$
H f_{b o c}=\frac{K}{2 g S_{b o c}^{2}} \mathrm{q}_{c i r c}^{2}
$$

É possivel reescrever a equação 19 atribuindo-se um valor para o diâmetro do bocal:

$$
H f_{b o c}=K_{1} q_{c i r c}^{2}
$$

em que,

$$
\begin{aligned}
& K_{1}=\frac{K}{2 g S_{b o c}^{2}} \\
& \mathrm{~S}_{\mathrm{boc}} \text { - área da secção transversal do bocal do injetor }
\end{aligned}
$$

\subsubsection{Combinação 1 (Flamant - Flamant)}

Observando-se a Figura 4 percebe-se que pelo trecho 1 da tubulação de sucção passa a vazão circulante ( $\mathrm{q}_{\text {circ }}$ ). Após o injetor, no trecho 2 , passam a vazão circulante e a vazão útil (qútil). A soma dessas vazões é a vazão do sistema injetor-bomba, ou simplesmente vazão da bomba $\left(\mathrm{q}_{\mathrm{bomba}}\right.$ ). Esse esquema de vazões de cada trecho será utilizado, juntamente com a Equação da Continuidade, para os cálculos de perda de carga na tubulação de sucção.

Nos trechos 1 e 2 dessa tubulação as perdas de carga são representadas pelas equações a seguir: 
Trecho 1:

$$
H f_{1}=\frac{4 b_{1} L_{1}}{D_{1}^{1,25} S_{1}^{1,75}} q_{\text {circ }}^{1,75}
$$

em que:

$$
\begin{aligned}
& \mathrm{Hf}_{1} \text { - perda de carga no trecho } 1 \\
& \mathrm{~b}_{1} \text { - fator de atrito da fórmula de Flamant para o trecho } 1 \\
& \mathrm{~L}_{1} \text { - comprimento do trecho } 1 \\
& \mathrm{D}_{1} \text { - diâmetro do trecho } 1 \\
& \mathrm{~S}_{1} \text { - área da seç̧ão transversal do trecho } 1 \\
& \mathrm{q}_{\text {circ }} \text { - vazão circulante }
\end{aligned}
$$

\section{Trecho 2:}

$$
H f_{2}=\frac{4 b_{2} L_{2}}{D_{2}^{1,25} S_{2}^{1,75}} q_{b o m b a}^{1,75}
$$

em que,

$$
\mathrm{Hf}_{2} \text { - perda de carga no trecho } 2
$$

b2 - fator de atrito da fórmula de Flamant para o trecho 2

$\mathrm{L}_{2}$ - comprimento do trecho 2

$\mathrm{D}_{2}$ - diâmetro do trecho 2

$\mathrm{S}_{2}$ - área da secção transversal do trecho 2

qbomba - vazão da bomba

Estabelecendo-se valores para o diâmetro e o comprimento de cada trecho da tubulação de sucção, e especificando o material da tubulação, é possível reescrever as Equações 22 e 23 da seguinte forma:

$$
\begin{aligned}
& H f_{1}=K_{2} q_{\text {circ }}^{1,75} \\
& H f_{2}=K_{3} q_{\text {bomba }}^{1,75}
\end{aligned}
$$

em que,

$$
\begin{aligned}
& K_{2}=\frac{4 b_{1} L_{1}}{D_{1}^{1,25} S_{1}^{1,75}} \\
& K_{3}=\frac{4 b_{2} L_{2}}{D_{2}^{1,25} S_{2}^{1,75}}
\end{aligned}
$$


A perda de carga que ocorre no sistema formado pelo injetor e pelos dois trechos da tubulação de sucção é representada pela soma das perdas de carga de cada um dos componentes. Introduzindo-se os termos das Equações 20, 24 e 25 na equação 11 obtém-se:

$$
H f_{\text {sist }}=K_{1} q_{\text {circ }}^{2}+K_{2} q_{\text {circ }}^{1,75}+K_{3} q_{\text {bomba }}^{1,75}
$$

\subsubsection{Combinação 2 (Flamant - Hazen-Williams)}

A obtenção de uma equação de perda de carga do sistema para este caso segue um raciocínio semelhante ao da combinação anterior. Partindo-se da equação 11 deve-se chegar a um resultado semelhante à equação 28 . O único termo que será modificado é o que descreve a perda de carga no trecho 2 da tubulação de sucção, no qual será utilizada a fórmula de Hazen-Williams.

No trecho 1 utiliza-se a equação 24. Para o trecho 2 tem-se:

$$
H f_{2}=\frac{10,65 L_{2}}{C_{2}^{1,852} D_{2}^{4,87}} q_{b o m b a}^{1,852}
$$

em que,

$\mathrm{C}_{2}$ - fator de atrito para o trecho 2 , dependente do material da tubulação

É possível, tal como no item anterior, tornar a equação 29 mais simples. Atribuindo-se valores ao diâmetro e ao comprimento, e especificando-se o material da tubulação no trecho2, pode-se reescrever essa equação da seguinte forma:

$$
H f_{2}=K_{4} \quad q_{b o m b a}^{1.852}
$$

em que,

$$
K_{4}=\frac{10,65 L_{2}}{C_{2}^{1,852} D_{2}^{4,87}}
$$

Assim chega-se à equação para determinação da perda de carga no sistema:

$$
H f_{\text {sist }}=K_{1} q_{\text {circ }}^{2}+K_{2} q_{\text {circ }}^{1,75}+K_{4} q_{\text {bomba }}^{1,852}
$$




\subsubsection{Combinação 3 (Hazen-Williams - Hazen-Williams)}

Neste caso ambas as equações de perda de carga do sistema utilizam a fórmula de Hazen-Williams. A equação 30 continua a determinar a perda de carga no trecho 2, tal qual no item anterior. A perda de carga no trecho 1 será determinada por:

$$
H f_{1}=\frac{10,65 L_{1}}{C_{1}^{1,852} D_{1}^{4,87}} q_{\text {circ }}^{1,852}
$$

em que,

$\mathrm{C}_{1}$ - fator de atrito para o trecho 1 , dependente do material da tubulação

Semelhantemente às combinações anteriores, parte da equação 33 pode tornar-se constante através da especificação do material da tubulação e da atribuição de valores ao diâmetro e comprimento do trecho1. A equação 33 torna-se, então:

$$
H f_{1}=K_{5} q_{\text {circ }}^{1,852}
$$

em que,

$$
K_{5}=\frac{10,65 L_{1}}{C_{1}^{1,852} D_{1}^{1,852}}
$$

Assim chega-se à equação que determina a perda de carga no sistema, neste caso:

$$
H f_{\text {sist }}=K_{1} q_{\text {circ }}^{2}+K_{5} q_{\text {circ }}^{1,852}+K_{4} q_{\text {bomba }}^{1,852}
$$

\subsection{Explicitação da vazão circulante ( $q_{\text {circ }}$ em equações solucionáveis por métodos numéricos}

Com a introdução dos termos das Equações 11 e 13 na equação 12, e sabendo-se que a perda de carga é composta por três partes distintas (bocal, trecho 1 e trecho 2 da sucção), chega-se a:

$$
\gamma q_{b o m b a} \Delta H_{b o m b a}=\gamma q_{u t i l} \Delta H_{u t i l}+\gamma q_{c i r c} H f_{b o c}+\gamma q_{c i r c} H f_{1}+\gamma q_{b o m b a} H f_{2}
$$


O incremento de pressão fornecido pela bomba é uma função conhecida e está representado pela equação 9 . A introdução dessa equação na equação 37 e a divisão de todos os termos por $\gamma$ resulta em:

$$
a q_{b o m b a}+b q_{b o m b a}^{2}+c q_{b o m b a}^{3}=q_{u t i l} \Delta H_{\text {atil }}+q_{c i r c}\left(H f_{b o c a l}+H f_{1}\right)+q_{b o m b a} H f_{2}
$$

$\mathrm{O}$ termo $\Delta \mathrm{H}_{\text {util }}$ representa um incremento de pressão útil, ou seja, o somatório da energia presente na massa de água que passa pela tubulação de recalque e da energia necessária para elevar a água até a bomba centrífuga. Assim tem-se:

$$
\Delta H_{u t i l}=\frac{\text { Pres }_{u t i l}}{\gamma}+\Delta z_{1}
$$

em que,

$\Delta \mathrm{H}_{\text {util }}$ - diferencial de pressão útil, mca

Pres $_{\text {util }}$ - pressão útil, $\mathrm{kgf} / \mathrm{m}^{2}$

$\gamma$ - peso específico do fluido, $\mathrm{kgf} / \mathrm{m}^{3}$

A partir deste ponto deve-se introduzir as equações de perda de carga calculadas nos itens 3.2.1 a 3.2.4, de acordo com a combinação de diâmetros dos dois trechos da tubulação de sucção.

\subsubsection{Combinação 1 - (Flamant - Flamant)}

A introdução dos termos da equação 28 na equação 38 e o agrupamento de todos os termos do lado esquerdo da igualdade resultam em:

$$
a q_{b o m b a}+b q_{b o m b a}^{2}+c q_{b o n b a}^{3}-q_{u t i l} \Delta H_{u t i l}-q_{c i r c}\left(K_{1} q_{c i r c}^{2}+K_{2} q_{c i r c}^{1,75}\right)-q_{b o m b a} K_{3} q_{b o m b a}^{1,75}=0
$$

Desenvolvendo os termos da equação 40 chega-se a:

$$
a q_{b o m b a}+b q_{b o m b a}^{2}+c q_{b o m b a}^{3}-q_{u t i l} \Delta H_{u t i l}-K_{1} q_{c i r c}^{3}-K_{2} q_{c i r c}^{2,75}-K_{3} q_{b o m b a}^{2,75}=0
$$

A vazão que flui pela bomba é igual à soma da vazão circulante com a vazão útil, ou seja:

$$
q_{b o m b a}=q_{c i r c}+q_{u t i l}
$$


Introduzindo os termos da equação 42 na equação 41 tem-se:

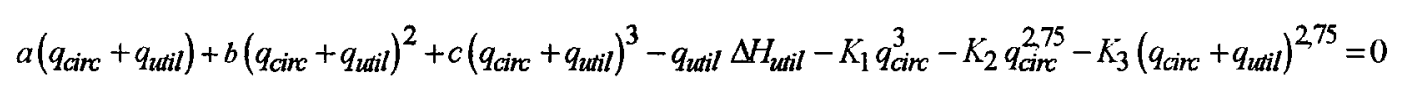

Evoluindo a equação 43 obtem-se:

$$
\begin{aligned}
& a q_{c i r c}+a q_{u t i l}+b q_{c i r c}^{2}+2 b q_{c i r c} q_{u t i l}+b q_{u t i l}^{2}+c q_{c i r c}^{3}+3 c q_{c i r c}^{2} q_{u t i l}+3 c q_{c i r c} q_{u t i l}^{2}+c q_{u t i l}^{3}- \\
& -\Delta H_{\text {util }} q_{\text {util }}-K_{1} q_{c i r c}^{3}-K_{2} q_{c i r c}^{2,75}-K_{3}\left(q_{c i r c}+q_{u t i l}\right)^{2,75}=0
\end{aligned}
$$

A vazão circulante é aquela que passa pelo bocal do injetor. A equação 10 relaciona a vazão circulante $\left(\mathrm{q}_{\text {circ }}\right)$ e a diferença entre a pressão de alimentação e a pressão de descarga do injetor. A pressão de alimentação é aquela existente no final do trecho 1 da tubulação de sucção, e a pressão de descarga é a que está presente na câmara de mistura do injetor.Assim,

$$
q_{\text {circ }}=C_{d} S_{\text {bocal }} \sqrt{2 g \Delta H_{i}}
$$

Essa diferença é chamada de diferencial de pressão do injetor ( $\Delta \mathrm{Hi})$, que é definido pela equação:

$$
\Delta H_{i}=\frac{\operatorname{Pres}_{u t i l}}{\gamma}+\Delta z_{1}-H f_{1}-\Delta z_{s u b}
$$

Mas sabe-se, pela equação 39 , que

$$
\Delta H_{u t i l}=\frac{\text { Pres }_{\text {util }}}{\gamma}+\Delta z_{1}
$$

Então a expressão de $\Delta H i$ torna-se

$$
\Delta H_{i}=\Delta H_{u t i l}-H f_{1}-\Delta z_{\text {sub }}
$$

Pode-se obter a expressão da vazão circulante do sistema injetor-bomba centrífuga através da introdução dos termos da equação 47 na equação 45 :

$$
q_{\text {circ }}=C_{d} S_{\text {bocal }} \sqrt{2 g\left(\Delta H_{u t i l}-H f_{1}-\Delta z_{\text {sub }}\right)}
$$

ou ainda: 


$$
q_{c i r c}=K_{6} \sqrt{\Delta H_{u t i l}-H f_{1}-\Delta z_{s u b}}
$$

em que,

$$
K_{6}=C_{d} S_{\text {bocal }} \sqrt{2 g}
$$

A partir da equação 49 pode-se isolar o termo $\Delta$ Hútil da seguinte forma:

$$
\Delta H_{u t i l}=\frac{q_{c i r c}^{2}}{K_{6}^{2}}+H f_{1}+\Delta z_{s u b}
$$

Sabe-se, pela observação da equação 24 , que a perda de carga no trecho 1 da tubulação $\left(\mathrm{Hf}_{1}\right)$ pode ser definida por:

$$
H f_{1}=K_{2} q_{\text {circ }}^{1,75}
$$

Então a equação 51 pode ser reescrita:

$$
\Delta H_{u t i l}=\frac{q_{c i r c}^{2}}{K_{6}^{2}}+K_{2} q_{c i r c}^{1,75}+\Delta z_{s u b}
$$

Introduzindo os termos da equação 53 na equação 44 chega-se a:

$$
\begin{aligned}
& a q_{c i r c}+a q_{u t i l}+b q_{c i r c}^{2}+2 b q_{c i r c} q_{u t i l}+b q_{u t i l}^{2}+c q_{c i r c}^{3}+3 c q_{c i r c}^{2} q_{u t i l}+3 c q_{c i r c} q_{u t i l}^{2}+c q_{u t i l}^{3}- \\
& -\left(\frac{q_{c i n c}^{2}}{K_{6}^{2}}+K_{2} q_{c i r c}^{1,75}+\Delta z_{\text {sub }}\right) q_{u t i l}-K_{1} q_{c i r c}^{3}-K_{2} q_{c i r c}^{2,75}-K_{3}\left(q_{c i r c}+q_{u t i l}\right)^{2,75}=0
\end{aligned}
$$

ou ainda:

$$
\begin{aligned}
& a q_{c i r c}+a q_{u t i l}+b q_{c i r c}^{2}+2 b q_{c i r c} q_{u t i l}+b q_{u t i l}^{2}+c q_{c i r c}^{3}+3 c q_{c i r c}^{2} q_{u t i l}+3 c q_{c i r c} q_{u t i l}^{2}+c q_{u t i l}^{3}- \\
& -\frac{q_{u t i l}}{K_{6}^{2}} q_{c i r c}^{2}-K_{2} q_{u t i l} q_{c i r c}^{1,75}+\Delta z_{\text {sub }} q_{u t i l}-K_{1} q_{c i r c}^{3}-K_{2} q_{c i r c}^{2,75}-K_{3}\left(q_{c i r c}+q_{u t i l}\right)^{2,75}=0
\end{aligned}
$$

Agrupando os os termos semelhantes em q qirc obtem-se:

$$
\begin{aligned}
& \left(c-K_{1}\right) q_{c i r c}^{3}-K_{2} q_{c i r c}^{2,75}-K_{3}\left(q_{c i r c}+q_{u t i l}\right)^{2,75}+\left(b+3 c q_{u t i l}-\frac{q_{u t i l}}{K_{6}^{2}}\right) q_{c i r c}^{2}-K_{2} q_{u t i l} q_{c i r c}^{1,75}+ \\
& +\left(a+2 b q_{u t i l}+3 c q_{u t i l}^{2}\right) q_{c i r c}+\left(a-\Delta v_{s u b}\right) q_{u t i l}+b q_{u t i l}^{2}+c q_{u t i l}^{3}=0
\end{aligned}
$$

Atribuindo um valor a qútil chega-se a: 


$$
\left(c-K_{1}\right) q_{c i r c}^{3}-K_{2} q_{c i r c}^{2,75}-K_{3}\left(q_{c i r c}+q_{u t i l}\right)^{2,75}+K_{7} q_{c i r c}^{2}-K_{8} q_{c i r c}^{1,75}+K_{9} q_{c i r c}+K_{10}=0
$$

em que,

$$
\begin{aligned}
& K_{7}=b+3 c q_{u t i l}-\frac{q_{u t i l}}{K_{6}^{2}} \\
& K_{8}=K_{2} q_{u t i l} \\
& K_{9}=a+2 b q_{u t i l}+3 c q_{u t i l}^{2} \\
& K_{10}=\left(a-\Delta z_{\text {sub }}\right) q_{u t i l}+b q_{u t i l}^{2}+c q_{u t i l}^{3}
\end{aligned}
$$

A equação 57 pode ser resolvida por métodos numéricos, fornecendo o valor da vazão circulante. A partir dessa vazão pode-se calcular o valor de $\Delta H_{\text {útil }}$, utilizando a equação 51. Com o valor de qưtil e quirc pode-se obter a vazão da bomba ( $q_{b o m b a}$, equação 42) e, conseqüentemente, o diferencial de pressão da bomba $\left(\Delta \mathrm{H}_{\text {bomba }}\right.$, equação 9$)$.

A equação 57 é solucionada por meio de um método numérico iterativo denominado Método de Newton-Raphson. A metodologia para sua solução será apresentada em um item específico. $\mathrm{O}$ mesmo método será utilizado também para a solução .das equações das demais combinações de fórmulas de perda de carga.

\subsubsection{Combinação 2 (Flamant - Hazen-Williams)}

A equação 32 representa a perda de carga que ocorre no sistema, neste caso. Utiliza-se a fórmula de perdas de carga localizadas para o injetor (primeiro termo da equação 32) e as fórmulas de Flamant e Hazen-Williams para o trechos 1 e 2 da tubulação de sucção, respectivamente (segundo e terceiro termos da equação 32).

Analogamente à combinação anterior, será obtida a equação que explicita a vazão circulante do sistema injetor-bomba centrífuga. Introduzindo a equação 32 (ao invés da equação 28 , utilizada no item anterior) na equação 38 obtém-se:

$a q_{b o n b a}+b q_{b o m b a}^{2}+c q_{b o m b a}^{3}-q_{u t i l} \Delta H_{u i l}-q_{c i r c}\left(K_{1} q_{c i r c}^{2}+K_{2} q_{c i r c}^{1,75}\right)-q_{b o m b a} K_{4} q_{b o m b a}^{1,852}=0$ 
A introdução dos termos das Equações 42 e 51 na equação 62 resulta em:

$$
\begin{aligned}
& a\left(q_{c i r c}+q_{u t i l}\right)+b\left(q_{c i r c}+q_{u t i l}\right)^{2}+c\left(q_{c i r c}+q_{u t i l}\right)^{3}-q_{u t i l}\left(\frac{q_{c i r c}^{2}}{K_{6}^{2}}+H f_{1}+\Delta z_{s u b}\right)-K_{1} q_{c i r c}^{3}- \\
& -K_{2} q_{c i r c}^{2,75}-K_{4}\left(q_{c i r c}+q_{u t i l}\right)^{2,852}=0
\end{aligned}
$$

Inserindo os termos da equação 24 na equação 63 (Cálculo de $\mathrm{Hf}_{1}$ ), fazendose sua evolução, atribuindo um valor a qutil e agrupando os termos semelhantes em relação a q $_{\text {circ }}$, chega-se a:

$$
\left(c-K_{1}\right) q_{\text {circ }}^{3}-K_{2} q_{\text {circ }}^{2,75}-K_{4}\left(q_{\text {circ }}+q_{\text {util }}\right)^{2,852}+K_{7} q_{\text {circ }}^{2}-K_{8} q_{\text {circ }}^{1,75}+K_{9} q_{\text {circ }}+K_{10}=0
$$

A equação 64 pode ser resolvida por métodos numéricos e o restante do processo é semelhante ao item anterior.

\subsubsection{Combinação 3 (Hazen-Williams - Hazen-Williams)}

Utiliza-se a fórmula de Hazen-Williams no cálculo das perdas de carga em ambos os trechos da tubulação. Introduzindo a equação 36 na equação 38 obtem-se:

$$
a q_{b o m b a}+b q_{b o m b a}^{2}+c q_{b o m b a}^{3}-q_{u t i l} \Delta H_{u t i l}-q_{c i r c}\left(K_{1} q_{c i r c}^{2}+K_{5} q_{c i r c}^{1,852}\right)-q_{b o m b a} K_{4} q_{b o m b a}^{1,852}=0
$$

A introdução dos termos das Equações 42 e 5 Ina equação 65 resulta em:

$$
\begin{aligned}
& a\left(q_{c i n c}+q_{u t i l}\right)+b\left(q_{c i n c}+q_{u t i l}\right)^{2}+c\left(q_{c i n c}+q_{u t i l}\right)^{3}-q_{u t i l}\left(\frac{q_{c i r c}^{2}}{K_{6}^{2}}+H f_{1}+\Delta z_{s u b}\right)-K_{1} q_{c i r c}^{3}- \\
& -K_{5} q_{c i n c}^{2,852}-K_{4}\left(q_{c i r c}+q_{u t i l}\right)^{2,852}=0
\end{aligned}
$$

Introduzindo os termos da equação 34 na equação 66 (Cálculo de $\mathrm{Hf}_{1}$ ), fazendo-se sua evolução, atribuindo um valor a qútil e agrupando os termos semelhantes em relação a $q_{\text {circ }}$, chega-se a:

$$
\begin{aligned}
& \left(c-K_{1}\right) q_{\text {circ }}^{3}-K_{5} q_{\text {circ }}^{2,852}-K_{4}\left(q_{\text {circ }}+q_{\text {util }}\right)^{2,75}+K_{7} q_{\text {circ }}^{2}-K_{11} q_{\text {circ }}^{1,852}+K_{9} q_{\text {circ }}+K_{10}=0 \\
& \text { em que, } \\
& \quad K_{11}=K_{5} \text { qutil }
\end{aligned}
$$


A equação 67 pode ser resolvida por métodos numéricos e o restante do processo de cálculo é semelhante às combinações anteriores.

\subsubsection{Resolução das equações de vazão circulante $\left(q_{\text {circ }}\right)$}

Nos itens 3.3.1 a 3.3.3 foram desenvolvidas 3 equações que explicitam a vazão circulante. Neste item mostra-se o método de resolução das equações obtidas.

O método a ser utilizado é o de Newton-Raphson. É um método iterativo que se inicia atribuirıdo um valor à variável da função (neste caso, $\mathrm{q}_{\mathrm{circ}}$ ). A seguir utiliza-se a seguinte equação para encontrar o próximo valor da variável :

$$
x_{i}=x_{i-1}-\frac{f\left(x_{i-1}\right)}{f^{\prime}\left(x_{i-1}\right)}
$$

em que,

$\mathrm{x}_{\mathrm{i}}$ - valor da variável na i-ésima iteração

$\mathrm{x}_{\mathrm{i}-1}$ - valor da variável na (i-1)-ésima iteração

$\mathrm{f}\left(\mathrm{x}_{\mathrm{i}-1}\right)$ - valor da função para o (i-1)-ésimo valor da variável

$f^{\prime}\left(x_{i-1}\right)$ - valor da derivada da função para o (i-1)-ésimo valor da variável

O processo é repetido várias vezes até que a diferença entre o valor de uma iteração e o valor da seguinte seja inferior ao valor limite, de acordo com o critério estabelecido por quem se utiliza do método.

Neste caso em particular tem-se:

$$
\begin{aligned}
& x=q_{\text {circ }} \\
& x_{o}=q_{\text {max }}
\end{aligned}
$$

Critério de parada: $\left|x_{i}-x_{i-1}\right| \leq 0,0000001 x_{i}$

Devem ser solucionadas por este método as equações 57,64 e 67. A seguir são apresentadas as suas derivadasem relação à vazão circulante $\left(\mathrm{q}_{\text {circ }}\right)$. 
Equação 57:

$$
\left(c-K_{1}\right) q_{\text {circ }}^{3}-K_{2} q_{\text {circ }}^{2,75}-K_{3}\left(q_{\text {circ }}+q_{\text {util }}\right)^{2,75}+K_{7} q_{\text {circ }}^{2}-K_{8} q_{\text {circ }}^{1,75}+K_{9} q_{c i r c}+K_{10}=0
$$

Derivada:

$$
3\left(c-K_{1}\right) q_{\text {circ }}^{2}-2,75 K_{2} q_{\text {circ }}^{1,75}-2,75 K_{3}\left(q_{\text {circ }}+q_{\text {util }}\right)^{1,75}+2 K_{7} q_{\text {circ }}-1,75 K_{8} q_{\text {circ }}^{0,75}+K_{9}^{\prime}=0
$$

Equação 64:

$$
\left(c-K_{1}\right) q_{\text {circ }}^{3}-K_{2} q_{\text {circ }}^{2,75}-K_{4}\left(q_{\text {circ }}+q_{\text {udil }}\right)^{2,852}+K_{7} q_{\text {circ }}^{2}-K_{8} q_{\text {circ }}^{1,75}+K_{9} q_{\text {circ }}+K_{10}=0
$$

Derivada:

$$
3\left(c-K_{1}\right) q_{\text {circ }}^{2}-2,75 K_{2} q_{\text {circ }}^{1,75}-2,852 K_{4}\left(q_{\text {circ }}+q_{\text {util }}\right)^{1,852}+2 K_{7} q_{\text {circ }}-1,75 K_{8} q_{\text {circ }}^{0,75}+K_{9}=0
$$

Equação 67:

$$
\left(c-K_{1}\right) q_{c i r c}^{3}-K_{5} q_{\text {circ }}^{2,852}-K_{4}\left(q_{\text {circ }}+q_{\text {util }}\right)^{2,75}+K_{7} q_{\text {circ }}^{2}-K_{11} q_{\text {circ }}^{1,852}+K_{9} q_{\text {circ }}+K_{10}=0
$$

Derivada:

$$
3\left(c-K_{1}\right) q_{c i r c}^{2}-2,852 K_{5} q_{c i r c}^{1,852}-2,75 K_{4}\left(q_{c i r c}+q_{\text {util }}\right)^{1,75}+2 K_{7} q_{\text {circ }}-1,852 K_{11} q_{c i r c}^{0,852}+K_{9}=0
$$

Após a obtenção do valor da vazão circulante ( $\left.\mathrm{q}_{\text {circ }}\right)$ faz-se o cálculo de $\Delta \mathrm{H}_{\text {útil }}$ utilizando a equação 53.

Com o valor de $\mathrm{q}_{\text {circ }}$ e qútil pode também calcular a vazão da bomba ( $\mathrm{q}_{\text {bomba }}$, equação 42) e, conseqüentemente, o valor de $\Delta \mathrm{H}_{\text {bomba }}$ (equação 9).

\subsection{Cálculo do rendimento do conjunto injetor-bomba centrífuga}

O rendimento do conjunto é definido na equação 8 como sendo

$$
\eta^{\prime}=1-\frac{P_{H f}}{P_{b o m b a}}
$$

Pela equação 12 sabe-se que

$$
P_{\text {bomba }}=P_{\text {util }}+P_{H f}
$$

Substituindo os termos da equação 12 na equação 8 tem-se:

$$
\eta^{\prime}=1-\frac{P_{H f}}{P_{u t i l}+P_{H f}}
$$


A equação 13 mostra que

$$
P_{h i d}=\gamma Q H
$$

Substituindo os termos da equação 13 na equação 71 , e sabendo que a perda de carga que ocorre no sistema injetor-bomba é composto por 3 partes (bocal trecho $1 \mathrm{e}$ trecho 2 da sucção), obtem-se:

$$
\eta^{\prime}=1-\frac{\gamma q_{c i r c} H f_{b o c a l}+\gamma q_{c i r c} H f_{1}+\gamma q_{b o m b a} H f_{2}}{\gamma q_{u t i l} \Delta H_{u t i l}+\gamma q_{c i r c} H f_{\text {bocal }}+\gamma q_{c i r c} H f_{1}+\gamma q_{b o m b a} H f_{2}}
$$

A equação 42 mostra que

$$
q_{\text {bomba }}=q_{c i r c}+q_{u t i l}
$$

Introduzindo os termos da equação 42 na equação 72 chega-se a:

$$
\eta^{\prime}=1-\frac{q_{c i r c} H f_{\text {bocal }}+q_{c i r c} H f_{1}+\left(q_{c i r c}+q_{u t i l}\right) H f_{2}}{q_{u t i l} \Delta H_{u t i l}+q_{c i r c} H f_{\text {bocal }}+q_{c i r c} H f_{1}+\left(q_{c i r c}+q_{u t i l}\right) H f_{2}}
$$

Reunindo os termos semelhantes obtem-se:

$$
\eta^{\prime}=1-\frac{q_{c i r c}\left(H f_{\text {bocal }}+H f_{1}+H f_{2}\right)+q_{u t i l} H f_{2}}{q_{c i r c}\left(H f_{\text {bocal }}+H f_{1}+H f_{2}\right)+q_{u t i l}\left(\Delta H_{u t i l}+H f_{2}\right)}
$$

A seguir apresenta-se a simplificação da equação 74 em três passos, chegando-se à equação final do rendimento do conjunto injetor-bomba centrífuga:

a) Voltando o primeiro termo para a forma de fração:

$$
\eta=\frac{q_{c i r c}\left(H f_{\text {bocal }}+H f_{1}+H f_{2}\right)+q_{u t i l}\left(\Delta H_{u t i l}+H f_{2}\right)-q_{c i r c}\left(H f_{\text {bocal }}+H f_{1}+H f_{2}\right)-q_{u t i l} H f_{2}}{q_{c i r c}\left(H f_{\text {bocal }}+H f_{1}+H f_{2}\right)+q_{u t i l}\left(\Delta H_{u t i l}+H f_{2}\right)}
$$

b) Subtraindo os termos semelhantes (iguais):

$$
\eta=\frac{q_{u t i l}\left(\Delta H_{u t i l}+H f_{2}\right)-q_{u t i l} H f_{2}}{q_{\text {circ }}\left(H f_{\text {bocal }}+H f_{1}+H f_{2}\right)+q_{u t i l}\left(\Delta H_{u t i l}+H f_{2}\right)}
$$

c) Evoluindo os termos do numerador:

$$
\eta^{\prime}=\frac{q_{u t i l} \Delta H_{u t i l}}{q_{\text {circ }} H f_{\text {sist }}+q_{\text {util }}\left(\Delta H_{u t i l}+H f_{2}\right)}
$$


A partir daqui cada combinação de equações de perda de carga levará a uma expressão particular para o rendimento do conjunto injetor-bomba centrífuga. Seu cálculo pode, entretanto, ser feito a partir da equação 77 , pois todos os seus termos podem ser calculados através da metodologia apresentada no item 3.3.4.

Com a teoria apresentada até aqui pode-se obter, por varredura, a relação entre a vazão útil ( $\left.\mathrm{q}_{\text {útil }}\right)$ e o diferencial de pressão útil $\left(\Delta \mathrm{H}_{\text {utili }}\right)$. Inicia-se o processo de cálculo com vazão útil nula ( $q_{\text {uutil }}=0$ ), calculando-se o valor de $\mathrm{q}_{\text {circ }}, \Delta \mathrm{H}_{\text {util }}, \Delta \mathrm{H}_{\text {bomba }}$ e do rendimento do conjunto injetor-bomba $\left(\eta^{\prime}\right)$. A partir dos valores iniciais deve-se incrementar o valor de $q_{\text {útil }}$ e calcular os valores das outras variáveis citadas neste parágrafo. O processo deve continuar até que um dos seguintes critérios de finalização sejam verdadeiros:

a) se o valor calculado de qbomba ultrapassar o máximo, que é obtido por experimentação;

b) se o valor de $\Delta \mathrm{H}_{\text {bomba }}$ tornar-se negativo;

c) se o rendimento for menor ou igual a zero.

De forma a aumentar a compreensão do funcionamento do sistema é interessante apresentar os resultados do cálculo das perdas de carga que ocorrem em cada parte do sistema, bem como a perda de carga total do mesmo. Essas variáveis podem ser apresentadas facilmente junto às demais envolvidas no funcionamento do sistema, pois fazem parte do processo de cálculo.

\subsection{Otimização do bocal do injetor}

Botrel(1996) formulou o conceito de bocal ótimo como sendo aquele que produz a máxima pressão para uma vazão preestabelecida, quando associado a uma bomba centrífuga. $O$ procedimento adotado para otimização do bocal do injetor neste trabalho foi adaptado a partir da metodologia do autor supracitado. $O$ método de otimização segue o mesmo processo de obtenção da relação entre vazão útil e diferencial de pressão útil, acrescentando apenas um processo de varredura para a variável $D_{\text {boc }}$ (diâmetro do bocal). 
Todos os parâmetros de entrada do processo de cálculo já são conhecidos, exceto o diâmetro do bocal. A partir daí estabelece-se um valor inicial (o menor possível) para o diâmetro do bocal, iniciando-se o processo de cálculo com a obtenção das constantes envolvidas no processo: $\mathrm{K}_{1}, \mathrm{~K}_{2}, \mathrm{~K}_{3}, \mathrm{~K}_{4}, \mathrm{~K}_{5}$ e $\mathrm{K}_{6}$.

Fixando valores para qútil entre um valor máximo e um mínimo, pode-se calcular as outras constantes $\left(K_{7}, K_{8}, K_{9}, K_{10}, K_{11}\right)$ e encontrar a relação entre qútil e $\Delta \mathrm{H}_{\text {util. }} \mathrm{O}$ valor máximo de $\Delta \mathrm{H}_{\mathrm{u} t \text { til }}$ é encontrado através do exame dos cálculos efetuados, ou de um gráfico dos resultados obtidos para um determinado valor de qutili.

Neste trabalho foi adotada a apresentação gráfica dos resultados, pois é uma maneira bastante adequada para a visualização dos resultados. Em um gráfico pode-se apresentar as curvas $\Delta \mathrm{H}_{\mathrm{uttil}} \times \mathrm{D}_{\mathrm{boc}}$ para os diversos valores de vazão útil preestabelecidos.

\subsection{Montagem experimental}

\subsubsection{Descrição geral do experimento}

Foi montado um experimento para verificar a aplicação do modelo matemático proposto. Foram escolhidos três modelos de bombas centrífugas da marca JACUZZI (3500 rpm), cada uma com seu respectivo modelo de injetor, conforme podese observar na Tabela 2. Juntamente à descrição dos modelos de bombas e injetores vem o diâmetro interno dos dois trechos de tubulação de sucção a serem usados (trecho 1 antes e trecho 2 após o injetor).

Tabela 2 - Conjuntos bomba-injetor JACUZZI utilizados no experimento

\begin{tabular}{ccc|cc}
\hline Modelo & $\begin{array}{c}\text { Potência } \\
\text { (CV) }\end{array}$ & $\begin{array}{c}\text { Diâmetro do bocal } \\
(\mathrm{mm})\end{array}$ & \multicolumn{2}{c}{ Tubulação de sucção } \\
\cline { 4 - 5 } & 3 & 5.9 & $\mathrm{D}_{1}(\mathrm{~mm})$ & $\mathrm{D}_{2}(\mathrm{~mm})$ \\
\hline 3VJE15-M 39G & 2 & 8,0 & 27.5 & 35.6 \\
2VJF15-T 39B & 2 & 6,1 & 35,6 & 43,5 \\
1VJF15-M 38J & 1 & 35,6 & 43,5 \\
\hline
\end{tabular}

Os objetivos do experimento são: a) obtenção dos parâmetros característicos das bombas centrífugas e dos injetores; b) observação do funcionamento dos conjuntos formados por uma bomba centrífuga, tubulação de sucção e um injetor, e comparação 
dos dados observados com os previstos pelo modelo matemático desenvolvido.

$\mathrm{O}$ experimento foi executado em duas etapas. A primeira foi realizada a uma altura de sucção de $16,47 \mathrm{~m}$ e a segunda, a $11,97 \mathrm{~m}$. Isto foi feito para verificar a precisão do modelo matemático na descrição do funcionamento dos conjuntos bombainjetor.

Para que se possa inserir as informações necessárias à execução do modelo é preciso conhecer as características da bomba centrífuga, do injetor e da tubulação de sucção. A tubulação de suç̧ão é subdividida em dois trechos $\left(\begin{array}{lll}1 & \text { e }\end{array}\right)$ de diâmetros diferentes $\left(D_{1}<D_{2}\right)$ devido à diferença de vazão em cada um. A respeito da tubulação é necessário conhecer o diâmetro e o material da mesma em cada trecho.

Os testes necessários para a obtenção dos parâmetros dos injetores e das bombas são os mesmos para ambas as alturas de sucção, e serão descritos nos itens a seguir.

\subsubsection{Testes para obtenção de parâmetros das bombas centrífugas}

Os parâmetros característicos da bomba centrífuga serão obtidos através do levantamento de sua curva de vazão x pressão. A partir desses dados pode-se obter, por regressão polinomial, os coeficientes empíricos $\mathbf{a}, \mathbf{b}$ e $\mathbf{c}$, que descrevem a relação vazão $\mathrm{x}$ pressão expressa pela equação 9 .

Para a obtenção dos parâmetros das bombas foi montada uma bancada para os testes, na qual foram medidos os pares de valores de vazão e pressão. Após a medição foi feita a regressão polinomial e calculou-se os parâmetros a, b e c.

\subsubsection{Testes para obtenção de parâmetros dos injetores}

Os parâmetros característicos do injetor são: diâmetro do bocal, coeficiente de perda de carga $(\mathrm{K})$ e coeficiente de descarga $(\mathrm{Cd})$. O diâmetro do bocal foi medido com paquímetro digital de precisão $0.05 \mathrm{~mm}$. Fixou-se a profundidade de imersão do injetor em $0,75 \mathrm{~m}$ para todos os conjuntos bomba-injetor.

Para se obter os coeficientes $\mathrm{K}$ e $\mathrm{Cd}$ do injetor foi montado o esquema 
experimental apresentado na Figura 5. A instalação dos conjuntos bomba-injetor foi feita no Laboratório de Hidráulica do Departamento de Engenharia Rural. As bombas centrífugas foram instaladas em uma torre de abastecimento de água, a 16,47 m de altura, na primeira etapa de testes, e a $11,97 \mathrm{~m}$, na segunda.

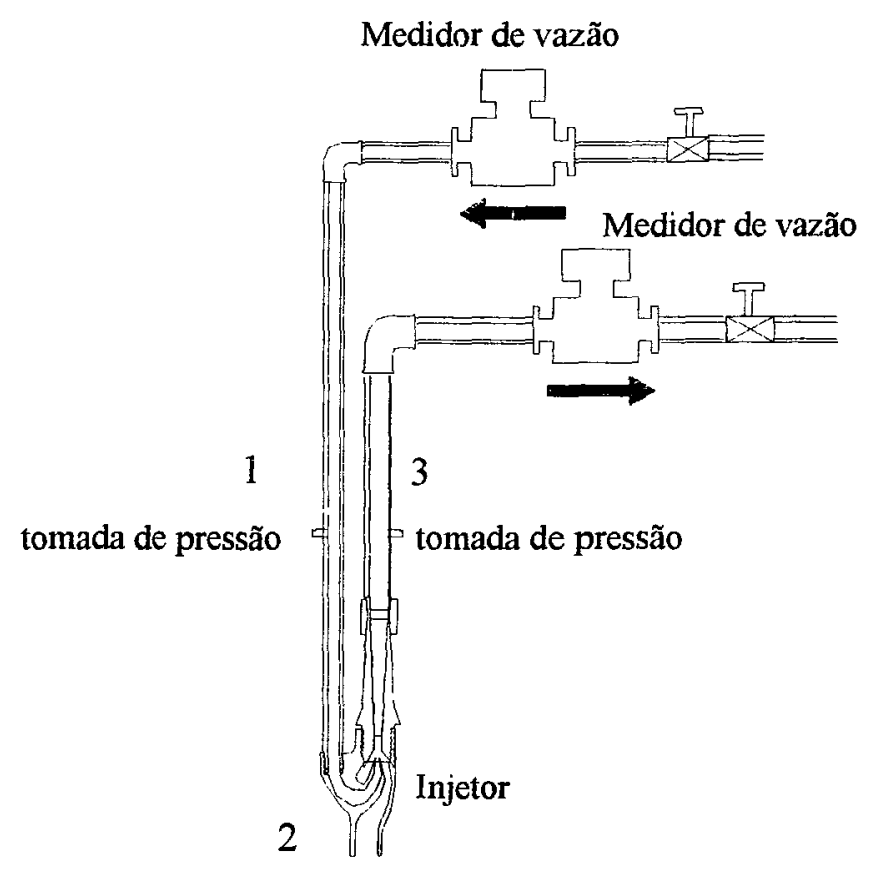

Figura 5 - Esquema experimental para obtenção dos parâmetros dos injetores

Os injetores foram instalados em um reservatório de água subterrâneo, situado exatamente abaixo da torre onde encontravam-se as bombas.

A coleta de dados para obtenção do coeficiente $\mathrm{K}$ foi feita no próprio local da instalação, variando-se a vazão circulante $\left(\mathrm{Q}_{1}\right)$.

Foram medidas e anotadas as pressões e vazões antes e após o injetor $\left(\mathrm{H}_{1} \mathrm{e}\right.$ $\mathrm{Q}_{1} ; \mathrm{H}_{3}$ e $\left.\mathrm{Q}_{3}\right)$.

Os diferenciais de pressão necessários à coleta de dados e determinação de $\mathrm{K}$ e $\mathrm{Cd}$ foram obtidos através da variação das vazões útil circulante. $\mathrm{O}$ aumento da abertura do registro situado no recalque da bomba centrífuga promoveu-se um aumento da vazão útil ( $\mathrm{Q}_{2}$, succionada, ou quutil), o que acarretou em uma diminuição da vazão circulante $\left(Q_{1}\right.$, motriz, ou $\left.q_{\text {circ }}\right)$. Desta forma foi possivel obter vários diferenciais de pressão e medir 
as pressões ocorrentes nos pontos de medição. As faixas de pressão de entrada utilizadas nos testes de cada conjunto bomba-injetor variaram com a altura de sucção utilizada $(16,47$ ou $11,97 \mathrm{~m})$ os limites extremos foram:
Conjunto 3VJE15-M 39G (1/3 CV):
193,61 a $417,79 \mathrm{kPa}(19$ a $41 \mathrm{mca})$
Conjunto 1VJF15-M 38J (1 CV):
366,84 a $499,31 \mathrm{kPa}(36$ - $49 \mathrm{mca})$
Conjunto 2VJF15-M 39B (2CV):
356,65 a $601,21 \mathrm{kPa}(35-59$ mca)

A vazão $Q_{1}$ é a vazão circulante ( $q_{\text {circ }}$ ) e a vazão $Q_{3}$ é a vazão da bomba ( $q_{\text {bomba }}$ ). A partir dessas medições pode-se calcular a vazão $\mathrm{Q}_{2}$, ou vazão útil ( $q_{\text {útil }}$ ):

$$
q_{u t i l}=Q_{3}-Q_{1}
$$

Também é possível calcular a perda de carga que ocorre no injetor e, conseqüentemente, determinar o coeficiente $\mathrm{K}$. Por haver acréscimo de massa no decorrer do processo $\left(\mathrm{q}_{2}\right.$, ou $\left.\mathrm{q}_{\text {útil }}\right)$ o cálculo da perda de carga é feito através de um balanço de energia, seguindo o esquema da Figura 5:

$$
E_{1}+E_{2}=E_{3}+H f E_{1-3}
$$

em que,

$$
\begin{aligned}
& E_{1} \text { - energia no ponto } 1 \\
& E_{2} \text { - energia no ponto } 2 \\
& E_{3} \text { - energia no ponto } 3 \\
& H \mathrm{HE}_{1-3} \text { - energia dissipada no injetor }
\end{aligned}
$$

Sabe-se que

$$
E_{\text {hid }}=\gamma Q H
$$

Substituindo os termos da equação 80 na equação 79 tem-se:

$$
\gamma Q_{1} H_{1}+\gamma Q_{2} H_{2}=\gamma Q_{3} H_{3}+\gamma Q_{3} H f_{1-3}
$$

em que,

$\mathrm{Hf}_{1-3}$ - perda de carga que ocorre no injetor $\left(\mathrm{Hf}_{\mathrm{boc}}\right)$

A seguir isola-se o termo $\mathrm{Hf}_{1-3}$, ou $\mathrm{Hf}_{\mathrm{boc}}$, para determinar seu valor:

$$
H f_{\text {boc }}=\frac{Q_{1} H_{1}+Q_{2} H_{2}-Q_{3} H_{3}}{Q_{3}}
$$

A equação 17 também apresenta a perda de carga que ocorre no injetor. Igualando-se os termos da equação 82 aos da equação 17 obtém-se: 


$$
\frac{Q_{1} H_{1}+Q_{2} H_{2}-Q_{3} H_{3}}{Q_{3}}=K \frac{V_{b o c}^{2}}{2 g}
$$

Utilizando-se a equação da Continuidade consegue-se, então, a equação do coeficiente $\mathrm{K}$ :

$$
K=\frac{g \pi^{2} D_{b o c}^{4}}{8 Q_{1}^{2}} \frac{Q_{1} H_{1}+Q_{2} H_{2}-Q_{3} H_{3}}{Q_{3}}
$$

A determinação do coeficiente de perda de carga do injetor foi feita de forma mais simples, utilizando-se o diâmetro do bocal, a vazão circulante $\left(Q_{1}\right)$ e o diferencial de pressão entre os pontos 1 e 2 . Essa determinação também foi feita no próprio local de instalação dos conjuntos bomba-injetor. No ponto 2 a pressão reinante é devida à profundidade de imersão do injetor $\left(\Delta \mathrm{z}_{\text {sub }}\right)$. Assim tem-se:

$$
C d=\frac{Q_{1}}{S_{b o c} \sqrt{2 g\left(H_{1}-H_{2}\right)}}
$$

ou ainda,

$$
C d=\frac{4 Q_{1}}{\pi D_{b o c}^{2} \sqrt{2 g\left(H_{1}-H_{2}\right)}}
$$

O injetor pode estar operando a diversos diferenciais de pressão. Os testes para a obtenção do coeficiente de descarga foram feitos no próprio local do experimento, utilizando-se as variações de pressão de entrada reinantes nas condições de funcionamento para obter um valor médio de $\mathrm{Cd}$.

\subsubsection{Cálculos com o modelo matemático proposto}

Após a obtenção dos parâmetros individuais de cada componente do sistema é possível simular o seu funcionamento através do modelo matemático desenvolvido.

Para facilitar os cálculos foi desenvolvido um modelo computacional para a execução do modelo matemático.

Os parâmetros de entrada para execução do modelo computacional são: 
a) diâmetro, comprimento e material de composição dos dois trechos da tubulação;

b) parâmetros empíricos a, b e c, da relação vazão versus pressão, e vazão máxima das bombas centrífugas;

c) diâmetro do bocal, profundidade de imersão e coeficientes $\mathrm{K}$ e $\mathrm{Cd}$ do injetor;

Após a entrada dos parâmetros o modelo computacional determina os coeficientes de atrito dos dois trechos da tubulação de sucção, realiza os cálculos e fornece uma tabela de resultados contendo: perdas de carga ocorrentes no sistema $\left(\mathrm{Hf}_{\mathrm{boc}}\right.$, $\mathrm{Hf}_{1}, \mathrm{Hf}_{2}, \mathrm{Hf}_{\text {sist }}$ ), vazões circulante, útil e da bomba ( $\left.\mathrm{q}_{\text {circ }}, \mathrm{q}_{\text {útil }}, \mathrm{q}_{\text {bomba }}\right)$; diferenciais de pressão da bomba e útil $\left(\Delta \mathrm{H}_{\mathrm{bomba}}, \Delta \mathrm{H}_{\text {utili }}\right)$ e rendimento do conjunto injetor-bomba centrífuga $\left(\eta^{\circ}\right)$.

O modelo computacional também permite fazer a otimização do bocal do injetor. Obtém-se, por um processo de varredura, as curvas de diferencial de pressão útil em relação ao diâmetro do bocal, para valores pré-fixados de vazão útil. Assim é possível determinar o diâmetro de bocal que maximiza a pressão útil para uma determinada vazão útil.

O fluxograma do modelo computacional, denominado INJETOR, encontra-se listado a seguir. 


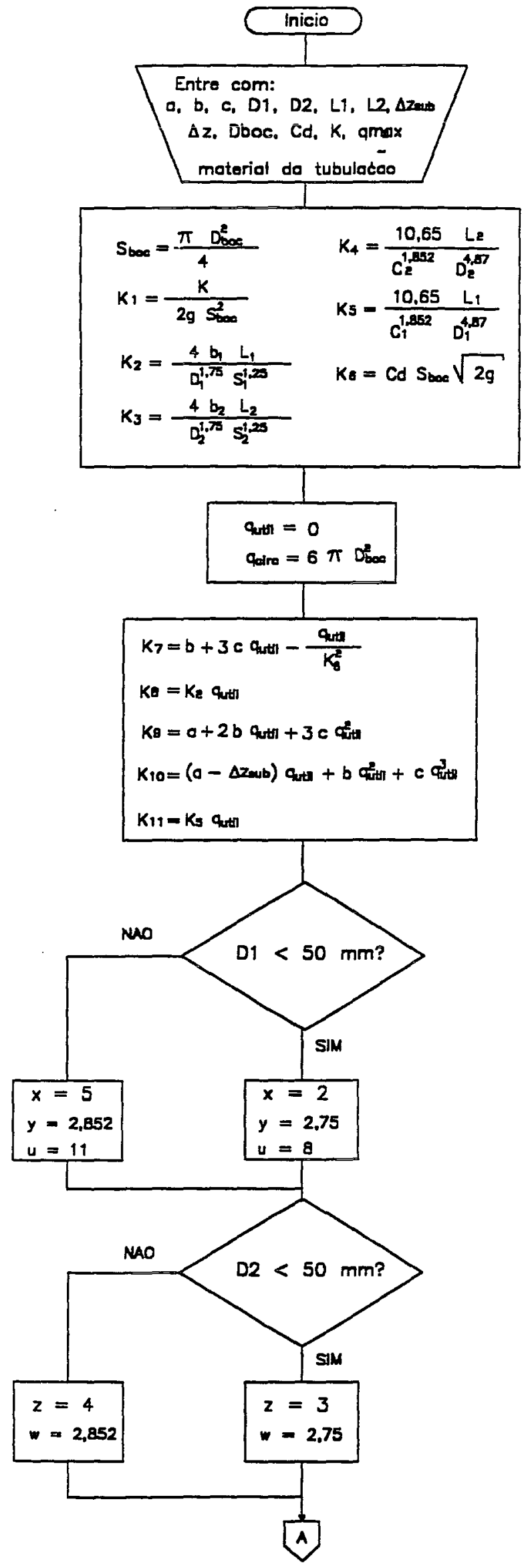




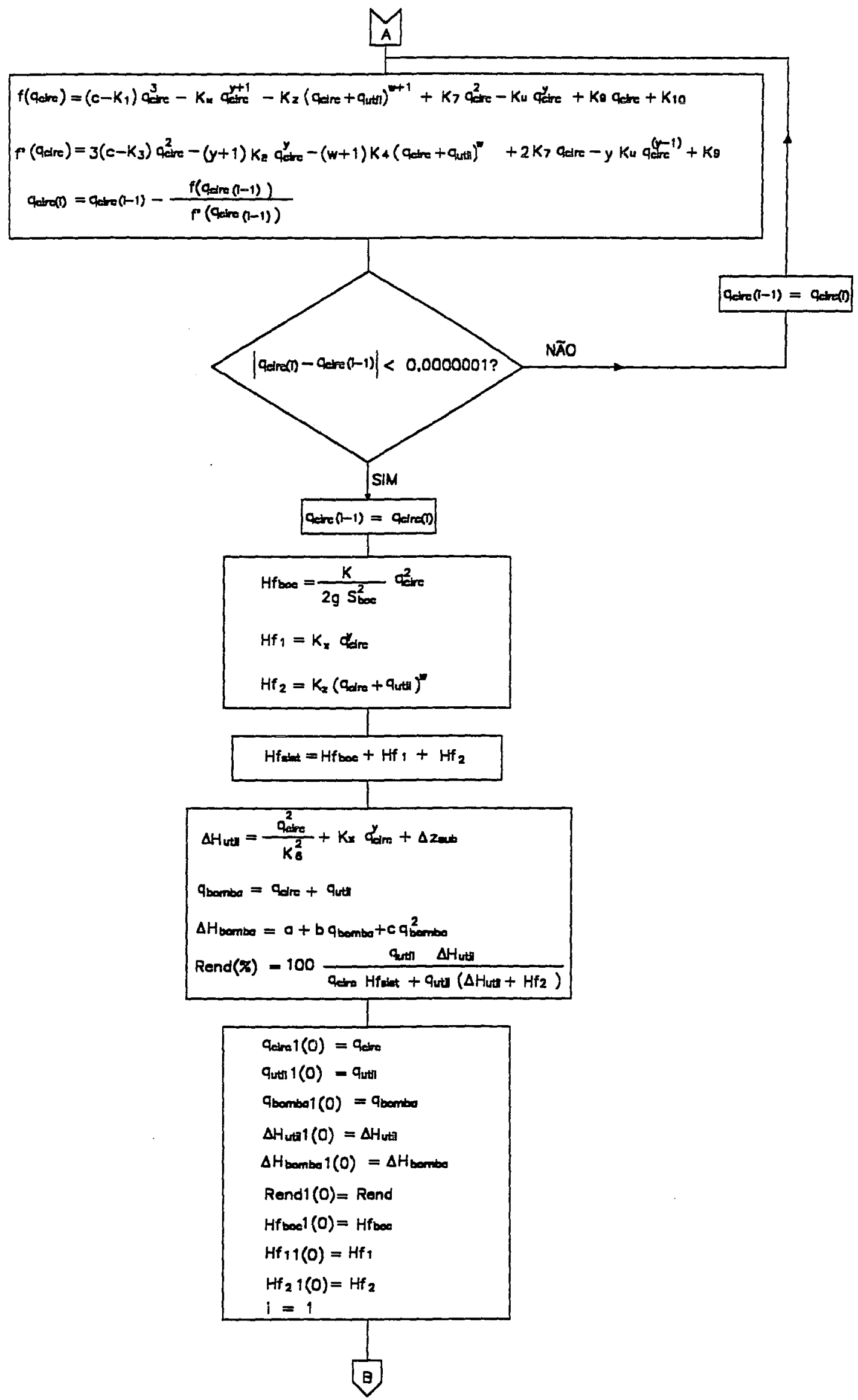




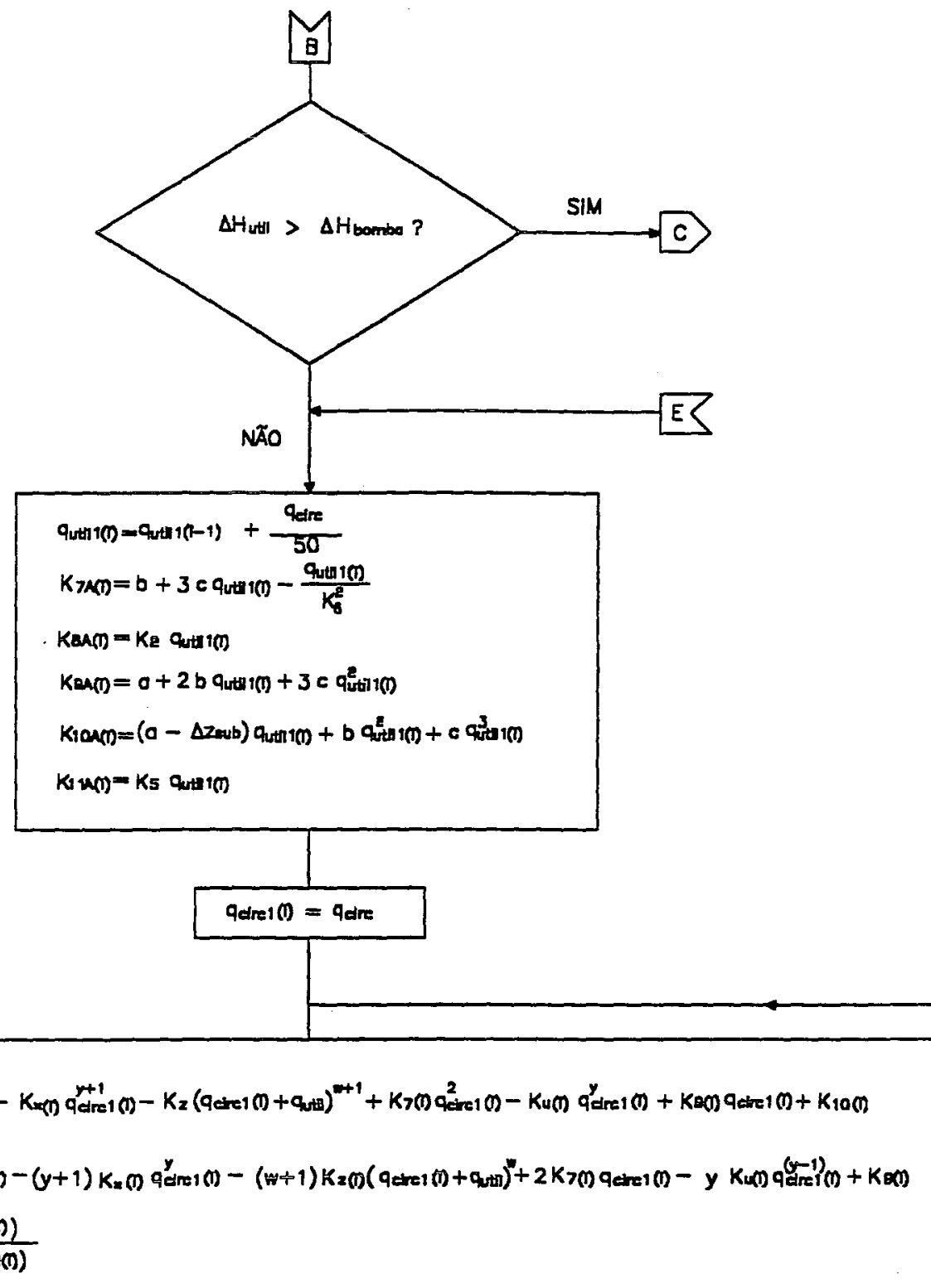

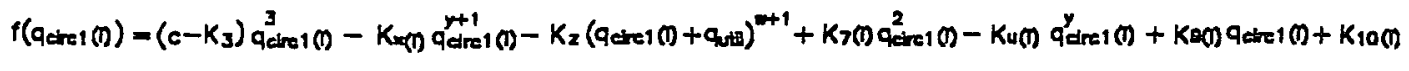

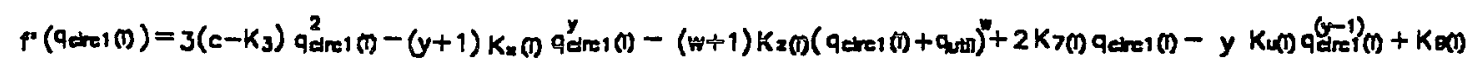

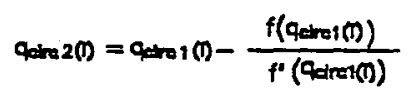

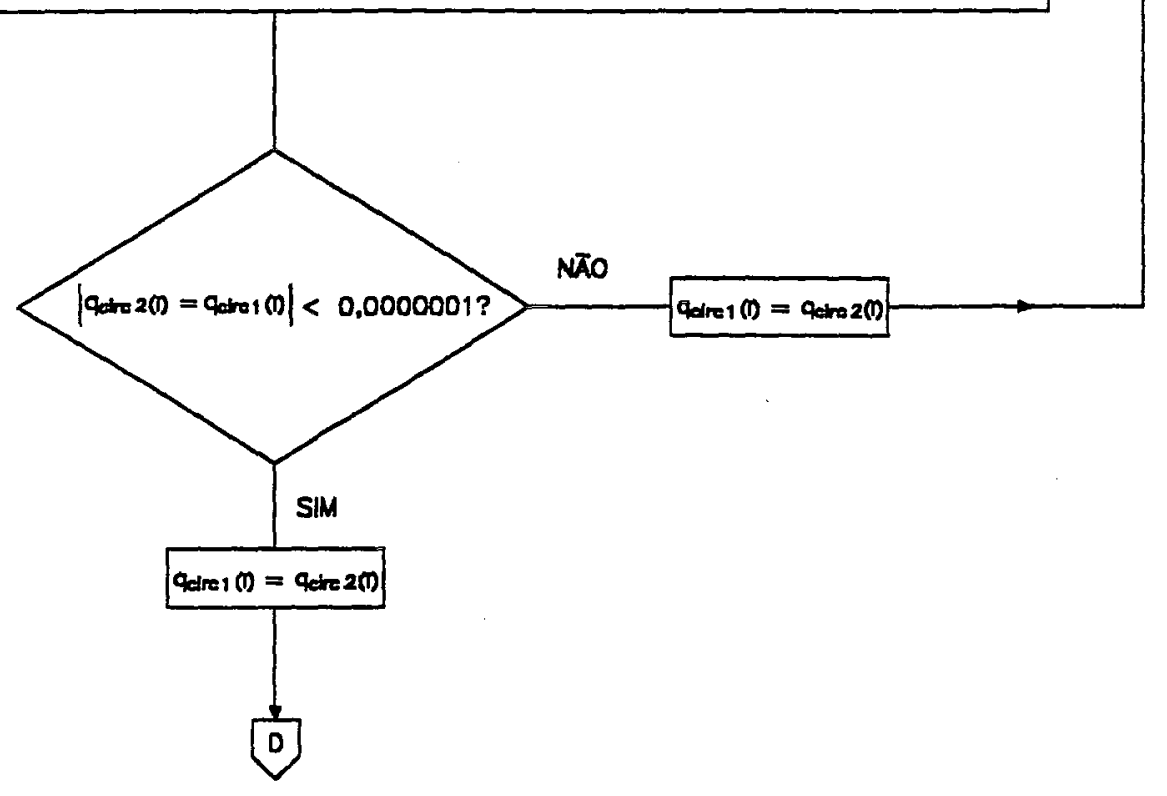




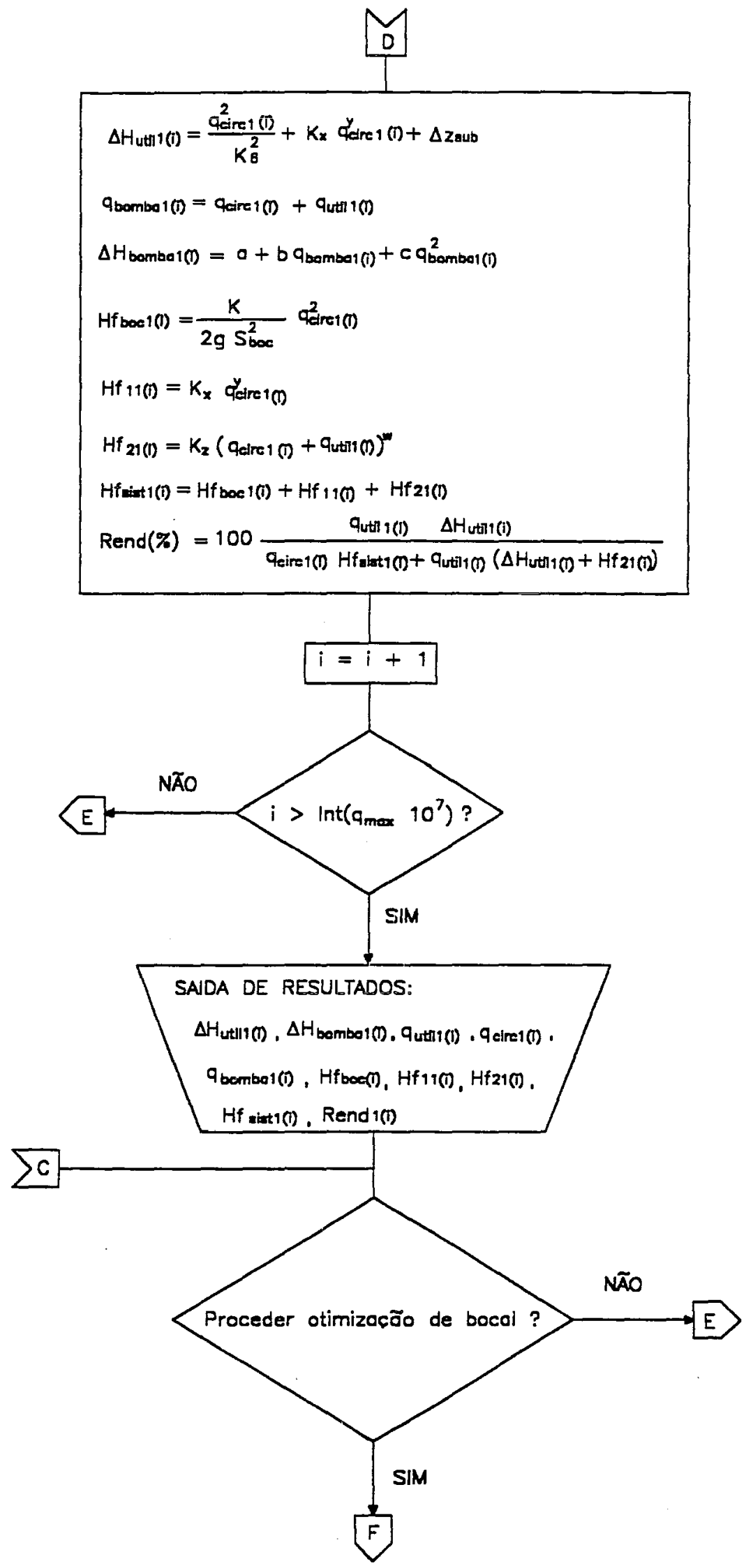




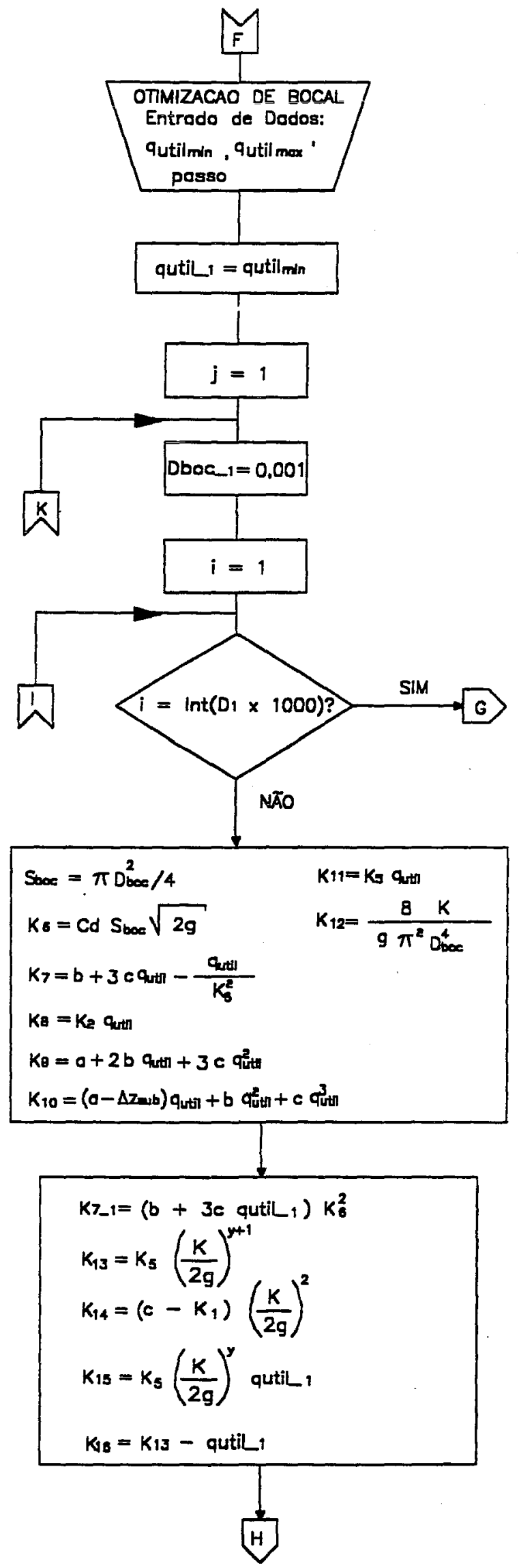




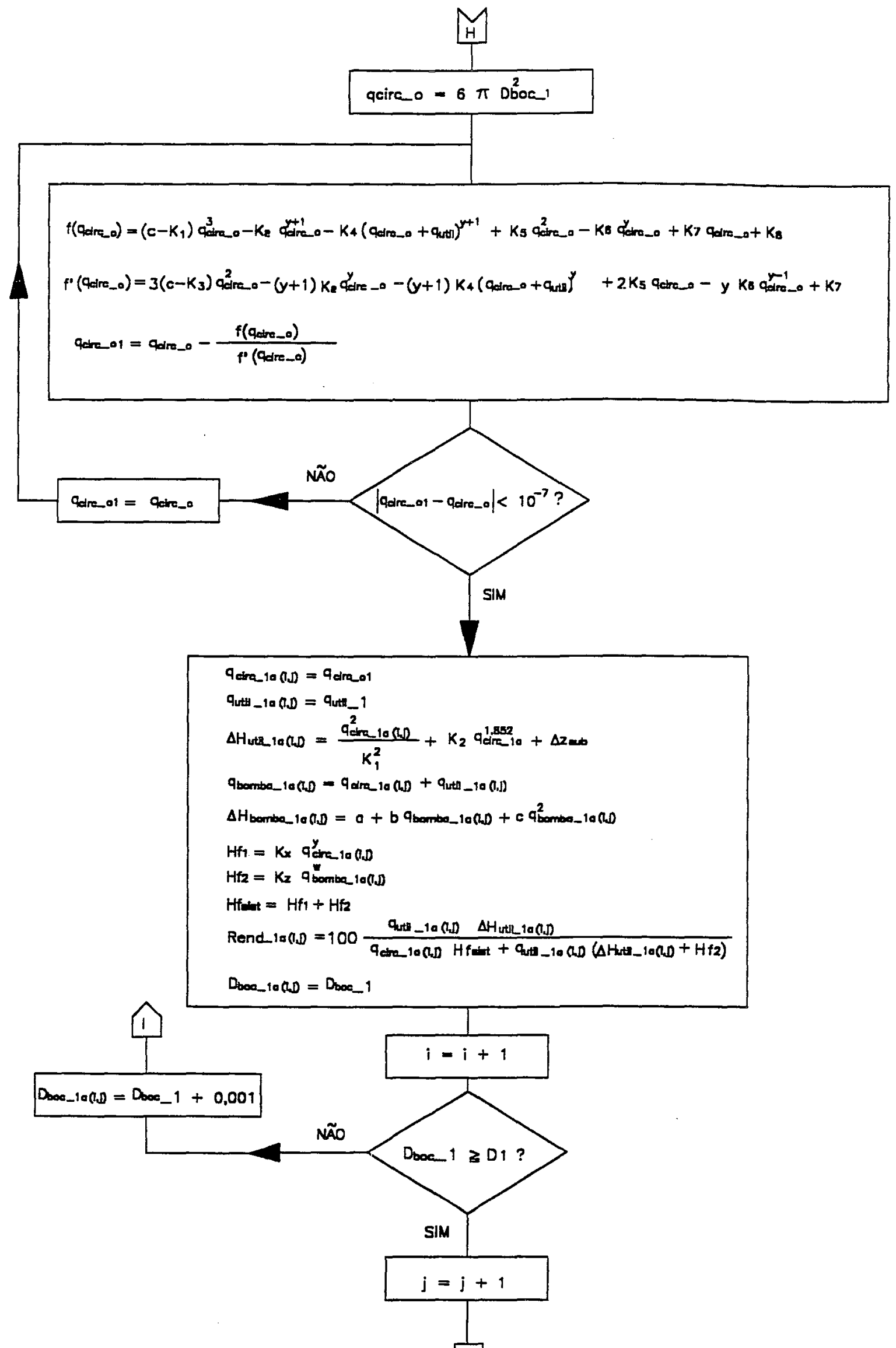




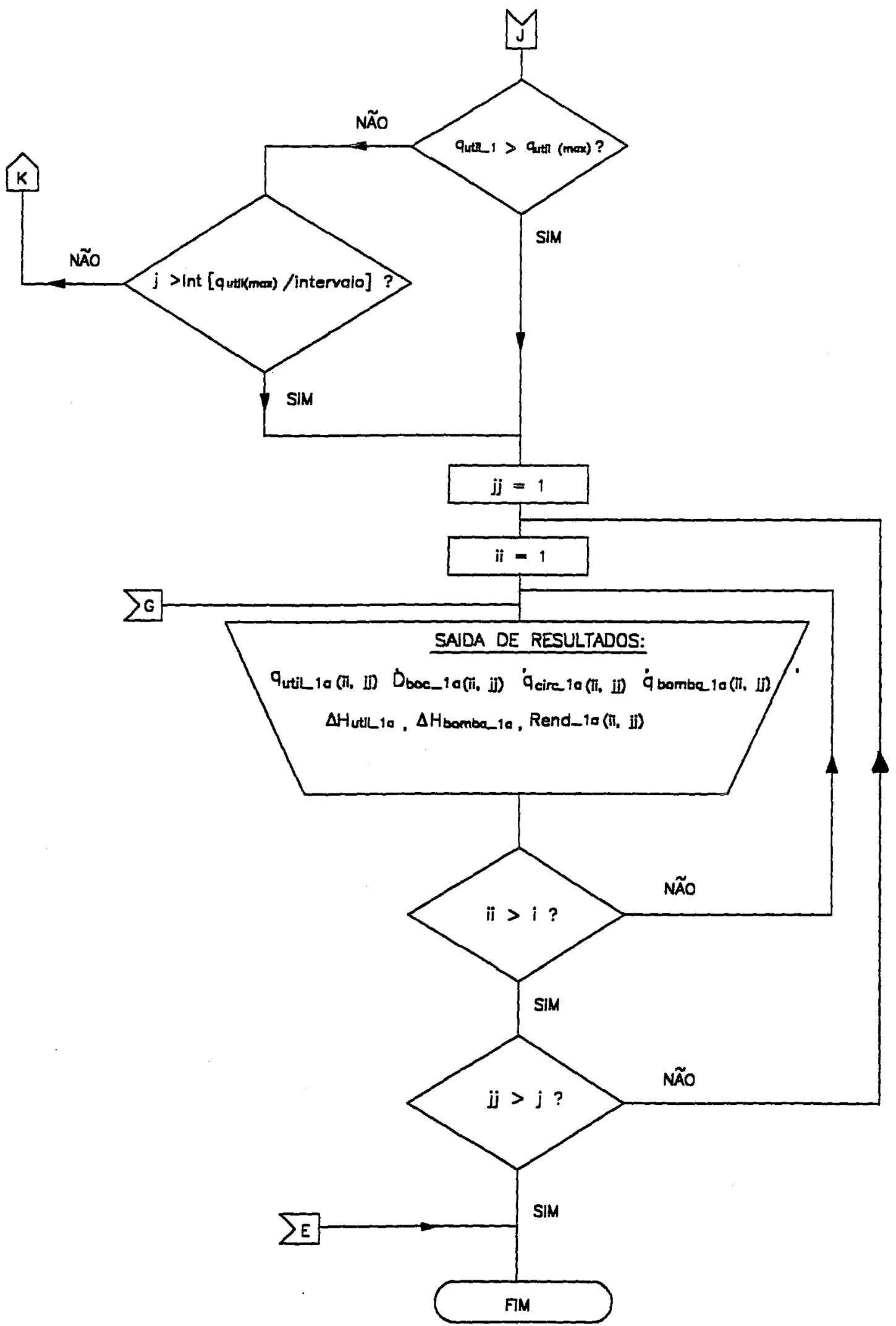




\subsubsection{Testes com o sistema injetor-bomba centrífuga}

Cada conjunto formado por injetor e bomba centrífuga foi testado para obtenção dos dados experimentais de seu funcionamento e comparação com os resultados previstos pelo modelo matemático.

O esquema experimental é apresentado na Figura 6. A vazão útil e a vazão circulante foram determinadas por medidores de vazão do tipo magnético indutivo, situados nas tubulações de recalque ( $\left.q_{u ́ t i l}\right)$ e no trecho 1 da sucção $\left(\mathrm{q}_{\text {circ }}\right)$.

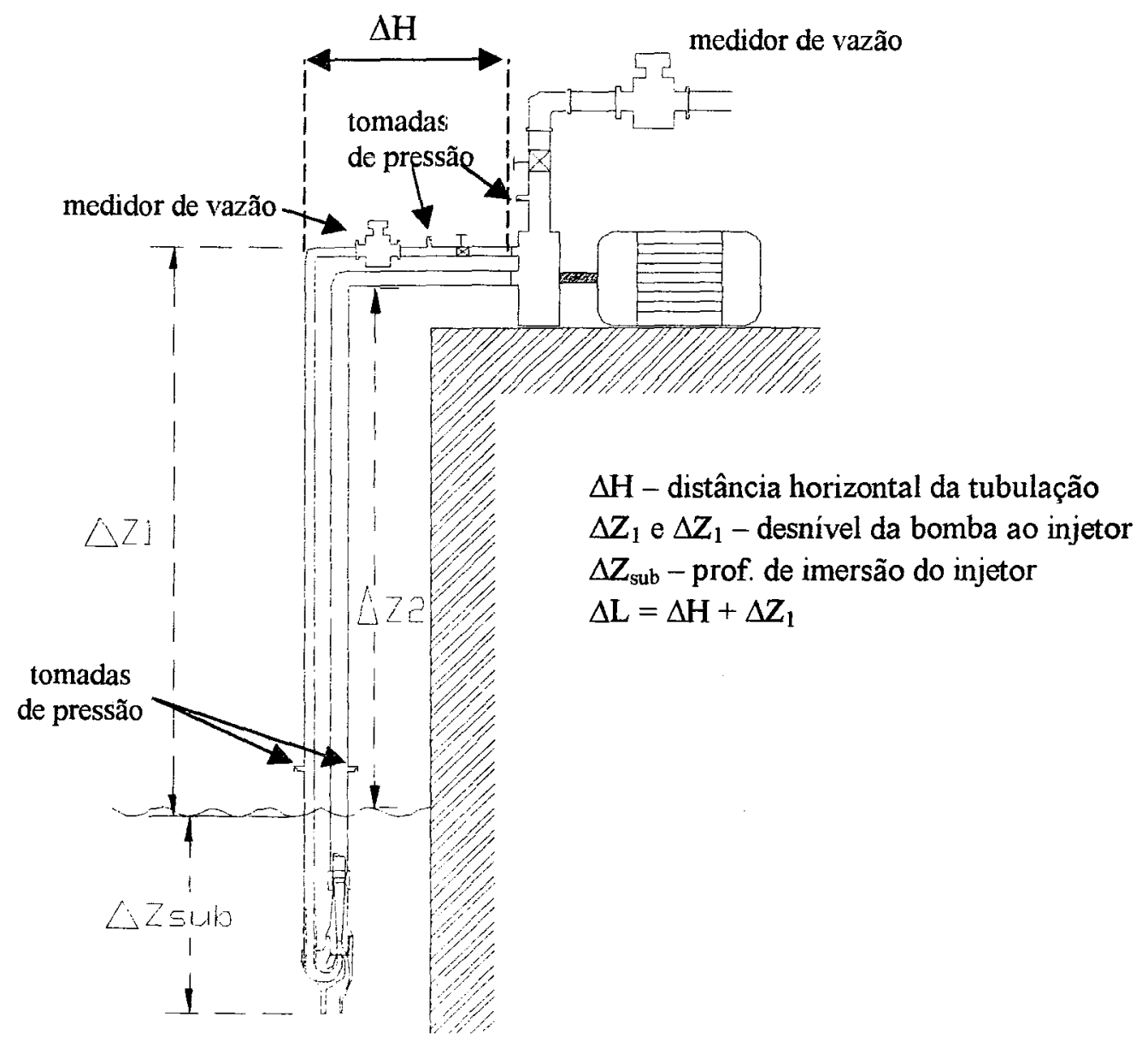

Figura 6 - Esquema de testes com o sistema injetor-bomba centrifuga

No sistema montado foram instaladas 5 tomadas de pressão. Duas delas estavam situadas na tubulação de sucção, uma antes e outra após o injetor, em local 
próximo a ele. As outras três situavam-se próximas à bomba: uma no trecho 1 da tubulação de sucção, outra no trecho 2 e a terceira, na tubulação de recalque. Essas tomadas serviram para medir a pressão existente em cada um desses pontos na tubulação e determinar as perdas de carga do sistema, o diferencial de pressão útil e a pressão proporcionada pela bomba.

$O$ registro situado na tubulação de recalque foi manuseado de forma a obterse diferentes valores de vazão útil e vazão circulante dentro do intervalo de operação da bomba centrífuga. Desta forma obteve-se a cada medição, direta ou indiretamente, os seguintes dados: vazão útil ( $\left.q_{\text {útil }}\right)$, diferencial de pressão útil $\left(\Delta H_{u}\right.$ util $)$, vazão circulante $\left(q_{\text {circ }}\right)$, pressão na entrada da bomba centrifuga $\left(\mathrm{H}^{\prime}{ }_{1}\right)$, perda de carga no injetor $\left(\mathrm{Hf}_{\text {boc }}\right)$ e perdas de carga nos trechos 1 e 2 da tubulação de sucção.

\subsubsection{Equipamentos empregados nos experimentos}

Os equipamentos empregados nos experimentos descritos nos itens 3.6.2, 3.6.3 e 3.6.5 estão disponíveis no Laboratório de Hidráulica do Departamento de Engenharia Rural da ESALQ/USP. Suas características são apresentadas a seguir.

\section{a) Medidores de vazão:}

Os medidores de vazão empregados nos testes são do tipo magnético indutivo, marca CONAUT. Esses medidores não causam perda de carga localizada, pois mantêm uniforme a seção transversal de escoamento da canalização, permitindo medições de vazão com erro máximo de $0,5 \%$ e fornecendo leitura digital.

\section{b) Medidores de pressão:}

A pressão foi medida por transdutores de pressão marca INTERFACE, aferidos com auxílio de um manômetro-padrão, permitindo medições com erro máximo de $0,2 \%$. 


\section{c) Conjunto moto-bomba:}

Os ensaios individuais de cada injetor foram realizados no próprio local do experimento, com as respectivas tubulações e bomba indicada para cada injetor, nas duas alturas de sucção utilizadas $(16,47$ e $11,97 \mathrm{~m})$. Além disso houve os ensaios das bombas centrífugas JACUZZI, já descritas no item 3.6.1.

d) Injetores:

Os injetores utilizados foram adquiridos juntamente com as bombas JACUZZI, formando um conjunto único, e foram representados esquematicamente na Figura 1. O diâmetro do bocal de cada um dos três modelos é apresentado na Tabela 2. 


\section{RESULTADOS E DISCUSSÃO}

As tabelas e figuras apresentadas e discutidas neste capítulo contêm os resultados observados nos ensaios com os conjuntos injetor-bomba centrífuga e a estimativa desses resultados, obtida através de cálculos efetuados com o auxílio do programa computacional INJETOR, desenvolvido para esta finalidade. Com o objetivo de proporcionar uma leitura facilitada do texto, as tabelas muito extensas são apresentadas em anexos, no final do trabalho. A discussão do trabalho proporciona a localização das tabelas e gráficos necessários ao entendimento dos resultados obtidos.

\subsection{Ensaios das bombas centrífugas}

As representações gráficas dos dados experimentais observados e estimados são mostradas nas Figuras 7, 8 e 9, apresentando a correspondência entre os dados de vazão e de pressão medidos para cada bomba centrífuga testada, operando isoladamente (sem o injetor).

Nos gráficos também é possível ver a regressão polinomial para a relação vazão versus pressão da respectiva bomba centrífuga, Os dados utilizados para a confecção dos gráficos encontram-se nas Tabelas 4, 5 e 6, no Anexo A.

As equações obtidas por regressão polinomial apresentaram coeficientes de determinação acima de 0,98 , mostrando um bom ajuste aos dados observados, e foram utilizadas no modelo matemático para simulação do funcionamento conjunto de bomba e injetor.

As Figuras 7,8 e 9 confirmam a primeira pressuposição feita para o modelo matemático, na qual afirma-se que a relação entre a vazão e a pressão da bomba centrífuga pode ser descrita por um polinômio de segundo grau. 


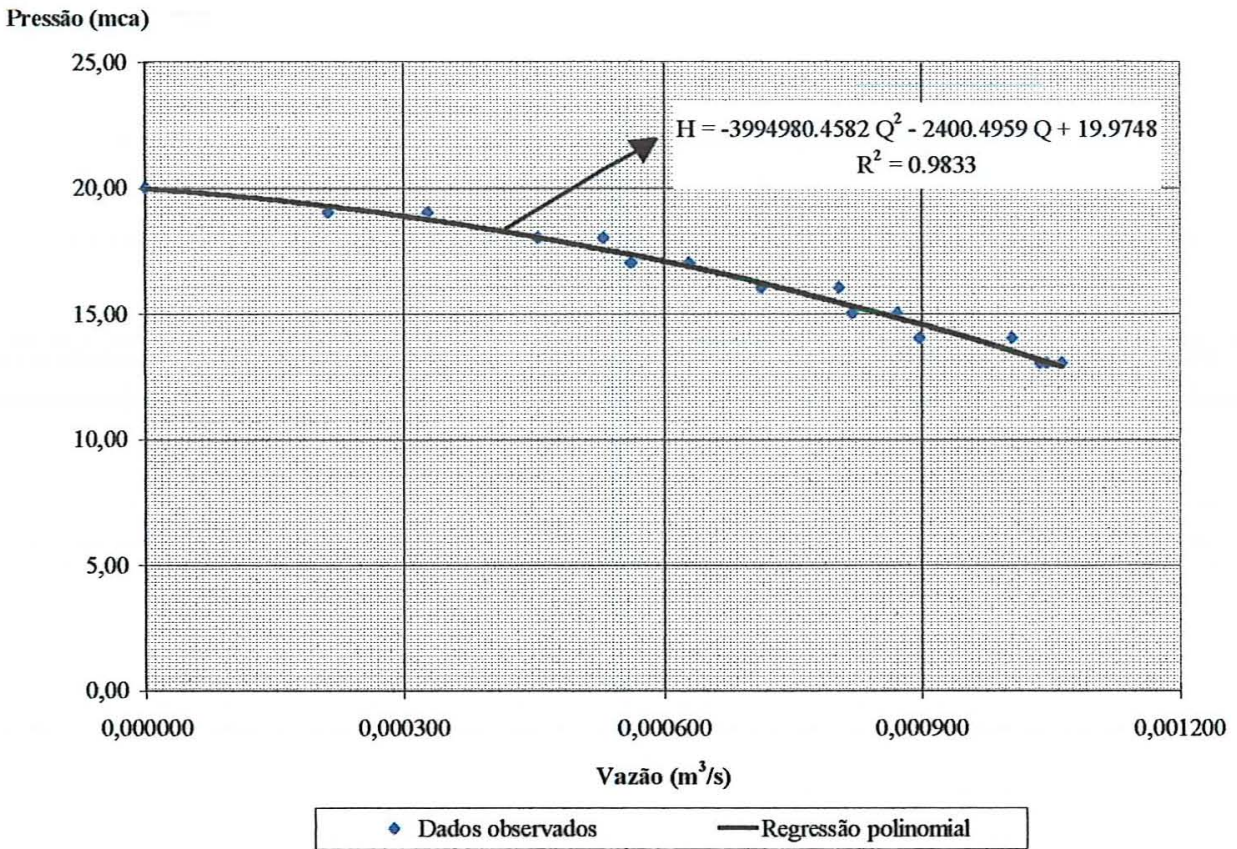

Figura 7- Representação gráfica dos dados observados e da regressão polinomial Bomba Jacuzzi mod. 3VJE15-M 39G

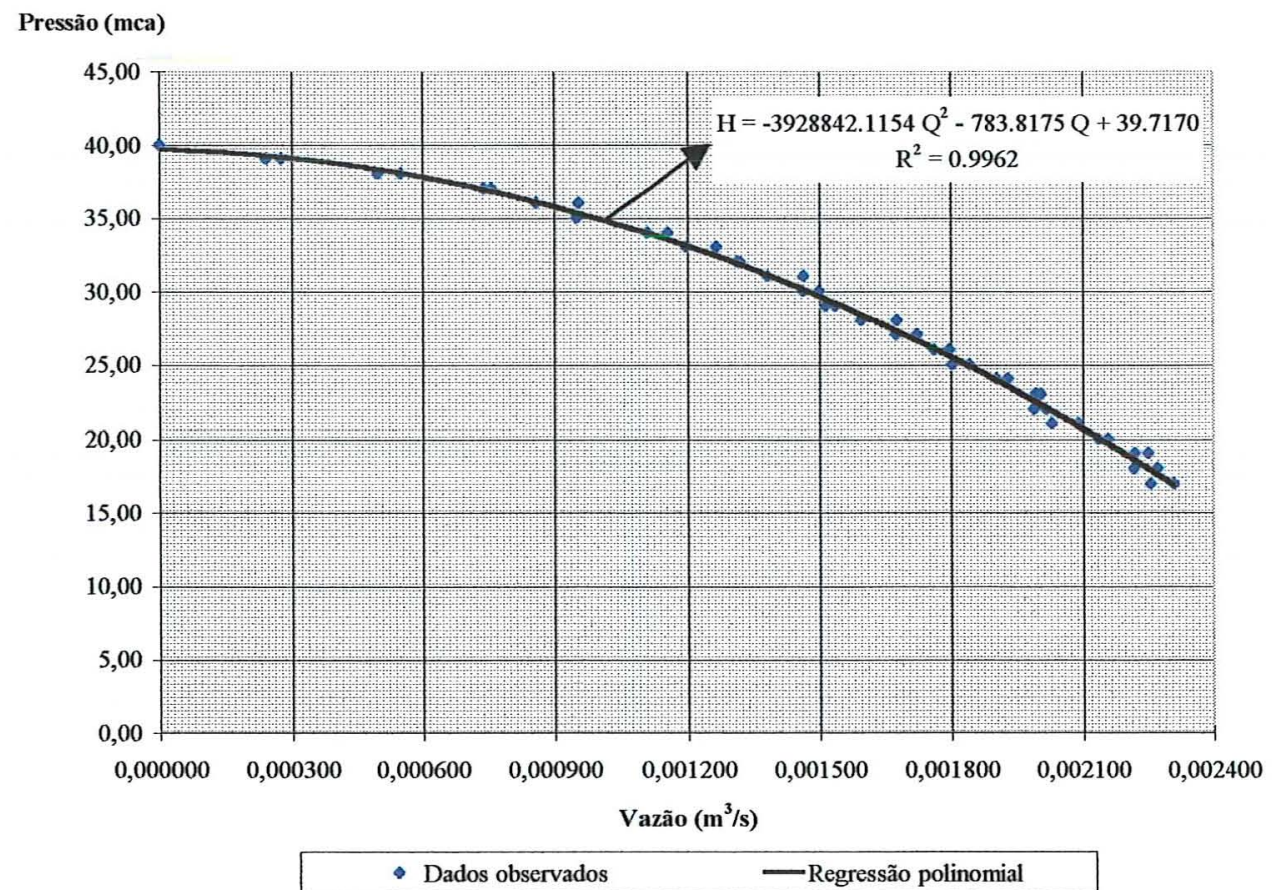

Figura 8- Representação gráfica dos dados observados da regressão polinomial Bomba Jacuzzi mod. 2VJF15-T 39B 


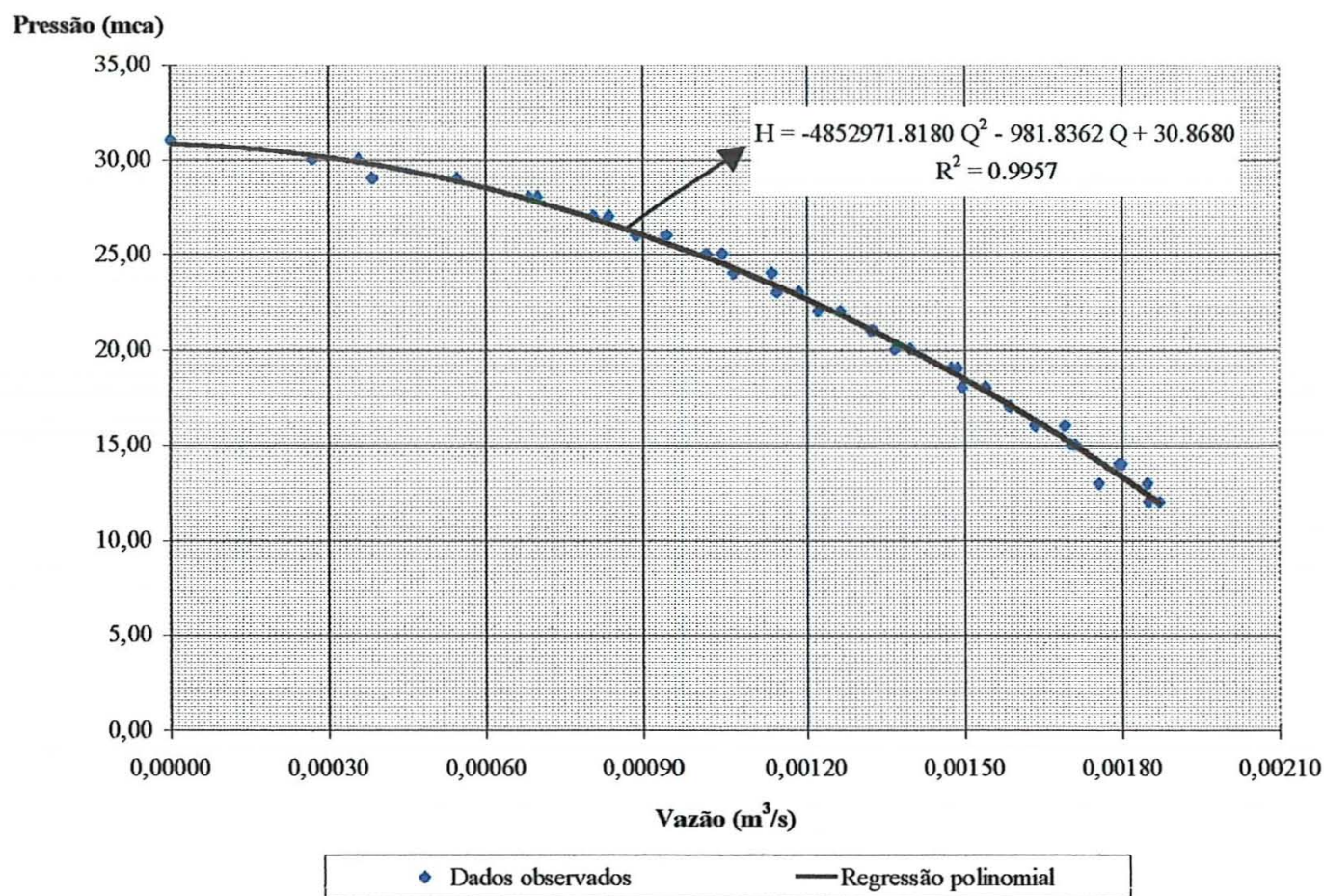

Figura 9 - Representação gráfica dos dados observados e da regressão polinomial Bomba Jacuzzi - mod. 1VJF15-M 38J

\subsection{Ensaios dos injetores}

Na Tabela 3 encontram-se os valores do coeficiente de descarga (Cd) e do coeficiente de perda de carga $(\mathrm{K})$ obtidos para cada injetor e utilizados nas simulações, em cada altura de sucção e nas faixas de pressão de entrada utilizadas nos testes.

Tabela 3- Valores médios e média geral do coeficientes de descarga $(\mathrm{Cd})$ e de perda de carga dos injetores para cada pressão de entrada

\begin{tabular}{ccccc}
\hline $\begin{array}{c}\text { Conjunto } \\
\text { bomba-injetor }\end{array}$ & $\begin{array}{c}\text { Potência } \\
(\mathrm{CV})\end{array}$ & $\begin{array}{c}\text { Altura de sucção } \\
(\mathrm{m})\end{array}$ & $\mathrm{Cd}$ & $\mathrm{K}$ \\
\hline 3VJE15-M 39G & $1 / 3 \mathrm{CV}$ & 16,47 & 0,823 & 0,643 \\
& & 11,97 & 0,827 & 0,704 \\
2VJF15-M 39B & 2 CV & 16,47 & 0,928 & 0,641 \\
& & 11,97 & 0,911 & 0,643 \\
1VJF15-M 38J & 1 CV & 16,47 & 0,730 & 0,749 \\
& & 11,97 & 0,901 & 0,681 \\
\hline
\end{tabular}


Os resultados obtidos mostraram diferenças nos valores dos coeficientes Cd e K, quando comparados aos resultados obtidos por Botrel(1996). Provavelmente isto é devido às características dos injetores testados, que são diferente daqueles utilizados pelo autor supracitado. Os injetores testados pelo autor foram do tipo " $\mathrm{T}$ " $\mathrm{e}$ apresentavam bocais convergente e divergente com ângulos maiores que os bocais testados neste trabalho, resultando em valores diferentes para os coeficientes. Os resultados completos encontram-se no Anexo A, apresentando as pressões na entrada e na saída dos injetores, as vazões circulante (motriz) e útil (succionada), o coeficiente de descarga (Cd) e o coeficiente de perda de carga (K).

Esses resultados mostram que os coeficientes de descarga variaram com a pressão de entrada do injetor. Como a variação foi bastante acentuada em alguns casos, optou-se por utilizar a mediana dos dados nas simulações de funcionamento, a fim de obter um melhor ajuste aos resultados observados. Este fato pode ser constatado através da comparação entre as médias e as medianas dos dados, apresentadas nas Tabelas 7 a 18 do Anexo A.

\subsection{Resultados simulados}

Os resultados das simulações de funcionamento dos conjuntos bombainjetor foram obtidos utilizando-se o programa computacional INJETOR, que efetuou os cálculos a partir dos parâmetros de entrada do sistema, conforme apresentado no seu fluxograma. Os resultados foram transferidos para uma planilha eletrônica e transformados em gráficos. Neles são apresentados os diferenciais de pressão útil e os rendimentos estimados e observados.

As simulações representam o funcionamento do esquema apresentado na Figura 6. Os resultados são apresentados de forma gráfica, mostrando 4 testes por conjunto, 2 em cada altura de sucção. Os dados completos encontram-se no Anexo B, no final deste trabalho. Os resultados simulados e observados encontram-se nas Figuras 10, 11 e 12, para a altura de sucção de $16,47 \mathrm{~m}$, e nas Figuras 13, 14 e 15, para a altura de sucção de $11,97 \mathrm{~m}$. 
A) Altura de sucção de $16,47 \mathrm{~m}$

SISTEMA BOMBA-INJETOR 3VJE15-M 39G (1/3 CV)
$\Delta \mathrm{Z}_{1}=16,47 ; \quad \Delta \mathrm{L}=19,87 \mathrm{~m} ;$
$\Delta Z_{\text {sub }}=0,75 \mathrm{~m}$
$\mathrm{D}_{1}=27,5 \mathrm{~mm}$
$\mathrm{D}_{2}=35,6 \mathrm{~mm}$
$\mathrm{D}_{\text {boc }}=5,9 \mathrm{~mm}$
$\mathrm{K}=0,633$
$\mathrm{Cd}=0,823$

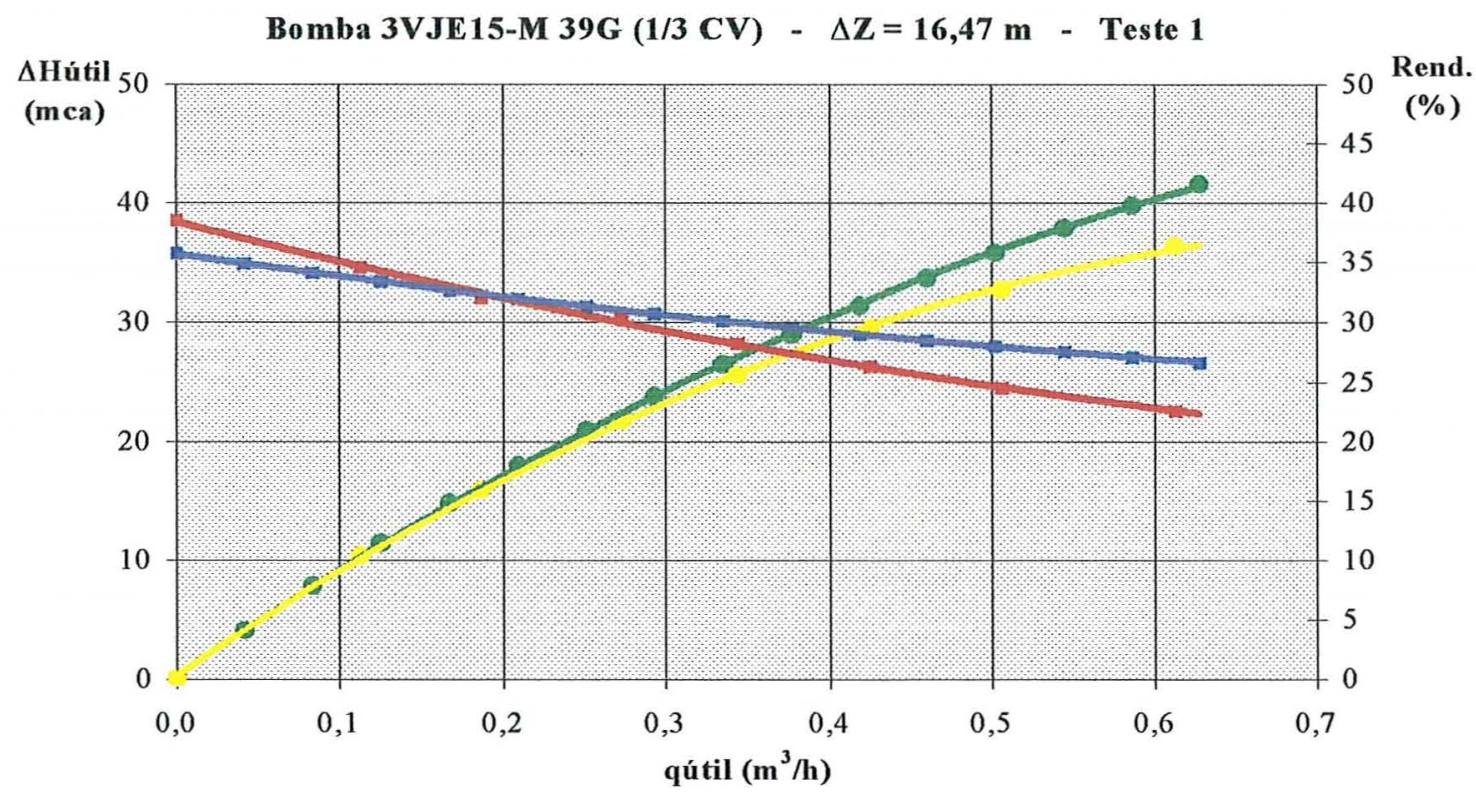

L Hútilest $\quad \Delta$ Hútil obs QRend est, Rend obs

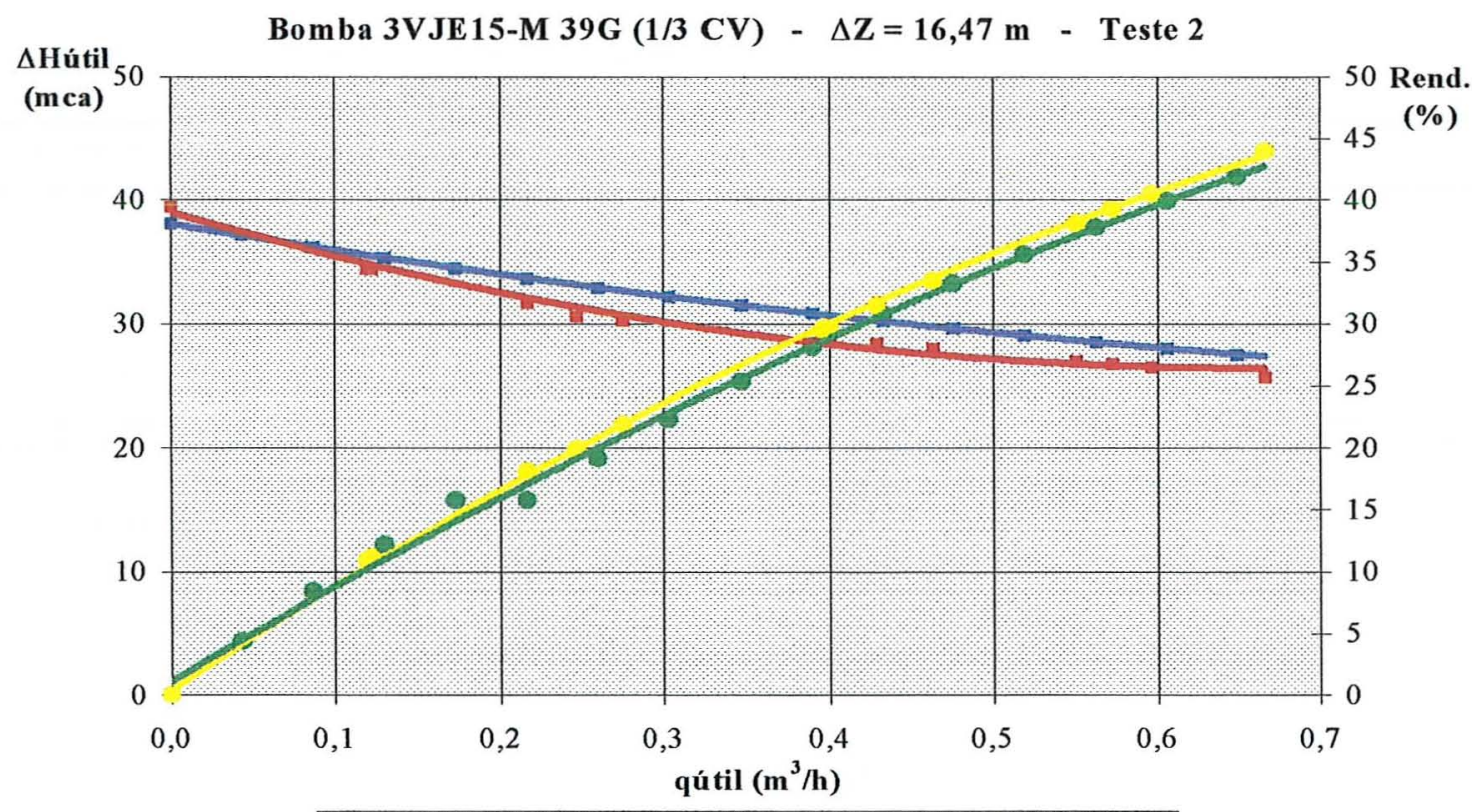

- $\Delta$ Hútil est. $\quad \Delta$ Hútil obs. ORend. est. Rend. obs.

Figura 10 - Comparação de resultados simulados e observados do conjunto bomba-injetor 3VJE15-M 39 G - Altura de sucção de 16,47 m 
SISTEMA BOMBA-INJETOR 2VJF15-T 39B (2 CV)
$\Delta Z_{1}=16,47 ; \Delta \mathrm{L}=20,17 \mathrm{~m} ; \Delta \mathrm{Z}_{\text {sub }}=0,75 \mathrm{~m}$
$\mathrm{D}_{1}=35,6 \mathrm{~mm}$
$\mathrm{D}_{2}=43,5 \mathrm{~mm}$
$\mathrm{D}_{\text {boc }}=6,1 \mathrm{~mm}$
$\mathrm{K}=0,633$
$\mathrm{Cd}=0,823$

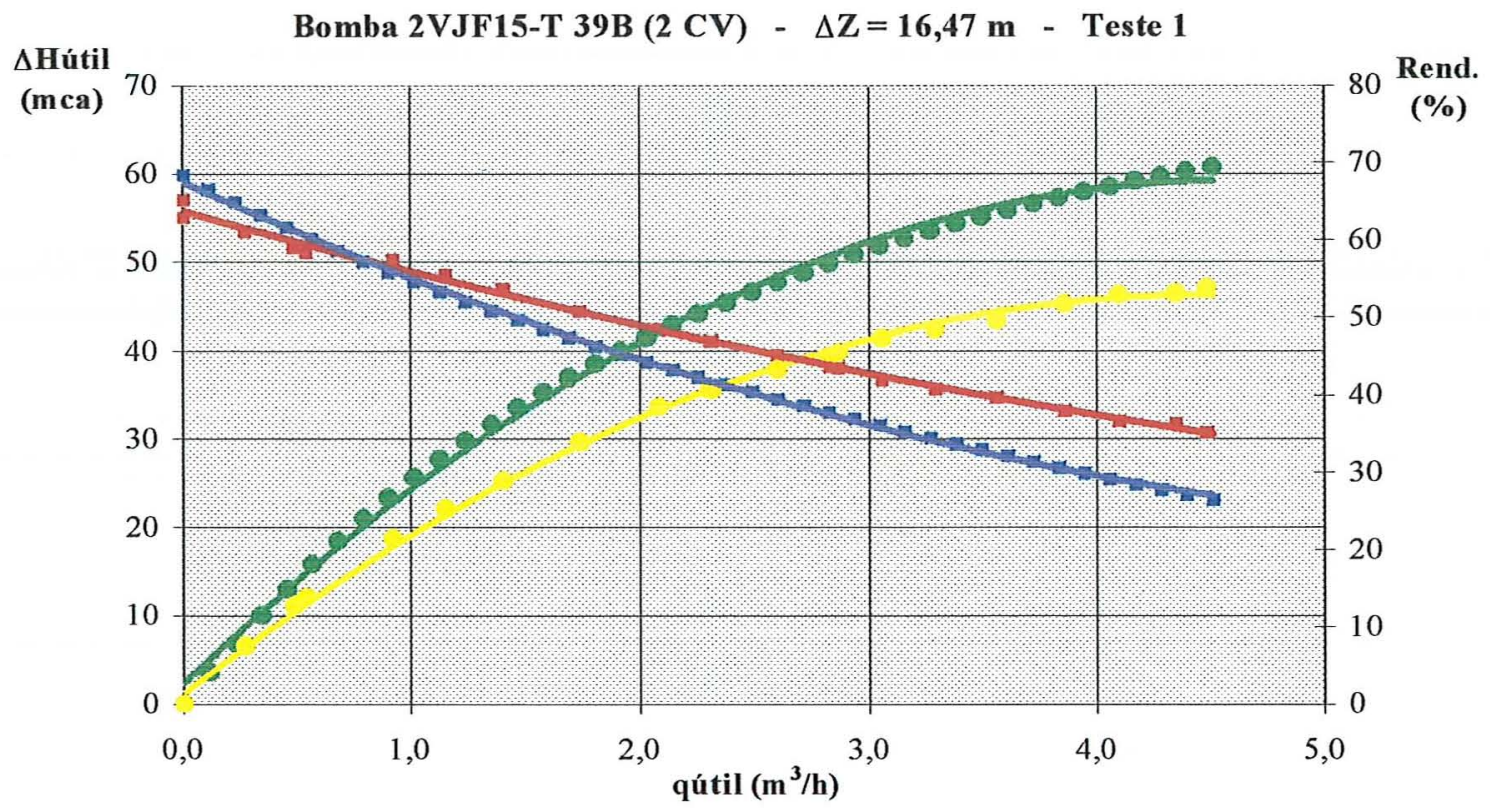

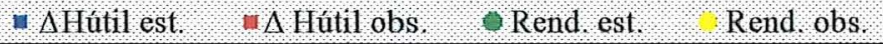

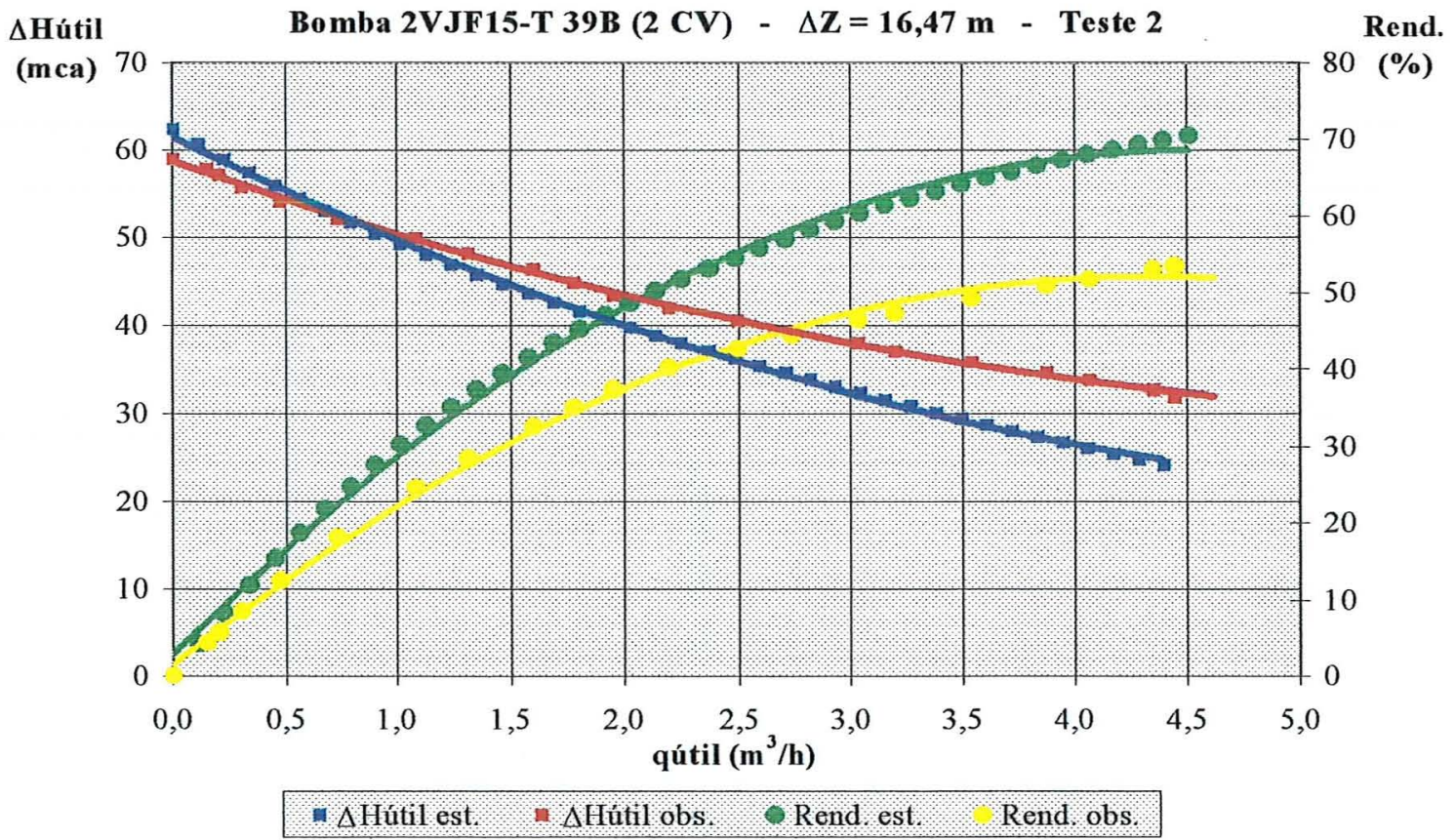

Figura 11 - Comparação de resultados simulados e observados do conjunto bomba-injetor 2VJF15-T 39 B - Altura de sucção de 16,47 m 
SISTEMA BOMBA-INJETOR 1VJF15-M 38J (1 CV)
$\Delta \mathrm{z}=16,47 ; \Delta \mathrm{L}=20,17 \mathrm{~m} ; \Delta \mathrm{z}_{\text {sub }}=0,75 \mathrm{~m}$
$\mathrm{D}_{\mathrm{boc}}=5,9 \mathrm{~mm}$
$\mathrm{K}=0,633$
$\mathrm{D}_{1}=27,5 \mathrm{~mm}$
$\mathrm{D}_{2}=35,6 \mathrm{~mm}$
$\mathrm{Cd}=0,823$

Bomba 1VJF15-M 38J (1 CV) - $\Delta \mathrm{Z}=16,47 \mathrm{~m}-$ Teste 1

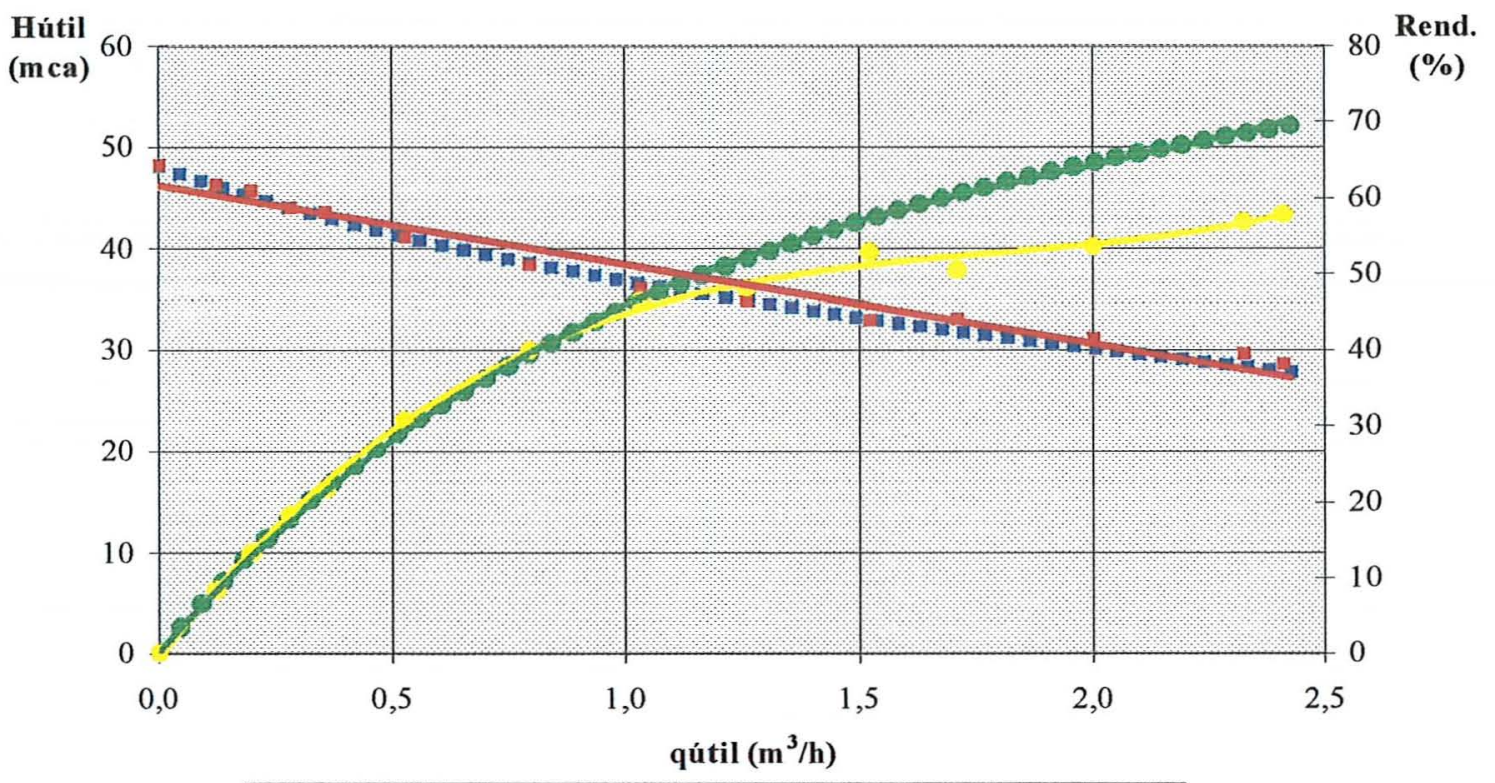

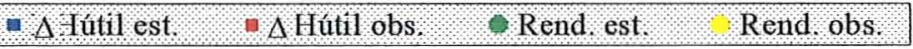

Bomba 1VJF15-M 38J (1 CV) - $\Delta \mathrm{Z}=16,47 \mathrm{~m}-$ Teste 2

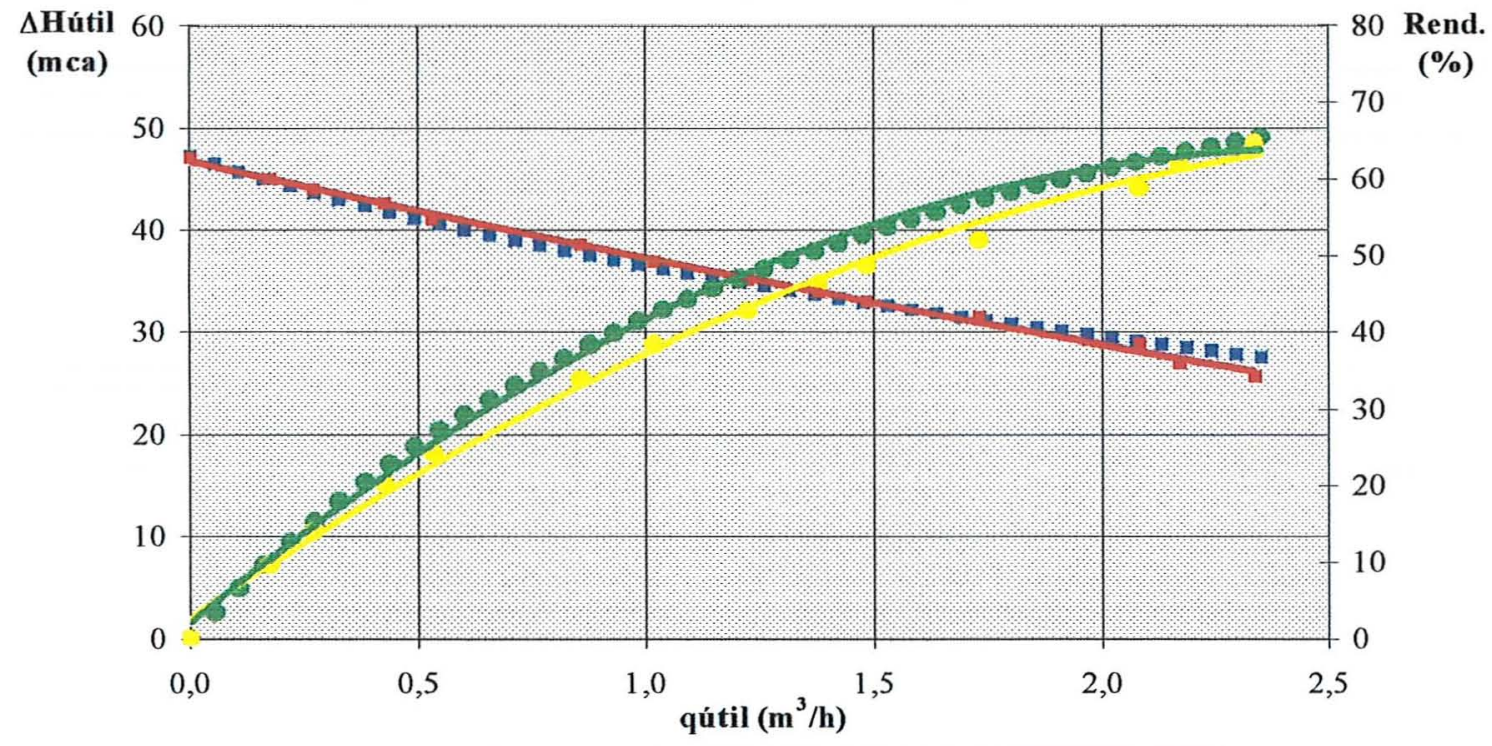

- $\Delta$ Hutil est " $\Delta$ Hutil obs. O Rend est Rend obs.

Figura 12 - Comparação de resultados simulados e observados do conjunto bomba-injetor 1VJF15-M 38 J - Altura de sucção de 16,47 m 
B) Altura de suç̧ão de $11,97 \mathrm{~m}$

\section{SISTEMA BOMBA-INJETOR 3VJE15-M 39G (1/3 CV)}
$\Delta \mathrm{z}=11,97 ; \Delta \mathrm{L}=14,97 \mathrm{~m} ; \Delta \mathrm{z}_{\mathrm{sub}}=0,75 \mathrm{~m}$
$\mathrm{D}_{1}=27,5 \mathrm{~mm}$
$\mathrm{D}_{2}=35,6 \mathrm{~mm}$
$\mathrm{D}_{\mathrm{boc}}=5,9 \mathrm{~mm}$
$\mathrm{K}=0,633$
$\mathrm{Cd}=0,823$

Bomba 3VJE15-M 39G (1/3 CV) - $\Delta \mathrm{Z}=11,97 \mathrm{~m}-$ Teste 1
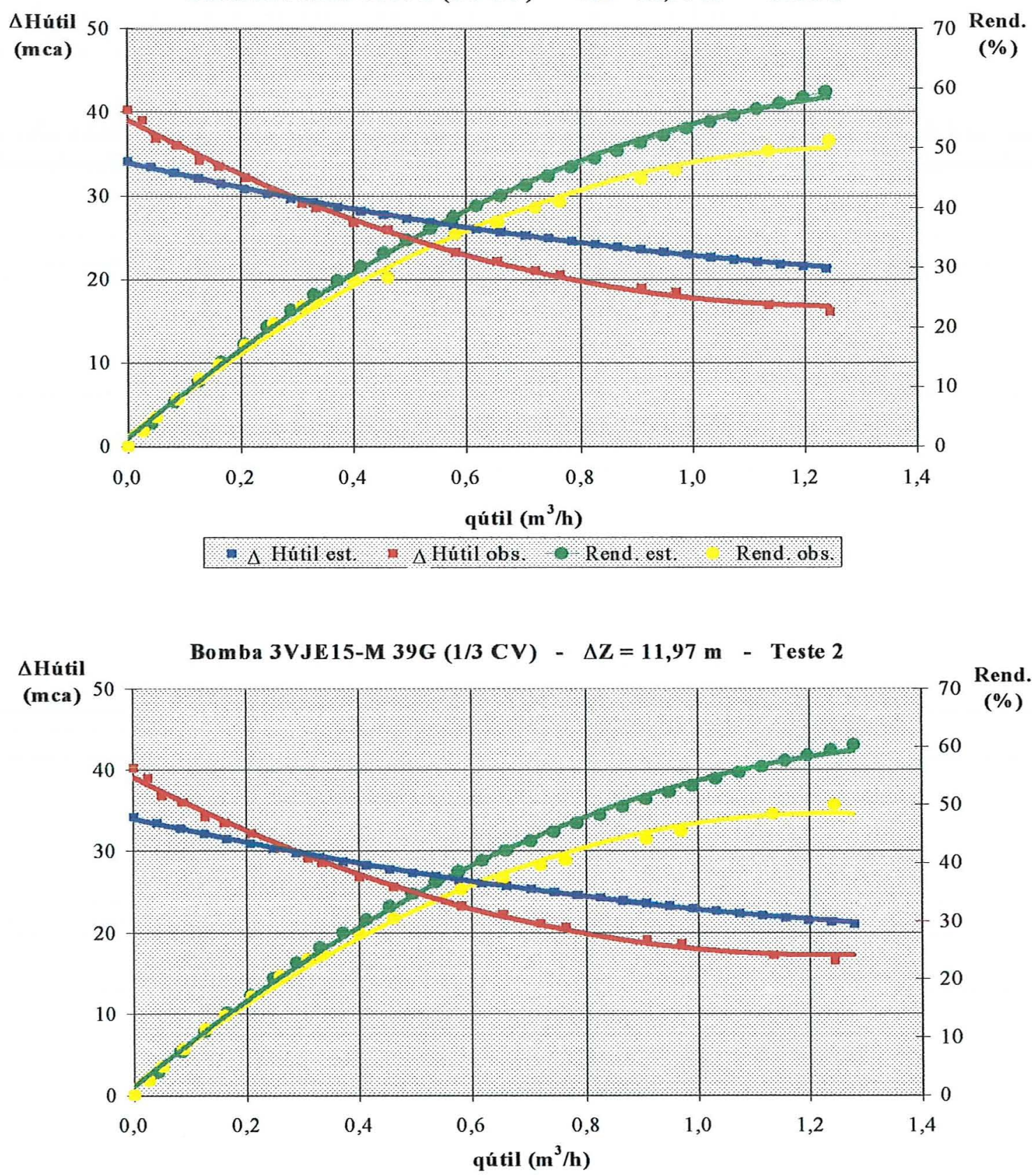

1 $\Delta$ Hútil est $\Delta$ Hútil obs, $\triangle$ Rend est, Rend obs.

Figura 13 - Comparação de resultados simulados e observados do conjunto bomba-injetor 3VJE15-M 39 G - Altura de sucção de 11,97 m 
SISTEMA BOMBA-INJETOR 2VJF15-T 39B (2 CV)

$\Delta \mathrm{z}=11,97 ; \Delta \mathrm{L}=15,37 \mathrm{~m} ; \Delta \mathrm{z}_{\text {sub }}=0,75 \mathrm{~m}$

$\mathrm{D}_{1}=35,6 \mathrm{~mm} \quad \mathrm{D}_{2}=43,5 \mathrm{~mm} \quad \mathrm{D}_{\text {boc }}=6,1 \mathrm{~mm} \quad \mathrm{~K}=0,633 \quad \mathrm{Cd}=0,823$

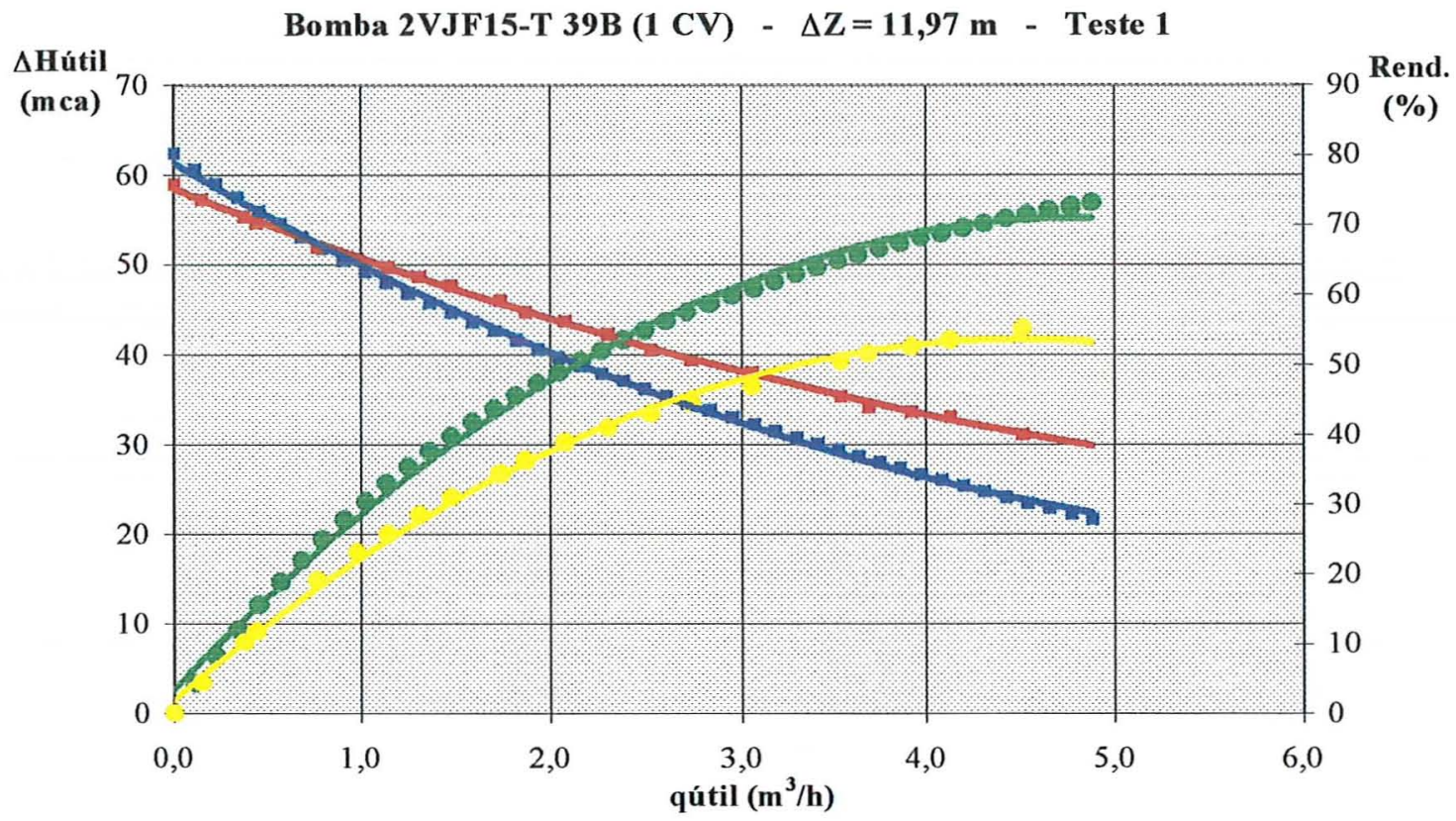

= $\Delta$ Hútil est. $: \Delta$ Hútil obs. o Rend. est: Rend obs.

Bomba 2VJF15-T 39B (1 CV) - $\Delta \mathrm{Z}=11,97 \mathrm{~m}-$ Teste 2

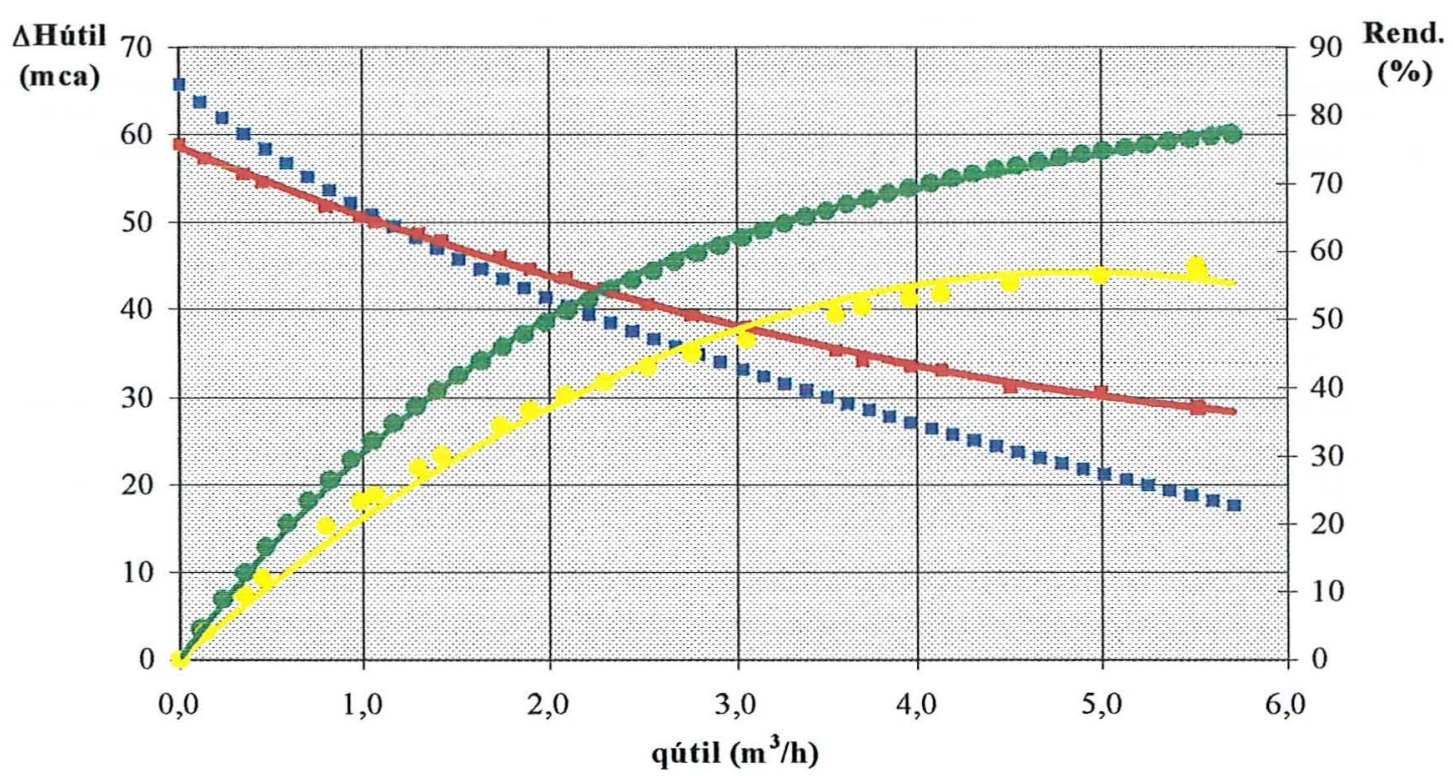

$1 / \Delta$ Iútil est. $1 \Delta$ Hutil obs, $\quad$ Rend. est $\quad$ Rend obs.

Figura 14 - Comparação de resultados simulados e observados do conjunto bomba-injetor 2VJF15-T 39 B - Altura de sucção de $11,97 \mathrm{~m}$ 
SISTEMA BOMBA-INJETOR 1VJF15-M 38J (1 CV)

$\Delta \mathrm{z}=11,97 ; \Delta \mathrm{L}=15,37 \mathrm{~m} ; \Delta \mathrm{z}_{\text {sub }}=0,75 \mathrm{~m}$

$\mathrm{D}_{1}=27,5 \mathrm{~mm} \quad \mathrm{D}_{2}=35,6 \mathrm{~mm} \quad \mathrm{D}_{\text {boc }}=5,9 \mathrm{~mm} \quad \mathrm{~K}=0,633 \quad \mathrm{Cd}=0,823$

Bomba 1VJF15-M 38J (1 CV) - $\Delta \mathrm{Z}=11,97 \mathrm{~m}-$ Teste 1

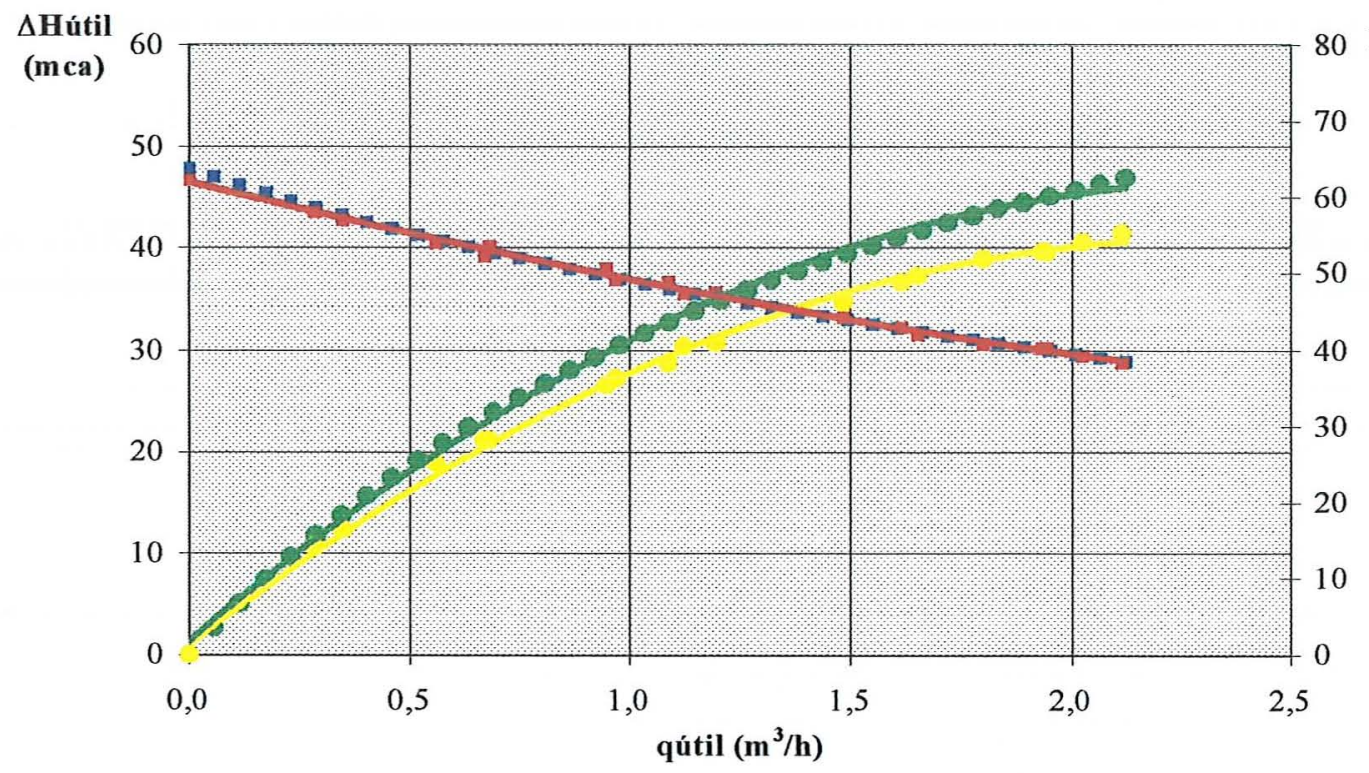

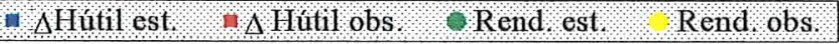

Bomba 1VJF15-M 38J (1 CV) - $\Delta Z=11,97 \mathrm{~m}-$ Teste 2

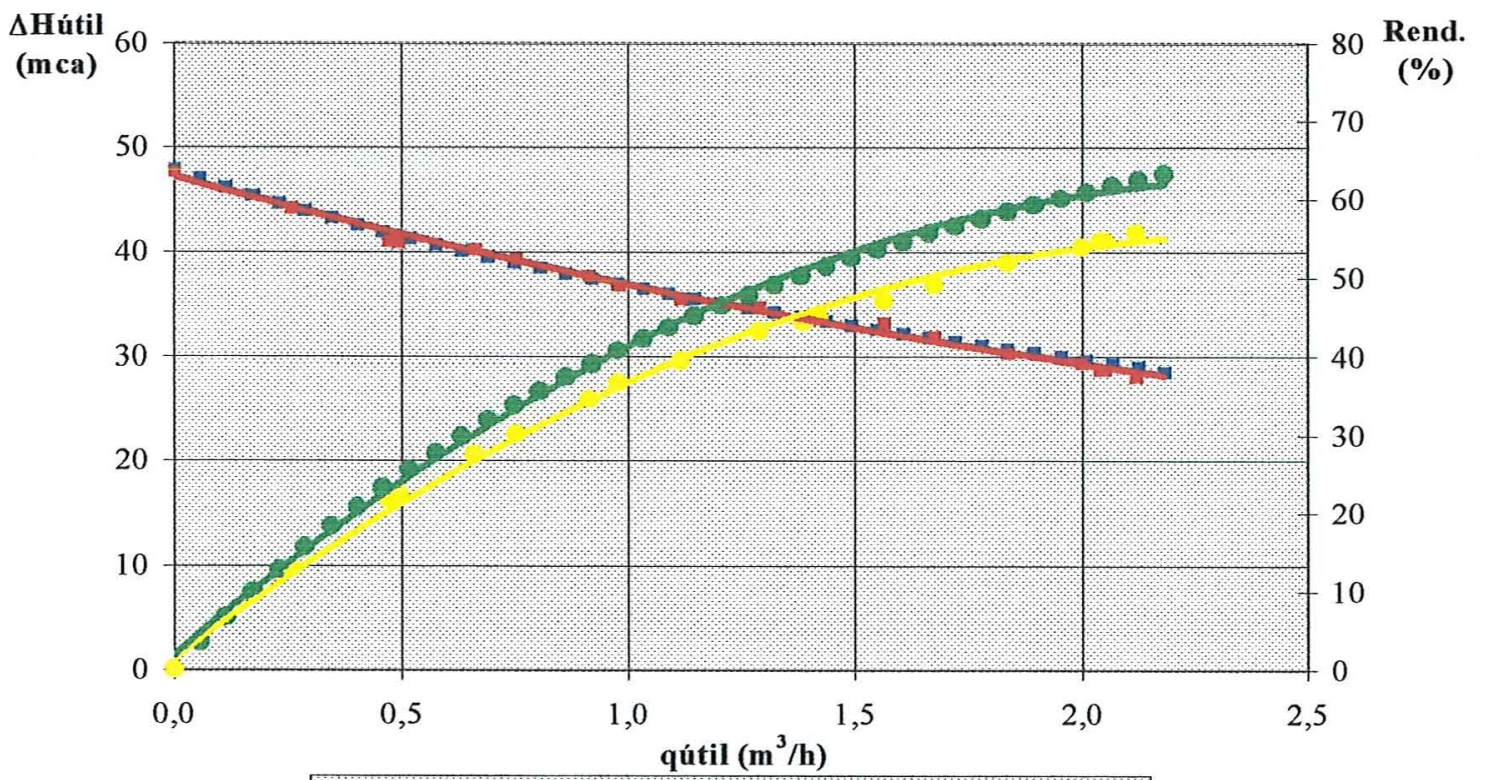

- $\Delta$ lutil est $=\Delta$ Hutil obs, $\odot$ Rend est, Rend obs:

Figura 15 - Comparação de resultados simulados e observados do conjunto bomba-injetor 1VJF15-M $38 \mathrm{~J}$ - Altura de sucção de 11,97 m 
Através da análise dos gráficos percebe-se que o modelo proporcionou uma estimativa adequada da relação entre o diferencial de pressão útil $\left(\Delta \mathrm{H}_{\text {util }}\right)$ e a vazão útil (qưtil) dos conjuntos injetor-bomba. Os melhores ajustes foram obtidos para o conjunto IVJF15-M 38J, em ambas as alturas de sucção, e para o conjunto 3VJE15-M $39 \mathrm{G}(1 / 3 \mathrm{CV})$ à altura de sucção de $16,47 \mathrm{~m}$. O modelo não apresentou um bom ajuste da relação $\Delta \mathrm{H}_{\text {util }}$ versus qutil para os conjuntos 3VJE15-M 39G à altura de sucção de 11,97 m e 2VJF15-T 39B operando em ambas as alturas de sucção testadas

A estimativa do rendimento dos conjuntos bomba-injetor também mostrou-se adequada, exceto para os conjunto 2VJF15-T 39B. Este fato pode estar relacionado a fatores não previstos pelo modelo. Uma análise do cálculo do rendimento e das simulações fornece esclarecimentos importantes, tal como se vê a seguir.

A Equação 77 apresenta a forma de cálculo do rendimento:

$$
\eta^{\prime}=\frac{q_{\text {util }} \Delta H_{u t i l}}{q_{\text {circ }} H f_{\text {sist }}+q_{u t i l}\left(\Delta H_{u t i l}+H f_{2}\right)}
$$

Conforme já foi dito, as melhores estimativas da relação $\Delta \mathrm{H}_{\text {útil }} \times$ qútil foram as do conjunto 1VJF15-M 38J e, portanto, o numerador da Equação 77 está corretamente dimensionado. Resta, portanto, analisar seu denominador.

Pode-se perceber, através das Tabelas 19 a 42 (Anexo B), que a perda de carga no trecho 2 da tubulação de sucção $\left(\mathrm{Hf}_{2}\right)$ apresenta valores baixos, tendo pouca influência nos resultados. Os fatores mais importantes são a perda de carga do sistema $\left(\mathrm{Hf}_{\text {sist }}\right)$ e o diferencial de pressão útil $\left(\Delta \mathrm{H}_{\mathrm{u} \text { util }}\right)$. Na perda de carga do sistema a parte mais importante é a perda de carga no bocal $\left(\mathrm{Hf}_{\mathrm{boc}}\right)$. A Figura 16 apresenta a comparação entre os resultados estimados e observados das duas variáveis, no Teste 1 do conjunto 1 VJF15-M 38J (1 CV), operando à altura de sucção de 16,47 m. Esse teste apresenta um desvio do rendimento para os valores mais altos de qútil, conforme pode-se verificar na Figura 16. Os resultados apresentados nessa figura evidenciam a diferença entre os valores estimados e observados da perda de carga do sistema, bem como a aproximação entre os resultados de diferencial de pressão útil. 
Resultados estimados e observados de perda de carga do sistema e diferencial de pressão útil -Conj. bomba-injetor 1VJF15-M 38J $\Delta \mathrm{z}=16,47 \mathrm{~m}$

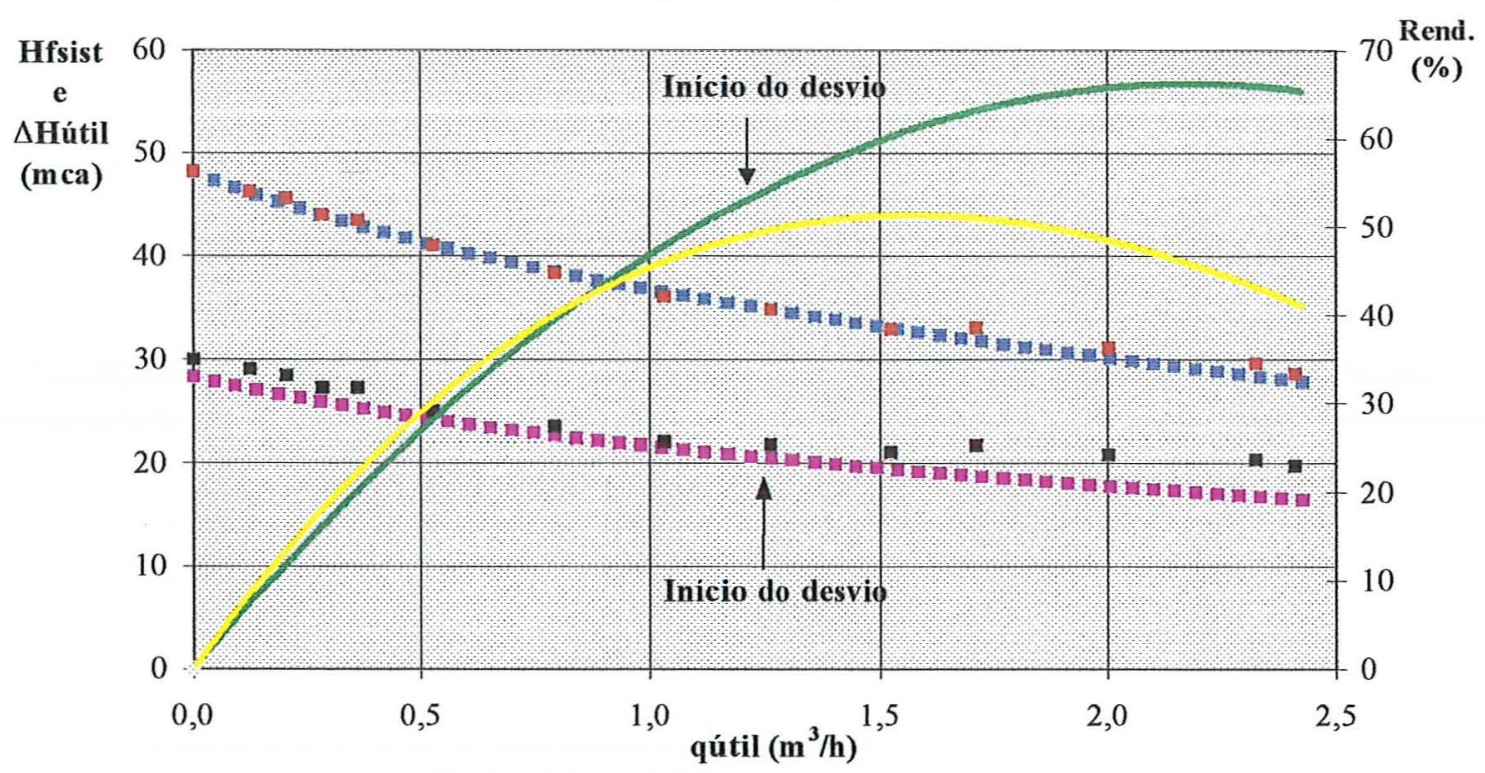

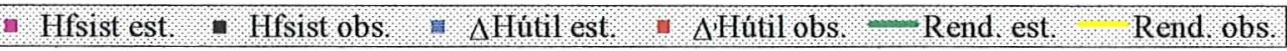

Figura 16- Comparação de $\mathrm{Hf}_{\text {sist }}$ e $\Delta \mathrm{H}_{\text {útil }}$ estimados e observados do conjunto bombainjetor 1VJF15-M 38J operando a uma altura de sucção de $16,47 \mathrm{~m}$

Baseando-se nessa diferença entre rendimento estimado e observado encontrada em um teste com bom ajuste da relação $\Delta \mathrm{H}_{\text {útil }} \times$ qútil , procurou-se verificar a ocorrência do mesmo fenômeno noTeste 1 do conjunto 3VJE15-M 39G, operando à altura de sucção de $11,97 \mathrm{~m}$, e no Teste 1 do conjunto $2 \mathrm{VJF} 15-\mathrm{T} 39 \mathrm{~B}$, operando à altura de sucção de $16,47 \mathrm{~m}$, a fim de comprovar a causa dos desvios no rendimento desse conjunto. As Figuras 17 e 18 apresentam os valores de perda de carga do sistema e diferencial de pressão útil, estimados e observados, para os conjuntos 3VJE15-M 39G e 2VJF15-T 39B, respectivamente.

Percebe-se que'no caso do conjunto 3VJE15-M 39G (Figura 17) a estimativa da perda de carga do sistema está bem ajustada aos resultados observados no teste. Já no conjunto 2VJF15-T 39B nota-se que aumentaram as diferenças entre as perdas de carga estimada e observada no sistema. Houve também diferenças entre o diferencial de pressão útil estimado e o observado, o que atenuou a diferença entre o rendimento estimado e o observado. 
Resultados estimados e observados de perda de carga do sistema, diferencial de Hfsist pressão útil e rendimento - Conj. bomba-injetor 3VJE15-M 39G $\Delta \mathrm{z}=11,97 \mathrm{~m}$

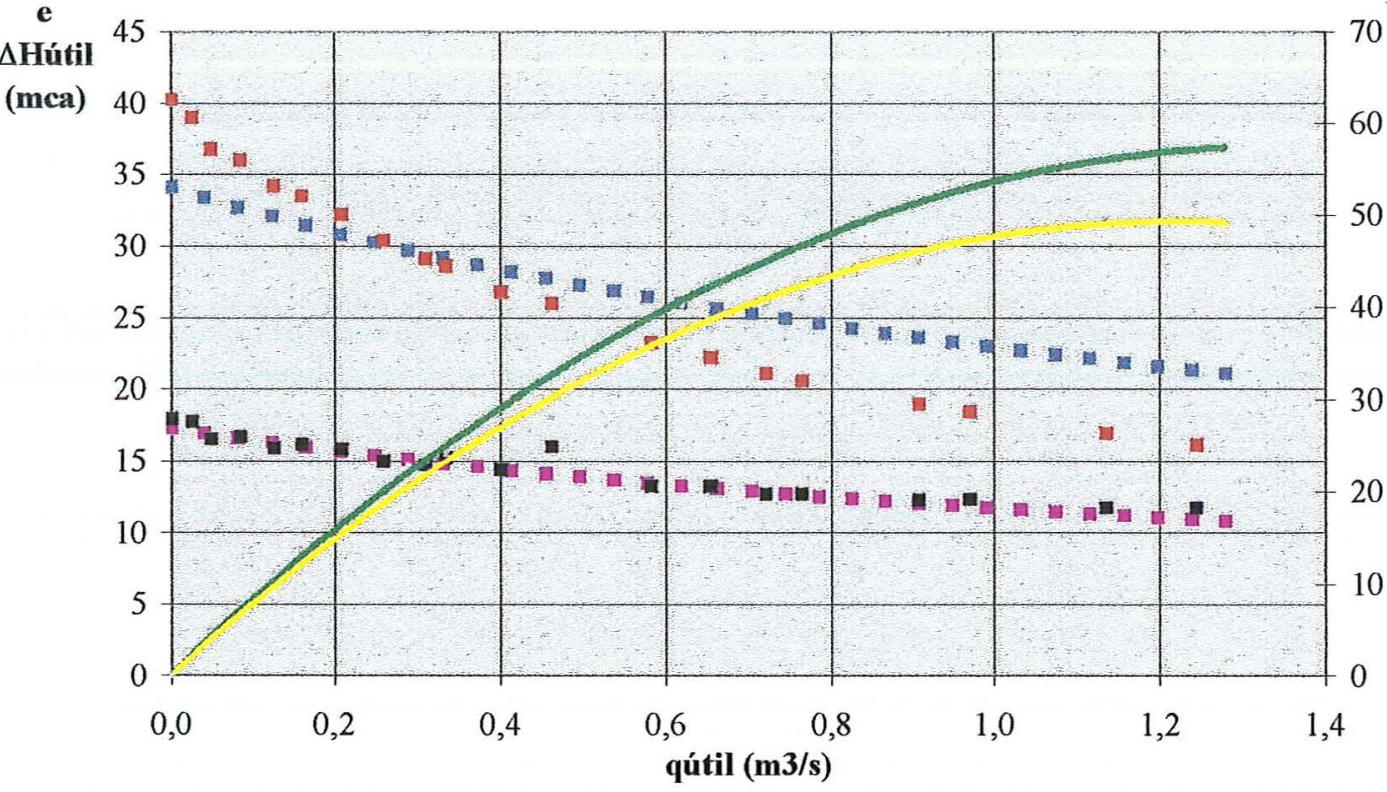

Rend.

0 (\%)

60

50

- Hfsist est. " Hfsist obs. $\Delta$ Hútil est $\Delta$ Hútil obs. - Rend. est. Rend. obs.

Figura 17 - Comparação de Hfsist e $\Delta$ Hútil estimados e observados do conjunto 3VJE15-M 39G

Resultados estimados e observados de perda de carga do sistema e diferencial de pressão útil - Conj. bomba-injetor 2VJF15-T 39B $\Delta z=16,47 \mathrm{~m}$

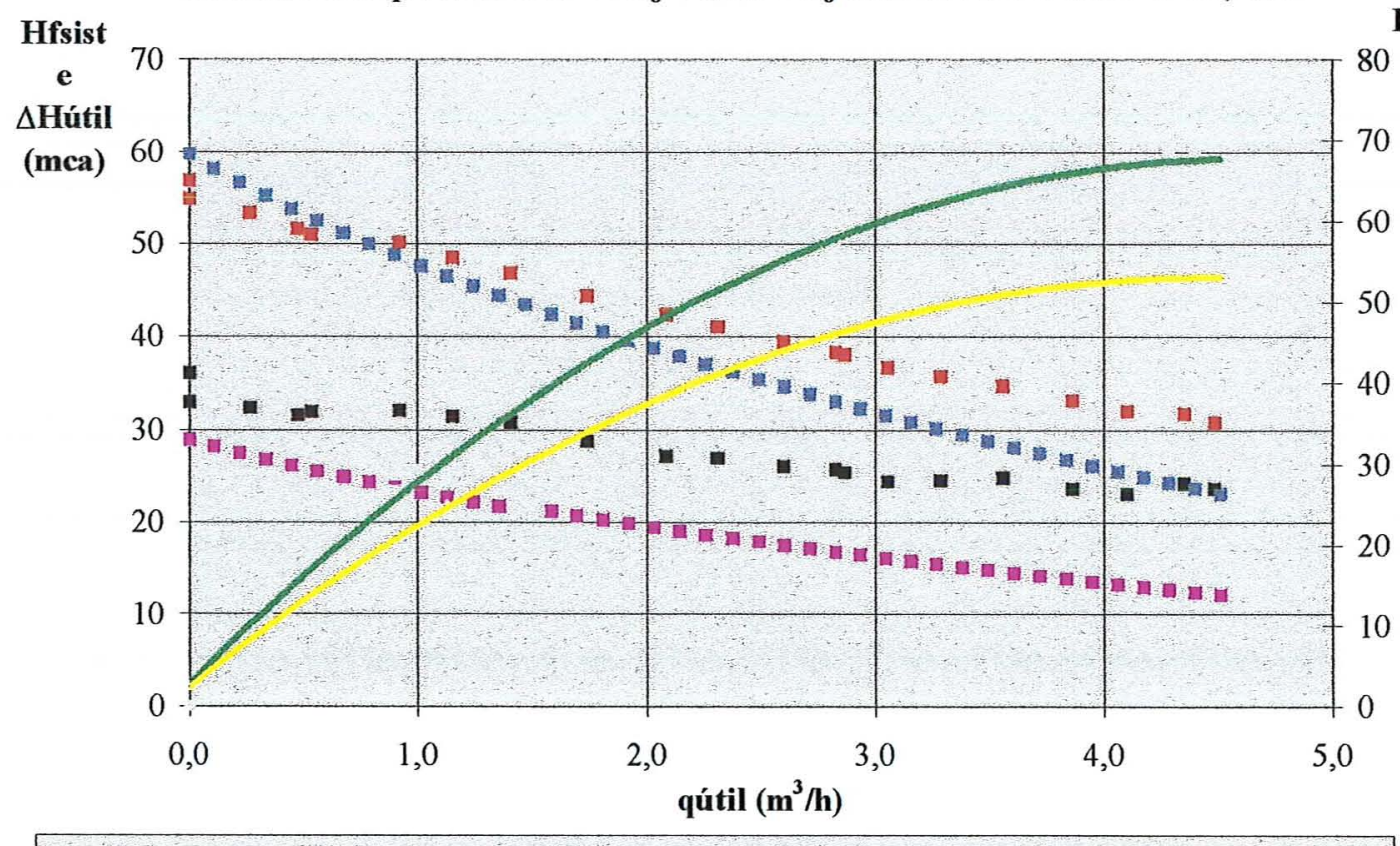

Rend.

- Hfsist est. Hfsist obs. = $\Delta$ Hútil est. $\Delta$ Hútil obs. $\quad$ Rend. est. Rend, obs.

Figura 18 - Comparação de Hfsist e $\Delta$ Hútil estimados e observados do conjunto 2VJF15-T 39B 
Essas diferenças podem ser atribuídas a dois fatores:

a) o modelo não considera as perdas de carga localizadas ocorrentes no sistema;

b) os coeficientes de descarga e de perda de carga do injetor são considerados constantes no modelo, o que não corresponde à realidade.

No caso do conjunto $3 \mathrm{VJE} 15-\mathrm{M} 39 \mathrm{G}$ a diferença entre os rendimentos estimado e observado está diretamente ligada à diferença entre a estimativa de $\Delta$ Hutil e os valores observados. Pela análise conjunta das equações 26 e 53 , percebe-se que o valor de $\Delta$ Hutil é dependente do coeficiente de descarga e do comprimento do trecho 1 da tubulação de sucção $\left(L_{1}\right)$. Se a perda de carga localizada no sistema for acentuadas, deve-se aumentar o valor de $\mathrm{L}_{1}$ para considerar essa perda nos cálculos. $\mathrm{O}$ modelo não considera as perdas localizadas e, portanto, pode haver erros na estimativa de $\Delta H u t i l$. Outra possível causa pode ser atribuída ao coeficiente de descarga. A análise conjunta das equações 50 e 53 mostra que o coeficiente de descarga entra no cálculo de $\Delta$ Hútil. Um coeficiente de descarga incorreto acarretará em erro na estimativa de $\Delta$ Hutil e, consequentemente, no cálculo do rendimento do conjunto. Através de várias simulações feitas com o auxílio do programa INJETOR, foi possivel perceber que o coeficiente de descarga tem influência bastante acentuada sobre $\Delta$ Hutil. $O$ incremento de $L_{1}$ não apresentou, no entanto, o mesmo grau de influência.

No caso do conjunto 2VJE15-T 39B é possível perceber, observando-se a Figura 18, que houve uma diferença bastante acentuada entre a estimativa e os resultados observados das perdas de carga do sistema $\left(\mathrm{Hf}_{\text {sist }}\right)$, além da diferença entre $\Delta$ Hutil observado e estimado. $\mathrm{O}$ modelo subestimou $\Delta \mathrm{H}_{\text {util }}$ e $\mathrm{Hf}_{\text {sist. }}$. Analisando-se a equação 77 é possível afirmar que o rendimento será superestimado, pois a utilização de um valor subestimado de $\mathrm{Hf}_{\text {sist }}$ tem grande influência sobre o cálculo do rendimento $(\eta)$. Como essa variável encontra-se no denominador da equação, a estimativa do valor de $\eta$ será superior ao valor real.

Outro fator a ser considerado como possível fonte de erro é o uso de valores fixos para o coeficientes de descarga (Cd) e de perda de carga do injetor (K). $\mathrm{Na}$ 
obtenção dos valores para esses coeficientes notou-se que houve variações de ambos ao longo dos testes. As perdas localizadas podem ter importância significativa em um sistema que utiliza muitas conexões e tem bruscas mudanças de direção do curso da água. Se os coeficientes de descarga e de perda de carga variarem significativamente, haverá mudanças nos valores previstos de diferencial de pressão útil e da perda de carga do sistema bomba-injetor.

Ambos os fatores podem causar distorções na estimava do modelo, especialmente quando se trata de vazões e pressões maiores. Isto explica a tendência de afastamento das estimativas do rendimento com o aumento da vazão útil, em relação aos resultados observados.

O conjunto 2 VJF15-T $39 \mathrm{~B}$ tem potência maior e, conseqüentemente, vazão e pressão maiores que os demais conjuntos. Isto evidenciou as diferenças entre as estimativas e a observação de resultados.

Conclui-se, portanto, que o modelo pode ser aperfeiçoado, melhorando sua capacidade de simulação da realidade, mediante um estudo mais aprofundado das perdas de carga localizadas ocorrentes no sistema e da inclusão de equações para cálculo dos coeficientes de descarga e perda de carga do injetor, pois esses coeficientes variam com a velocidade de escoamento de água no bocal.

\subsection{Otimização dos bocais dos injetores}

As Figuras 19 a 24 apresentam os resultados da otimização dos bocais dos injetores para diversos valores de vazão útil e para cada altura de sucção. Apresentou-se uma otimização por conjunto e por altura de sucção, suprimindo-se as repetições de testes. Pela figuras pode-se determinar qual diâmetro de bocal do injetor maximizará o diferencial de pressão útil.

Como os resultados coletados são muito extensos, os valores de vazão útil utilizados nas figuras foram escolhidos ao longo dos resultados disponíveis. Procurou-se utilizar sete pontos aproximadamente equidistantes, ao longo da faixa de qutil disponível. 
Otimização do diâmetro do bocal do injetor para diversos valores de vazão útil (Dboc x $\Delta$ Hútil) - Bomba 3VJE15-M 39G - 1/3 CV

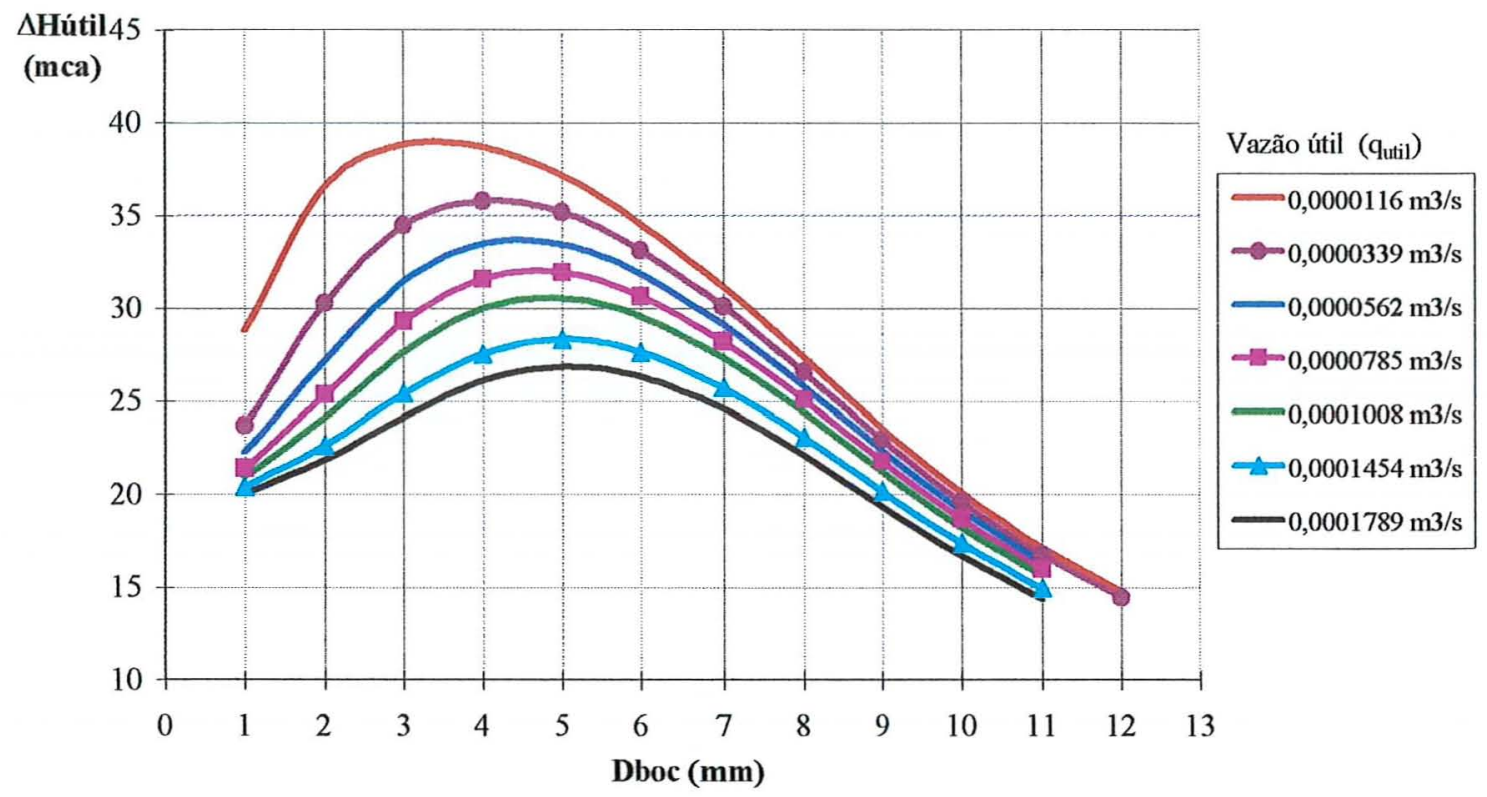

Figura 19 - Sistema bomba-injetor 3VJE15-M 39G - Curvas $\Delta$ Hútil x Dboc para otimização do bocal do injetor (Altura de sucção de 16,47 m)

Otimização do diâmetro do bocal do injetor para diversos valores de vazão útil

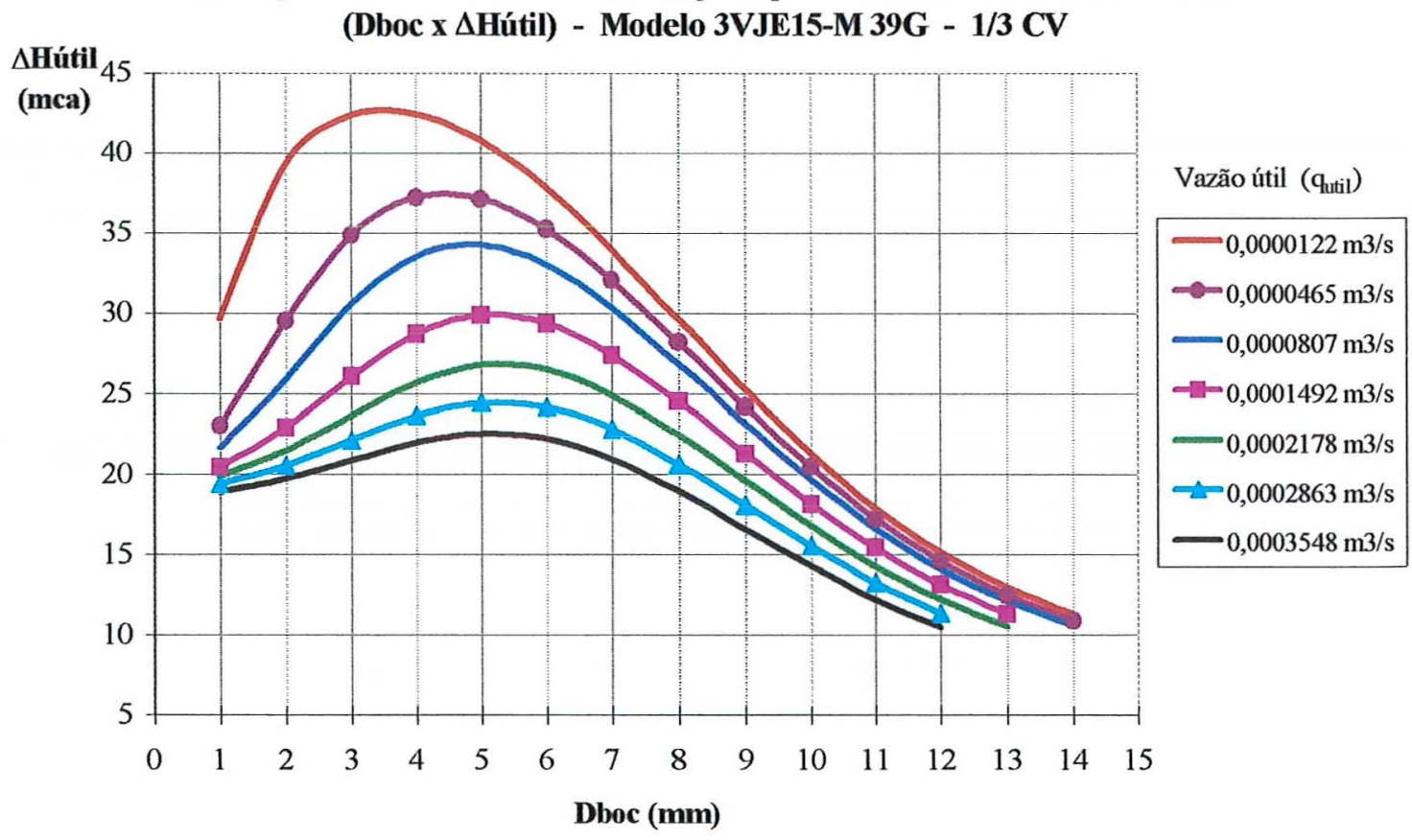

Figura 20 - Sistema bomba-injetor 3VJE15-M 39G - Curvas $\Delta \mathrm{H}_{\text {util }} \times \mathrm{D}_{\text {boc }}$ para otimização do bocal do injetor (Altura de sucção de 11,97 m) 
Otimização do diâmetro do bocal do injetor para diversos valores de vazão útil

$\Delta$ Hútil

(Dboc x $\Delta$ Hútil) - Modelo 2VJF15-M 39B - 2 CV

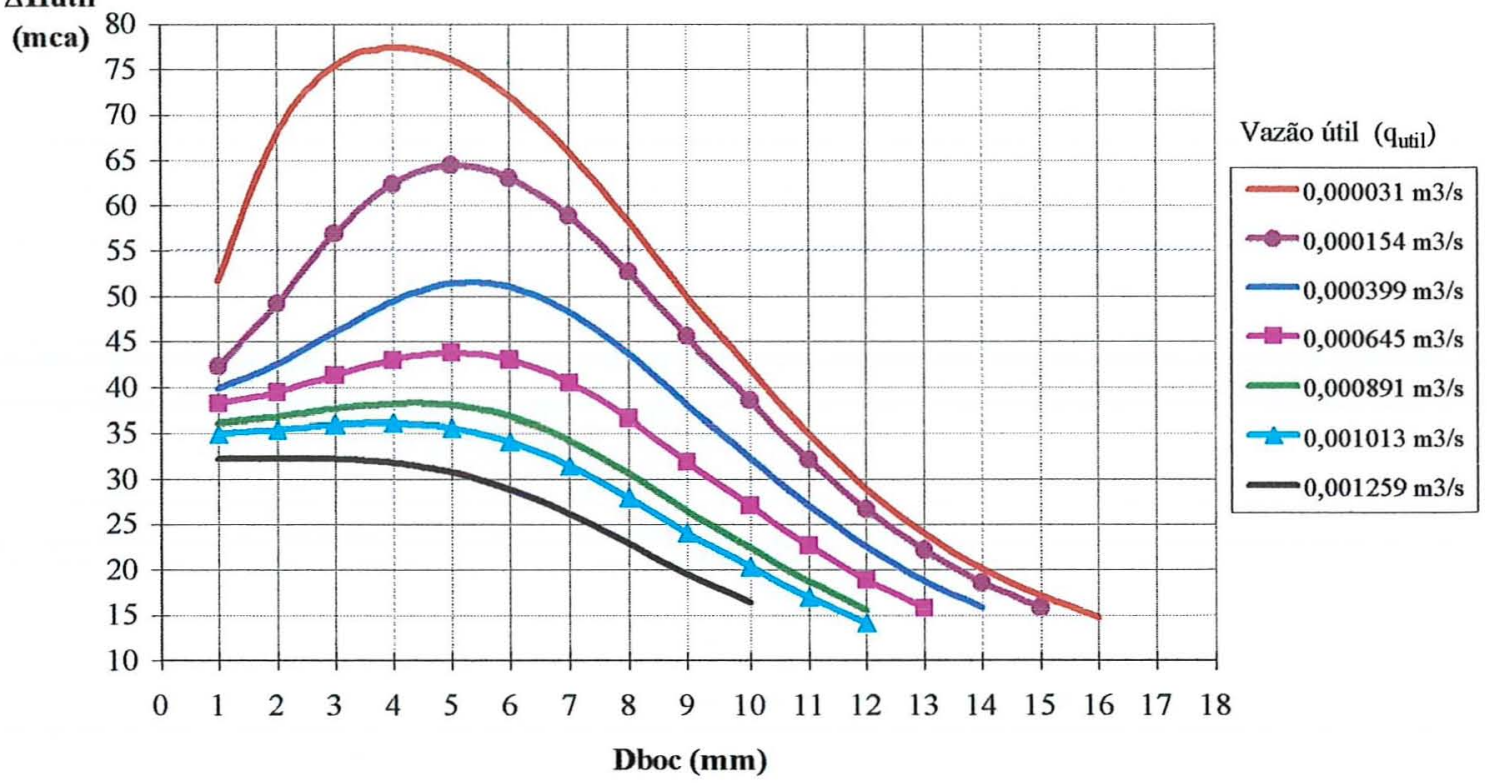

Figura 21 - Sistema bomba-injetor 2VJF15-T 39B - Curvas $\Delta$ Hútil x Dboc para otimização do bocal do injetor (Altura de sucção de $16,47 \mathrm{~m}$ )

Otimização do diâmetro do bocal do injetor para diversos valores de vazão

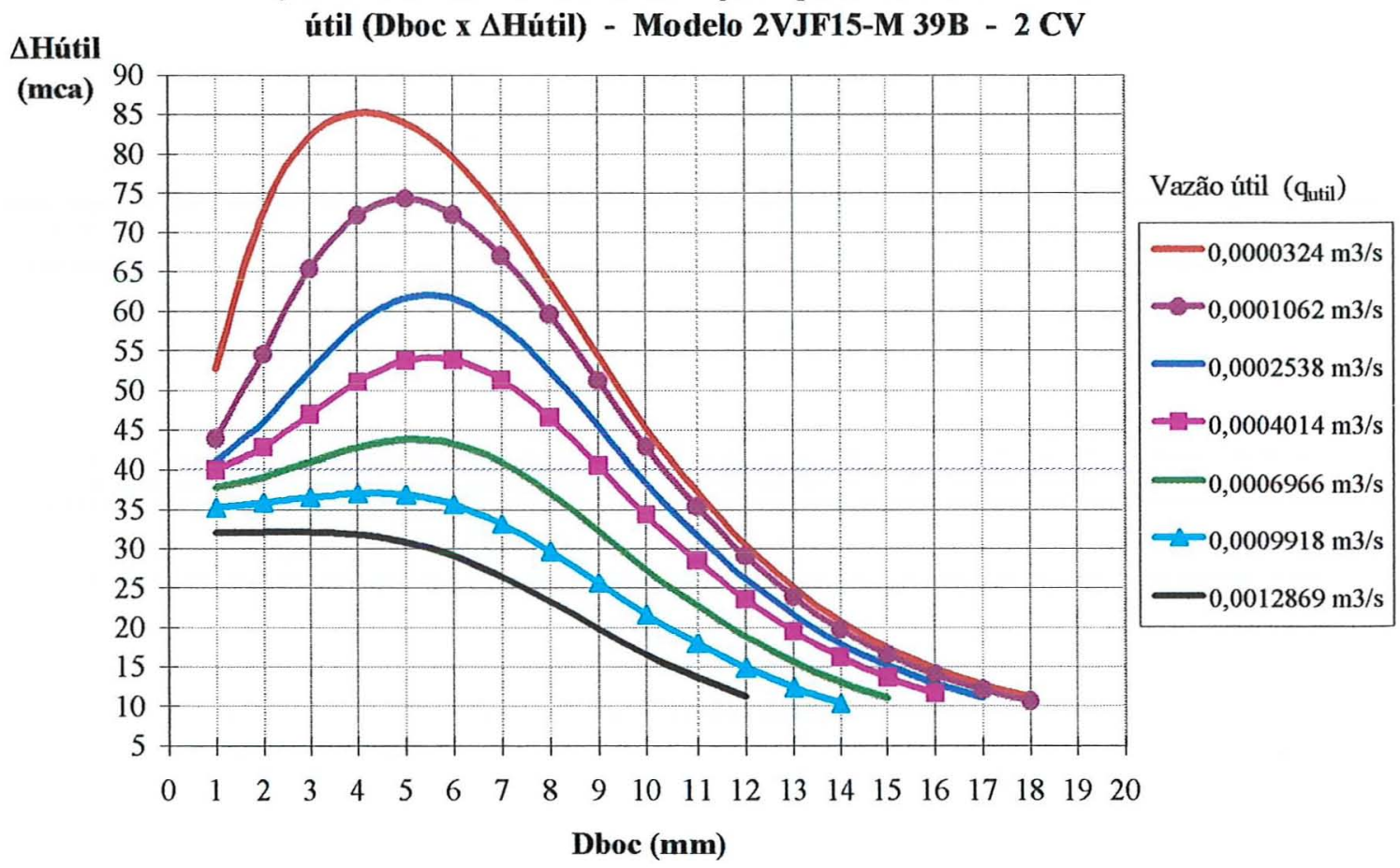

Figura 22 - Sistema bomba-injetor 2VJF15-T 39B - Curvas $\square$ Hútil x Dboc para otimização do bocal do injetor (Altura de sucção de 11,97 m) 
Otimização do diâmetro do bocal do injetor para diversos valores de vazão útil (Dboc x $\Delta$ Hútil) - Modelo 1VJF15-M 38J - 1 CV

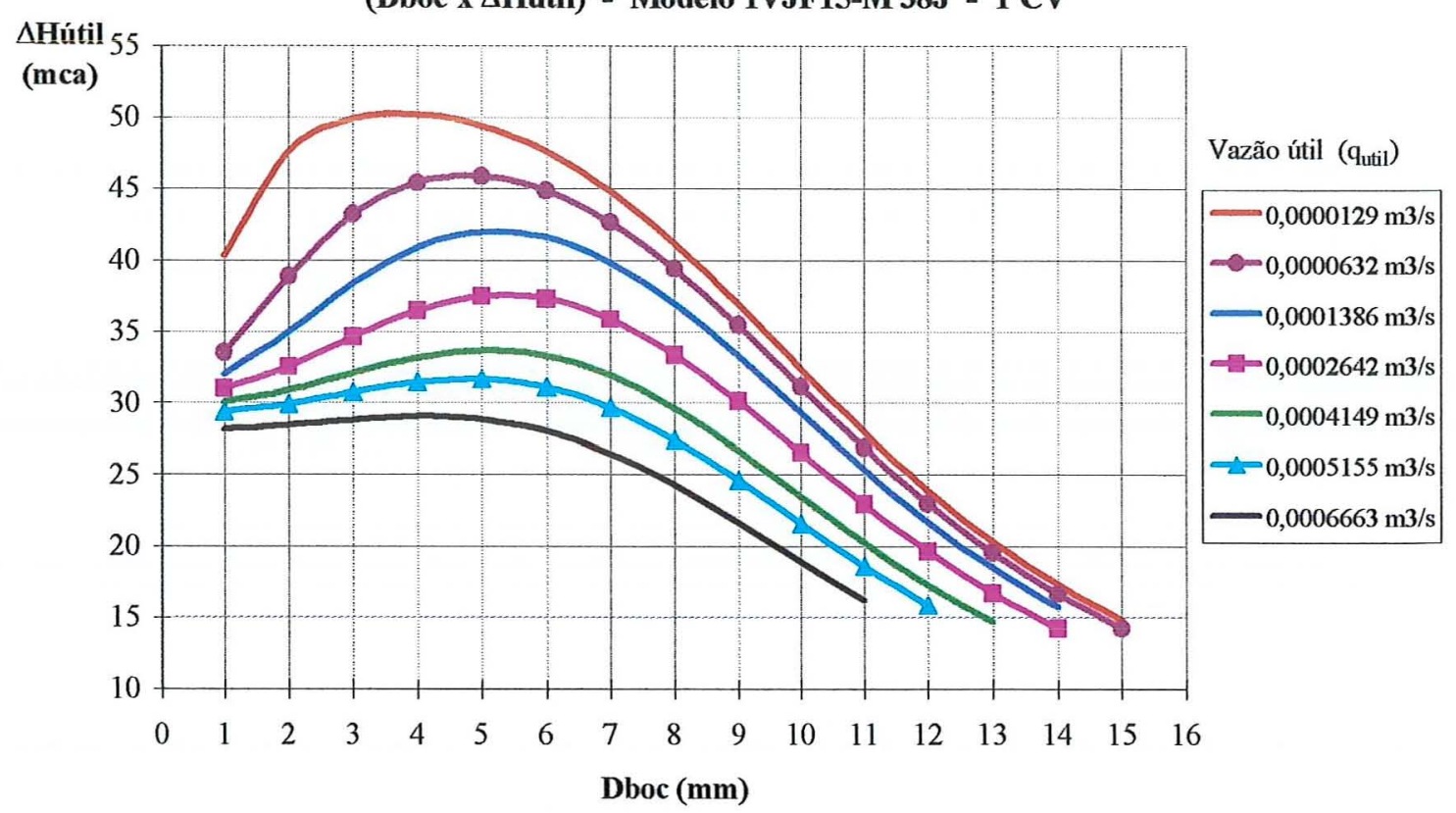

Figura 23 - Sistema bomba-injetor 1VJF15-M 38J - Curvas $\square$ Hútil x Dboc para otimização do bocal do injetor (Altura de sucção de 16,47 m)

Otimização do diâmetro do bocal do injetor para diversos valores de vazão útil (Dboc x $\Delta$ Hútil) - Modelo 1VJF15-M 38J - 1 CV

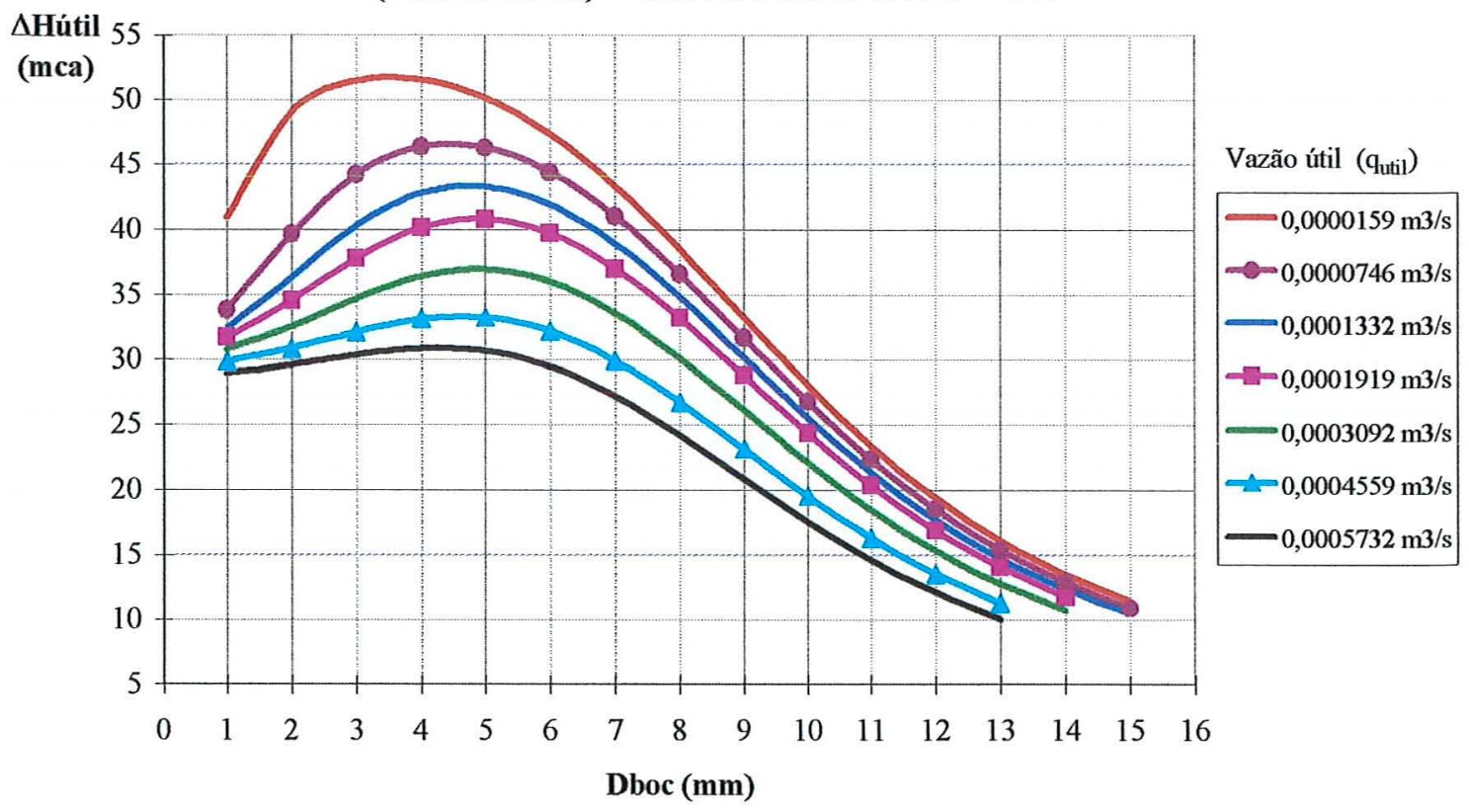

Figura 24 - Sistema bomba-injetor 1VJF15-M 38J - Curvas $\square$ Hútil x Dboc para otimização do bocal do injetor (Altura de sucção de 11,97 m) 
O aumento do diâmetro do bocal inicialmente aumenta o diferencial de pressão útil $\left(\Delta \mathrm{H}_{\text {útil }}\right)$ até um certo ponto, a partir do qual começa a haver uma diminuição desse diferencial. $\mathrm{O}$ ponto de máximo $\Delta \mathrm{H}_{\text {útil }}$ determina o diâmetro ótimo do bocal do injetor a ser utilizado para cada vazão útil estudada.

Pelas Figuras 19 a 24 percebe-se que o incremento de $\Delta \mathrm{H}_{\text {útil }}$ devido ao redimensionamento do bocal é maior nos menores valores de vazão útil.

O aumento da vazão útil, e a conseqüente diminuição da vazão circulante, vão diminuindo a capacidade do injetor aumentar $\Delta \mathrm{H}_{\text {utill. }}$ A partir de um determinado valor de qútil torna-se inviável o uso do injetor, pois o diferencial de pressão útil obtido é menor que a altura de sucção. Quando isto ocorre o sistema para de funcionar.

No conjunto 2VJF15-T 39B esse incremento ocorreu até um certo valor de vazão útil. Nas vazões maiores não houve uma elevação de $\Delta \mathrm{H}_{\text {útil }}$ com o aumento do diâmetro do bocal, indicando que o injetor funcionará em condições precárias, fora de suas especificações de vazão e/ou de pressão.

A redução da altura de sucção de 16,47 para $11,97 \mathrm{~m}$ praticamente duplicou o limite superior de vazão útil do conjunto 3VJE15-M 39G (Aumento de $98,32 \%$ ). Esse comportamento não foi verificado nos conjuntos 2VJF15-T 39B (Aumento de 2,22\%) e 1VJF15-M 38J (Redução de 13,97\%). Esse comportamento forneceu indícios sobre as diferenças de construção de cada conjunto.

São bombas que apresentam comportamentos diferenciados em relação à variação da altura de sucção e, entretanto, o modelo proporcionou uma boa estimativa de seu funcionamento. Com isto demonstra-se a utilidade da utilização do modelo matemático na previsão do funcionamento de sistemas formados por bombas centrífugas e injetores utilizados em poços.

A análise das Figuras 19 a 24 apresenta um aspecto fundamental do uso de conjuntos injetor-bomba centrífuga, que é o acréscimo de $\Delta \mathrm{H}_{\text {util }}$ devido à mudança de diâmetro do bocal do injetor. Para os conjuntos 3VJE15-M 39G e 1VJF15-M 38J o diâmetro do bocal ótimo variou de 3 a $6 \mathrm{~mm}$, considerando-se as duas alturas de sucção 
testadas, e os diâmetros dos bocais comercializados são 5,9 e $6,1 \mathrm{~mm}$, respectivamente. No conjunto 2VJF15-T 39B o diâmetro do bocal ótimo variou de 4 a $6 \mathrm{~mm}$ em ambas as alturas de sucção, e o diâmetro do bocal comercializado é $8,0 \mathrm{~mm}$.

O projeto dos conjuntos 3VJE15-M 39G e 1VJF15-M 38J prevê um bocal adequado à vazão útil máxima dos conjuntos, pois seu diâmetro está próximo do ideal para a maior vazão (Ver Figuras 19, 20,23 e 24). Já o conjunto 2VJF15-T 39B não apresentou um bocal otimizado, de acordo com a previsão do modelo, pois o diâmetro utilizado proporciona um valor de $\Delta \mathrm{H}_{\text {util }}$ inferior ao do bocal ótimo (Ver Figuras $21 \mathrm{e}$ 22). Deve-se lembrar, entretanto, que o modelo não teve um bom ajuste ao comportamento do conjunto $2 \mathrm{VJF} 15-\mathrm{T} 39 \mathrm{~B}$, e as diferenças entre a estimativa do modelo e os resultados observados provavelmente justificam as diferenças de $\Delta \mathrm{H}_{\text {util }}$ entre o bocal ótimo (modelo) e o bocal utilizado no injetor. 


\section{CONCLUSÕES}

Com base nos resultados apresentados pode-se afirmar que:

a) $\mathrm{O}$ modelo matemático proporcionou uma simulação adequada da relação $\Delta \mathrm{H}_{\text {util }}$ versus qútil, para os conjuntos 3VJE15-M 39G (1/3 CV), na altura de sucção de 16,47 m, e 1VJE15-M 38J, nas duas alturas de sucção testadas;

b) O modelo matemático proporcionou uma estimativa adequada do rendimento do sistema bomba-injetor para os conjuntos 3VJE15-M 39G (1/3 CV), na altura de sucção de 16,47 m, e 1VJE15-M 38J nas duas alturas de sucção testadas;

c) A melhor relação entre $\Delta$ Hutil e diâmetro do bocal do injetor varia de acordo com a vazão útil desejada. De modo geral, para os injetores e vazões úteis testados, os maiores valores de $\Delta$ Hutil podem ser obtidos com o diâmetro de bocal variando de 3 a $6 \mathrm{~mm}$;

d) Para a vazão máxima de cada conjunto injetor-bomba centrífuga, os diâmetros de bocais que proporcionam o maior valor de $\Delta \mathrm{H}_{\text {util }}$ foram: $5 \mathrm{~mm}$ para $\mathrm{o}$ conjunto 3VJE15-M 39G (1/3 CV); $4 \mathrm{~mm}$, para o conjunto 1VJF15-M 38J (1 CV) e $3 \mathrm{~mm}$, para o conjunto 2VJF15-T 39B (2 CV);

e) $\mathrm{O}$ ajuste do modelo aos dados observados pode ser melhorado, utilizando-se expressões matemáticas para o cálculo dos coeficientes de descarga e de perda de carga do injetor, pois eles sofreram variações com a velocidade de escoamento de água pelo bocal;

f) $\mathrm{O}$ modelo computacional desenvolvido mostrou-se adequado à obtenção das estimativas de funcionamento de conjuntos injetor-bomba centrifuga. 
ANEXO A

Curva Vazão x Pressão das Bombas

Coeficientes de descarga $(\mathrm{Cd})$ e de perda de carga $(\mathrm{K})$ dos injetores 


\section{Relação vazão versus pressão para as bombas centrífugas utilizadas}

Tabela 4 - Dados experimentais de vazão e pressão da bomba JACUZZI, modelo 1VJF15-M $38 \mathrm{~J}(1 \mathrm{CV})$

\begin{tabular}{ccc|ccc}
\hline Ordem & $\begin{array}{c}\text { Vazão } \\
(\mathrm{m} 3 / \mathrm{s})\end{array}$ & $\begin{array}{c}\text { Pressão } \\
(\mathrm{mca})\end{array}$ & Ordem & $\begin{array}{c}\text { Vazão } \\
(\mathrm{m} 3 / \mathrm{s})\end{array}$ & $\begin{array}{c}\text { Pressão } \\
(\mathrm{mca})\end{array}$ \\
\hline 1 & 0.0000000 & 31 & 11 & 0.00132430 & 21 \\
2 & 0.0003137 & 30 & 12 & 0.00138329 & 20 \\
3 & 0.0004645 & 29 & 13 & 0.001480454 & 19 \\
4 & 0.0006919 & 28 & 14 & 0.001518329 & 18 \\
5 & 0.0008208 & 27 & 15 & 0.001584044 & 17 \\
6 & 0.0009162 & 26 & 16 & 0.001661144 & 16 \\
7 & 0.0010295 & 25 & 17 & 0.001705489 & 15 \\
8 & 0.0011001 & 24 & 18 & 0.001797079 & 14 \\
9 & 0.0011651 & 23 & 19 & 0.001802466 & 13 \\
10 & 0.0012428 & 22 & 20 & 0.00186160 & 12 \\
\hline
\end{tabular}

Regressão polinomial para a bomba 1VJF15-M 38J:

$\Delta H_{b o m b a}=-4,852971818 \times 10^{6} q_{b o m b a}^{2}-981,8362 q_{b o m b a}+30,868 \quad\left(\mathrm{R}^{2}=0,9957\right)$ Vazão máxima: $6,74 \mathrm{~m}^{3} / \mathrm{h}$

Tabela 5 - Dados experimentais de vazão e pressão da bomba JACUZZI, modelo 2VJF15-T 39B (2CV)

\begin{tabular}{ccc|ccc}
\hline Ordem & $\begin{array}{c}\text { Vazão } \\
(\mathrm{m} 3 / \mathrm{s})\end{array}$ & $\begin{array}{c}\text { Pressão } \\
(\mathrm{mca})\end{array}$ & Ordem & $\begin{array}{c}\text { Vazão } \\
(\mathrm{m} 3 / \mathrm{s})\end{array}$ & $\begin{array}{c}\text { Pressão } \\
(\mathrm{mca})\end{array}$ \\
\hline 1 & 0.0000000 & 40 & 13 & 0.00163679 & 28 \\
2 & 0.0002576 & 39 & 14 & 0.0016988 & 27 \\
3 & 0.0005220 & 38 & 15 & 0.00177959 & 26 \\
4 & 0.0007475 & 37 & 16 & 0.0018214 & 25 \\
5 & 0.0009072 & 36 & 17 & 0.00191445 & 24 \\
6 & 0.0009524 & 35 & 18 & 0.00199754 & 23 \\
7 & 0.0011302 & 34 & 19 & 0.00200136 & 22 \\
8 & 0.0012288 & 33 & 20 & 0.00205984 & 21 \\
9 & 0.0013128 & 32 & 21 & 0.00214606 & 20 \\
10 & 0.0014207 & 31 & 22 & 0.00223432 & 19 \\
11 & 0.0014802 & 30 & 23 & 0.00224317 & 18 \\
12 & 0.0015257 & 29 & 24 & 0.00228189 & 17 \\
\hline
\end{tabular}

Regressão polinomial para a bomba 2VJF15-M 39B:

$\Delta H_{b o m b a}=-3,9288421154 \times 10^{6} q_{b o m b a}^{2}-783,8175 q_{b o m b a}+39,717 \quad\left(\mathrm{R}^{2}=0,9962\right)$ Vazão máxima: $8.31 \mathrm{~m}^{3} / \mathrm{h}$ 
Tabela 6 - Dados experimentais de vazão e pressão da bomba JACUZZI, modelo 3VJE15M 39G (1/3 CV)

\begin{tabular}{ccc}
\hline Ordem & $\begin{array}{c}\text { Vazão } \\
(\mathrm{m} 3 / \mathrm{s})\end{array}$ & $\begin{array}{c}\text { Pressão } \\
(\mathrm{mca})\end{array}$ \\
\hline 1 & 0.0000000 & 20 \\
2 & 0.0002703 & 19 \\
3 & 0.0004946 & 18 \\
4 & 0.0005958 & 17 \\
5 & 0.0007589 & 16 \\
6 & 0.0008465 & 15 \\
7 & 0.0009516 & 14 \\
8 & 0.0010487 & 13 \\
\hline
\end{tabular}

Regressão polinomial para a bomba 3VJE15-M 39G:

$\Delta H_{b o m b a}=-3,9949804582 \times 10^{6} q_{b o m b a}^{2}-2400,4959 q_{b o m b a}+19,9748 \quad\left(\mathrm{R}^{2}=0,9833\right)$ Vazão máxima: $3,83 \mathrm{~m}^{3} / \mathrm{h}$ 
Coeficientes de descarga $(\mathrm{Cd})$ e de perda de carga $(\mathrm{K})$ dos injetores testados

\begin{tabular}{|c|c|c|c|c|c|}
\hline $\begin{array}{c}\mathrm{H} 1 \\
\text { (mca) }\end{array}$ & $\begin{array}{c}\mathrm{H} 3 \\
\text { (mca) }\end{array}$ & $\begin{array}{c}\text { qútil } \\
\text { (m3/s) }\end{array}$ & $\begin{array}{c}\text { qcirc } \\
(\mathrm{m} 3 / \mathrm{s})\end{array}$ & $\begin{array}{c}\text { Cd } \\
\text { obs. }\end{array}$ & $\begin{array}{c}\mathrm{K} \\
\text { obs. }\end{array}$ \\
\hline 38.47 & 22.77 & 0.0000000 & 0.0006124 & 0.823 & 0.614 \\
\hline 35.49 & 19.77 & 0.0000313 & 0.0005877 & 0.823 & 0.624 \\
\hline 33.51 & 17.78 & 0.0000518 & 0.0005708 & 0.823 & 0.639 \\
\hline 32.43 & 16.79 & 0.0000757 & 0.0005613 & 0.823 & 0.627 \\
\hline 30.70 & 15.05 & 0.0000953 & 0.0005457 & 0.823 & 0.648 \\
\hline 29.04 & 13.42 & 0.0001181 & 0.0005304 & 0.823 & 0.667 \\
\hline 27.47 & 11.87 & 0.0001405 & 0.0005155 & 0.823 & 0.694 \\
\hline \multirow[t]{3}{*}{25.74} & 10.21 & 0.0001700 & 0.0004985 & 0.823 & 0.726 \\
\hline & & & Méd & 0.823 & 0.655 \\
\hline & & & Medians & 0.823 & 0.643 \\
\hline
\end{tabular}

Tabela 8 - Injetor 3VJE15-M 39G (1/3 CV) - $\Delta z=16,47 \mathrm{~m}$ - Teste 2

\begin{tabular}{cccccc}
\hline $\begin{array}{c}\mathrm{H} 1 \\
(\mathrm{mca})\end{array}$ & $\begin{array}{c}\mathrm{H} 3 \\
(\mathrm{mca})\end{array}$ & $\begin{array}{c}\text { qútil } \\
(\mathrm{m} 3 / \mathrm{s})\end{array}$ & $\begin{array}{c}\text { qcirc } \\
(\mathrm{m} 3 / \mathrm{s})\end{array}$ & $\begin{array}{c}\mathrm{Cd} \\
\text { obs. }\end{array}$ & $\begin{array}{c}\mathrm{K} \\
\text { obs. }\end{array}$ \\
\hline 39.39 & 23.77 & 0.0000000 & 0.0006195 & 0.823 & 0.762 \\
39.39 & 23.77 & 0.0000000 & 0.0006195 & 0.823 & 0.762 \\
35.48 & 19.77 & 0.0000331 & 0.0005874 & 0.823 & 0.791 \\
35.47 & 19.77 & 0.0000339 & 0.0005873 & 0.823 & 0.790 \\
33.46 & 17.78 & 0.0000602 & 0.0005700 & 0.823 & 0.795 \\
32.48 & 16.78 & 0.0000684 & 0.0005614 & 0.823 & 0.811 \\
32.42 & 16.79 & 0.0000763 & 0.0005609 & 0.823 & 0.795 \\
31.84 & 16.44 & 0.0001111 & 0.0005558 & 0.823 & 0.738 \\
31.89 & 16.48 & 0.0001097 & 0.0005562 & 0.823 & 0.739 \\
31.67 & 16.32 & 0.0001191 & 0.0005542 & 0.823 & 0.726 \\
31.58 & 16.31 & 0.0001287 & 0.0005534 & 0.823 & 0.707 \\
31.18 & 16.08 & 0.0001528 & 0.0005498 & 0.823 & 0.666 \\
31.14 & 16.08 & 0.0001589 & 0.0005494 & 0.823 & 0.653 \\
31.02 & 16.02 & 0.0001657 & 0.0005483 & 0.823 & 0.641 \\
30.76 & 15.91 & 0.0001850 & 0.0005460 & 0.823 & 0.605 \\
\hline & & & Média: & 0.823 & 0.732 \\
& & & Mediana: & 0.823 & 0.739
\end{tabular}


Coeficientes de descarga (Cd) e de perda de carga (K) dos injetores testados

Tabela 9 - Injetor 2VJF15-T 39B (2 CV) - $\Delta \mathrm{z}=16,47 \mathrm{~m}$ - Teste 1

\begin{tabular}{|c|c|c|c|c|c|}
\hline $\begin{array}{c}\mathrm{H} 1 \\
\text { (mca) }\end{array}$ & $\begin{array}{c}\mathrm{H} 3 \\
\text { (mca) }\end{array}$ & $\begin{array}{c}\text { qútil } \\
(\mathrm{m} 3 / \mathrm{s})\end{array}$ & $\begin{array}{l}\text { qcirc } \\
(\mathrm{m} 3 / \mathrm{s})\end{array}$ & $\begin{array}{l}\mathrm{Cd} \\
\mathrm{obs} .\end{array}$ & $\begin{array}{c}\mathrm{K} \\
\text { obs. }\end{array}$ \\
\hline 56.89 & 23.06 & 0.0000000 & 0.001530 & 0.917 & 0.716 \\
\hline 54.88 & 24.07 & 0.0000000 & 0.001535 & 0.937 & 0.648 \\
\hline 54.42 & 23.11 & 0.0000748 & 0.001514 & 0.928 & 0.653 \\
\hline 53.45 & 22.14 & 0.0001335 & 0.001501 & 0.929 & 0.647 \\
\hline 53.51 & 20.21 & 0.0002559 & 0.001468 & 0.908 & 0.688 \\
\hline 52.96 & 21.15 & 0.0001500 & 0.001494 & 0.929 & 0.661 \\
\hline 52.53 & 19.26 & 0.0003204 & 0.001459 & 0.911 & 0.680 \\
\hline 51.54 & 18.31 & 0.0003898 & 0.001453 & 0.916 & 0.670 \\
\hline 50.07 & 17.87 & 0.0004822 & 0.001437 & 0.919 & 0.635 \\
\hline 49.10 & 17.44 & 0.0005786 & 0.001420 & 0.917 & 0.611 \\
\hline 48.13 & 16.40 & 0.0006409 & 0.001402 & 0.915 & 0.620 \\
\hline 47.14 & 15.72 & 0.0007195 & 0.001395 & 0.920 & 0.604 \\
\hline 46.15 & 14.89 & 0.0007830 & 0.001390 & 0.927 & 0.598 \\
\hline 46.16 & 15.01 & 0.0007948 & 0.001386 & 0.924 & 0.593 \\
\hline 45.17 & 14.67 & 0.0008482 & 0.001378 & 0.929 & 0.573 \\
\hline 44.19 & 13.58 & 0.0009134 & 0.001364 & 0.929 & 0.587 \\
\hline 43.21 & 12.44 & 0.0009885 & 0.001355 & 0.934 & 0.601 \\
\hline 42.23 & 12.15 & 0.0010721 & 0.001344 & 0.937 & 0.576 \\
\hline 41.24 & 11.60 & 0.0011384 & 0.001336 & 0.943 & 0.567 \\
\hline 40.26 & 10.17 & 0.0012082 & 0.001325 & 0.947 & 0.607 \\
\hline 39.28 & 9.82 & 0.0012454 & 0.001316 & 0.952 & 0.598 \\
\hline & & & Méc & 0.927 & 0.625 \\
\hline
\end{tabular}

Tabela 10 - Injetor 2VJF15-T 39B(2 CV) - $\Delta \mathrm{z}=16,47 \mathrm{~m}$ - Teste 2

\begin{tabular}{cccccc}
\hline $\begin{array}{c}\mathrm{H} 1 \\
(\mathrm{mca})\end{array}$ & $\begin{array}{c}\mathrm{H} 3 \\
(\mathrm{mca})\end{array}$ & $\begin{array}{c}\text { qútil } \\
(\mathrm{m} 3 / \mathrm{s})\end{array}$ & $\begin{array}{c}\text { qcirc } \\
(\mathrm{m} 3 / \mathrm{s})\end{array}$ & $\begin{array}{c}\mathrm{Cd} \\
\text { obs. }\end{array}$ & $\begin{array}{c}\mathrm{K} \\
\text { obs. }\end{array}$ \\
\hline 58.89 & 25.06 & 0.0000000 & 0.001529 & 0.901 & 0.717 \\
58.41 & 24.59 & 0.0000419 & 0.001520 & 0.899 & 0.712 \\
57.92 & 24.10 & 0.0000567 & 0.001516 & 0.901 & 0.711 \\
56.93 & 24.11 & 0.0000843 & 0.001509 & 0.904 & 0.686 \\
55.95 & 23.14 & 0.0001312 & 0.001499 & 0.906 & 0.681 \\
54.99 & 22.18 & 0.0002029 & 0.001480 & 0.903 & 0.676 \\
54.02 & 20.74 & 0.0003011 & 0.001460 & 0.898 & 0.678 \\
53.03 & 20.29 & 0.0003651 & 0.001455 & 0.904 & 0.652 \\
52.06 & 19.35 & 0.0004448 & 0.001442 & 0.904 & 0.643 \\
51.07 & 18.88 & 0.0004941 & 0.001433 & 0.907 & 0.626 \\
\hline
\end{tabular}


Tabela 10 - Injetor 2VJF15-T 39B(2 CV) - $\Delta \mathrm{z}=16,47 \mathrm{~m}-$ Teste 2 (cont.)

\begin{tabular}{llllll}
\hline 50.09 & 18.42 & 0.0005427 & 0.001424 & 0.911 & 0.610 \\
49.12 & 17.46 & 0.0006109 & 0.001406 & 0.908 & 0.612 \\
48.15 & 16.23 & 0.0006920 & 0.001392 & 0.908 & 0.620 \\
47.16 & 15.34 & 0.0007594 & 0.001386 & 0.914 & 0.615 \\
46.17 & 14.25 & 0.0008427 & 0.001376 & 0.917 & 0.619 \\
45.20 & 13.33 & 0.0008889 & 0.001359 & 0.915 & 0.635 \\
44.22 & 12.37 & 0.0009834 & 0.001350 & 0.920 & 0.636 \\
43.24 & 11.52 & 0.0010760 & 0.001339 & 0.923 & 0.638 \\
42.25 & 10.82 & 0.0011295 & 0.001330 & 0.927 & 0.641 \\
41.27 & 10.23 & 0.0012088 & 0.001322 & 0.933 & 0.634 \\
40.30 & 9.76 & 0.0012345 & 0.001304 & 0.931 & 0.641 \\
\hline & & & Média: & 0.911 & 0.652 \\
& & & Mediana: & 0.908 & 0.641
\end{tabular}

Tabela 11 - Injetor 1VJF15-M 39B (1 CV) - $\Delta z=16,47 \mathrm{~m}-$ Teste 1

\begin{tabular}{cccccc}
\hline $\begin{array}{c}\mathrm{H} 1 \\
(\mathrm{mca})\end{array}$ & $\begin{array}{c}\mathrm{H} 3 \\
(\mathrm{mca})\end{array}$ & $\begin{array}{c}\text { qútil } \\
(\mathrm{m} 3 / \mathrm{s})\end{array}$ & $\begin{array}{c}\text { qcirc } \\
(\mathrm{m} 3 / \mathrm{s})\end{array}$ & $\begin{array}{c}\mathrm{Cd} \\
\text { obs. }\end{array}$ & $\begin{array}{c}\mathrm{K} \\
\text { obs. }\end{array}$ \\
\hline 48.16 & 18.59 & 0.0000000 & 0.000620 & 0.696 & 1.289 \\
47.17 & 17.60 & 0.0000349 & 0.000616 & 0.698 & 1.266 \\
47.19 & 17.60 & 0.0000561 & 0.000593 & 0.672 & 1.336 \\
46.20 & 17.10 & 0.0000788 & 0.000572 & 0.655 & 1.375 \\
46.20 & 16.61 & 0.0001000 & 0.000578 & 0.662 & 1.349 \\
45.23 & 16.37 & 0.0001466 & 0.000541 & 0.626 & 1.412 \\
44.23 & 15.18 & 0.0002202 & 0.000538 & 0.630 & 1.340 \\
43.23 & 14.37 & 0.0002866 & 0.000540 & 0.639 & 1.245 \\
42.18 & 13.50 & 0.0003493 & 0.000599 & 0.719 & 0.992 \\
41.19 & 12.29 & 0.0004231 & 0.000584 & 0.709 & 1.011 \\
40.58 & 12.03 & 0.0004758 & 0.000707 & 0.865 & 0.703 \\
39.08 & 10.99 & 0.0005559 & 0.000706 & 0.881 & 0.674 \\
38.09 & 9.99 & 0.0006452 & 0.000697 & 0.881 & 0.674 \\
37.10 & 9.61 & 0.0006690 & 0.000692 & 0.887 & 0.662 \\
\hline & & & Média: & 0.730 & 1.095 \\
& & & Mediana: & 0.697 & 1.255
\end{tabular}


Tabela 12 - Injetor IVJF15-M 39B (1 CV) - $\Delta \mathrm{z}=16,47 \mathrm{~m}$ - Teste 2

\begin{tabular}{cccccc}
\hline $\begin{array}{c}\mathrm{H} 1 \\
(\mathrm{mca})\end{array}$ & $\begin{array}{c}\mathrm{H} 3 \\
(\mathrm{mca})\end{array}$ & $\begin{array}{c}\text { qútil } \\
(\mathrm{m} 3 / \mathrm{s})\end{array}$ & $\begin{array}{c}\text { qcirc } \\
(\mathrm{m} 3 / \mathrm{s})\end{array}$ & $\begin{array}{c}\mathrm{Cd} \\
\text { obs. }\end{array}$ & $\begin{array}{c}\mathrm{K} \\
\text { obs. }\end{array}$ \\
\hline 47.03 & 19.14 & 0.0000000 & 0.000770 & 0.874 & 0.788 \\
46.04 & 18.65 & 0.0000484 & 0.000762 & 0.875 & 0.757 \\
45.54 & 17.66 & 0.0000754 & 0.000759 & 0.876 & 0.762 \\
45.05 & 16.68 & 0.0001184 & 0.000751 & 0.872 & 0.768 \\
44.05 & 16.44 & 0.0001474 & 0.000746 & 0.876 & 0.738 \\
43.07 & 14.88 & 0.0002374 & 0.000731 & 0.868 & 0.740 \\
42.08 & 14.31 & 0.0002826 & 0.000720 & 0.865 & 0.725 \\
41.09 & 13.40 & 0.0003388 & 0.000710 & 0.864 & 0.720 \\
40.60 & 13.11 & 0.0003818 & 0.000696 & 0.852 & 0.717 \\
40.12 & 12.70 & 0.0004120 & 0.000682 & 0.840 & 0.728 \\
39.12 & 11.67 & 0.0004815 & 0.000678 & 0.846 & 0.718 \\
38.18 & 10.60 & 0.0005785 & 0.000610 & 0.770 & 0.822 \\
37.22 & 10.43 & 0.0006027 & 0.000568 & 0.726 & 0.859 \\
36.25 & 9.27 & 0.0006485 & 0.000522 & 0.677 & 1.009 \\
\hline & & & Média: & 0.834 & 0.775 \\
& & & Mediana: & 0.864 & 0.749
\end{tabular}

Tabela 13 - Injetor 3VJE15-M 39G (1/3 CV) - $\Delta z=11,97 \mathrm{~m}$ - Teste 1

\begin{tabular}{cccccc}
\hline $\begin{array}{c}\mathrm{H} 1 \\
(\mathrm{mca})\end{array}$ & $\begin{array}{c}\mathrm{H} 3 \\
(\mathrm{mca})\end{array}$ & $\begin{array}{c}\text { qútil } \\
(\mathrm{m} 3 / \mathrm{s})\end{array}$ & $\begin{array}{c}\text { qcirc } \\
(\mathrm{m} 3 / \mathrm{s})\end{array}$ & $\begin{array}{c}\mathrm{Cd} \\
\text { obs. }\end{array}$ & $\begin{array}{c}\mathrm{K} \\
\text { obs. }\end{array}$ \\
\hline 40.19 & 23.20 & 0.0000000 & 0.0006200 & 0.815 & 0.648 \\
39.21 & 22.20 & 0.0000072 & 0.0006120 & 0.815 & 0.656 \\
37.22 & 21.20 & 0.0000139 & 0.0006050 & 0.827 & 0.623 \\
36.74 & 20.20 & 0.0000239 & 0.0005990 & 0.825 & 0.644 \\
35.26 & 19.20 & 0.0000350 & 0.0005900 & 0.829 & 0.630 \\
34.77 & 18.20 & 0.0000447 & 0.0005840 & 0.827 & 0.655 \\
33.80 & 17.20 & 0.0000578 & 0.0005710 & 0.820 & 0.671 \\
32.32 & 16.21 & 0.0000719 & 0.0005610 & 0.825 & 0.658 \\
31.34 & 15.21 & 0.0000858 & 0.0005520 & 0.824 & 0.668 \\
30.85 & 14.21 & 0.0000928 & 0.0005460 & 0.822 & 0.706 \\
29.37 & 13.21 & 0.0001111 & 0.0005320 & 0.821 & 0.703 \\
28.39 & 10.76 & 0.0001281 & 0.0005240 & 0.823 & 0.811 \\
26.42 & 10.77 & 0.0001617 & 0.0005090 & 0.830 & 0.706 \\
25.44 & 9.72 & 0.0001817 & 0.0005000 & 0.831 & 0.730 \\
24.45 & 9.13 & 0.0001997 & 0.0004920 & 0.835 & 0.722 \\
23.96 & 8.62 & 0.0002119 & 0.0004890 & 0.838 & 0.732 \\
22.49 & 7.42 & 0.0002522 & 0.0004720 & 0.836 & 0.758 \\
22.00 & 6.87 & 0.0002694 & 0.0004620 & 0.828 & 0.794 \\
20.52 & 5.96 & 0.0003150 & 0.0004560 & 0.847 & 0.772 \\
19.54 & 5.12 & 0.0003456 & 0.0004420 & 0.842 & 0.825 \\
\hline & & & Média: & 0.828 & 0.706 \\
& & & Mediana: & 0.827 & 0.704
\end{tabular}


Tabela 14 - Injetor 3VJE15-M 39G (1/3 CV) - $\Delta z=11,97 \mathrm{~m}$ - Teste 2

\begin{tabular}{cccccc}
\hline $\begin{array}{c}\mathrm{H} 1 \\
(\mathrm{mca})\end{array}$ & $\begin{array}{c}\mathrm{H} 3 \\
(\mathrm{mca})\end{array}$ & $\begin{array}{c}\text { qứtil } \\
(\mathrm{m} 3 / \mathrm{s})\end{array}$ & $\begin{array}{c}\text { acirc } \\
(\mathrm{m} 3 / \mathrm{s})\end{array}$ & $\begin{array}{c}\mathrm{Cd} \\
\text { obs. }\end{array}$ & $\begin{array}{c}\mathrm{K} \\
\text { obs. }\end{array}$ \\
\hline 40.19 & 23.20 & 0.0000000 & 0.0006200 & 0.815 & 0.648 \\
39.21 & 22.20 & 0.0000072 & 0.0006120 & 0.815 & 0.656 \\
37.22 & 21.20 & 0.0000139 & 0.0006050 & 0.827 & 0.623 \\
36.74 & 20.20 & 0.0000239 & 0.0005990 & 0.825 & 0.644 \\
35.26 & 19.20 & 0.0000350 & 0.0005900 & 0.829 & 0.630 \\
34.77 & 18.20 & 0.0000447 & 0.0005840 & 0.827 & 0.655 \\
33.80 & 17.20 & 0.0000578 & 0.0005710 & 0.820 & 0.671 \\
32.32 & 16.21 & 0.0000719 & 0.0005610 & 0.825 & 0.658 \\
31.34 & 15.21 & 0.0000858 & 0.0005520 & 0.824 & 0.668 \\
30.85 & 14.21 & 0.0000928 & 0.0005460 & 0.822 & 0.706 \\
29.37 & 13.21 & 0.0001111 & 0.0005320 & 0.821 & 0.703 \\
28.39 & 12.22 & 0.0001281 & 0.0005240 & 0.823 & 0.714 \\
26.42 & 10.67 & 0.0001617 & 0.0005090 & 0.830 & 0.713 \\
25.44 & 9.55 & 0.0001817 & 0.0005000 & 0.831 & 0.744 \\
24.45 & 8.92 & 0.0001997 & 0.0004920 & 0.835 & 0.740 \\
23.96 & 8.37 & 0.0002119 & 0.0004890 & 0.838 & 0.754 \\
22.49 & 7.08 & 0.0002522 & 0.0004720 & 0.836 & 0.792 \\
22.00 & 6.50 & 0.0002694 & 0.0004620 & 0.828 & 0.835 \\
20.52 & 5.52 & 0.0003150 & 0.0004560 & 0.847 & 0.825 \\
19.54 & 4.62 & 0.0003456 & 0.0004420 & 0.842 & 0.892 \\
\hline
\end{tabular}

Tabela 15 - Injetor 2VJF15-M 39B (2 CV) - $\Delta z=11,97 \mathrm{~m}$ - Teste 1

\begin{tabular}{cccccc}
\hline $\begin{array}{c}\mathrm{H} 1 \\
(\mathrm{mca})\end{array}$ & $\begin{array}{c}\mathrm{H} 3 \\
(\mathrm{mca})\end{array}$ & $\begin{array}{c}\text { qútil } \\
(\mathrm{m} 3 / \mathrm{s})\end{array}$ & $\begin{array}{c}\text { acirc } \\
(\mathrm{m} 3 / \mathrm{s})\end{array}$ & $\begin{array}{c}\mathrm{Cd} \\
\text { obs. }\end{array}$ & $\begin{array}{c}\mathrm{K} \\
\text { obs. }\end{array}$ \\
\hline 58.82 & 25.41 & 0.0000000 & 0.001535 & 0.905 & 0.703 \\
57.84 & 24.43 & 0.0000417 & 0.001522 & 0.905 & 0.701 \\
56.86 & 23.45 & 0.0001039 & 0.001511 & 0.906 & 0.691 \\
56.36 & 22.96 & 0.0001222 & 0.001507 & 0.908 & 0.690 \\
54.88 & 22.00 & 0.0002133 & 0.001491 & 0.910 & 0.665 \\
54.39 & 21.53 & 0.0002722 & 0.001482 & 0.909 & 0.656 \\
53.90 & 20.55 & 0.0003172 & 0.001476 & 0.909 & 0.662 \\
53.41 & 20.07 & 0.0003633 & 0.001465 & 0.907 & 0.659 \\
52.92 & 19.59 & 0.0004100 & 0.001457 & 0.906 & 0.655 \\
51.94 & 18.63 & 0.0004806 & 0.001444 & 0.906 & 0.651 \\
50.95 & 18.14 & 0.0005183 & 0.001433 & 0.908 & 0.640 \\
50.47 & 17.67 & 0.0005768 & 0.001420 & 0.904 & 0.637 \\
49.48 & 16.71 & 0.0006394 & 0.001416 & 0.911 & 0.632 \\
47.99 & 15.74 & 0.0007027 & 0.001407 & 0.919 & 0.620 \\
47.00 & 14.77 & 0.0007619 & 0.001394 & 0.921 & 0.627 \\
46.02 & 13.82 & 0.0008478 & 0.001379 & 0.921 & 0.630 \\
44.04 & 12.84 & 0.0009811 & 0.001361 & 0.929 & 0.602 \\
43.05 & 12.51 & 0.0010233 & 0.001354 & 0.935 & 0.585 \\
42.56 & 11.79 & 0.0010889 & 0.001345 & 0.934 & 0.598 \\
42.07 & 11.24 & 0.0011465 & 0.001339 & 0.936 & 0.604 \\
40.08 & 10.24 & 0.0012536 & 0.001326 & 0.950 & 0.588 \\
39.11 & 8.77 & 0.0013917 & 0.001306 & 0.947 & 0.634 \\
36.14 & 6.99 & 0.0015302 & 0.001281 & 0.967 & 0.655 \\
34.66 & 5.76 & 0.0015352 & 0.001259 & 0.971 & 0.713 \\
\hline & & & Média: & 0.922 & 0.646 \\
& & & & &
\end{tabular}


Tabela 16 - Injetor 2VJF15-M 39B (2 CV) - $\Delta z=11,97 \mathrm{~m}$ - Teste 2

\begin{tabular}{cccccc}
\hline $\begin{array}{c}\text { H1 } \\
(\mathrm{mca})\end{array}$ & $\begin{array}{c}\mathrm{H} 3 \\
(\mathrm{mca})\end{array}$ & $\begin{array}{c}\text { qútil } \\
(\mathrm{m} 3 / \mathrm{s})\end{array}$ & $\begin{array}{c}\text { qcirc } \\
(\mathrm{m} 3 / \mathrm{s})\end{array}$ & $\begin{array}{c}\text { Cd } \\
\text { obs. }\end{array}$ & $\begin{array}{c}\mathrm{K} \\
\text { obs. }\end{array}$ \\
\hline 58.83 & 25.41 & 0.0000000 & 0.001531 & 0.902 & 0.707 \\
57.84 & 24.43 & 0.0000383 & 0.001523 & 0.905 & 0.701 \\
56.85 & 23.45 & 0.0000967 & 0.001514 & 0.908 & 0.691 \\
56.36 & 22.96 & 0.0001244 & 0.001505 & 0.906 & 0.691 \\
54.88 & 22.00 & 0.0002206 & 0.001490 & 0.910 & 0.664 \\
54.39 & 21.53 & 0.0002739 & 0.001482 & 0.909 & 0.655 \\
53.90 & 20.54 & 0.0002950 & 0.001477 & 0.910 & 0.668 \\
53.41 & 20.07 & 0.0003600 & 0.001465 & 0.907 & 0.661 \\
52.92 & 19.59 & 0.0003950 & 0.001459 & 0.907 & 0.658 \\
51.94 & 18.63 & 0.0004811 & 0.001443 & 0.906 & 0.651 \\
50.96 & 18.15 & 0.0005267 & 0.001431 & 0.907 & 0.639 \\
50.47 & 17.67 & 0.0005793 & 0.001418 & 0.903 & 0.638 \\
49.48 & 16.71 & 0.0006377 & 0.001415 & 0.910 & 0.633 \\
47.99 & 15.74 & 0.0007027 & 0.001406 & 0.919 & 0.621 \\
47.00 & 14.77 & 0.0007686 & 0.001392 & 0.919 & 0.626 \\
46.03 & 13.82 & 0.0008478 & 0.001375 & 0.918 & 0.633 \\
44.04 & 12.84 & 0.0009856 & 0.001359 & 0.928 & 0.602 \\
43.05 & 12.51 & 0.0010267 & 0.001351 & 0.933 & 0.587 \\
42.57 & 11.80 & 0.0011000 & 0.001341 & 0.931 & 0.598 \\
42.07 & 11.24 & 0.0011479 & 0.001336 & 0.933 & 0.606 \\
40.08 & 10.24 & 0.0012522 & 0.001325 & 0.949 & 0.590 \\
39.11 & 8.76 & 0.0013867 & 0.001306 & 0.947 & 0.635 \\
37.13 & 7.54 & 0.0015302 & 0.001288 & 0.959 & 0.643 \\
36.14 & 6.99 & 0.0015302 & 0.001275 & 0.963 & 0.661 \\
35.15 & 6.03 & 0.0015336 & 0.001266 & 0.969 & 0.703 \\
\hline & & & Média: & 0.922 & 0.646 \\
& & & Mediana: & 0.910 & 0.643
\end{tabular}

Tabela 17 - Injetor 1VJF15-M 39B (1 CV) - $\Delta z=11,97 \mathrm{~m}$ - Teste 1

\begin{tabular}{cccccc}
\hline $\begin{array}{c}\mathrm{H} 1 \\
(\mathrm{mca})\end{array}$ & $\begin{array}{c}\mathrm{H} 3 \\
(\mathrm{mca})\end{array}$ & $\begin{array}{c}\text { qútil } \\
(\mathrm{m} 3 / \mathrm{s})\end{array}$ & $\begin{array}{c}\text { gcirc } \\
(\mathrm{m} 3 / \mathrm{s})\end{array}$ & $\begin{array}{c}\text { Cd } \\
\text { obs. }\end{array}$ & $\begin{array}{c}\mathrm{K} \\
\text { obs. }\end{array}$ \\
\hline 46.61 & 18.11 & 0.0000000 & 0.000786 & 0.897 & 0.773 \\
46.62 & 18.11 & 0.0000000 & 0.000784 & 0.894 & 0.777 \\
45.13 & 17.13 & 0.0000789 & 0.000772 & 0.895 & 0.740 \\
44.63 & 16.13 & 0.0000961 & 0.000769 & 0.897 & 0.753 \\
43.63 & 16.65 & 0.0001544 & 0.000761 & 0.898 & 0.687 \\
43.64 & 15.16 & 0.0001883 & 0.000756 & 0.892 & 0.730 \\
42.65 & 14.18 & 0.0002622 & 0.000746 & 0.890 & 0.715 \\
42.64 & 15.16 & 0.0001856 & 0.000756 & 0.902 & 0.702 \\
41.65 & 14.18 & 0.0002683 & 0.000746 & 0.901 & 0.681 \\
41.65 & 13.19 & 0.0003022 & 0.000741 & 0.895 & 0.713 \\
41.15 & 13.21 & 0.0003317 & 0.000739 & 0.898 & 0.686 \\
41.15 & 14.20 & 0.0003122 & 0.000739 & 0.898 & 0.653 \\
39.66 & 12.23 & 0.0004122 & 0.000729 & 0.903 & 0.660 \\
39.66 & 12.23 & 0.0004117 & 0.000731 & 0.905 & 0.657 \\
39.16 & 12.03 & 0.0004489 & 0.000725 & 0.904 & 0.642 \\
38.66 & 12.02 & 0.0004589 & 0.000725 & 0.910 & 0.622 \\
38.17 & 11.63 & 0.0005006 & 0.000720 & 0.909 & 0.613 \\
37.67 & 10.81 & 0.0005372 & 0.000717 & 0.912 & 0.630 \\
37.67 & 10.70 & 0.0005394 & 0.000717 & 0.912 & 0.635 \\
37.17 & 10.63 & 0.0005624 & 0.000715 & 0.915 & 0.615 \\
36.67 & 10.40 & 0.0005874 & 0.000712 & 0.918 & 0.605 \\
\hline
\end{tabular}


Tabela 18 - Injetor 1VJF 15-M 39B(1 CV) - $\Delta z=11,97 \mathrm{~m}$ - Teste 2

\begin{tabular}{cccccc}
\hline $\begin{array}{c}\text { H1 } \\
(\mathrm{mca})\end{array}$ & $\begin{array}{c}\mathrm{H} 3 \\
(\mathrm{mca})\end{array}$ & $\begin{array}{c}\text { qútil } \\
(\mathrm{m} 3 / \mathrm{s})\end{array}$ & $\begin{array}{c}\text { qcirc } \\
(\mathrm{m} 3 / \mathrm{s})\end{array}$ & $\begin{array}{c}\mathrm{Cd} \\
\text { obs. }\end{array}$ & $\begin{array}{c}\mathrm{K} \\
\text { obs. }\end{array}$ \\
\hline 47.62 & 18.11 & 0.0000000 & 0.000782 & 0.882 & 0.809 \\
47.61 & 18.11 & 0.0000000 & 0.000786 & 0.887 & 0.800 \\
45.62 & 17.13 & 0.0000717 & 0.000774 & 0.893 & 0.755 \\
43.63 & 16.14 & 0.0001311 & 0.000766 & 0.904 & 0.710 \\
43.63 & 16.14 & 0.0001367 & 0.000762 & 0.899 & 0.714 \\
43.64 & 15.16 & 0.0001833 & 0.000759 & 0.895 & 0.727 \\
43.14 & 14.66 & 0.0002083 & 0.000752 & 0.892 & 0.730 \\
42.14 & 14.18 & 0.0002533 & 0.000750 & 0.901 & 0.698 \\
41.65 & 14.18 & 0.0002717 & 0.000745 & 0.900 & 0.681 \\
40.65 & 13.20 & 0.0003106 & 0.000740 & 0.905 & 0.680 \\
40.65 & 13.22 & 0.0003572 & 0.000739 & 0.904 & 0.657 \\
39.66 & 12.17 & 0.0003839 & 0.000732 & 0.907 & 0.672 \\
39.65 & 12.23 & 0.0003939 & 0.000735 & 0.910 & 0.660 \\
39.66 & 11.75 & 0.0004344 & 0.000731 & 0.905 & 0.670 \\
38.66 & 11.43 & 0.0004656 & 0.000724 & 0.908 & 0.651 \\
37.66 & 11.20 & 0.0005106 & 0.000721 & 0.917 & 0.614 \\
37.17 & 10.83 & 0.0005550 & 0.000717 & 0.918 & 0.604 \\
36.67 & 10.75 & 0.0005666 & 0.000715 & 0.922 & 0.590 \\
36.67 & 10.68 & 0.0005694 & 0.000714 & 0.920 & 0.594 \\
36.17 & 10.57 & 0.0005881 & 0.000711 & 0.923 & 0.579 \\
\hline & & & Média: & 0.905 & 0.680 \\
& & & Mediana: & 0.904 & 0.676
\end{tabular}




\section{ANEXO B}

Resultados estimados (simulação) e observados (testes) do funcionamento dos conjuntos bomba- injetor 
Tabela 19 - Simulação da relação entre vazão útil e diferencial de pressão útil

Conjunto 3VJE15-M 39G (1/3 CV) $\quad \Delta z=16,47 \mathrm{~m} \quad$ TESTE 1

$\mathrm{K}=0,697 \quad \mathrm{Cd}=0,823$

\begin{tabular}{cccccccccc}
\hline $\begin{array}{c}\mathrm{Hf}_{\text {boc }} \\
(\mathrm{mca})\end{array}$ & $\begin{array}{c}\mathrm{Hf}_{1} \\
(\mathrm{mca})\end{array}$ & $\begin{array}{c}\mathrm{Hf}_{2} \\
(\mathrm{mca})\end{array}$ & $\begin{array}{c}\mathrm{Hf}_{\text {sist }} \\
(\mathrm{mca})\end{array}$ & $\begin{array}{c}\mathrm{q}_{\text {circ }} \\
(\mathrm{m} 3 / \mathrm{s})\end{array}$ & $\begin{array}{c}\mathrm{qútil}_{(\mathrm{m} 3 / \mathrm{s})} \\
(\mathrm{mca})\end{array}$ & $\begin{array}{c}\Delta \mathrm{H}_{\text {util }} \\
(\mathrm{mca})\end{array}$ & $\begin{array}{c}\Delta \mathrm{H}_{\text {bomba }} \\
(\mathrm{m} 3 / \mathrm{s})\end{array}$ & $\begin{array}{c}\text { quomba } \\
(\%)\end{array}$ \\
\hline 16.04 & 0.92 & 0.27 & 17.23 & 0.00058094 & 0.00000000 & 35.65 & 17.23 & 0.00058094 & 0.00 \\
15.66 & 0.90 & 0.27 & 16.84 & 0.00057401 & 0.00001162 & 34.82 & 17.20 & 0.00058563 & 4.02 \\
15.30 & 0.88 & 0.28 & 16.46 & 0.00056735 & 0.00002324 & 34.04 & 17.16 & 0.00059059 & 7.80 \\
14.95 & 0.87 & 0.28 & 16.10 & 0.00056094 & 0.00003486 & 33.29 & 17.13 & 0.00059580 & 11.37 \\
14.63 & 0.85 & 0.29 & 15.77 & 0.00055477 & 0.00004647 & 32.58 & 17.09 & 0.00060125 & 14.74 \\
14.32 & 0.83 & 0.29 & 15.44 & 0.00054883 & 0.00005809 & 31.91 & 17.05 & 0.00060692 & 17.92 \\
14.02 & 0.82 & 0.30 & 15.13 & 0.00054310 & 0.00006971 & 31.26 & 17.00 & 0.00061282 & 20.92 \\
13.74 & 0.80 & 0.30 & 14.84 & 0.00053758 & 0.00008133 & 30.65 & 16.96 & 0.00061891 & 23.75 \\
13.46 & 0.79 & 0.31 & 14.56 & 0.00053225 & 0.00009295 & 30.06 & 16.91 & 0.00062520 & 26.43 \\
13.21 & 0.78 & 0.31 & 14.30 & 0.00052711 & 0.00010457 & 29.50 & 16.86 & 0.00063168 & 28.96 \\
12.96 & 0.76 & 0.32 & 14.04 & 0.00052214 & 0.00011619 & 28.96 & 16.81 & 0.00063833 & 31.35 \\
12.72 & 0.75 & 0.32 & 13.80 & 0.00051733 & 0.00012781 & 28.45 & 16.76 & 0.00064514 & 33.62 \\
12.49 & 0.74 & 0.33 & 13.56 & 0.00051268 & 0.00013942 & 27.95 & 16.71 & 0.00065210 & 35.76 \\
12.27 & 0.73 & 0.34 & 13.34 & 0.00050817 & 0.00015104 & 27.48 & 16.66 & 0.00065921 & 37.80 \\
12.06 & 0.72 & 0.34 & 13.13 & 0.00050380 & 0.00016266 & 27.02 & 16.60 & 0.00066646 & 39.73 \\
11.86 & 0.71 & 0.35 & 12.92 & 0.00049956 & 0.00017428 & 26.58 & 16.54 & 0.00067384 & 41.56 \\
\hline
\end{tabular}

Tabela 20-Dados coletados do sistema injetor-bomba centrifuga (Obtidos por experimentação) - Conjunto 3VJE15-M 39G(1/3 CV)

\begin{tabular}{cccccccccc}
\hline $\begin{array}{c}\mathrm{Hf}_{1} \\
(\mathrm{mca})\end{array}$ & $\begin{array}{c}\mathrm{Hf}_{2} \\
(\mathrm{mca})\end{array}$ & $\begin{array}{c}\mathrm{Hf}_{\text {boc }} \\
(\mathrm{mca})\end{array}$ & $\begin{array}{c}\mathrm{Hf}_{\text {sist }} \\
(\mathrm{mca})\end{array}$ & $\begin{array}{c}\mathrm{q}_{\text {util }} \\
\left(\mathrm{m}^{3} / \mathrm{s}\right)\end{array}$ & $\begin{array}{c}\mathrm{q}_{\text {circ }} \\
\left(\mathrm{m}^{3} / \mathrm{s}\right)\end{array}$ & $\begin{array}{c}\mathrm{q}_{\text {bomba }} \\
\left(\mathrm{m}^{3} / \mathrm{s}\right)\end{array}$ & $\begin{array}{c}\Delta \mathrm{H}_{\text {bomba }} \\
(\mathrm{mca})\end{array}$ & $\begin{array}{c}\Delta \mathrm{H}_{\text {útil }} \\
(\mathrm{mca})\end{array}$ & $\begin{array}{c}\text { Rend. } \\
(\%)\end{array}$ \\
\hline 1,011 & 0,297 & 15,70 & 17,01 & 0,0000000 & 0,0006124 & 0,0006124 & 17,01 & 38,47 & 0,00 \\
0,941 & 0,302 & 14,70 & 15,94 & 0,0000313 & 0,0005877 & 0,0006191 & 16,96 & 34,47 & 10,32 \\
0,894 & 0,305 & 14,19 & 15,39 & 0,0000518 & 0,0005708 & 0,0006225 & 16,93 & 31,96 & 15,83 \\
0,868 & 0,318 & 13,48 & 14,66 & 0,0000757 & 0,0005613 & 0,0006370 & 16,83 & 30,26 & 21,73 \\
0,826 & 0,321 & 13,15 & 14,30 & 0,0000953 & 0,0005457 & 0,0006410 & 16,79 & 28,20 & 25,55 \\
0,786 & 0,328 & 12,80 & 13,92 & 0,0001181 & 0,0005304 & 0,0006485 & 16,74 & 26,22 & 29,43 \\
0,748 & 0,334 & 12,57 & 13,65 & 0,0001405 & 0,0005155 & 0,0006560 & 16,68 & 24,44 & 32,65 \\
0,705 & 0,346 & 12,31 & 13,36 & 0,0001700 & 0,0004985 & 0,0006685 & 16,58 & 22,52 & 36,30 \\
\hline
\end{tabular}


Tabela 21 - Simulação da relação entre vazão útil e diferencial de pressão útil

Conjunto 3VJE15-M 39G (1/3 CV) $\quad \Delta \mathrm{z}=16,47 \mathrm{~m} \quad$ TESTE 2

$\mathrm{K}=0,643 \quad \mathrm{Cd}=0,823$

\begin{tabular}{|c|c|c|c|c|c|c|c|c|c|}
\hline $\begin{array}{l}\mathrm{Hf}_{\text {boc }} \\
\text { (mca) }\end{array}$ & $\begin{array}{c}\mathrm{Hf}_{1} \\
\text { (mca) }\end{array}$ & $\begin{array}{c}\mathrm{Hf}_{2} \\
\text { (mca) }\end{array}$ & $\begin{array}{c}\mathrm{Hf}_{\text {sist }} \\
(\mathrm{mca})\end{array}$ & $\begin{array}{c}\mathbf{q}_{\text {circ }} \\
(\mathrm{m} 3 / \mathrm{s})\end{array}$ & $\begin{array}{c}\text { qútil } \\
(\mathrm{m} 3 / \mathrm{s})\end{array}$ & $\begin{array}{l}\Delta H_{\text {util }} \\
\text { (mca) }\end{array}$ & $\begin{array}{c}\Delta \mathrm{H}_{\text {bomba }} \\
\text { (mca) }\end{array}$ & $\begin{array}{r}\text { qbomba } \\
\text { (m3/s) }\end{array}$ & $\begin{array}{l}\text { Rend } \\
(\%)\end{array}$ \\
\hline 15.83 & 0.98 & 0.29 & 17.09 & 0.000600 & 0.000000 & 38.07 & & 00060080 & 0.00 \\
\hline 15.4 & 0.95 & 0.29 & 16.65 & 0.000592 & 0.000012 & 08 & 06 & 00060477 & 4.32 \\
\hline 15.01 & 0.93 & 0.29 & 23 & 0.000585 & 0.000024 & 3 & 03 & .0006 & 8.37 \\
\hline 14.63 & 0.91 & 0.30 & 15.84 & 0.000577 & 0.000036 & 35.25 & 17.00 & 0.00061368 & 12.18 \\
\hline 14.27 & 0.89 & 0.30 & 15.47 & 0.000570 & 0.000048 & 34.41 & 16.96 & 0.00061858 & 15.76 \\
\hline 13.93 & 0.87 & 0.31 & 15.11 & 0.000563 & 0.000060 & 33.61 & 16.92 & 0.00062376 & 19.13 \\
\hline 13.61 & 0.86 & 0.31 & 14.78 & 0.000557 & 0.000072 & & 16.88 & 2921 & 22.30 \\
\hline 13.30 & 0.84 & 0.32 & 14.46 & 0.000550 & 0.000084 & & 84 & 0.0 & 25.28 \\
\hline 13.01 & 0.82 & 0.32 & 14.15 & 0.0 & & & & & 28.08 \\
\hline 12.73 & 0.81 & 0.33 & 13.87 & 0.0 & 0.0 & & 75 & 00 & 30.73 \\
\hline 12.47 & 0.79 & 0.33 & 13.59 & 0.0 & 0.0 & 17 & 16.70 & 0.00 & 33.22 \\
\hline 12.21 & 0.78 & 0.34 & 13.33 & 0.000527 & 0.000132 & 29.57 & 16.65 & 0.00065995 & 35.57 \\
\hline 11.97 & 0.77 & 0.34 & 13.08 & 0.000522 & 0.000144 & 29.00 & 16.60 & 0.00066671 & 37.79 \\
\hline 11.74 & 0.75 & 0.35 & 12.84 & 0.000517 & 0.000156 & 28.46 & 16.54 & 0.00067365 & 39.88 \\
\hline 11.52 & 0.74 & 0.36 & 12.61 & 0.000512 & 0.000168 & 27.94 & 16.49 & 0.00068076 & 41.87 \\
\hline 11.31 & 0.73 & 0.36 & 12.40 & 0.000507 & 0.000180 & 27.44 & 16.43 & 0.00068802 & 43.74 \\
\hline 11.10 & 0.72 & 0.37 & 12.19 & 0.000503 & 0.000192 & 26.96 & 16.37 & 0.00069543 & 45.51 \\
\hline
\end{tabular}

Tabela 22-Dados coletados do sistema injetor-bomba centrífuga (Obtidos por experimentacão) - Conjunto 3VJE15-M 39G(1/3 CV) $\Delta \mathrm{z}=16,47 \mathrm{~m} \quad$ TESTE 2

\begin{tabular}{cccccccccc}
\hline $\begin{array}{c}\mathrm{Hf}_{1} \\
(\mathrm{mca})\end{array}$ & $\begin{array}{c}\mathrm{Hf}_{2} \\
(\mathrm{mca})\end{array}$ & $\begin{array}{c}\mathrm{Hf}_{\text {boc }} \\
(\mathrm{mca})\end{array}$ & $\begin{array}{c}\mathbf{H f}_{\text {sist }} \\
(\mathrm{mca})\end{array}$ & $\begin{array}{c}\mathrm{qutil} \\
\left(\mathrm{m}^{3} / \mathrm{s}\right)\end{array}$ & $\begin{array}{c}\mathrm{q}_{\text {circ }} \\
\left(\mathrm{m}^{3} / \mathrm{s}\right)\end{array}$ & $\begin{array}{c}\mathrm{q}_{\text {bomba }} \\
\left(\mathrm{m}^{3} / \mathrm{s}\right)\end{array}$ & $\begin{array}{c}\Delta \mathrm{H}_{\text {bomba }} \\
(\mathrm{mca})\end{array}$ & $\begin{array}{c}\Delta \mathrm{H}_{\text {util }} \\
(\mathrm{mca})\end{array}$ & $\begin{array}{c}\text { Rend. } \\
(\%)\end{array}$ \\
\hline 1,03 & 0,30 & 15,62 & 16,95 & 0,0000000 & 0,0006195 & 0,0006195 & 16,95 & 39,39 & 0,00 \\
1,03 & 0,30 & 15,62 & 16,95 & 0,0000000 & 0,0006195 & 0,0006195 & 16,95 & 39,39 & 0,00 \\
0,94 & 0,30 & 14,63 & 15,88 & 0,0000331 & 0,0005874 & 0,0006205 & 16,95 & 34,41 & 10,88 \\
0,94 & 0,30 & 14,60 & 15,84 & 0,0000339 & 0,0005873 & 0,0006212 & 16,94 & 34,37 & 11,13 \\
0,89 & 0,31 & 13,88 & 15,08 & 0,0000602 & 0,0005700 & 0,0006301 & 16,88 & 31,66 & 18,10 \\
0,87 & 0,31 & 13,75 & 14,93 & 0,0000684 & 0,0005614 & 0,0006298 & 16,88 & 30,53 & 19,90 \\
0,87 & 0,32 & 13,45 & 14,64 & 0,0000763 & 0,0005609 & 0,0006373 & 16,82 & 30,24 & 21,90 \\
0,85 & 0,34 & 12,26 & 13,46 & 0,0001111 & 0,0005558 & 0,0006668 & 16,60 & 28,71 & 29,78 \\
0,85 & 0,34 & 12,31 & 13,50 & 0,0001097 & 0,0005562 & 0,0006658 & 16,61 & 28,79 & 29,50 \\
0,85 & 0,35 & 12,00 & 13,20 & 0,0001191 & 0,0005542 & 0,0006733 & 16,55 & 28,33 & 31,44 \\
0,85 & 0,36 & 11,65 & 12,86 & 0,0001287 & 0,0005534 & 0,0006822 & 16,48 & 27,96 & 33,45 \\
0,84 & 0,38 & 10,84 & 12,06 & 0,0001528 & 0,0005498 & 0,0007026 & 16,32 & 26,92 & 38,08 \\
0,84 & 0,38 & 10,62 & 11,83 & 0,0001589 & 0,0005494 & 0,0007083 & 16,27 & 26,70 & 39,27 \\
0,83 & 0,39 & 10,39 & 11,61 & 0,0001657 & 0,0005483 & 0,0007140 & 16,22 & 26,41 & 40,48 \\
0,83 & 0,40 & 9,72 & 10,95 & 0,0001850 & 0,0005460 & 0,0007310 & 16,09 & 25,63 & 43,92 \\
\hline
\end{tabular}


Tabela 23 Simulação da relação entre vazão útil e diferencial de pressão útil

$\begin{array}{lcrr}\text { Conjunto 3VJE15-M 39G }(1 / 3 \mathrm{CV}) & \Delta \mathrm{z}=11,97 \mathrm{~m} & \text { TESTE } 1 \\ \mathrm{~K}=0.733 & \mathrm{Cd}=0.828 & \end{array}$

\begin{tabular}{|c|c|c|c|c|c|c|c|c|c|}
\hline $\begin{array}{l}\mathrm{Hf}_{\text {boc }} \\
\text { (mca) }\end{array}$ & $\begin{array}{c}\mathrm{Hf}_{1} \\
(\mathrm{mca})\end{array}$ & $\begin{array}{c}\mathrm{Hf}_{2} \\
(\mathrm{mca})\end{array}$ & $\begin{array}{l}\mathrm{Hf}_{\text {ist }} \\
(\mathrm{mca})\end{array}$ & $\begin{array}{c}\mathrm{q}_{\mathrm{circ}} \\
\left(\mathrm{m}^{3} / \mathrm{s}\right)\end{array}$ & $\begin{array}{c}\text { quitil } \\
\left(\mathrm{m}^{3} / \mathrm{s}\right)\end{array}$ & $\begin{array}{l}\Delta H_{\text {util }} \\
\text { (mca) }\end{array}$ & $\begin{array}{c}\Delta \mathrm{H}_{\text {bomba }} \\
\text { (mca) }\end{array}$ & $\begin{array}{l}\text { qbomba } \\
\left(\mathrm{m}^{3} / \mathrm{s}\right)\end{array}$ & $\begin{array}{c}\text { Rend. } \\
(\%)\end{array}$ \\
\hline 16.41 & 0.68 & 0.20 & .29 & 00057300 & 0.00000000 & 4.08 & 9 & 00057300 & 0.00 \\
\hline 16.05 & 0.66 & 0.20 & 92 & 0.000 & 146 & 33.36 & .25 & 820 & 3.83 \\
\hline 15.71 & 0.65 & 0.21 & 57 & 0.00056072 & 0.00002292 & 32.67 & & 364 & 7.45 \\
\hline 15.39 & 0.64 & 0.21 & 16.24 & .00055491 & 0.00003438 & 32.02 & .17 & 8929 & 10.88 \\
\hline 15.08 & 0.63 & 0.21 & 92 & 0.00054930 & 0.00004584 & 31.39 & 3 & 59514 & 14.11 \\
\hline 14.79 & 0.62 & 0.22 & 15.62 & 0.00054390 & 0.00005730 & 30.79 & 7.09 & 0.00060120 & 17.17 \\
\hline 14.50 & 0.61 & 0.22 & 15.33 & 0.00053868 & 0.00006876 & 30.22 & 4 & 0.00060744 & 20.07 \\
\hline 14.23 & 0.60 & 0.22 & 15.06 & 0.00053364 & 0.00008022 & 29.67 & 17.00 & 0.00061386 & 22.82 \\
\hline 13.97 & 0.59 & 0.23 & 79 & & & & & & 25.41 \\
\hline 13.73 & 0.58 & 0.23 & 14.54 & 0.00052406 & 0.00010314 & 28.65 & 16.90 & 0.00062720 & 27.88 \\
\hline 13.49 & 0.57 & 0.24 & 14.30 & 0.00051950 & 0.00011460 & 28.16 & & 10 & 30.21 \\
\hline 13.26 & 0.56 & 0.24 & 14.07 & 0.00051508 & 0.00012606 & 27.70 & 79 & 0.00 & 32.43 \\
\hline 13.04 & 0.55 & 0.25 & 13.84 & 0.00051079 & 0.00013752 & 27.25 & 16.74 & 0.00064831 & 34.54 \\
\hline 12.83 & 0.55 & 0.25 & & & & & & & .54 \\
\hline 12.63 & 0.54 & 0.26 & 13.42 & 0.00050259 & 0.00016044 & 26.41 & 16.63 & 0.00066303 & 38.44 \\
\hline 12.43 & 0.53 & 0.26 & 13.22 & 0.00049867 & 0.00017190 & 26.01 & .57 & 0.000 & 40.25 \\
\hline 12.24 & 0.52 & 0.27 & 13.03 & 0.00049484 & 0.00018336 & 25.63 & 16.51 & 0.000 & 41.97 \\
\hline 12.06 & 0.52 & 0.27 & 12.85 & 0.00049112 & 0.00019482 & 25.26 & 16.45 & 0.00068594 & 43.61 \\
\hline 11.88 & 0.51 & 0.28 & 12.67 & 0.00048750 & 0.00020628 & 24.90 & & 0.00069378 & 45.18 \\
\hline 11.71 & 0.50 & 0.28 & 12.49 & 0.00048396 & 0.00021774 & 24.55 & 16.32 & 0.00070170 & 46.67 \\
\hline 11.54 & 0.50 & 0.29 & & 0.0004 & 0.00022920 & 24.21 & & 0.00070970 & 48.09 \\
\hline 11.38 & 0.49 & 0.29 & 12.17 & 0.00047713 & 0.00024066 & 23.88 & & 0.00071779 & 49.45 \\
\hline 11.22 & 0.49 & 0.30 & 12.01 & 0.00047382 & 0.00025212 & 23.57 & 16.13 & 2594 & 50.75 \\
\hline 11.07 & 0.48 & 0.31 & 11.86 & 0.00047059 & 0.00026358 & 23.26 & 16.06 & 0.00073417 & 51.99 \\
\hline 10.92 & 0.47 & 0.31 & 11.71 & 0.00046742 & 0.00027504 & 22.96 & 15.99 & 0.00074246 & 53.18 \\
\hline 10.78 & 0.47 & 0.32 & 11.56 & 0.00046431 & 0.00028650 & 22.66 & 15.92 & 0.00075082 & 54.32 \\
\hline 10.63 & 0.46 & 0.33 & 11.42 & 0.00046126 & 0.00029796 & 22.38 & 15.85 & 0.00075923 & 55.40 \\
\hline 10.50 & 0.46 & 0.33 & 11.29 & 0.00045827 & 0.00030942 & 22.10 & 15.78 & 0.00076769 & 56.45 \\
\hline 10.36 & 0.45 & 0.34 & 11.15 & 0.00045532 & 0.00032088 & 21.82 & 15.70 & 0.00077621 & 57.45 \\
\hline 10.23 & 0.45 & 0.34 & 11.02 & 0.00045243 & 0.00033234 & 21.56 & 15.63 & 0.00078477 & 58.41 \\
\hline 10.10 & 0.44 & 0.35 & 10.90 & 0.00044957 & 0.00034380 & 21.30 & 15.56 & 0.00079338 & 59.33 \\
\hline
\end{tabular}


Tabela 24- Dados coletados do sistema injetor-bomba centrífuga (Obtidos por experimentacão) - Conjunto 3VJE15-M 39G (1/3 CV)

$\Delta \mathrm{z}=11,97 \mathrm{~m}$

TESTE 1

\begin{tabular}{|c|c|c|c|c|c|c|c|c|c|}
\hline $\begin{array}{c}\mathrm{Hf}_{1} \\
\text { (mca) }\end{array}$ & $\begin{array}{c}\mathrm{Hf}_{2} \\
\text { (mca) }\end{array}$ & $\begin{array}{l}\mathrm{Hf}_{\mathrm{boc}} \\
\text { (mca) }\end{array}$ & $\begin{array}{l}\mathrm{Hf}_{\mathrm{sist}} \\
(\mathrm{mca})\end{array}$ & $\begin{array}{c}\text { qutil } \\
\left(\mathrm{m}^{3} / \mathrm{s}\right)\end{array}$ & $\begin{array}{c}\text { qcirc }^{3} \\
\left(\mathrm{~m}^{3} / \mathrm{s}\right)\end{array}$ & $\begin{array}{l}\text { qbomba } \\
\left(\mathrm{m}^{3} / \mathrm{s}\right)\end{array}$ & $\begin{array}{c}\Delta \mathrm{H}_{\text {bomba }} \\
(\mathrm{mca})\end{array}$ & $\begin{array}{l}\Delta \mathrm{H}_{\text {util }} \\
\text { (mca) }\end{array}$ & $\begin{array}{c}\text { Rend. } \\
(\%)\end{array}$ \\
\hline 0,778 & 0,228 & 994 & 18,000 & 0,0000000 & 0,0006200 & 0,0006200 & 18,0 & 40,19 & 0,00 \\
\hline 761 & 0,228 & 16,758 & 17,747 & 0,0000072 & 0,0006120 & 0,0006192 & 18,0 & 38,96 & 2,52 \\
\hline 0,745 & 0,228 & 15,558 & 16,531 & $0,000 c$ & 006050 & 0,000 & 17,0 & 6,76 & 4,86 \\
\hline 0,733 & 0,230 & 15,762 & 16,724 & 0,00 & 990 & 0,000 & 17,5 & 35,96 & 7,89 \\
\hline 0,713 & 0,232 & 14,960 & 15,905 & $0,000 c$ & 0,000 & 0,000 & 17,0 & 34,16 & 11,29 \\
\hline 0,701 & 0,234 & 15,229 & 16,163 & & & & & 43 & 13,66 \\
\hline 0,674 & 0,234 & 14,927 & 15,835 & 0,000 & 0,0005710 & 0,000 & 17,5 & 32,13 & 17,01 \\
\hline 0,653 & 0,237 & 14,128 & 15,018 & 0,000 & 0,000 & 0,000 & 17,0 & 30,33 & 20,54 \\
\hline 0,635 & 0,240 & 13,877 & 14,752 & & & 0,00 & 17 & 29,09 & 23,42 \\
\hline 0,623 & 0,241 & 14,349 & 15,213 & 0,00 & 0,000 & 0,000 & 17,5 & 28,56 & 24,14 \\
\hline 0,595 & 0,243 & 13,558 & 14,397 & 0,00 & 20 & 0,00 & 17,0 & 26,77 & 27,90 \\
\hline 0,580 & 0,249 & 15,187 & 16,016 & & 40 & 0,000 & 18,5 & 25,94 & 28,28 \\
\hline 0,551 & 0,262 & 12,466 & 13,279 & 0,0001617 & 0,0005090 & 0,0006707 & 16,5 & 23,24 & 35,58 \\
\hline 0,534 & 0,270 & 12,452 & 13,256 & 0,000 & 0,000 & 0,0006817 & 16,5 & 22,18 & 37,63 \\
\hline 0,519 & 0,277 & 11,915 & 12,710 & 0,00 & & 0,000 & 16,1 & 21,05 & 39,99 \\
\hline 0,514 & 0,283 & 11,927 & 12,724 & 0,000 & 0,00 & 0,000 & 16,1 & 20,55 & 40,94 \\
\hline 0,483 & 0,300 & 11,510 & 12,293 & 0,0002522 & 0,000 & 0,0007242 & 15,9 & 18,93 & 44,82 \\
\hline 0,465 & 0,305 & 11,559 & 12,329 & 0,0002694 & 0,0004620 & 0,0007314 & 15,9 & 18,43 & 46,22 \\
\hline 0,455 & 0,334 & 10,951 & 11,740 & 0,0003150 & 0,0004560 & 0,0007710 & 15,3 & 16,91 & 49,39 \\
\hline 0,430 & 0,347 & 10,995 & 11,773 & 0,0003456 & 0,0004420 & 0,0007876 & 15,2 & 16,12 & 51,13 \\
\hline
\end{tabular}


Tabela 25 - Simulação da relação entre vazão útil e diferencial de pressão útil Conjunto 3VJE15-M 39G $(1 / 3 \mathrm{CV}) \quad \Delta \mathrm{z}=11,97 \mathrm{~m} \quad$ TESTE 2 $\mathrm{K}=0.733 \mathrm{Cd}=0.827$

\begin{tabular}{|c|c|c|c|c|c|c|c|c|c|}
\hline $\begin{array}{l}\mathrm{Hf}_{\text {boc }} \\
\text { (mca) }\end{array}$ & $\begin{array}{c}\mathrm{Hf}_{1} \\
\text { (mca) }\end{array}$ & $\begin{array}{c}\mathrm{Hf}_{2} \\
\text { (mca) }\end{array}$ & $\begin{array}{l}\mathrm{Hf}_{\text {sist }} \\
\text { (mca) }\end{array}$ & $\begin{array}{c}\text { qcirc } \\
\left(\mathrm{m}^{3} / \mathrm{s}\right)\end{array}$ & $\begin{array}{c}\text { quitil } \\
\left(\mathrm{m}^{3} / \mathrm{s}\right)\end{array}$ & $\begin{array}{l}\Delta \mathrm{H}_{\text {util }} \\
\text { (mca) }\end{array}$ & $\begin{array}{c}\Delta \mathrm{H}_{\text {bomba }} \\
\text { (mca) }\end{array}$ & $\begin{array}{l}\text { qbomba } \\
\left(\mathrm{m}^{3} / \mathrm{s}\right)\end{array}$ & $\begin{array}{l}\text { Rend. } \\
(\%)\end{array}$ \\
\hline 16.41 & 0.68 & 0.20 & 17.29 & 0.00057300 & 0.00000000 & 34.16 & 17.29 & 0.00057300 & 0.00 \\
\hline 16.05 & 0.66 & 0.20 & 16.92 & 0.00056672 & 0.00001146 & 33.44 & 17.25 & 0.00057818 & 3.84 \\
\hline 15.71 & 0.65 & 0.21 & 16.57 & 0.00056067 & 0.00002292 & 32.74 & 7.21 & 359 & 7.47 \\
\hline 15.39 & 0.64 & 0.21 & 16.24 & 0.000 & 0.00003438 & 32.08 & 17 & 922 & 10.90 \\
\hline 15.08 & 0.63 & 0.21 & 15.92 & 0.00054922 & 0.00004584 & 31.45 & 17.13 & 0.00059506 & 14.14 \\
\hline 14.78 & 0.62 & 0.22 & 15.62 & 0.00054380 & 0.00005730 & 30.85 & 17.09 & 0.00060110 & 17.21 \\
\hline 14.50 & 0.61 & 0.22 & 15.33 & 0.00053856 & 0.00006876 & 30.28 & 7.04 & 0.00060732 & 20.11 \\
\hline 14.23 & 0.60 & 0.22 & 15.05 & 0.00 & 0.00008022 & 29.73 & .00 & 0.00061373 & 22.86 \\
\hline 13.97 & 0.59 & 0.23 & 14.78 & 0.00052862 & 0.00009168 & 29.20 & 16.95 & 0.000 & 25.46 \\
\hline 13.72 & 0.58 & 0.23 & 14.53 & 0.000 & 0.00 & 28.69 & 90 & & 27.93 \\
\hline 13.48 & 0.57 & 0.24 & 14.29 & 0.00051932 & 0.00011460 & 28.21 & 16.85 & 0.00063392 & 30.27 \\
\hline 13.25 & 0.56 & 0.24 & 14.06 & 0.00051489 & 0.00012606 & 27.74 & 16.79 & 995 & 32.49 \\
\hline 13.03 & 0.55 & 0.25 & 13.83 & 0.00051059 & 0.00013752 & 27.30 & 16.74 & 0.00 & 34.60 \\
\hline 12.82 & 0.55 & 0.25 & 13.62 & 0.00050642 & 0.00014898 & 26.87 & 16.69 & 0.00065540 & 36.60 \\
\hline 12.61 & 0.54 & 0.26 & 13.41 & $0.0005 \mathrm{C}$ & 0.000 & 26.45 & .63 & & 38.50 \\
\hline 12.42 & 0.53 & 0.26 & 13.21 & 0.00049844 & 0.00017190 & 26.05 & 16.57 & 0.00067034 & 40.32 \\
\hline 12.23 & 0.52 & 0.27 & 13.02 & 0.00049461 & 0.0001 & 25.66 & 16.51 & 7797 & 42.04 \\
\hline 12.04 & 0.52 & 0.27 & 12.83 & 0.00049088 & 0.00019482 & 25.29 & 16.45 & 0.00068570 & 43.68 \\
\hline 11.87 & 0.51 & 0.28 & 12.65 & 0.00048725 & 0.00020628 & 24.93 & 16.39 & 0.00069353 & 45.25 \\
\hline 11.69 & 0.50 & 0.28 & 12 & 0.00048370 & 0.00021774 & 24.58 & 16.33 & 0.00 & 46.74 \\
\hline 11.53 & 0.50 & 0.29 & 12.31 & 0.00048024 & 0.00022920 & 24.24 & 16.26 & 0.00070944 & 48.16 \\
\hline 11.37 & 0.49 & 0.29 & 12.15 & 0.00047686 & 0.00024066 & 23.91 & 16.20 & 0.00071752 & 49.52 \\
\hline 11.21 & 0.49 & 0.30 & 11.99 & 0.00047355 & 0.00025212 & 23.59 & 16.13 & $0.000^{\circ}$ & 50.82 \\
\hline 11.06 & 0.48 & 0.31 & 11.84 & 0.00047031 & 0.00026358 & 23.28 & 16.06 & 0.00073389 & 52.06 \\
\hline 10.91 & 0.47 & 0.31 & 11.69 & 0.00046714 & 0.00027504 & 22.98 & 15.99 & 0.00074218 & 53.25 \\
\hline 10.76 & 0.47 & 0.32 & 11.55 & 0.00046403 & 0.00028650 & 22.69 & 15.92 & 0.00075053 & 54.39 \\
\hline 10.62 & 0.46 & 0.33 & 11.41 & 0.00046097 & 0.00029796 & 22.40 & 15.85 & 0.00075894 & 55.48 \\
\hline 10.48 & 0.46 & 0.33 & 11.27 & 0.00045797 & 0.00030942 & 22.12 & 15.78 & 0.00076740 & 56.52 \\
\hline 10.35 & 0.45 & 0.34 & 11.14 & 0.00045503 & 0.00032088 & 21.85 & 15.71 & 0.00077591 & 57.52 \\
\hline 10.22 & 0.45 & 0.34 & 11.01 & 0.00045213 & 0.00033234 & 21.58 & 15.63 & 0.00078447 & 58.48 \\
\hline 10.09 & 0.44 & 0.35 & 10.88 & 0.00044927 & 0.00034380 & 21.32 & 15.56 & 0.00079307 & 59.40 \\
\hline 9.96 & 0.44 & 0.36 & 10.76 & 0.00044646 & 0.00035526 & 21.06 & 15.48 & 0.00080172 & 60.28 \\
\hline
\end{tabular}


Tabela 26- Dados coletados do sistema injetor-bomba centrífuga (Obtidos por experimentação) - Conjunto 3VJE15-M 39G (1/3 CV) $\quad \Delta \mathrm{z}=11,97 \mathrm{~m}$

TESTE 2

\begin{tabular}{cccccccccc}
\hline $\begin{array}{c}\mathrm{Hf}_{1} \\
\text { (mca) }\end{array}$ & $\begin{array}{c}\mathrm{Hf}_{2} \\
(\mathrm{mca})\end{array}$ & $\begin{array}{c}\mathrm{Hf}_{\text {boc }} \\
(\mathrm{mca})\end{array}$ & $\begin{array}{c}\mathrm{Hf}_{\text {sist }} \\
(\mathrm{mca})\end{array}$ & $\begin{array}{c}\mathbf{q}_{\text {util }} \\
\left(\mathrm{m}^{3} / \mathrm{s}\right)\end{array}$ & $\begin{array}{c}\mathrm{q}_{\text {circ }} \\
\left(\mathrm{m}^{3} / \mathrm{s}\right)\end{array}$ & $\begin{array}{c}\mathbf{q}_{\text {bomba }} \\
\left(\mathrm{m}^{3} / \mathrm{s}\right)\end{array}$ & $\begin{array}{c}\Delta \mathrm{H}_{\text {bomba }} \\
(\mathrm{mca})\end{array}$ & $\begin{array}{c}\Delta \mathrm{H}_{\text {util }} \\
(\mathrm{mca})\end{array}$ & $\begin{array}{c}\text { Rend } \\
(\%)\end{array}$ \\
\hline 0,778 & 0,228 & 16,994 & 18,000 & 0,0000000 & 0,0006200 & 0,0006200 & 18,0 & 40,19 & 0,00 \\
0,761 & 0,228 & 16,758 & 17,747 & 0,0000072 & 0,0006120 & 0,0006192 & 18,0 & 38,96 & 2,52 \\
0,745 & 0,228 & 15,558 & 16,531 & 0,0000139 & 0,0006050 & 0,0006189 & 17,0 & 36,76 & 4,86 \\
0,733 & 0,230 & 15,762 & 16,724 & 0,0000239 & 0,0005990 & 0,0006229 & 17,5 & 35,96 & 7,89 \\
0,713 & 0,232 & 14,960 & 15,905 & 0,0000350 & 0,0005900 & 0,0006250 & 17,0 & 34,16 & 11,29 \\
0,701 & 0,234 & 15,229 & 16,163 & 0,0000447 & 0,0005840 & 0,0006287 & 17,5 & 33,43 & 13,66 \\
0,674 & 0,234 & 14,927 & 15,835 & 0,0000578 & 0,0005710 & 0,0006288 & 17,5 & 32,13 & 17,01 \\
0,653 & 0,237 & 14,128 & 15,018 & 0,0000719 & 0,0005610 & 0,0006329 & 17,0 & 30,33 & 20,54 \\
0,635 & 0,240 & 13,877 & 14,752 & 0,0000858 & 0,0005520 & 0,0006378 & 17,0 & 29,09 & 23,42 \\
0,623 & 0,241 & 14,349 & 15,213 & 0,0000928 & 0,0005460 & 0,0006388 & 17,5 & 28,56 & 24,14 \\
0,595 & 0,243 & 13,558 & 14,397 & 0,0001111 & 0,0005320 & 0,0006431 & 17,0 & 26,77 & 27,90 \\
0,580 & 0,249 & 13,368 & 14,197 & 0,0001281 & 0,0005240 & 0,0006521 & 17,0 & 25,59 & 30,49 \\
0,551 & 0,262 & 12,600 & 13,413 & 0,0001617 & 0,0005090 & 0,0006707 & 16,6 & 23,27 & 35,38 \\
0,534 & 0,270 & 12,691 & 13,495 & 0,0001817 & 0,0005000 & 0,0006817 & 16,7 & 22,24 & 37,28 \\
0,519 & 0,277 & 12,219 & 13,015 & 0,0001997 & 0,0004920 & 0,0006917 & 16,3 & 21,14 & 39,53 \\
0,514 & 0,283 & 12,290 & 13,087 & 0,0002119 & 0,0004890 & 0,0007009 & 16,4 & 20,66 & 40,40 \\
0,483 & 0,300 & 12,029 & 12,811 & 0,0002522 & 0,0004720 & 0,0007242 & 16,2 & 19,11 & 44,04 \\
0,465 & 0,305 & 12,154 & 12,924 & 0,0002694 & 0,0004620 & 0,0007314 & 16,3 & 18,65 & 45,36 \\
0,455 & 0,334 & 11,697 & 12,486 & 0,0003150 & 0,0004560 & 0,0007710 & 15,8 & 17,22 & 48,33 \\
0,430 & 0,347 & 11,887 & 12,665 & 0,0003456 & 0,0004420 & 0,0007876 & 15,7 & 16,51 & 49,95 \\
\hline
\end{tabular}


Tabela 27 - Simulação da relação entre vazão útil e diferencial de pressão útil Conjunto 2VJF15-T 39B (2 CV) $\Delta z=16,47 \mathrm{~m} \quad$ TESTE 1 $\mathrm{K}=0.540 \quad \mathrm{Cd}=0,928$

\begin{tabular}{|c|c|c|c|c|c|c|c|c|c|}
\hline $\begin{array}{l}\mathrm{Hf}_{\mathrm{boc}} \\
\text { (mca) }\end{array}$ & $\begin{array}{c}\mathrm{Hf}_{1} \\
\text { (mca) }\end{array}$ & $\begin{array}{c}\mathrm{Hf}_{2} \\
\text { (mca) }\end{array}$ & $\begin{array}{l}\mathrm{Hf}_{\text {sist }} \\
\text { (mca) }\end{array}$ & $\begin{array}{c}\text { quirc } \\
\left(\mathrm{m}^{3} / \mathrm{s}\right)\end{array}$ & $\begin{array}{c}\text { Qútil } \\
\left(\mathrm{m}^{3} / \mathrm{s}\right)\end{array}$ & $\begin{array}{l}\Delta H_{\text {útil }} \\
\text { (mca) }\end{array}$ & $\begin{array}{c}\Delta \mathrm{H}_{\text {bomba }} \\
\text { (mca) }\end{array}$ & $\begin{array}{l}\text { qbomba } \\
\left(\mathrm{m}^{3} / \mathrm{s}\right)\end{array}$ & $\begin{array}{l}\text { Rend. } \\
(\%)\end{array}$ \\
\hline 26.70 & 1.56 & 0.60 & 28.86 & 0.00156566 & 0.00000000 & 59.73 & 28.86 & .0015656 & 0.00 \\
\hline 25.99 & 1.52 & 0.61 & 28.12 & 0.00154459 & 0.00003131 & 58.15 & 28.72 & .0015759 & 4.02 \\
\hline 25.30 & 1.48 & 0.61 & 27.40 & 0.00152411 & 0.00006263 & 56.65 & 28.58 & 0.0015867 & 7.82 \\
\hline 24.65 & 1.45 & 0.62 & 26.72 & 0.00150418 & 0.00009394 & 55.20 & 28.43 & 0.0015981 & 11.41 \\
\hline 24.01 & 1.42 & 0.63 & 26.06 & 0.00148477 & 0.00012525 & 53.81 & 28.27 & 0.0016100 & 14.81 \\
\hline 23.41 & 1.39 & 0.64 & 25.43 & 0.00146586 & 0.00015657 & 52.47 & 28.10 & 0.0016224 & 18.02 \\
\hline 22.82 & 1.36 & 0.65 & 24.83 & 0.00144743 & 0.00018788 & 51.18 & 27.93 & 0.0016353 & 21.05 \\
\hline 22.26 & 1.33 & 0.66 & 24.24 & 0.00142944 & 0.00021919 & 49.94 & 27.75 & 16486 & 23.93 \\
\hline 21.71 & 1.30 & 0.67 & 23.68 & 0.00141187 & 0.00025051 & 48.74 & 27.56 & 0.0016623 & 26.65 \\
\hline 21.19 & 1.27 & 0.68 & 23.14 & 0.00139469 & 0.00028182 & 47.58 & 27.36 & 6765 & 29.24 \\
\hline 20.68 & 1.24 & 0.69 & 22.61 & 0.00137788 & 0.00031313 & 46.47 & 27.16 & 6910 & 31.68 \\
\hline 20.19 & 1.22 & 0.70 & 22.11 & 0.00136141 & 0.00034445 & 45.38 & 26.95 & 7058 & 34.01 \\
\hline 19.71 & 1.19 & 0.71 & 21.62 & 0.00134527 & 0.00037576 & 44.34 & 26.73 & 7210 & 36.21 \\
\hline 19.25 & 1.17 & 0.72 & 21.14 & 0.00132943 & 0.00040707 & 43.32 & 26.51 & 365 & 38.31 \\
\hline 18.80 & 1.14 & 0.73 & 20.68 & 0.00131387 & 0.00043839 & 42.33 & 26.28 & 0.0017522 & 40.30 \\
\hline 18.37 & 1.12 & 0.74 & 20.23 & 29858 & 0.00046970 & 41.37 & 26.05 & 82 & 42.19 \\
\hline 17.95 & 1.10 & 0.76 & 19.80 & 0.00128353 & 0.00050101 & 40.44 & 25.81 & 45 & 43.99 \\
\hline 17.53 & 1.08 & 0.77 & 19.38 & 26870 & 53232 & 39.53 & 25.56 & 10 & 45.71 \\
\hline 17.13 & 1.06 & 0.78 & 18.97 & 0.00125409 & 0.00056364 & 38.65 & 25.31 & 177 & 47.34 \\
\hline 16.74 & 1.03 & 0.79 & 18.57 & 0.00123966 & 0.00059495 & 37.78 & 25.06 & 346 & 48.90 \\
\hline 16.36 & 1.01 & 0.81 & 18.18 & 0.00122542 & 0.00062626 & 36.94 & 24.79 & 0.0018516 & 50.39 \\
\hline 15.98 & 0.99 & 0.82 & 17.80 & 0.00121134 & 0.00065758 & 36.11 & 24.53 & 0.00 & 51.80 \\
\hline 15.62 & 0.97 & 0.83 & 17.42 & 0.00119740 & 0.00068889 & 35.31 & 24.26 & 0.0018862 & 53.15 \\
\hline 15.26 & 0.95 & 0.85 & 17.06 & 0.00118361 & 72020 & 34.52 & 23.98 & 38 & 54.45 \\
\hline & 0.93 & 0.86 & 16 & 16993 & 0.0 & & 23.71 & & 55.68 \\
\hline 14.57 & 0.92 & 0.87 & 16 & 537 & & & 23.42 & & 56.86 \\
\hline 14.23 & 0.90 & 0.89 & 16.01 & 0.00114291 & 0.00081414 & 32.25 & 23.14 & 0.0019570 & 57.98 \\
\hline 13.90 & 0.88 & 0.90 & 15.68 & 0.00112954 & 0.00084546 & 31.52 & 22.84 & 0.0019750 & 59.06 \\
\hline 13.57 & 0.86 & 0.92 & 15.35 & 0.00111625 & 0.00087677 & 30.80 & 22.55 & 0.0019930 & 60.09 \\
\hline 13.25 & 0.84 & 0.93 & 15.03 & 0.00110303 & 0.00090808 & 30.09 & 22.25 & 0.0020111 & 61.07 \\
\hline 12.94 & 0.83 & 0.95 & 14 & 0.00108987 & 093940 & 29.40 & 21.95 & 0.0020292 & 62.01 \\
\hline 12.63 & 0.81 & 0.96 & 14.40 & 0.00107676 & 097071 & 28.72 & 21.64 & 474 & 62.91 \\
\hline 12.32 & 0.79 & 0.98 & 14.09 & 0.00106369 & 0.00100202 & 28.04 & 21.33 & 0.0020657 & 63.77 \\
\hline 12.02 & 0.77 & 0.99 & 13.79 & 0.00105066 & 0.00103334 & 27.38 & 21.02 & 0.0020839 & 64.59 \\
\hline 11.73 & 0.76 & 1.01 & 13.49 & 0.00103765 & 0.00106465 & 26.73 & 20.71 & 0.0021023 & 65.38 \\
\hline 11.44 & 0.74 & 1.02 & 13.20 & 0.00102466 & 0.00109596 & 26.08 & 20.39 & 0.0021206 & 66.13 \\
\hline 11.15 & 0.72 & 1.04 & 12.91 & 0.00101169 & 0.00112728 & 25.45 & 20.07 & 0.0021389 & 66.84 \\
\hline 10.87 & 0.71 & 1.05 & 12.63 & 0.00099871 & 0.00115859 & 24.82 & 19.74 & 0.0021573 & 67.53 \\
\hline 10.58 & 0.69 & 1.07 & 12.35 & 0.00098574 & 0.00118990 & 24.20 & 19.41 & 0.0021756 & 68.18 \\
\hline 10.31 & 0.68 & 1.08 & 12.07 & 0.00097275 & 0.00122122 & 23.59 & 19.09 & 0.0021939 & 68.80 \\
\hline 10.03 & 0.66 & 1.10 & 11.79 & 0.00095975 & 0.00125253 & 22.99 & 18.75 & 0.0022122 & 69.40 \\
\hline
\end{tabular}


Tabela 28- Dados coletados do sistema injetor-bomba centrífuga (Obtidos por experimentação) - Conjunto 2VJF15-T 39B (2 CV)

\begin{tabular}{cccccccccc}
\hline $\begin{array}{c}\mathrm{Hf}_{1} \\
(\mathrm{mca})\end{array}$ & $\begin{array}{c}\mathrm{Hf}_{2} \\
(\mathrm{mca})\end{array}$ & $\begin{array}{c}\mathrm{Hf}_{\mathrm{boc}} \\
(\mathrm{mca})\end{array}$ & $\begin{array}{c}\mathrm{Hf}_{\text {sist }} \\
(\mathrm{mca})\end{array}$ & $\begin{array}{c}\mathrm{q}_{\text {util }} \\
\left(\mathrm{m}^{3} / \mathrm{s}\right)\end{array}$ & $\begin{array}{c}\mathrm{q}_{\text {circ }} \\
\left(\mathrm{m}^{3} / \mathrm{s}\right)\end{array}$ & $\begin{array}{c}\mathrm{q}_{\text {bomba }} \\
\left(\mathrm{m}^{3} / \mathrm{s}\right)\end{array}$ & $\begin{array}{c}\Delta \mathrm{H}_{\text {bomba }} \\
(\mathrm{mca})\end{array}$ & $\begin{array}{c}\Delta \overline{\mathrm{H}}_{\text {átil }} \\
(\mathrm{mca})\end{array}$ & $\begin{array}{c}\text { Rend. } \\
(\%)\end{array}$ \\
\hline 1,577 & 0,594 & 33,828 & 36,00 & 0,0000000 & 0,001530 & 0,0015300 & 36,0 & 56,89 & 0,00 \\
1,587 & 0,598 & 30,815 & 33,00 & 0,0000000 & 0,001535 & 0,0015350 & 33,0 & 54,88 & 0,00 \\
1,547 & 0,637 & 30,211 & 32,40 & 0,0000748 & 0,001514 & 0,0015888 & 33,5 & 53,32 & 7,51 \\
1,522 & 0,672 & 29,404 & 31,60 & 0,0001335 & 0,001501 & 0,0016345 & 33,5 & 51,55 & 12,65 \\
1,461 & 0,741 & 29,905 & 32,11 & 0,0002559 & 0,001468 & 0,0017239 & 35,5 & 50,12 & 21,32 \\
1,509 & 0,679 & 29,764 & 31,95 & 0,0001500 & 0,001494 & 0,0016440 & 34,0 & 50,91 & 13,77 \\
1,444 & 0,786 & 29,206 & 31,44 & 0,0003204 & 0,001459 & 0,0017794 & 35,5 & 48,46 & 25,19 \\
1,433 & 0,839 & 28,518 & 30,79 & 0,0003898 & 0,001453 & 0,0018428 & 35,5 & 46,83 & 28,83 \\
1,404 & 0,904 & 26,445 & 28,75 & 0,0004822 & 0,001437 & 0,0019192 & 34,5 & 44,32 & 33,86 \\
1,374 & 0,975 & 24,849 & 27,20 & 0,0005786 & 0,001420 & 0,0019986 & 34,0 & 42,29 & 38,44 \\
1,342 & 1,015 & 24,577 & 26,93 & 0,0006409 & 0,001402 & 0,0020429 & 34,1 & 40,97 & 40,61 \\
1,329 & 1,082 & 23,704 & 26,12 & 0,0007195 & 0,001395 & 0,0021145 & 33,8 & 39,42 & 43,25 \\
1,320 & 1,138 & 23,295 & 25,75 & 0,0007830 & 0,001390 & 0,0021730 & 33,7 & 38,18 & 44,90 \\
1,313 & 1,146 & 22,975 & 25,43 & 0,0007948 & 0,001386 & 0,0021808 & 33,6 & 37,98 & 45,50 \\
1,299 & 1,190 & 21,933 & 24,42 & 0,0008482 & 0,001378 & 0,0022262 & 33,0 & 36,60 & 47,25 \\
1,275 & 1,242 & 22,024 & 24,54 & 0,0009134 & 0,001364 & 0,0022774 & 33,1 & 35,60 & 48,45 \\
1,260 & 1,309 & 22,246 & 24,82 & 0,0009885 & 0,001355 & 0,0023435 & 33,3 & 34,68 & 49,54 \\
1,241 & 1,385 & 20,992 & 23,62 & 0,0010721 & 0,001344 & 0,0024161 & 32,7 & 33,14 & 51,67 \\
1,227 & 1,448 & 20,403 & 23,08 & 0,0011384 & 0,001336 & 0,0024744 & 32,3 & 32,00 & 52,87 \\
1,208 & 1,512 & 21,508 & 24,23 & 0,0012082 & 0,001325 & 0,0025332 & 32,8 & 31,67 & 53,01 \\
1,193 & 1,543 & 20,878 & 23,61 & 0,0012454 & 0,001316 & 0,0025614 & 32,2 & 30,70 & 53,67 \\
\hline
\end{tabular}


Tabela 29 - Simulação da relação entre vazão útil e diferencial de pressão útil Conjunto 2VJF15-T 39B (2 CV) $\Delta z=16,47 \mathrm{~m} \quad$ TESTE 2 $\mathrm{K}=0.540 \quad \mathrm{Cd}=0,908$

\begin{tabular}{|c|c|c|c|c|c|c|c|c|c|}
\hline $\begin{array}{r}\mathrm{Hf}_{\mathrm{boc}} \\
\text { (mca) }\end{array}$ & $\begin{array}{c}\mathrm{Hf}_{1} \\
\text { (mca) }\end{array}$ & $\begin{array}{c}\mathrm{Hf}_{2} \\
\text { (mca) }\end{array}$ & $\begin{array}{r}\mathrm{Hf}_{\text {sist }} \\
(\mathrm{mca})\end{array}$ & $\begin{array}{c}\mathrm{q}_{\mathrm{circ}} \\
\left(\mathrm{m}^{3} / \mathrm{s}\right)\end{array}$ & $\begin{array}{c}\text { qutil } \\
\left(\mathrm{m}^{3} / \mathrm{s}\right)\end{array}$ & $\begin{array}{c}\Delta \text { Hútil } \\
\text { (mca) }\end{array}$ & $\begin{array}{c}\Delta \mathrm{H}_{\text {bomba }} \\
\text { (mca) }\end{array}$ & $\begin{array}{l}\text { qbomba } \\
\left(\mathrm{m}^{3} / \mathrm{s}\right)\end{array}$ & $\begin{array}{c}\text { Rend. } \\
(\%)\end{array}$ \\
\hline ) & 1.56 & 060 & 386 & 6 & 000 & 62.28 & 28.86 & 156566 & 0.00 \\
\hline & .52 & 61 & & & & 60.57 & & 191 & \\
\hline 25.24 & 1.48 & 0.61 & 27.33 & 0.00152218 & 0.00006263 & 58.92 & 28.61 & 481 & 8.14 \\
\hline 24.55 & 1.45 & 0.62 & 26.62 & 138 & 0.000 & 57.35 & 28.47 & 532 & 11.86 \\
\hline 3.90 & 1.41 & 0.63 & 25.94 & 0.001 & 0.000 & 55.84 & 32 & 43 & 15.37 \\
\hline 27 & .38 & 0.64 & 25.28 & & 0.000 & 54.39 & & & 18.69 \\
\hline 6 & 1.35 & 0.64 & 24.66 & & & 53 & & & 21.82 \\
\hline 22. & 1.32 & 0.65 & 24. & & 0.0 & 51.67 & & & 24.11 \\
\hline 21 & 1.29 & 0.66 & 23.41 & & & 50.38 & & & 27.57 \\
\hline 20. & 1.26 & 0.67 & 22.92 & & 0.00 & 49.14 & & & 30.21 \\
\hline 20.46 & 1.23 & 0.68 & 22.38 & & & 47.94 & & & 32.71 \\
\hline 19.96 & 1.21 & 0.69 & 21.86 & & 0.0 & 46.79 & 06 & & 35.08 \\
\hline 48 & 1.18 & 0.70 & 21.36 & & & 45.68 & & & 37.32 \\
\hline & 1.16 & 0.71 & 20.88 & & & 44.60 & & & 94 \\
\hline & 1.1 & 0.72 & 2 & & & 43 & & & 41.47 \\
\hline & 1.1 & 0.74 & 19. & & & 42.54 & & & 43.38 \\
\hline 17. & 1.08 & 0.75 & 15 & & 0. & 41.55 & & & 45.20 \\
\hline 17.27 & 1.06 & 0.76 & 19.09 & & 0.0 & 40.60 & 71 & & 46.93 \\
\hline 16.86 & 1.04 & 0.77 & 18.68 & 16 & 0.0 & 39.66 & 46 & 80 & 48.57 \\
\hline 16.47 & 1.02 & 0.78 & 18.27 & & & 38.76 & 21 & & 30.14 \\
\hline 16 & 1.00 & 0.80 & 17.88 & & & 37.88 & & & 51.63 \\
\hline & 0. & 0.81 & & & & & & & \\
\hline & & 0 & & & & & & & 54.39 \\
\hline & 0.94 & 0.84 & & & & 35.35 & & & 55.68 \\
\hline 14 & 0.92 & 0.85 & 2 & & & 34.55 & & & 56.91 \\
\hline 14 & 0.90 & 0.86 & 6 & & 0.0 & 33.76 & 60 & & 58.08 \\
\hline 13 & 0.88 & 0.88 & 72 & & 0.0 & 32.99 & 23.31 & 16 & 59.20 \\
\hline 13 & 0.8 & 0.89 & 15.39 & & 0.0 & 32.23 & .02 & 06 & 60.26 \\
\hline 13.31 & 0.8 & 0.91 & .06 & & 0.0 & 31.49 & 2.73 & 06 & 61.28 \\
\hline 12 & 0. & 0.9 & 14.74 & & & 6 & 13 & & 5 \\
\hline & & 0.9 & & & & 30.04 & & & 63.18 \\
\hline & & 0. & & & & & & & 64.07 \\
\hline & 0 & 0. & & & & & & & 64.91 \\
\hline & 0.7 & 0.98 & 13 & & & 27.96 & 2 & & 65.72 \\
\hline 1 & 0.74 & 1.00 & 13.23 & & 0.0 & 27.29 & 20.89 & 44 & 66.49 \\
\hline 1$]$ & 0.7 & 1.01 & 12 & & 0.0 & 26.63 & 2 & 82 & 67.23 \\
\hline 10 & 0.7 & 1.0 & 12 & 15 & 0.0 & 25.98 & 25 & 322 & 67.93 \\
\hline 10 & 0.7 & 1.04 & 12.37 & 5 & & 25.33 & 93 & 64 & 68.60 \\
\hline & & & & & & 24.70 & 19.60 & & 69.24 \\
\hline 10.0 & 0.6 & $1.0^{\circ}$ & 11.83 & & & 24.07 & 19.27 & & 69.84 \\
\hline 9.8 & 0.6 & 1.09 & 11.56 & & & 23.45 & 18.94 & & 70.42 \\
\hline & 0.63 & 1.1 & & & & 22.84 & & & 70.97 \\
\hline 9.2 & 0.62 & 1.12 & 11.03 & 0.000 & 0.00 & 22.23 & 18.27 & 0.00223865 & 71.4 \\
\hline
\end{tabular}


Tabela 30- Dados coletados do sistema injetor-bomba centrífuga (Obtidos por experimentação) - Conjunto 2VJF15-T 39B (2 CV)

$\Delta \mathrm{z}=\mathbf{1 6 , 4 7 \mathrm { m }}$

TESTE 2

\begin{tabular}{|c|c|c|c|c|c|c|c|c|c|}
\hline (mca) & (mca) & $\begin{array}{l}\mathrm{Hf}_{\mathrm{boc}} \\
\text { (mca) }\end{array}$ & $\begin{array}{c}\mathrm{Hf}_{\text {sistem }} \\
\mathrm{a} \\
\text { (mca) }\end{array}$ & $\begin{array}{c}\text { qútil } \\
\left(\mathrm{m}^{3} / \mathrm{s}\right)\end{array}$ & $\begin{array}{c}q_{\text {circ }} \\
\left(\mathrm{m}^{3} / \mathrm{s}\right)\end{array}$ & $\begin{array}{l}\text { qbomba } \\
\left(\mathrm{m}^{3} / \mathrm{s}\right)\end{array}$ & $\begin{array}{c}\Delta \mathrm{H}_{\text {bomba }} \\
\text { (mca) }\end{array}$ & $\Delta \mathbf{H}_{\text {util }}$ & (\%) \\
\hline 1,575 & 594 & 33,83 & 36,00 & 0,0000000 & 0,001529 & 0,0015290 & 36,0 & 58,89 & 0,00 \\
\hline 1,558 & ,617 & 33,17 & 35,34 & 0,0000419 & 0,001520 & 0015619 & 36,0 & 57,76 & 4,30 \\
\hline 1,551 & 0,625 & 32,95 & 35,13 & 0,0000567 & 0,001516 & 0,0015727 & 36,0 & 57,05 & 5,72 \\
\hline 1,537 & 0,641 & 31,52 & 33,69 & 0,0000843 & 0,001509 & 0,0015933 & $;, 0$ & 55,63 & 8,44 \\
\hline 1,519 & 0,668 & 30,85 & 33,04 & 0,0001312 & 0,001499 & 0,0016302 & 35,0 & 53,99 & 12,49 \\
\hline 1,483 & 0,709 & 29,87 & 32,06 & 0,00 & & & & & 18,16 \\
\hline 1,446 & 0,771 & 29,16 & 31,38 & 0,0003011 & 0,001460 & 7611 & 35,5 & 49,90 & 24,61 \\
\hline 1,437 & 0,820 & 27,84 & 30,10 & 0,0003651 & 0,001455 & 0,0018201 & 35,0 & 48,13 & 28,50 \\
\hline 1,413 & 0,876 & 26,97 & 29,26 & 0,0004448 & 0,001442 & 0,0018868 & ,0 & 46,32 & 32,61 \\
\hline 1,397 & 0,911 & 25,94 & 28,25 & 0,0004941 & 0,001433 & 19271 & 34,5 & 44,82 & 35,11 \\
\hline 1,381 & 0,946 & 24,94 & 27,27 & 0,0005427 & 0,001424 & 0,0019667 & 34,0 & 43,36 & 37,43 \\
\hline 1,349 & 0,991 & 24,40 & 26,74 & 0,0006109 & 0,001406 & 0,0020169 & 34,0 & 41,86 & 40,10 \\
\hline 1,324 & 1,053 & 24,22 & 26,59 & 0,0006920 & 0,001392 & 0,0020840 & 34,3 & 40,45 & 42,58 \\
\hline 1,313 & 1,112 & 23,82 & 26,25 & 0,0007594 & 0,001386 & 0,0021454 & 34,2 & 39,16 & 44,41 \\
\hline 1,296 & 1,183 & 23,65 & 26,13 & 0,0008427 & 0,001376 & 0,0022187 & 34,4 & 37,90 & 46,37 \\
\hline 1,266 & 1,212 & 23,64 & 26,12 & 0,0008889 & 0,001359 & 0,0022479 & 34,3 & 36,97 & 47,33 \\
\hline 1,251 & 1,299 & 23,38 & 25,93 & 0,0009834 & 0,001350 & 0,0023334 & 34,4 & 35,75 & 49,21 \\
\hline 1,232 & 1,384 & 23,06 & 25,68 & 0,0010760 & 0,001339 & 0,0024150 & 34,3 & 34,58 & 50,92 \\
\hline 1,217 & 1,432 & 22,88 & 25,53 & 0,0011295 & 0,001330 & 0,0024595 & 34,1 & 33,70 & 51,69 \\
\hline 1,203 & 1,509 & 22,36 & 25,08 & 0,0012088 & 0,001322 & 0,0025308 & 33,7 & 32,60 & 52,97 \\
\hline 1,173 & 1,518 & 22,00 & 24,69 & 0,0012345 & 0,001304 & 0,0025385 & 33,2 & 31,76 & 53,51 \\
\hline
\end{tabular}


Tabela 31 - Simulação da relação entre vazão útil e diferencial de pressão útil

Conjunto 2VJF15-T 39B (2 CV) $\Delta \mathrm{z}=11,97 \mathrm{~m} \quad$ TESTE 1

$\mathrm{K}=0,600 \quad \mathrm{Cd}=0,911$

\begin{tabular}{|c|c|c|c|c|c|c|c|c|c|}
\hline $\begin{array}{l}\mathrm{Hf}_{\text {boc }} \\
\text { (mca) }\end{array}$ & $\begin{array}{c}\mathrm{Hf}_{1} \\
\text { (mca) }\end{array}$ & $\begin{array}{c}\mathrm{Hf}_{2} \\
\text { (mca) }\end{array}$ & $\begin{array}{l}\mathrm{Hf}_{\text {sist }} \\
\text { (mca) }\end{array}$ & $\begin{array}{c}q_{\text {circ }} \\
\left(\mathrm{m}^{3} / \mathrm{s}\right)\end{array}$ & $\begin{array}{c}\text { qútil }^{\text {qutil }} \\
\left(\mathrm{m}^{3} / \mathrm{s}\right)\end{array}$ & $\begin{array}{l}\Delta \mathrm{H}_{\text {útil }} \\
\text { (mca) }\end{array}$ & $\begin{array}{c}\Delta \mathrm{H}_{\text {bomba }} \\
\text { (mca) }\end{array}$ & $\begin{array}{l}\text { qbomba } \\
\left(\mathrm{m}^{3} / \mathrm{s}\right)\end{array}$ & $\begin{array}{c}\text { Rend. } \\
(\%)\end{array}$ \\
\hline 27.06 & 1.20 & 0.46 & 28.72 & 0.00157609 & 0.00000000 & 62.33 & 28.72 & 0.00157609 & 0.00 \\
\hline 26.30 & 1.17 & 0.47 & 27.94 & 0.00155389 & 0.00003152 & 60.61 & 28.60 & 0.00158541 & 4.21 \\
\hline 25.58 & 1.14 & 0.47 & 27.19 & 0.00153233 & 0.00006304 & 58.96 & 28.47 & 0.00159537 & 8.19 \\
\hline 24.88 & 1.11 & 0.48 & 26.48 & 0.00151140 & 0.00009457 & 57.39 & 28.33 & 0.00160596 & 11.93 \\
\hline 24.22 & 1.09 & 0.48 & 25.79 & 0.00149106 & 0.00012609 & 55.88 & 28.17 & 0.00161714 & 15.46 \\
\hline 23.58 & 1.06 & 0.49 & 25.13 & 0.00147128 & 0.00015761 & 54.43 & 28.02 & 0.00162889 & 18.80 \\
\hline 22.97 & 1.04 & 0.50 & 24.50 & 0.00145202 & 0.00018913 & 53.04 & 27.85 & 116 & 21.95 \\
\hline 22.38 & 1.02 & 0.50 & 23.90 & 0.00143327 & 0.00022065 & 51.70 & 27.67 & 393 & 24.92 \\
\hline 21.81 & 0.99 & 0.51 & 23.31 & 0.00141499 & 0.00025218 & 50.41 & 27.49 & 0.00166717 & 27.74 \\
\hline 21.26 & 0.97 & 0.52 & 22.75 & 0.00139715 & 0.00028370 & 49.17 & 27.30 & 0.0016 & 30.40 \\
\hline 20.74 & 0.95 & 0.53 & 22.21 & 0.00137973 & 0.00031522 & 47.97 & 27.10 & 195 & 32.92 \\
\hline 20.23 & 0.93 & 0.53 & 21.69 & 0.00136270 & 0.00034674 & 46.82 & 26.90 & 0.00170944 & 35.31 \\
\hline 19.74 & 0.91 & 0.54 & 21.19 & 0.00134603 & 0.00037826 & 45.70 & 26.68 & 430 & 37.57 \\
\hline 19.26 & 0.89 & 0.55 & 20.70 & 0.00132971 & 0.00040978 & 44.62 & 26.47 & 0.00 & 39.72 \\
\hline 18.80 & 0.87 & 0.56 & 20.23 & 0.00131370 & 0.00044131 & 43.57 & 26.24 & 501 & 41.75 \\
\hline 18.35 & 0.85 & 0.57 & 19.77 & 0.00129799 & 0.00047283 & 42.56 & 26.01 & 82 & 43.69 \\
\hline 17.92 & 0.84 & 0.58 & 19.33 & 0.00128256 & 0.00050435 & 41.57 & 25.77 & 8691 & 45.53 \\
\hline 17.50 & 0.82 & 0.59 & 18.90 & 0.00126738 & 0.00053587 & 40.61 & 25.53 & 26 & 47.28 \\
\hline 17.09 & 0.80 & 0.60 & 18.49 & 0.00125244 & 0.00056739 & 39.68 & 25.28 & 0.001 & 48.94 \\
\hline 16.69 & 0.79 & 0.61 & 18.08 & 0.00123773 & 0.00059892 & 38.77 & 25.02 & 0.00 & 50.52 \\
\hline 16.30 & 0.77 & 0.62 & 17.68 & & & 37.89 & & 0.0 & 03 \\
\hline 15.92 & 0.75 & 0.63 & 17.30 & 0.00120888 & 0.00066196 & 37.03 & 24.50 & 884 & 53.47 \\
\hline 15.55 & 0.74 & 0.64 & 16.92 & 0.00119472 & 0.00069 & 36.18 & 24.23 & 20 & 54.85 \\
\hline 15.19 & 0.72 & 0.65 & 16.56 & 0.00118072 & 0.00072500 & 35.36 & 23.95 & 0.00 & 56.16 \\
\hline 14.83 & 0.71 & 0.66 & 16.20 & 0.00116686 & 0.00075653 & 34.55 & 23.68 & 0.00 & 57.41 \\
\hline 14.48 & 0.69 & 0.67 & 15.85 & 0.00115313 & 0.00078805 & 33.76 & 23.39 & 118 & 58.60 \\
\hline 14.14 & 0.68 & 0.68 & 15.50 & 0.00113952 & 0.00081957 & 32.99 & 23.10 & 908 & 59.74 \\
\hline 13.81 & 0.67 & 0.69 & 15.17 & 0.00112601 & 0.00085109 & 32.23 & 22.81 & 710 & 60.83 \\
\hline 13.48 & 0.65 & 0.70 & 14.84 & 0.00111260 & 0.00088261 & 31.49 & 22.51 & 0.00 & 61.88 \\
\hline 13.16 & 0.64 & 0.71 & 14.51 & 0.00109927 & 0.00091413 & 30.76 & 22.21 & 0.00 & 62.88 \\
\hline 12.85 & 0.63 & 0.72 & 14.19 & 0.00108601 & 0.00094566 & 30.04 & 21.91 & 0.00 & 63.83 \\
\hline 12.54 & 0.61 & 0.73 & 13.88 & 0.00107282 & 0.00097718 & 29.34 & 21.60 & 0.00205000 & 64.74 \\
\hline 12.23 & 0.60 & 0.75 & 13.58 & 0.00105968 & 0.00100870 & 28.64 & 21.29 & 0.00206838 & 65.62 \\
\hline 11.93 & 0.59 & 0.76 & 13.27 & 0.00104659 & 0.00104022 & 27.96 & 20.97 & 0.00208681 & 66.46 \\
\hline 11.64 & 0.57 & 0.77 & 12.98 & 0.00103353 & 0.00107174 & 27.29 & 20.65 & 0527 & 67.26 \\
\hline 11.34 & 0.56 & 0.78 & 12.69 & 0.00102050 & 0.00110327 & 26.62 & 20.33 & 0.00212377 & 68.03 \\
\hline 11.06 & 0.55 & 0.79 & 12.40 & 0.00100749 & 0.00113479 & 25.97 & 20.01 & 0.00214228 & 68.76 \\
\hline 10.77 & 0.54 & 0.80 & 12.11 & 0.00099450 & 0.00116631 & 25.33 & 19.68 & 0.00216081 & 69.46 \\
\hline 10.49 & 0.52 & 0.82 & 11.83 & 0.00098151 & 0.00119783 & 24.69 & 19.35 & 0.00217934 & 70.14 \\
\hline 10.22 & 0.51 & 0.83 & 11.56 & 0.00096852 & 0.00122935 & 24.06 & 19.02 & 0.00219787 & 70.78 \\
\hline 9.95 & 0.50 & 0.84 & 11.29 & 0.00095552 & 0.00126088 & 23.44 & 18.68 & 0.00221639 & 71.39 \\
\hline 9.68 & 0.49 & 0.85 & 11.02 & 0.00094250 & 0.00129240 & 22.83 & 18.34 & 0.00223490 & 71.98 \\
\hline 9.41 & 0.48 & 0.87 & 10.75 & 0.00092946 & 0.00132392 & 22.22 & 18.00 & 0.00225338 & 72.54 \\
\hline 9.15 & 0.46 & 0.88 & 10.49 & 0.00091640 & 0.00135544 & 21.63 & 17.66 & 0.00227184 & 73.07 \\
\hline
\end{tabular}


Tabela 32- Dados coletados do sistema injetor-bomba centrífuga (Obtidos por experimentação) - Conjunto 2VJF15-T 39B (2 CV)

\begin{tabular}{|c|c|c|c|c|c|c|c|c|c|}
\hline $\begin{array}{c}\mathrm{Hf}_{\mathrm{i}} \\
\text { (mca) }\end{array}$ & $\begin{array}{c}\mathrm{Hf}_{2} \\
\text { (mca) }\end{array}$ & $\begin{array}{r}\mathrm{Hf}_{\mathrm{boc}} \\
(\mathrm{mca})\end{array}$ & $\begin{array}{l}\mathrm{Hf}_{\text {sist }} \\
\text { (mca) }\end{array}$ & $\begin{array}{c}\text { qutil } \\
\left(\mathrm{m}^{3} / \mathrm{s}\right)\end{array}$ & $\begin{array}{c}\text { qcirc } \\
\left(\mathrm{m}^{3} / \mathrm{s}\right)\end{array}$ & $\begin{array}{r}\text { qbomba } \\
\left(\mathrm{m}^{3} / \mathrm{s}\right) \\
\end{array}$ & $\begin{array}{c}\Delta H_{\text {bomba }} \\
(\mathrm{mca})\end{array}$ & $\begin{array}{l}\Delta \mathrm{H}_{\text {util }} \\
\text { (mca) }\end{array}$ & $\begin{array}{c}\text { Rend. } \\
(\%)\end{array}$ \\
\hline 1,145 & 0,442 & 33,412 & 35,00 & 0,0000000 & 0,001535 & 0,0015350 & 35,000 & 58,82 & 0,00 \\
\hline 1,128 & 0,457 & 32,767 & 34,35 & 0,0000417 & 0,001522 & 0,0015637 & 35,000 & 57,19 & 4,36 \\
\hline 1,114 & 0,483 & 31,842 & 33,44 & 0,00 & 0,00 & 0,00 & 35,000 & 55,29 & 10,20 \\
\hline 1,109 & 0,491 & 31,599 & 33,20 & 0,00 & 0,0 & & 35,000 & 54,56 & 11,75 \\
\hline 1,089 & 0,531 & 29,840 & 31,46 & 0,00 & 91 & 43 & 34 & 51,84 & 19,04 \\
\hline 1,077 & 0,558 & 29,048 & 30,68 & 0,0 & 82 & 42 & & 50,58 & 23,18 \\
\hline 1,069 & 0,580 & 29,095 & 30,74 & 0,0 & 76 & 32 & 0 & 49,65 & 25,69 \\
\hline 1,056 & 0,600 & 28,552 & 30,21 & 0,0 & & & & 48,62 & 28,43 \\
\hline 1,046 & 0,623 & 28,029 & 29,70 & $0,0 c$ & & & & 47,62 & 30,97 \\
\hline 1,029 & 0,657 & 27,365 & 29,05 & 0,000 & & & & 45,99 & 34,34 \\
\hline 1,016 & 0,673 & 26,520 & 28,21 & 0,00 & 0,0 & & & 44,66 & 36,22 \\
\hline 0,999 & 0,701 & 25,926 & 27,63 & $0,0 c$ & 0,0 & & & 43,60 & 38,82 \\
\hline 0,995 & 0,737 & 25,564 & 27,30 & 0,00 & $0,0 c$ & & 34 & 42,27 & 40,86 \\
\hline 0,984 & 0,771 & 24,758 & 26,51 & 0,0007027 & 0,00 & 0,00 & 34,000 & 40,50 & 42,92 \\
\hline 0,968 & 0,801 & 24,568 & 26,34 & 19 & 94 & 59 & 34 & 39,34 & 44,54 \\
\hline 0,950 & 0,848 & 24,169 & 25,97 & 78 & 79 & 68 & 34 & 37,99 & 46,86 \\
\hline 0,928 & 0,926 & 22,484 & 24,34 & 0,0 & 0,0 & 21 & 33 & 35,33 & 50,46 \\
\hline 0,920 & 0,951 & 21,647 & 23,52 & 0,0 & 0,0 & 0,0 & 32 , & 34,16 & 51,58 \\
\hline 0,909 & 0,991 & 21,830 & 23,73 & 0,0010889 & 0,001345 & 0,0024339 & 32,669 & 33,62 & 52,60 \\
\hline 0,902 & 1,028 & 21,838 & 23,77 & 0,0011465 & 0,001339 & 0,0024855 & 32,753 & 33,08 & 53,47 \\
\hline 0,887 & 1,097 & 20,873 & 22,86 & 0,0012536 & 0,001326 & 0,0025796 & 31,827 & 31,11 & 55,18 \\
\hline 0,863 & 1,186 & 21,799 & 23,85 & 0,0013917 & 0,001306 & 0,0026977 & 32,390 & 30,56 & 56,47 \\
\hline 0,835 & 1,275 & 21,686 & 23,80 & 0,0015302 & 0,001281 & 0,0028112 & 31 , & 28,68 & 57,50 \\
\hline 0,810 & 1,261 & 22,801 & 24,87 & 0,0015352 & 0,001259 & 0,0027942 & 30,976 & 28,56 & 56,87 \\
\hline
\end{tabular}


Tabela 33 - Simulação da relação entre vazão útil e diferencial de pressão útil $\begin{array}{lll}\text { Conjunto 2VJF15-T 39B (2 CV) } \Delta \mathrm{z}=11,97 \mathrm{~m} & \text { TESTE } 2\end{array}$

$\mathrm{K}=0,500 \quad \mathrm{Cd}=0,911$

\begin{tabular}{|c|c|c|c|c|c|c|c|c|c|}
\hline $\begin{array}{l}\mathrm{Hf}_{\mathrm{boc}} \\
\text { (mca) }\end{array}$ & $\begin{array}{c}\mathrm{Hf}_{1} \\
\text { (mca) }\end{array}$ & $\begin{array}{c}\mathrm{Hf}_{2} \\
\text { (mca) }\end{array}$ & $\begin{array}{l}\mathrm{Hf}_{\text {sist }} \\
\text { (mca) }\end{array}$ & $\begin{array}{c}q_{\text {circ }} \\
\left(\mathrm{m}^{3} / \mathrm{s}\right)\end{array}$ & $\begin{array}{c}\begin{array}{c}\text { qútil } \\
\left(\mathrm{m}^{3} / \mathrm{s}\right)\end{array}\end{array}$ & $\begin{array}{l}\Delta H_{\text {útil }} \\
\text { (mca) }\end{array}$ & $\begin{array}{c}\Delta \mathrm{H}_{\text {bomba }} \\
\text { (mca) }\end{array}$ & $\begin{array}{l}\text { qbomba } \\
\left(\mathrm{m}^{3} / \mathrm{s}\right)\end{array}$ & $\begin{array}{l}\text { Rend. } \\
(\%)\end{array}$ \\
\hline 26.42 & 1.26 & 0.48 & 28.16 & 0.00161836 & 0.00000000 & 65.67 & 28.16 & 0.0016183 & 0.00 \\
\hline 25.61 & 1.22 & 0.49 & 27.32 & 0.00159350 & 0.00003237 & 63.69 & 28.06 & 0.0016258 & 4.52 \\
\hline 24.84 & 1.19 & 0.49 & 26.53 & 0.00156942 & 0.00006473 & 61.81 & 27.94 & 0.0016341 & 8.76 \\
\hline 24.11 & 1.16 & 0.50 & 25.77 & 0.00154608 & 0.00009710 & 60.01 & 27.82 & 0.0016431 & 12.75 \\
\hline 23.41 & 1.13 & 0.50 & 25.04 & 0.00152346 & 0.00012947 & 58.29 & 27.69 & 0.0016529 & 16.49 \\
\hline 22.74 & 1.10 & 0.51 & 24.35 & 0.00150151 & 0.00016184 & 56.65 & 27.54 & 0.0016633 & 20.01 \\
\hline 22.10 & 1.07 & 0.51 & 23.69 & 0.00148021 & 0.00019420 & 55.08 & 27,39 & 0.0016744 & 23.32 \\
\hline 21.49 & 1.05 & 0.52 & 23.06 & 0.00145950 & 0.00022657 & 53.58 & 27.23 & 0.0016860 & 26.44 \\
\hline 20.90 & 1.02 & 0.53 & 22.45 & 0.00143937 & 0.00025894 & 52.13 & 27.05 & 0.0016983 & 29.38 \\
\hline 20.33 & 1.00 & 0.53 & 21.87 & 0.00141977 & 0.00029131 & 50.75 & 26.87 & 0.0017110 & 32.15 \\
\hline 19.79 & 0.98 & 0.54 & 21.31 & 0.00140068 & 0.000 & 49.41 & 26.68 & 0.0017243 & 34.76 \\
\hline 19.27 & 0.95 & 0.55 & 20.77 & 0.00138205 & 0.000 & 48.13 & 26.49 & 17380 & 37.22 \\
\hline 18.76 & 0.93 & 0.56 & 20.25 & 0.00136387 & 0.00038841 & 46.90 & 26.28 & 0.0017522 & 39.55 \\
\hline 18.28 & 0.91 & 0.57 & 19.75 & 0.00134610 & 0.00042077 & 45.70 & 26.07 & 0.0017668 & 41.75 \\
\hline 17.81 & 0.89 & 0.57 & 19.27 & 0.00132872 & 0.00045314 & 44.55 & 25.85 & 0.0017818 & 43.84 \\
\hline 17.35 & 0.87 & 0.58 & 18.81 & 0.0 & 0.00 & 43.44 & 25.62 & 972 & 45.81 \\
\hline 16.91 & 0.85 & 0.59 & 18.36 & 0.0 & 0.00 & 42.36 & 25.38 & 128 & 47.68 \\
\hline 16.49 & 0.83 & 0.60 & 17.92 & 0.00127862 & 0.000 & 41.32 & 25.14 & & 49.45 \\
\hline 16.08 & 0.81 & 0.61 & 17.50 & 0.00126252 & 0.00058261 & 40.31 & 24.89 & 0.001 & 51.12 \\
\hline 15.68 & 0.80 & 0.62 & 17.09 & 0.00124670 & 0.00061498 & 39.32 & 24.64 & 0.0018616 & 52.72 \\
\hline 15.29 & 0.78 & 0.63 & 16.70 & 112 & 0.0 & 38.37 & 24.38 & 84 & 54.23 \\
\hline 14.91 & 0.76 & 0.64 & 16.31 & 76 & 71 & 37.44 & 24.12 & & 55.67 \\
\hline 14.54 & 0.75 & 0.65 & 15.93 & 0.0 & 0.00 & 36.53 & 23.84 & 27 & 57.04 \\
\hline 14.18 & 0.73 & 0.66 & 15.57 & 0.00 & 0.00 & 35.65 & 23.57 & 301 & 58.34 \\
\hline 13.83 & 0.71 & 0.67 & 15.21 & 0.00117088 & 0.00 & 34.79 & 23.29 & & 59.58 \\
\hline 13.48 & 0.70 & 0.68 & 14.86 & 0.00115626 & 0.000 & 33.94 & 23.00 & 0.00 & 60.76 \\
\hline 13.15 & 0.68 & 0.69 & 14.52 & 178 & 55 & 33.12 & 22.71 & 33 & 61.89 \\
\hline 12.82 & 0.67 & 0.70 & 14.19 & 0.0 & 92 & 32.31 & 22.41 & & 62.96 \\
\hline 12.50 & 0.65 & 0.71 & 13.87 & 0.0 & 000 & 31.52 & 22.11 & 94 & 63.98 \\
\hline 12.18 & 0.64 & 0.73 & 13.55 & 0.0 & 365 & 30.75 & 21.81 & 377 & 64.96 \\
\hline 11.87 & 0.62 & 0.74 & 13.24 & 0.00108503 & 0.00097102 & 29.99 & 21.50 & 0560 & 65.89 \\
\hline 11.57 & 0.61 & 0.75 & 12.93 & 0.00107108 & 0.00100339 & 29.24 & 21.18 & 0.0020744 & 66.77 \\
\hline 11.27 & 0.60 & 0.76 & 12.63 & 0.00 & 0.0 & 28.51 & 20.87 & 929 & 67.62 \\
\hline 10.98 & 0.58 & 0.77 & 12.34 & 0.0 & 0.0 & 27.79 & 20.55 & 14 & 68.43 \\
\hline 10.69 & 0.57 & 0.78 & 12.05 & 959 & 49 & 27.09 & 20.22 & 00 & 69.20 \\
\hline 10.41 & 0.56 & 0.80 & 11.76 & 0.00101585 & 0.00113285 & 26.39 & 19.89 & 0.0021487 & 69.94 \\
\hline 10.13 & 0.54 & 0.81 & 11.48 & 0.00100215 & 0.00116522 & 25.70 & 19.56 & 0.0021673 & 70.64 \\
\hline 9.85 & 0.53 & 0.82 & 11.21 & 0.0 & 759 & 25.03 & 19.23 & & 71.31 \\
\hline 9.58 & 0.52 & 0.83 & 10.93 & 0.0 & 0. & 24.36 & 18.89 & 47 & 71.95 \\
\hline 9.32 & 0.50 & 0.85 & 10.67 & 0.0 & 32 & 23.71 & 18.55 & 34 & 72.56 \\
\hline 9.05 & 0.49 & 0.86 & 10.40 & 0.00094745 & 0.00129469 & 23.06 & 18.21 & 0.0022421 & 73.13 \\
\hline 8.79 & 0.48 & 0.87 & 10.15 & 0.00093377 & 0.00132706 & 22.42 & 17.86 & 0.0022608 & 73.68 \\
\hline 8.54 & 0.47 & 0.88 & 9.89 & 0.00092007 & 0.00135943 & 21.79 & 17.52 & 0.0022795 & 74.20 \\
\hline 8.29 & 0.46 & 0.90 & 9.64 & 0.00 & & 21.17 & 17.17 & & 74.70 \\
\hline 8.04 & 0.44 & 0.91 & 9.39 & 0.00 & 0.00142416 & 20.56 & 16.81 & 3167 & 75.17 \\
\hline 7.79 & 0.43 & 0.92 & 9.14 & 0.00087880 & 0.00145653 & 19.95 & 16.46 & 0.0023353 & 75.61 \\
\hline 7.55 & 0.42 & 0.93 & 8.90 & 0.00086495 & 0.00148889 & 19.35 & 16.10 & 0.0023538 & 76.02 \\
\hline 7.31 & 0.41 & 0.95 & 8.66 & 0.00085106 & 0.00152126 & 18.76 & 15.75 & 0.0023723 & 76.41 \\
\hline 7.07 & 0.40 & 0.96 & 8.42 & 0.00083710 & 0.00155363 & 18.18 & 15.39 & 0.0023907 & 76.78 \\
\hline
\end{tabular}


Tabela 34- Dados coletados do sistema injetor-bomba centrifuga (Obtidos por experimentação) - Conjunto 2VJF15-T 39B (2 CV)

\begin{tabular}{|c|c|c|c|c|c|c|c|c|c|}
\hline (mca) & (mca) & $\mathrm{Hf}_{\mathrm{boc}}$ & $\mathrm{Hf}_{\text {sist }}$ & $\left(\mathrm{m}^{3} / \mathrm{s}\right)$ & $\left(\mathrm{m}^{3} / \mathrm{s}\right)$ & $\left(\mathrm{m}^{3} / \mathrm{s}\right)$ & $\begin{array}{l}\Delta \mathrm{H}_{\mathrm{bomb}} \\
\text { (mca) } \\
\text { (mate }\end{array}$ & $\Delta \mathrm{H}_{\text {util }}$ & Rend. \\
\hline 1,140 & 0,440 & 33,420 & 35,00 & 0,0000000 & 0,001531 & 0,0015310 & 35,0 & 58,83 & 0,00 \\
\hline 1,130 & 0,455 & 32,819 & 34,40 & 0,0000383 & 0,001523 & 0,0015613 & 35,0 & 57,24 & 4,02 \\
\hline 1,118 & 0,481 & 31,952 & 33,55 & 0,0000967 & 0,001514 & 0,0016107 & 35,0 & 55,40 & 9,53 \\
\hline 1,107 & 0,491 & 31,566 & 33,16 & 0,0001244 & 0,001505 & 0,0016294 & 35,0 & 53 & 11,96 \\
\hline 1,087 & 0,534 & 29,732 & 31,35 & 0,0002206 & 0,001490 & 0,0017106 & 34,5 & 74 & 15 \\
\hline 1,077 & 0,559 & 29,023 & 30,66 & 0,0002739 & 0,001482 & 0,0017559 & 34,5 & 50,55 & 23,30 \\
\hline 1,071 & 0,568 & 29,409 & 31,05 & 0,0002950 & 0,001477 & 0,0017720 & 35,0 & 49,95 & 24,25 \\
\hline 1,056 & 0,598 & 28,599 & 30,25 & 0,0003600 & 0,001465 & 0,0018250 & 35,0 & 48,67 & 28,23 \\
\hline 1,048 & 0,615 & 28,237 & 29,90 & 0,0003950 & 0,001459 & 0,0018540 & 35,0 & 47,82 & 30,10 \\
\hline 1,028 & 0,657 & 27,355 & 29,04 & 0,0004811 & 0,001443 & 0,0019241 & 35,0 & 45,98 & 34,38 \\
\hline 1,013 & 0,677 & 26,408 & 28,10 & 0,0005267 & 0,001431 & 0,0019577 & 34,5 & 44,55 & 36,65 \\
\hline 0,997 & 0,701 & 25,889 & 27,59 & 0,0005793 & 0,001418 & 0,0019973 & 34,5 & 43,56 & 38,97 \\
\hline 0,993 & 0,735 & 25,581 & 27,31 & 0,0006377 & 415 & 0,0 & 34,5 & 42 & 40,81 \\
\hline 0,982 & 0,771 & 24,755 & 26,51 & 0,0 & 06 & & 34,0 & 0 & 42,94 \\
\hline 0,965 & 0,804 & 24,487 & 26,26 & 0,0007686 & 0,001392 & 0,0021606 & 34,0 & 39,26 & 44,81 \\
\hline 0,945 & 0,845 & 24,155 & 25,94 & 0,0008478 & 0,001375 & 0,0022228 & 34,0 & 37,97 & 46,94 \\
\hline 0,926 & 0,928 & 22,431 & 24,28 & 0,0009856 & 0,001359 & 3446 & 33,1 & 35,27 & 50,62 \\
\hline 0,916 & 0,951 & 21,602 & 23,47 & 0,00 & 0,001351 & 0,0023777 & 32,4 & 34,11 & 51,73 \\
\hline 0,904 & 0,996 & 21,708 & 23,61 & 0,0011000 & 0,001341 & 0,0024410 & 32,7 & 33,50 & 52,95 \\
\hline 0,898 & 1,026 & 21,813 & 23,74 & 0,0011479 & 0,001336 & 0,0024839 & 32,8 & 33,06 & 53,57 \\
\hline 0,885 & 1,095 & 20,881 & 22,86 & 0,0012522 & 0,001325 & 0,0025772 & 31,8 & 31,12 & 55,17 \\
\hline 0,863 & 1,182 & 21,838 & 23,88 & 0,0013867 & 0,001306 & 0,0026927 & 32,4 & 30,60 & 56,38 \\
\hline 0,843 & 1,280 & 21,517 & 23,64 & 0,0015302 & 0,001288 & 0,0028182 & 31,7 & 29,06 & 57,84 \\
\hline 0,828 & 1,270 & 21,668 & 23,77 & 0,0015302 & 0,001275 & 0,0028052 & 31,3 & 28,66 & 57,63 \\
\hline 0,818 & 1,265 & 22,723 & 24,81 & 0,0015336 & 0,001266 & 0,0027996 & 31,2 & 28,75 & 56,94 \\
\hline
\end{tabular}


Tabela 35 - Simulação da relação entre vazão útil e diferencial de pressão útil Conjunto 1VJF15-M 38J (1 CV) $\Delta z=16,47 \mathrm{~m} \quad$ TESTE 1 $\mathrm{K}=1.108 \quad \mathrm{Cd}=0.730$

\begin{tabular}{|c|c|c|c|c|c|c|c|c|c|}
\hline $\begin{array}{l}\mathrm{Hf}_{\mathrm{boc}} \\
(\mathrm{mca})\end{array}$ & $\begin{array}{c}\mathrm{Hf}_{1} \\
(\mathrm{mca})\end{array}$ & $\begin{array}{c}\mathrm{Hf}_{2} \\
(\mathrm{mca})\end{array}$ & $\begin{array}{c}\mathrm{Hf}_{\text {sisit }} \\
\text { (mca) }\end{array}$ & $\begin{array}{c}\text { 9circ } \\
\left(\mathrm{m}^{3} / \mathrm{s}\right)\end{array}$ & $\begin{array}{c}\text { qútii } \\
\left(\mathrm{m}^{3} / \mathrm{s}\right)\end{array}$ & $\begin{array}{l}\Delta \mathrm{H}_{\text {útil }} \\
\text { (mca) }\end{array}$ & $\begin{array}{c}\Delta \mathrm{H}_{\text {bomb }} \\
\text { (mca) }\end{array}$ & $\begin{array}{l}\text { qbomba } \\
\left(\mathrm{m}^{3} / \mathrm{s}\right)\end{array}$ & $\begin{array}{c}\text { Rend. } \\
(\%) \\
\end{array}$ \\
\hline 27.74 & 0.33 & 0.13 & 28.20 & 0.00064767 & 0.00000000 & 48.06 & 28.20 & 0.00064767 & 0.00 \\
\hline 27.29 & 0.33 & 0.13 & 27.75 & 0.00064247 & 0.00001295 & 47.30 & 28.14 & 0.00065542 & 3.32 \\
\hline 26.87 & 0.32 & 0.13 & 27.32 & 0.00063745 & 0.00002591 & 46.58 & 28.08 & 0.00066335 & 6.48 \\
\hline 26.46 & 0.32 & 0.14 & 26.92 & 0.00063259 & 0.00003886 & 45.88 & 28.02 & 0.00067145 & 9.48 \\
\hline 26.07 & 0.31 & 0.14 & 26.52 & 0.00062790 & 0.00005181 & 45.22 & 27.96 & 0.00067971 & 12.33 \\
\hline 25.69 & 0.31 & 0.14 & 26.15 & 0.00062336 & 0.00006477 & 44.58 & 27.89 & 0.00068813 & 15.04 \\
\hline 25.33 & 0.31 & 0.15 & 25.78 & 0.00061897 & 0.00007772 & 43.96 & 27.83 & 0.00069669 & 17.62 \\
\hline 24.98 & 0.30 & 0.15 & 25.44 & 0.00061471 & 0.00009067 & 43.37 & 27.76 & 0.00070538 & 20.08 \\
\hline 24.65 & 0.30 & 0.15 & 25.10 & 0.00061058 & 0.00010363 & 42.80 & 27.69 & 0.00071420 & 22.42 \\
\hline 24.33 & 0.30 & 0.16 & 24.78 & 0.00060657 & 0.00011658 & 42.25 & 27.62 & 0.00072315 & 24.66 \\
\hline 24.02 & 0.29 & 0.16 & 24.47 & 0.00060267 & 0.00012953 & 41.72 & 27.55 & 0.00073220 & 26.79 \\
\hline 23.72 & 0.29 & 0.16 & 24.17 & 0.00059888 & 0.00014249 & 41.20 & 27.47 & 0.00074137 & 28.83 \\
\hline 23.42 & 0.29 & 0.17 & 23.88 & 0.00059520 & 0.00015544 & 40.71 & 27.40 & 0.00075064 & 30.77 \\
\hline 23.14 & 0.28 & 0.17 & 23.60 & 0.00059161 & 0.00016839 & 40.23 & 27.32 & 0.00076001 & 32.63 \\
\hline 22.87 & 0.28 & 0.17 & 23.32 & 0.00058812 & 0.00018135 & 39.76 & 27.24 & 0.00076946 & 34.40 \\
\hline 22.61 & 0.28 & 0.18 & 23.06 & 0.00058471 & 0.00019430 & 39.31 & 27.16 & 0.00077901 & 36.10 \\
\hline 22.35 & 0.27 & 0.18 & 22.80 & 0.00058137 & 0.00020725 & 38.88 & 27.08 & 0.00078863 & 37.73 \\
\hline 22.10 & 0.27 & 0.18 & 22.56 & 0.00057812 & 0.00022021 & 38.45 & 26.99 & 0.00079833 & 39.29 \\
\hline 21.86 & 0.27 & 0.19 & 22.31 & 0.00057494 & 0.00023316 & 38.04 & 26.91 & 0.00080810 & 40.79 \\
\hline 21.62 & 0.27 & 0.19 & 22.08 & 0.00057182 & 0.00024611 & 37.63 & 26.82 & 0.00081794 & 42.22 \\
\hline 21.39 & 0.26 & 0.20 & 21.85 & 0.00056877 & 0.00025907 & 37.24 & 26.73 & 0.00082784 & 43.60 \\
\hline 21.17 & 0.26 & 0.20 & 21.63 & 0.00056578 & 0.00027202 & 36.86 & 26.64 & 0.00083780 & 44.92 \\
\hline 20.95 & 0.26 & 0.21 & 21.41 & 0.00056284 & 0.00028497 & 36.49 & 26.55 & 0.00084782 & 46.20 \\
\hline 20.73 & 0.26 & 0.21 & 21.20 & 0.00055996 & 0.00029793 & 36.12 & 26.45 & 0.00085789 & 47.42 \\
\hline 20.52 & 0.26 & 0.21 & 20.99 & 0.00055712 & 0.00031088 & 35.76 & 26.36 & 0.00086801 & 48.59 \\
\hline 20.32 & 0.25 & 0.22 & 20.79 & 0.00055434 & 0.00032383 & 35.41 & 26.26 & 0.00087817 & 49.73 \\
\hline 20.12 & 0.25 & 0.22 & 20.59 & 0.00055159 & 0.00033679 & 35.07 & 26.17 & 0.00088838 & 50.82 \\
\hline 19.92 & 0.25 & 0.23 & 20.40 & 0.00054889 & 0.00034974 & 34.74 & 26.07 & 0.00089863 & 51.87 \\
\hline 19.73 & 0.25 & 0.23 & 20.21 & 0.00054623 & 0.00036269 & 34.41 & 25.97 & 0.00090892 & 52.88 \\
\hline 19.54 & 0.24 & 0.24 & 20.02 & 0.00054360 & 0.00037565 & 34.09 & 25.86 & 0.00091925 & 53.85 \\
\hline 19.35 & 0.24 & 0.24 & 19.84 & 0.00054101 & 0.00038860 & 33.77 & 25.76 & 0.00092961 & 54.80 \\
\hline 19.17 & 0.24 & 0.25 & 19.66 & 0.00053845 & 0.00040155 & 33.46 & 25.66 & 0.00094000 & 55.71 \\
\hline 18.99 & 0.24 & 0.25 & 19.48 & 0.00053591 & 0.00041451 & 33.15 & 25.55 & 0.00095042 & 56.58 \\
\hline 18.81 & 0.24 & $0.2 \overline{6}$ & 19.31 & 0.00053341 & 0.00042746 & 32.85 & 25.44 & 0.00096087 & 57.43 \\
\hline 18.64 & 0.23 & 0.26 & 19.13 & 0.00053093 & 0.00044041 & 32.55 & 25.34 & 0.00097134 & 58.25 \\
\hline 18.47 & 0.23 & 0.27 & 18.96 & 0.00052848 & 0.00045337 & 32.26 & 25.23 & 0.00098184 & 59.05 \\
\hline 18.30 & 0.23 & 0.27 & 18.80 & 0.00052604 & 0.00046632 & 31.97 & 25.11 & 0.00099236 & 59.82 \\
\hline 18.13 & 0.23 & 0.28 & 18.63 & 0.00052363 & 0.00047927 & 31.68 & 25.00 & 0.00100291 & 60.56 \\
\hline 17.96 & 0.23 & 0.28 & 18.47 & 0.00052124 & 0.00049223 & 31.40 & 24.89 & 0.00101347 & 61.28 \\
\hline 17.80 & 0.23 & 0.29 & 18.31 & 0.00051887 & 0.00050518 & 31.12 & 24.77 & 0.00102405 & 61.98 \\
\hline 17.64 & 0.22 & 0.29 & 18.15 & 0.00051651 & 0.00051813 & 30.85 & 24.66 & 0.00103464 & 62.65 \\
\hline 17.48 & 0.22 & 0.30 & 18.00 & 0.00051417 & 0.00053109 & 30.58 & 24.54 & 0.00104525 & 63.31 \\
\hline 17.32 & 0.22 & 0.30 & 17.84 & 0.00051184 & 0.00054404 & 30.31 & 24.42 & 0.00105588 & 63.94 \\
\hline 17.17 & 0.22 & 0.31 & 17.69 & 0.00050952 & 0.00055699 & 30.04 & 24.30 & 0.00106652 & 64.56 \\
\hline 17.01 & 0.22 & 0.31 & 17.54 & 0.00050722 & 0.00056995 & 29.78 & 24.18 & 0.00107717 & 65.16 \\
\hline 16.86 & 0.21 & 0.32 & 17.39 & 0.00050492 & 0.00058290 & 29.51 & 24.06 & 0.00108783 & 65.74 \\
\hline
\end{tabular}


Tabela 35 - Simulação da relação entre vazão útil e diferencial de pressão útil (cont.) Conjunto 1VJF15-M 38J (1 CV) $\quad \Delta \mathrm{z}=16,47 \mathrm{~m} \quad$ TESTE 1 $\mathrm{K}=1.108 \quad \mathrm{Cd}=0.730$

\begin{tabular}{cccccccccc}
\hline $\begin{array}{c}\mathrm{Hf}_{\mathrm{boc}} \\
(\mathrm{mca})\end{array}$ & $\begin{array}{c}\mathrm{Hf}_{1} \\
(\mathrm{mca})\end{array}$ & $\begin{array}{c}\mathrm{Hf}_{2} \\
(\mathrm{mca})\end{array}$ & $\begin{array}{c}\mathrm{Hf}_{\text {sist }} \\
(\mathrm{mca})\end{array}$ & $\begin{array}{c}\mathrm{q}_{\text {circ }} \\
\left(\mathrm{m}^{3} / \mathrm{s}\right)\end{array}$ & $\begin{array}{c}\mathrm{q}_{\text {útil }} \\
\left(\mathrm{m}^{3} / \mathrm{s}\right)\end{array}$ & $\begin{array}{c}\Delta \mathrm{H}_{\text {útil }} \\
(\mathrm{mca})\end{array}$ & $\begin{array}{c}\Delta \mathrm{H}_{\text {bomb }} \\
(\mathrm{mca})\end{array}$ & $\begin{array}{c}\mathrm{q}_{\text {boomba }} \\
\left(\mathrm{m}^{3} / \mathrm{s}\right)\end{array}$ & $\begin{array}{c}\text { Rend. } \\
(\%)\end{array}$ \\
\hline 16.71 & 0.21 & 0.32 & 17.24 & 0.00050264 & 0.00059585 & 29.26 & 23.93 & 0.00109849 & 66.30 \\
16.55 & 0.21 & 0.33 & 17.09 & 0.00050036 & 0.00060881 & 29.00 & 23.81 & 0.00110917 & 66.85 \\
16.40 & 0.21 & 0.33 & 16.95 & 0.00049810 & 0.00062176 & 28.74 & 23.68 & 0.00111986 & 67.39 \\
16.26 & 0.21 & 0.34 & 16.80 & 0.00049583 & 0.00063471 & 28.49 & 23.56 & 0.00113055 & 67.90 \\
16.11 & 0.21 & 0.35 & 16.66 & 0.00049358 & 0.00064767 & 28.24 & 23.43 & 0.00114125 & 68.41 \\
15.96 & 0.20 & 0.35 & 16.52 & 0.00049133 & 0.00066062 & 27.99 & 23.30 & 0.00115195 & 68.90 \\
15.82 & 0.20 & 0.36 & 16.38 & 0.00048908 & 0.00067358 & 27.74 & 23.17 & 0.00116266 & 69.37 \\
\hline
\end{tabular}

Tabela 36- Dados coletados do sistema injetor-bomba centrífuga (Obtidos por experimentaç̃o) - Conjunto 1VJF15-M 38J

\begin{tabular}{cccccccccc}
\hline $\begin{array}{c}\mathrm{Hf}_{1} \\
(\mathrm{mca})\end{array}$ & $\begin{array}{c}\mathrm{Hf}_{2} \\
(\mathrm{mca})\end{array}$ & $\begin{array}{c}\mathrm{Hf}_{\text {boc }} \\
(\mathrm{mca})\end{array}$ & $\begin{array}{c}\mathrm{Hf}_{\text {sist }} \\
(\mathrm{mca})\end{array}$ & $\begin{array}{c}\mathrm{q}_{\text {util }} \\
\left(\mathrm{m}^{3} / \mathrm{s}\right)\end{array}$ & $\begin{array}{c}\mathrm{q}_{\text {circ }} \\
\left(\mathrm{m}^{3 / s}\right)\end{array}$ & $\begin{array}{c}\mathrm{q}_{\text {bomba }} \\
\left(\mathrm{m}^{3} / \mathrm{s}\right)\end{array}$ & $\begin{array}{c}\Delta \mathrm{H}_{\text {bomba }} \\
(\mathrm{mca})\end{array}$ & $\begin{array}{c}\Delta \mathrm{H}_{\text {util }} \\
(\mathrm{mca})\end{array}$ & $\begin{array}{c}\text { Rend. } \\
(\%)\end{array}$ \\
\hline 0,308 & 0,119 & 29,57 & 30,00 & 0,0000000 & 0,000620 & 0,0006200 & 30,0 & 48,16 & 0,00 \\
0,304 & 0,129 & 28,61 & 29,04 & 0,0000349 & 0,000616 & 0,0006504 & 30,0 & 46,21 & 8,28 \\
0,284 & 0,128 & 27,99 & 28,41 & 0,0000561 & 0,000593 & 0,0006486 & 30,0 & 45,59 & 13,18 \\
0,267 & 0,129 & 26,85 & 27,25 & 0,0000788 & 0,000572 & 0,0006508 & 29,5 & 43,95 & 18,17 \\
0,272 & 0,139 & 26,84 & 27,25 & 0,0001000 & 0,000578 & 0,0006775 & 30,0 & 43,45 & 21,62 \\
0,242 & 0,142 & 24,62 & 25,00 & 0,0001466 & 0,000541 & 0,0006871 & 29,2 & 40,99 & 30,75 \\
0,240 & 0,169 & 23,15 & 23,56 & 0,0002202 & 0,000538 & 0,0007582 & 29,5 & 38,33 & 39,90 \\
0,241 & 0,196 & 21,63 & 22,07 & 0,0002866 & 0,000540 & 0,0008261 & 29,3 & 36,00 & 46,31 \\
0,290 & 0,250 & 21,24 & 21,78 & 0,0003493 & 0,000599 & 0,0009483 & 29,2 & 34,74 & 48,03 \\
0,277 & 0,277 & 20,54 & 21,09 & 0,0004231 & 0,000584 & 0,0010066 & 29,5 & 32,83 & 52,78 \\
0,387 & 0,367 & 20,95 & 21,70 & 0,0004758 & 0,000707 & 0,0011823 & 29,3 & 32,98 & 50,30 \\
0,386 & 0,412 & 20,04 & 20,84 & 0,0005559 & 0,000706 & 0,0012619 & 28,9 & 31,02 & 53,58 \\
0,378 & 0,459 & 19,55 & 20,39 & 0,0006452 & 0,000697 & 0,0013422 & 28,9 & 29,54 & 56,78 \\
0,373 & 0,470 & 18,93 & 19,77 & 0,0006690 & 0,000692 & 0,0013610 & 28,3 & 28,53 & 57,70 \\
\hline
\end{tabular}


Tabela 37 - Simulação da relação entre vazão útil e diferencial de pressão útil

\begin{tabular}{|c|c|c|c|c|c|c|c|c|c|}
\hline 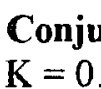 & $\begin{array}{l}0 \\
8\end{array}$ & 1 & & & $\Delta z=1$ & & & & \\
\hline $\begin{array}{l}\text { Hf } f_{\text {boc }} \\
\text { (mca) }\end{array}$ & $\begin{array}{c}\mathrm{Hf}_{1} \\
\text { (mca) }\end{array}$ & $\begin{array}{c}\mathrm{Hf}_{2} \\
\text { (mca) }\end{array}$ & $\begin{array}{l}\mathrm{Hf}_{\text {sist }} \\
\text { (mca) }\end{array}$ & $\begin{array}{c}\left.\text { qcirc }_{\text {con }} / \mathrm{s}\right) \\
\left(\mathrm{m}^{3}\right.\end{array}$ & $\begin{array}{c}\text { qutil } \\
\left(\mathrm{m}^{3} / \mathrm{s}\right)\end{array}$ & $\begin{array}{l}\Delta \mathrm{H}_{\text {útil }} \\
\text { (mca) }\end{array}$ & $\begin{array}{c}\Delta \mathrm{H}_{\text {bomba }} \\
\text { (mca) }\end{array}$ & $\begin{array}{l}\text { qbomba } \\
\left(\mathrm{m}^{3} / \mathrm{s}\right)\end{array}$ & $\begin{array}{c}\text { Rend. } \\
(\%)\end{array}$ \\
\hline 26.72 & 0.44 & 0.17 & 27.33 & 0.00075867 & 0.00000000 & 47.20 & 27.33 & 0.00075867 & 0.00 \\
\hline 26.26 & 0.43 & 0.17 & 26.87 & 0.00075212 & 0.00001517 & 46.40 & 27.26 & 0.00076730 & 3.37 \\
\hline 25.82 & 0.42 & 0.18 & 26.42 & 0.00074579 & 0.00003035 & 45.64 & 27.18 & 0.00077614 & 6.56 \\
\hline 25.40 & 0.42 & 0.18 & 26.00 & 0.00073966 & 0.00004552 & 44.90 & 27.11 & 0.00078518 & 9.60 \\
\hline 24.99 & 0.41 & 0.18 & 25.59 & 0.00073371 & 0.00006069 & 44.20 & 27.03 & 0.00079440 & 12.49 \\
\hline 24.60 & 0.41 & 0.19 & 25.20 & 0.00072794 & 0.00007587 & 43.52 & 26.94 & 0.00080380 & 15.24 \\
\hline 24.22 & 0.40 & 0.19 & 24.82 & 0.00072234 & 0.00009104 & 42.86 & 26.86 & 0.00081338 & 17.86 \\
\hline 23.86 & 0.40 & 0.19 & 24.45 & 0.00071689 & 0.00010621 & 42.23 & 26.77 & 2311 & 20.36 \\
\hline 23.51 & 0.39 & 0.20 & 24.10 & 0.00071160 & 0.00012139 & 41.62 & 26.68 & 0.00083299 & 22.73 \\
\hline 23.17 & 0.39 & 0.20 & 23.76 & 0.00070645 & 0.00013656 & 41.03 & 26.59 & 0.000 & 25.00 \\
\hline 22.84 & 0.38 & 0.21 & 23.43 & 0.00070143 & 0.00015173 & 40.46 & 26.50 & 0.00085316 & 27.16 \\
\hline 22.53 & 0.38 & 0.21 & 23.11 & 0.00069653 & 0.00016691 & 39.91 & 26.40 & 0.00086344 & 29.22 \\
\hline 22.22 & 0.37 & 0.22 & 22.81 & 0.00069176 & 0.00018208 & 39.38 & 26.30 & 384 & 31.19 \\
\hline 21.92 & 0.37 & 0.22 & 22.51 & 0.00068710 & 0.00019725 & 38.86 & 26.20 & 0.00088435 & 33.08 \\
\hline 21.63 & 0.36 & 0.23 & 22.22 & 0.00068254 & 0.00021243 & 38.36 & 26.10 & 196 & 34.88 \\
\hline 21.35 & 0.36 & 0.23 & 21.94 & 0.00067808 & 0.00022760 & 37.87 & 26.00 & 568 & 36.60 \\
\hline 21.07 & 0.36 & 0.24 & 21.66 & 0.00067371 & 0.00024277 & 37.39 & 25.89 & 0.00091648 & 38.25 \\
\hline 20.81 & 0.35 & 0.24 & 21.40 & 0.00066943 & 0.00025795 & 36.93 & 25.78 & 737 & 39.83 \\
\hline 20.55 & 0.35 & 0.25 & 21.14 & 0.00066522 & 0.00027312 & 36.47 & 25.67 & 3835 & 41.35 \\
\hline 20.29 & 0.34 & 0.25 & 20.89 & 0.00066110 & 0.00028829 & 36.03 & 25.56 & 0.000 & 42.81 \\
\hline 20.04 & 0.34 & 0.26 & 20.64 & 0.00065705 & 0.00030347 & 35.60 & 25.45 & 5052 & 44.20 \\
\hline 19.80 & 0.34 & 0.26 & 20.40 & 0.00065306 & 0.00031864 & 35.18 & 25.33 & 0.00097170 & 45.54 \\
\hline 19.56 & 0.33 & 0.27 & 20.16 & 0.00064914 & 0.00033381 & 34.77 & 25.21 & 0.00 & 46.83 \\
\hline 19.33 & 0.33 & 0.27 & 19.93 & 0.00064528 & 0.00034899 & 34.37 & 25.09 & 0.00099426 & 48.07 \\
\hline 19.10 & 0.33 & 0.28 & 19.71 & 0.00064147 & 0.00036416 & 33.97 & 24.97 & 0.00100563 & 49.26 \\
\hline 18.88 & 0.32 & 0.28 & 19.49 & 0.00063771 & 0.00037933 & 33.58 & 24.85 & 0.00101704 & 50.41 \\
\hline 18.66 & 0.32 & 0.29 & 19.27 & 0.00063400 & 0.00039451 & 33.20 & 24.72 & 0.00102851 & 51.51 \\
\hline 18.45 & 0.32 & 0.29 & 19.06 & 0.00063033 & 0.00040968 & 32.83 & 24.60 & 0.00104001 & 52.57 \\
\hline 18.24 & 0.31 & 0.30 & 18.85 & 0.00062671 & 0.00042485 & 32.46 & 24.47 & 0.00105156 & 53.60 \\
\hline 18.03 & 0.31 & 0.31 & 18.64 & 0.00062312 & 0.00044003 & 32.10 & 24.34 & 0.00106315 & 54.59 \\
\hline 17.82 & 0.31 & 0.31 & 18.44 & 0.00061957 & 0.00045520 & 31.74 & 24.21 & 0.00107477 & 55.54 \\
\hline 17.62 & 0.30 & 0.32 & 18.24 & 0.00061606 & 0.00047037 & 31.39 & 24.07 & 0.00108643 & 56.46 \\
\hline 17.42 & 0.30 & 0.32 & 18.05 & 0.00061257 & 0.00048555 & 31.05 & 23.94 & 0.00109811 & 57.35 \\
\hline 17.23 & 0.30 & 0.33 & 17.85 & 0.00060911 & 0.00050072 & 30.71 & 23.80 & 0.00110983 & 58.21 \\
\hline 17.03 & 0.30 & 0.34 & 17.66 & 0.00060568 & 0.00051589 & 30.37 & 23.66 & 0.00112157 & 59.04 \\
\hline 16.84 & 0.29 & 0.34 & 17.47 & 0.00060227 & 0.00053107 & 30.04 & 23.52 & 0.00113333 & 59.84 \\
\hline 16.65 & 0.29 & 0.35 & 17.29 & 0.00059888 & 0.00054624 & 29.71 & 23.38 & 0.00114512 & 60.62 \\
\hline 16.46 & 0.29 & 0.35 & 17.11 & 0.00059551 & 0.00056141 & 29.39 & 23.24 & 0.00115692 & 61.37 \\
\hline 16.28 & 0.28 & 0.36 & 16.92 & 0.00059216 & 0.00057659 & 29.07 & 23.09 & 0.00116874 & 62.10 \\
\hline 16.10 & 0.28 & 0.37 & 16.74 & 0.00058882 & 0.00059176 & 28.75 & 22.94 & 0.00118058 & 62.80 \\
\hline 15.92 & 0.28 & 0.37 & 16.57 & 0.00058550 & 0.00060693 & 28.43 & 22.80 & 0.00119244 & 63.48 \\
\hline 15.74 & 0.28 & 0.38 & 16.39 & 0.00058219 & 0.00062211 & 28.12 & 22.65 & 0.00120430 & 64.14 \\
\hline 15.56 & 0.27 & 0.39 & 16.22 & 0.00057890 & 0.00063728 & 27.81 & 22.50 & 0.00121618 & 64.79 \\
\hline 15.38 & 0.27 & 0.39 & 16.05 & 0.00057561 & 0.00065245 & 27.51 & 22.34 & 0.00122806 & 65.41 \\
\hline
\end{tabular}


Tabela 38- Dados coletados do sistema injetor-bomba centrífuga (Obtidos por experimentação) - Conjunto 1VJF15-M 38J (1 CV) $\Delta z=16,47 \mathrm{~m} \quad$ TESTE 2

\begin{tabular}{cccccccccc}
\hline $\begin{array}{c}\mathrm{Hf}_{1} \\
(\mathrm{mca})\end{array}$ & $\begin{array}{c}\mathrm{Hf}_{2} \\
(\mathrm{mca})\end{array}$ & $\begin{array}{c}\mathrm{Hf}_{\text {boc }} \\
(\mathrm{mca})\end{array}$ & $\begin{array}{c}\mathrm{Hf}_{\text {sist }} \\
(\mathrm{mca})\end{array}$ & $\begin{array}{c}\mathrm{q}_{\text {util }} \\
\left(\mathrm{m}^{3} / \mathrm{s}\right)\end{array}$ & $\begin{array}{c}\mathrm{q}_{\text {circ }} \\
\left(\mathrm{m}^{3} / \mathrm{s}\right)\end{array}$ & $\begin{array}{c}\mathrm{q}_{\text {bomba }} \\
\left(\mathrm{m}^{3} / \mathrm{s}\right)\end{array}$ & $\begin{array}{c}\Delta \mathrm{H}_{\text {bomba }} \\
(\mathrm{mca})\end{array}$ & $\begin{array}{c}\Delta \mathrm{H}_{\text {util }} \\
(\mathrm{mca})\end{array}$ & $\begin{array}{c}\text { Rend. } \\
(\%)\end{array}$ \\
\hline 0,442 & 0,167 & 27,89 & 28,50 & 0,0000000 & 0,000770 & 0,0007700 & 28,5 & 47,03 & 0,00 \\
0,434 & 0,183 & 26,25 & 26,86 & 0,0000484 & 0,000762 & 0,0008104 & 28,0 & 44,90 & 9,59 \\
0,431 & 0,193 & 26,20 & 26,82 & 0,0000754 & 0,000759 & 0,0008344 & 28,5 & 43,86 & 13,97 \\
0,422 & 0,209 & 25,86 & 26,49 & 0,0001184 & 0,000751 & 0,0008694 & 29,0 & 42,54 & 20,18 \\
0,417 & 0,219 & 24,52 & 25,15 & 0,0001474 & 0,000746 & 0,0008934 & 28,3 & 40,95 & 24,31 \\
0,402 & 0,255 & 23,60 & 24,25 & 0,0002374 & 0,000731 & 0,0009684 & 28,8 & 38,48 & 33,93 \\
0,391 & 0,272 & 22,44 & 23,10 & 0,0002826 & 0,000720 & 0,0010026 & 28,4 & 36,75 & 38,34 \\
0,381 & 0,295 & 21,66 & 22,33 & 0,0003388 & 0,000710 & 0,0010488 & 28,4 & 35,05 & 42,67 \\
0,367 & 0,311 & 20,72 & 21,39 & 0,0003818 & 0,000696 & 0,0010778 & 28,2 & 33,82 & 46,25 \\
0,353 & 0,319 & 20,20 & 20,87 & 0,0004120 & 0,000682 & 0,0010940 & 28,1 & 32,90 & 48,55 \\
0,349 & 0,356 & 19,70 & 20,41 & 0,0004815 & 0,000678 & 0,0011595 & 28,2 & 31,37 & 51,88 \\
0,287 & 0,372 & 18,23 & 18,89 & 0,0005785 & 0,000610 & 0,0011880 & 28,2 & 28,83 & 58,71 \\
0,251 & 0,362 & 16,51 & 17,13 & 0,0006027 & 0,000568 & 0,0011702 & 27,4 & 26,94 & 62,03 \\
0,215 & 0,362 & 16,40 & 16,98 & 0,0006485 & 0,000522 & 0,0011705 & 27,6 & 25,67 & 64,66 \\
\hline
\end{tabular}


Tabela 39 - Simulação da relação entre vazão útil e diferencial de pressão útil

Conjunto 1VJF15-M 38J (1 CV) $\Delta \mathrm{z}=11,97 \mathrm{~m} \quad$ TESTE 1

$\mathrm{K}=0.699 \mathrm{Cd}=0.901$

\begin{tabular}{|c|c|c|c|c|c|c|c|c|c|}
\hline $\begin{array}{l}\mathrm{Hf}_{\mathrm{boc}} \\
\text { (mca) }\end{array}$ & $\begin{array}{c}\mathrm{Hf}_{1} \\
\text { (mca) }\end{array}$ & $\begin{array}{c}\mathrm{Hf}_{2} \\
\text { (mca) }\end{array}$ & $\begin{array}{l}\mathrm{Hf}_{\text {sist }} \\
(\mathrm{mca})\end{array}$ & $\begin{array}{c}\mathrm{q}_{\text {cire }} \\
\left(\mathrm{m}^{3} / \mathrm{s}\right)\end{array}$ & $\begin{array}{c}\text { quitil } \\
\left(\mathrm{m}^{3} / \mathrm{s}\right)\end{array}$ & $\begin{array}{l}\Delta \mathrm{H}_{\text {tuti }} \\
(\mathrm{mca})\end{array}$ & $\begin{array}{l}\Delta \mathrm{H}_{\text {tomitua }} \\
\text { (mca) }\end{array}$ & $\begin{array}{l}\text { qubomba } \\
\left(\mathrm{m}^{3} / \mathrm{s}\right)\end{array}$ & $\begin{array}{l}\text { Rend. } \\
(\%)\end{array}$ \\
\hline 26.50 & 0.36 & 0.14 & 27.00 & 0.00079702 & 0.00000000 & 47.81 & 27.00 & 0.00079702 & 0.00 \\
\hline 26.02 & 0.36 & 0.14 & 26.52 & 0.00078977 & .00001594 & 46.96 & 26.93 & 0.00080571 & 3.45 \\
\hline 25.56 & 0.35 & 0.15 & 26.06 & 0.00078274 & .00003188 & 46.14 & 26.85 & 0.00081463 & 6.73 \\
\hline 25.12 & 0.35 & 0.15 & 25.61 & 0.00077594 & .00004782 & 45.36 & 26.77 & 0.00082376 & 9.84 \\
\hline 24.69 & 0.34 & 0.15 & 25.18 & 0.0007693 & 00006376 & 44.60 & 26.68 & 0.00083311 & 12.79 \\
\hline 24.28 & 0.34 & 0.15 & 24.77 & 0.00076295 & .00007970 & 43.88 & 26.59 & 0.000 & 15.61 \\
\hline 23.89 & 0.33 & 0.16 & 24.38 & 0.00075674 & .00009564 & 43.18 & 26.51 & 0.0008 & 18.28 \\
\hline 23.51 & 0.33 & 0.16 & 24.00 & 0.0007 & .000 & 42.51 & 26.41 & 0.000 & 20.82 \\
\hline 23.14 & 0.32 & 0.16 & 23.63 & 0.00074484 & .00012752 & 41.86 & 26.32 & 0.00087236 & 23.25 \\
\hline 22.79 & 0.32 & 0.17 & 23.28 & 0.00073913 & .00014346 & 41.23 & 26.22 & 0.00088260 & 25.56 \\
\hline 22.45 & 0.31 & 0.17 & 22.93 & 0.00073357 & .00015940 & 40.62 & 26.12 & 0.0008 & 27.76 \\
\hline 22.12 & 0.31 & 0.17 & 22.60 & $0.000^{\prime}$ & .000 & 40.04 & 26.02 & 0.000 & 29.86 \\
\hline 21.80 & 0.31 & 0.18 & 22.28 & 0.00072286 & 9129 & 39.47 & 25.92 & 0.000 & 31.87 \\
\hline 21.49 & 0.30 & 0.18 & 21.97 & 0.0007 & .00020723 & 38.92 & 25.81 & 0.00 & 33.78 \\
\hline 21.18 & 0.30 & 0.19 & 21.67 & 0.0 & 17 & 38.38 & 25.70 & 0.0 & 35.62 \\
\hline 20.89 & 0.30 & 0.19 & 21.38 & 0.00 & 0.00 & 37.86 & 25.59 & 0.0 & 37.37 \\
\hline 20.61 & 0.29 & 0.19 & 21.09 & 0.00 & 0.00 & 37.36 & 25.47 & 0.0 & 39.04 \\
\hline 20.33 & 0.29 & 0.20 & 20.82 & 0.000 & 0.00 & 36.86 & 25.36 & 0.00 & 40.65 \\
\hline 20.06 & 0.29 & 0.20 & 20.55 & $0.0006 \mathrm{~s}$ & .000 & 36.39 & 25.24 & 0.00 & 42.19 \\
\hline 19.80 & 0.28 & 0.21 & 20.28 & 0.000 & 0.000 & 35.92 & 25.12 & 0.00 & 43.66 \\
\hline 19.54 & 0.28 & 0.21 & 20.03 & 0.0006 & .0003 & 35.46 & 25.00 & 0.00 & 45.08 \\
\hline 19.29 & 0.28 & 0.21 & 19.78 & 0.00067998 & 0.0003 & 35.02 & 24.87 & 0.001 & 46.44 \\
\hline 19.04 & 0.27 & 0.22 & 19.53 & 0.00067563 & .00035069 & 34.58 & 24.75 & 0.00102632 & 47.74 \\
\hline 18.80 & 0.27 & 0.22 & 19.29 & 0.000671 & 0.000 & 34.15 & 24.62 & 0.001 & 49.00 \\
\hline 18.57 & 0.27 & 0.23 & 19.06 & 0.00066713 & .00038257 & 33.73 & 24.49 & 0.001 & 50.20 \\
\hline 18.33 & 0.26 & 0.23 & 18.83 & 0.0006 & .00039851 & 33.32 & 24.36 & 0.00 & 51.36 \\
\hline 18.11 & 0.26 & 0.24 & 18.60 & 0.000 & 0.000 & 32.92 & 24.22 & 0.00 & 52.48 \\
\hline 17.88 & 0.26 & 0.24 & 18.38 & 0.0 & 39 & 32.53 & 24.09 & 0.00 & 53.55 \\
\hline 17.67 & 0.26 & 0.25 & 18.17 & 0.000 & 0.00 & 32.14 & 23.95 & 0.00 & 54.59 \\
\hline 17.45 & 0.25 & 0.25 & 17.95 & 0.0006 & .0004 & 31.75 & 23.81 & 0.00110906 & 55.59 \\
\hline 17.24 & 0.25 & 0.26 & 17.74 & 0.00064285 & .00047821 & 31.38 & 23.67 & 0.00112106 & 56.55 \\
\hline 17.03 & 0.25 & 0.26 & 17.54 & 0.00063894 & .00049415 & 31.01 & 23.52 & 0.00113310 & 57.48 \\
\hline 16.82 & 0.24 & 0.26 & 17.33 & 0.00063507 & .00051009 & 30.64 & 23.38 & 0.00114517 & 58.38 \\
\hline 16.62 & 0.24 & 0.27 & 17.13 & 0.00063123 & .00052603 & 30.28 & 23.23 & 0.00115726 & 59.25 \\
\hline 16.42 & 0.24 & 0.27 & 16.93 & 0.00062742 & .00054198 & 29.93 & 23.08 & 0.00116939 & 60.09 \\
\hline 16.22 & 0.24 & 0.28 & 16.74 & 0.000623 & .00055792 & 29.58 & 22.93 & 0.00118154 & 60.90 \\
\hline 16.03 & 0.23 & 0.28 & 16.55 & 0.0006 & .0005 & 29.23 & 22.78 & 0.00119372 & 61.68 \\
\hline 15.83 & 0.23 & 0.29 & 16.36 & 0.00061612 & .00058980 & 28.89 & 22.63 & 0.00120592 & 62.44 \\
\hline
\end{tabular}


Tabela 40- Dados coletados do sistema injetor-bomba centrífuga (Obtidos por experimentação) - Conjunto 1VJF15-M 38J (1 CV) $\Delta \mathrm{z}=11,97 \mathrm{~m}$ TESTE 1

\begin{tabular}{cccccccccc}
\hline $\begin{array}{c}\mathrm{Hf}_{1} \\
(\mathrm{mca})\end{array}$ & $\begin{array}{c}\mathrm{Hf}_{2} \\
(\mathrm{mca})\end{array}$ & $\begin{array}{c}\mathrm{Hf}_{\text {boc }}(\mathrm{mca}) \\
\left(\mathrm{Hf}_{\text {sist }}\right.\end{array}$ & $\begin{array}{c}\mathrm{q}_{\text {util }} \\
\left(\mathrm{m}^{3} / \mathrm{s}\right)\end{array}$ & $\begin{array}{c}\mathrm{q}_{\text {circ }} \\
\left(\mathrm{m}^{3} / \mathrm{s}\right)\end{array}$ & $\begin{array}{c}\mathrm{q}_{\text {bomba }} \\
\left(\mathrm{m}^{3} / \mathrm{s}\right)\end{array}$ & $\begin{array}{c}\Delta \mathrm{H}_{\text {bomba }} \\
(\mathrm{mca})\end{array}$ & $\begin{array}{c}\Delta \mathrm{H}_{\text {útil }} \\
(\mathrm{mca})\end{array}$ & $\begin{array}{c}\text { Rend. } \\
(\%)\end{array}$ \\
\hline 0,355 & 0,137 & 28,51 & 29,00 & 0,0000000 & 0,000786 & 0,0007860 & 29,0 & 46,61 & 0,00 \\
0,353 & 0,136 & 28,51 & 29,00 & 0,0000000 & 0,000784 & 0,0007840 & 29,0 & 46,62 & 0,00 \\
0,344 & 0,157 & 26,32 & 26,83 & 0,0000789 & 0,000772 & 0,0008509 & 28,5 & 43,45 & 14,19 \\
0,342 & 0,162 & 26,57 & 27,08 & 0,0000961 & 0,000769 & 0,0008651 & 29,0 & 42,71 & 16,46 \\
0,336 & 0,179 & 23,76 & 24,27 & 0,0001544 & 0,000761 & 0,0009154 & 27,5 & 40,41 & 25,22 \\
0,332 & 0,189 & 24,89 & 25,41 & 0,0001883 & 0,000756 & 0,0009443 & 29,0 & 40,05 & 28,16 \\
0,324 & 0,212 & 23,74 & 24,28 & 0,0002622 & 0,000746 & 0,0010082 & 29,0 & 37,92 & 35,38 \\
0,332 & 0,188 & 23,94 & 24,46 & 0,0001856 & 0,000756 & 0,0009416 & 28,0 & 39,10 & 28,14 \\
0,324 & 0,214 & 22,63 & 23,17 & 0,0002683 & 0,000746 & 0,0010143 & 28,0 & 36,81 & 36,29 \\
0,320 & 0,225 & 23,38 & 23,92 & 0,0003022 & 0,000741 & 0,0010432 & 29,0 & 36,57 & 38,31 \\
0,319 & 0,235 & 22,36 & 22,91 & 0,0003317 & 0,000739 & 0,0010707 & 28,5 & 35,56 & 40,95 \\
0,319 & 0,228 & 21,27 & 21,82 & 0,0003122 & 0,000739 & 0,0010512 & 27,5 & 35,47 & 40,61 \\
0,311 & 0,263 & 20,93 & 21,51 & 0,0004122 & 0,000729 & 0,0011412 & 28,0 & 33,17 & 46,41 \\
0,313 & 0,264 & 20,96 & 21,53 & 0,0004117 & 0,000731 & 0,0011427 & 28,0 & 33,19 & 46,30 \\
0,308 & 0,276 & 20,15 & 20,73 & 0,0004489 & 0,000725 & 0,0011739 & 27,7 & 32,18 & 48,80 \\
0,308 & 0,281 & 19,51 & 20,10 & 0,0004589 & 0,000725 & 0,0011839 & 27,2 & 31,53 & 49,60 \\
0,305 & 0,296 & 18,98 & 19,58 & 0,0005006 & 0,000720 & 0,0012206 & 27,1 & 30,60 & 51,82 \\
0,302 & 0,310 & 19,32 & 19,93 & 0,0005372 & 0,000717 & 0,0012542 & 27,5 & 30,13 & 52,82 \\
0,302 & 0,311 & 19,47 & 20,09 & 0,0005394 & 0,000717 & 0,0012564 & 27,6 & 30,18 & 52,77 \\
0,301 & 0,321 & 18,76 & 19,38 & 0,0005624 & 0,000715 & 0,0012774 & 27,2 & 29,40 & 54,08 \\
0,299 & 0,330 & 18,31 & 18,94 & 0,0005874 & 0,000712 & 0,0012994 & 26,9 & 28,71 & 55,21 \\
\hline
\end{tabular}


Tabela 41 - Simulação da relação entre vazão útil e diferencial de pressão útil

$\begin{array}{llll}\text { Conjunto 1VJF15-M 38J (1 CV) } \Delta \mathrm{z}=11,97 \mathrm{~m} & \text { TESTE } 2\end{array}$

$\mathrm{K}=0.699 \mathrm{Cd}=0.901$

\begin{tabular}{|c|c|c|c|c|c|c|c|c|c|}
\hline $\begin{array}{l}\mathrm{Hf}_{\mathrm{boc}} \\
\text { (mca) }\end{array}$ & $\begin{array}{c}\mathrm{Hf}_{1} \\
\text { (mca) }\end{array}$ & $\begin{array}{c}\mathrm{Hf}_{2} \\
\text { (mca) }\end{array}$ & $\begin{array}{l}\mathrm{Hf}_{\text {sist }} \\
\text { (mca) }\end{array}$ & $\begin{array}{c}q_{\text {circ }} \\
\left(\mathrm{m}^{3} / \mathrm{s}\right)\end{array}$ & $\begin{array}{c}\text { Qútil } \\
\left(\mathrm{m}^{3} / \mathrm{s}\right)\end{array}$ & $\begin{array}{l}\Delta \mathrm{H}_{\text {util }} \\
\text { (mca) }\end{array}$ & $\begin{array}{c}\Delta \mathrm{H}_{\text {bomba }} \\
\text { (mca) }\end{array}$ & $\begin{array}{l}\text { qbomba } \\
\left(\mathrm{m}^{3} / \mathrm{s}\right)\end{array}$ & $\begin{array}{c}\text { Rend. } \\
(\%)\end{array}$ \\
\hline 26.50 & 0.36 & 0.14 & 27.00 & 0.00079702 & 0.00000000 & 47.81 & 27.00 & 0.00079702 & 0.00 \\
\hline 26.02 & 0.36 & 0.14 & 26.52 & 0.00078977 & 0.00001594 & 46.96 & 26.93 & 0.00080571 & 3.45 \\
\hline 25.56 & 0.35 & 0.15 & 26.06 & 0.00078274 & 0.00003188 & 46.14 & 26.85 & 0.00081463 & 6.73 \\
\hline 25.12 & 0.35 & 0.15 & 25.61 & 0.00077594 & 0.00004782 & 45.36 & 26.77 & 0.000 & 9.84 \\
\hline 24.69 & 0.34 & 0.15 & 25.18 & 0.00076935 & 0.00006376 & 44.60 & 26.68 & 311 & 12.79 \\
\hline 24.28 & 0.34 & 0.15 & 24.77 & 0.00076295 & 0.00007970 & 43.88 & 26.59 & 265 & 15.61 \\
\hline 23.89 & 0.33 & 0.16 & 24.38 & 0.00075674 & 0.00009564 & 43.18 & 26.51 & 0.000 & 18.28 \\
\hline 23.51 & 0.33 & 0.16 & 24.00 & 0.00075071 & 0.00011158 & 42.51 & 26.41 & 0.00086229 & 20.82 \\
\hline 23.14 & 0.32 & 0.16 & 23.63 & 0.00074484 & 0.00012752 & 41.86 & 26.32 & 0.00087236 & 23.25 \\
\hline 22.79 & 0.32 & 0.17 & 23.28 & 0.00073913 & 0.00014346 & 41.23 & 26.22 & 0.00 & 25.56 \\
\hline 22.45 & 0.31 & 0.17 & 22.93 & 0.00073357 & 0.00015940 & 40.62 & 26.12 & 0.00 & 27.76 \\
\hline 22.12 & 0.31 & 0.17 & 22.60 & 0.00072815 & 0.00017534 & 40.04 & 26.02 & 49 & 29.86 \\
\hline 21.80 & 0.31 & 0.18 & 22.28 & 0.00072286 & 0.00 & 39.47 & 25.92 & 14 & 31.87 \\
\hline 21.49 & 0.30 & 0.18 & 21.97 & 0.0007 & 0.000 & 38.92 & 81 & 492 & 33.78 \\
\hline 21.18 & 0.30 & 0.19 & 21.67 & 0.00071264 & 0.000 & 38.38 & 25.70 & 80 & 35.62 \\
\hline 20.89 & 0.30 & 0.19 & 21.38 & 0.00070770 & 0.0 & 37.86 & 59 & 80 & 37.37 \\
\hline 20.61 & 0.29 & 0.19 & 21.09 & 0.00070286 & 0.00 & 37.36 & .47 & 790 & 39.04 \\
\hline 20.33 & 0.29 & 0.20 & 20.82 & 0.00069811 & 0.00027099 & 36.86 & 25.36 & 6910 & 40.65 \\
\hline 20.06 & 0.29 & 0.20 & 20.55 & 0.00069346 & 0.00028693 & 36.39 & 25.24 & 0.00 & 42.19 \\
\hline 19.80 & 0.28 & 0.21 & 20.28 & 0.00068889 & 0.00030287 & 35.92 & 25.12 & 0.000 & 43.66 \\
\hline 19.54 & 0.28 & 0.21 & 20.03 & 0.00068440 & 0.00031881 & 35.46 & 25.00 & 321 & 45.08 \\
\hline 19.29 & 0.28 & 0.21 & 19.78 & 0.00067998 & 0.0 & 92 & & & 46.44 \\
\hline 19.04 & 0.27 & 0.22 & 19.53 & & 0.0 & 58 & & & 47.74 \\
\hline 18.80 & 0.27 & 0.22 & 19.29 & 0.00067135 & 6663 & 34.15 & 24.62 & 3798 & 49.00 \\
\hline 18.57 & 0.27 & 0.23 & 19.06 & 0.00066713 & 0.00038257 & 33.73 & 24.49 & 0.00104970 & 50.20 \\
\hline 18.33 & 0.26 & 0.23 & 18.83 & 0.00066296 & 0.00039851 & 33.32 & 24.36 & 0.00106147 & 51.36 \\
\hline 18.11 & 0.26 & 0.24 & 18.60 & 0.00065885 & 0.00041445 & 32.92 & 24.22 & 0.00107330 & 52.48 \\
\hline 17.88 & 0.26 & 0.24 & 18.38 & 0.00065478 & 0.00043039 & 32.53 & 24.09 & 08518 & 53.55 \\
\hline 17.67 & 0.26 & 0.25 & 18.17 & 0.00065076 & 0.00044633 & 32.14 & & 99710 & 54.59 \\
\hline 17.45 & 0.25 & 0.25 & 17.95 & 0.00064679 & 0.00046227 & 31.75 & 23.81 & 9906 & 55.59 \\
\hline 17.24 & 0.25 & 0.26 & 17.74 & 0.00064285 & 0.00047821 & 31.38 & 23.67 & 0.00112106 & 56.55 \\
\hline 17.03 & 0.25 & 0.26 & 17.54 & 0.00063894 & 0.00049415 & 31.01 & 23.52 & 0.00113310 & 57.48 \\
\hline 16.82 & 0.24 & 0.26 & 17.33 & 0.00063507 & 0.00051009 & 30.64 & 23.38 & 0.00114517 & 58.38 \\
\hline 16.62 & 0.24 & 0.27 & 17.13 & 0.00063123 & 0.00052603 & 30.28 & 23.23 & 0.00115726 & 59.25 \\
\hline 16.42 & 0.24 & 0.27 & 16.93 & 0.00062742 & 0.00054198 & 29.93 & 23.08 & 0.00116939 & 60.09 \\
\hline 16.22 & 0.24 & 0.28 & 16.74 & 0.00062363 & 0.00055792 & 29.58 & 22.93 & 0.00118154 & 60.90 \\
\hline 16.03 & 0.23 & 0.28 & 16.55 & 0.00061986 & 0.00057386 & 29.23 & 22.78 & 0.00119372 & 61.68 \\
\hline 15.83 & 0.23 & 0.29 & 16.36 & 0.00061612 & 0.00058980 & 28.89 & 22.63 & 0.00120592 & 62.44 \\
\hline 15.64 & 0.23 & 0.29 & 16.17 & 0.00061239 & 0.00060574 & 28.55 & 22.47 & 0.00121813 & 63.17 \\
\hline
\end{tabular}


Tabela 42- Dados coletados do sistema injetor-bomba centrífuga (Obtidos por experimentação) - Conjunto 1VJF15-M 38J (1 CV)

$\Delta \mathrm{z}=11,97 \mathrm{~m}$

TESTE 2

\begin{tabular}{|c|c|c|c|c|c|c|c|c|c|}
\hline $\mathrm{Hf}_{1}$ & $\mathrm{Hf}_{2}$ & $\mathrm{Hf}_{\mathrm{boc}}$ & $\mathrm{Hf}_{\text {sist }}$ & qutil & qeirc & qbomba & $\Delta \mathrm{H}_{\text {bomba }}$ & $\Delta H_{\text {util }}$ & Rend. \\
\hline $\begin{array}{l}\mathrm{Hf}_{\mathrm{i}-2} \\
\text { (mca) }\end{array}$ & $\begin{array}{l}\mathrm{Hf}_{2-3} \\
\text { (mca) }\end{array}$ & $\begin{array}{l}\text { Hfboc } \\
\text { (mca) }\end{array}$ & $\begin{array}{l}\text { Hfsist } \\
\text { (mca) }\end{array}$ & $\begin{array}{c}\text { qútil } \\
\left(\mathrm{m}^{3} / \mathrm{s}\right)\end{array}$ & $\begin{array}{c}\text { qcirc } \\
\left(\mathrm{m}^{3} / \mathrm{s}\right)\end{array}$ & $\begin{array}{c}\text { qbomba } \\
\left(\mathrm{m}^{3} / \mathrm{s}\right)\end{array}$ & $\begin{array}{c}\Delta \mathrm{H}_{\text {bomba }} \\
\text { (mca) }\end{array}$ & $\begin{array}{l}\Delta \mathrm{H}_{\mathrm{util}} \\
\text { (mca) }\end{array}$ & $\begin{array}{c}\text { Rend. } \\
(\%)\end{array}$ \\
\hline 0,352 & 0,136 & 29,51 & 30,00 & 0,0000000 & 0,000782 & 0,0007820 & 30,0 & 47,62 & 0,00 \\
\hline 0,355 & 0,137 & 29,51 & 30,00 & 0,0000000 & 36 & 0007 & 1,0 & 47,61 & 00 \\
\hline 0,346 & 0,156 & 26,98 & 27,48 & 0,0000717 & 0,00 & 000 & 0 & 44,11 & 2,93 \\
\hline 0,339 & 0,173 & 24,85 & 25,37 & 0,00 & 0,00 & 71 & 0 & 00 & 21,65 \\
\hline 0,336 & 0,173 & 24,73 & 25,24 & 0,00 & 0,00 & 0,0008 &, 0 & 7 & 22,49 \\
\hline 0,334 & 0,188 & 25,00 & 25,52 & 0,0 & 0,00 & 0,0009423 & 29,0 & 40 & 27,50 \\
\hline 0,329 & 0,195 & 24,62 & 25,15 & 0,0002083 & 0,000752 & 0,0009603 & 29,0 & 39,29 & 30,16 \\
\hline 0,327 & 0,210 & 23,43 & 23,96 & 0,0002533 & 0,000750 & 0,0010033 & 28,5 & 37,61 & 34,58 \\
\hline 0,323 & 0,215 & 22,56 & 23,10 & 0,0002717 & 0,000745 & 0,00 & 28,0 & 36,75 & 36,63 \\
\hline 0,319 & 0,228 & 22,23 & 22,78 & 0,0003106 & 0,000740 & 0,001 & 28,0 & 35,43 & 39,40 \\
\hline 0,319 & 0,245 & 21,41 & 21,97 & 0,0003572 & 0,000739 & 0,0010962 & 28,0 & 34,63 & 43,10 \\
\hline 0,313 & 0,253 & 21,49 & 22,06 & 0,0003839 & 0,000732 & 0,0011159 & 28,1 & 33,67 & 44,31 \\
\hline 0,316 & 0,258 & 21,27 & 21,85 & 0,0 & 0,00 & 89 & 28,0 & 33,50 & 44,95 \\
\hline 0,313 & 0,273 & 21,37 & 21,96 & 0,000 & 0,000731 & 0,0011654 & 28,5 & 33,12 & 47,08 \\
\hline 0,307 & 0,283 & 20,37 & 20,96 & 0,0004656 & 0,000724 & 0,0011896 & 27,8 & 31,80 & 49,16 \\
\hline 0,305 & 0,301 & 19,06 & 19,67 & 0,0005106 & 0,000721 & 0,0012316 & 27,1 & 30,26 & 51,88 \\
\hline 0,302 & 0,318 & 18,54 & 19,16 & 0,0005550 & 0,000717 & 0,0012720 & 27,0 & 29,37 & 53,94 \\
\hline 0,301 & 0,322 & 17,99 & 18,61 & 0,0 & 0,000 & 0,00 & 26,5 & 28,74 & 54,69 \\
\hline 0,300 & 0,323 & 18,07 & 18,70 & 0,00 & 0,00 & 0,00 & 26,6 & 28,75 & 54,74 \\
\hline 0,298 & 0,330 & 17,48 & 18,10 & 0,0005881 & 0,000711 & 0,0012991 & 26,2 & 28,05 & 55,80 \\
\hline
\end{tabular}




\section{REFERÊNCIAS BIBLIOGRÁFICAS}

ABREU, J.M.H.; LOPEZ, J.R.; REGALADO, A.P.; HERNANDEZ, J.F.G. El riego localizado. Madrid, Instituto Nacional de Investigaciones Agrarias, 1987. 317 p.

BOTREL, T.A. Modelo matemático aplicável ao sistema injetor-bomba centrífuga a fim de aumentar a altura manométrica. Piracicaba, 1996. 57 p. Tese (Livre-docência) - Escola Superior de Agricultura "Luiz de Queiroz", Universidade de São Paulo.

CARLIER, M. Machines hydrauliques. Paris. Imprimiére Louis-Jean, 1968.

DELMÉE, G.J. Manual de medição de vazão. 2a. Ed. São Paulo, Edgard Blücher, 1983. $476 p$.

FEITOSA FILHO, J.C. \& ARRUDA, N.T. Protótipo, dimensionamento e metodologia de construção de um injetor de produtos químicos "Tipo Venturi", metálico, para uso na quimigação. In: CONGRESSO BRASILEIRO DE ENGENHARIA AGRÍCOLA, 20., Campinas, 1994. Resumos, Campinas, 1994.

FEITOSA FILHO, J.C. BOTREL, T.A.; PINTO, J.M; MENDONÇA, F.C. Avaliação de características hidráulicas que condicionem melhor rendimento e limite operacional de injetores tipo venturi. In: CONGRESSO BRASILEIRO DE ENGENHARIA AGRÍCOLA, 25. Resumos, Bauru, 1996, p. 91.

FEITOSA FILHO, J.C.; BOTREL, T.A.; PINTO, J.M.; HEINEMANN, A.B. Influência da relação entre os diâmetros dos bocais no desempenho de injetores tipo venturi. Engenharia Agrícola, v. 17, n. 4, p. 15-24, Jun. 1998.

FERREIRA, J.O.P. Caracterização hidráulica de dois injetores de fertilizantes tipo Venturi. Piracicaba, 1994. 76 p. Dissertação (M.S.) - Escola Superior de Agricultura "Luiz de Queiroz", Universidade de São Paulo. 
HIRSCHMANN, R.J. Características de los distintos tipos de bombas. In: HIRSCHMAN, R.J. Bombas; características y aplicación. Santiago de Chile, Ed. Universitaria, 1958, cap. 4, p.85-139.

MACINTYRE, A. J. Bombas e instalações de bombeamento. 2a. Ed. Guanabara Koogan, Rio de Janeiro, 1987. 782 p.

SILVESTER, R.; MUELLER, N.G. Design data for the liquid-liquid jet pump. Journal of Hydraulic Research, v.6, n.2, p.129-61, 1968

TROSKOLANSKI, A.T. Dispositifs d'appareils a jet. In:TROSKOLANSKI, A.T. Les turbopompes: théorie, tracé et construction. Paris, Eyrolles, 1977, cap. 16, p.329-33.

URQUHART, L.C. Civil engineering handbook. 3a ed. New York, Mc Graw-Hill, 1950.

VENNARD, J.K. \& STREET, R.L. Medidor Venturi. In: VENNARD, J.K. \& STREET, R.L. Elementos de mecânica dos fluidos. 5a ed. Rio de Janeiro, Guanabara Dois, 1978 , p.516-8.

ZÁRATE ROJAS, R.N.; BOTREL, T.A.; MENDONÇA, F.C. Desenvolvimento e avaliação de dois injetores de fertilizantes tipo venturi. In: CONGRESSO BRASILEIRO DE ENGENHARIA AGRÍCOLA, 25. Resumos, Bauru, 1996, p.442. 